MARINE COMMUNITIES

Governing oil \& gas activities and cruise tourism in the Arctic and the Caribbean

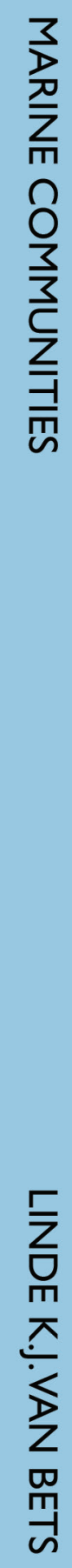

Linde K.J.van Bets

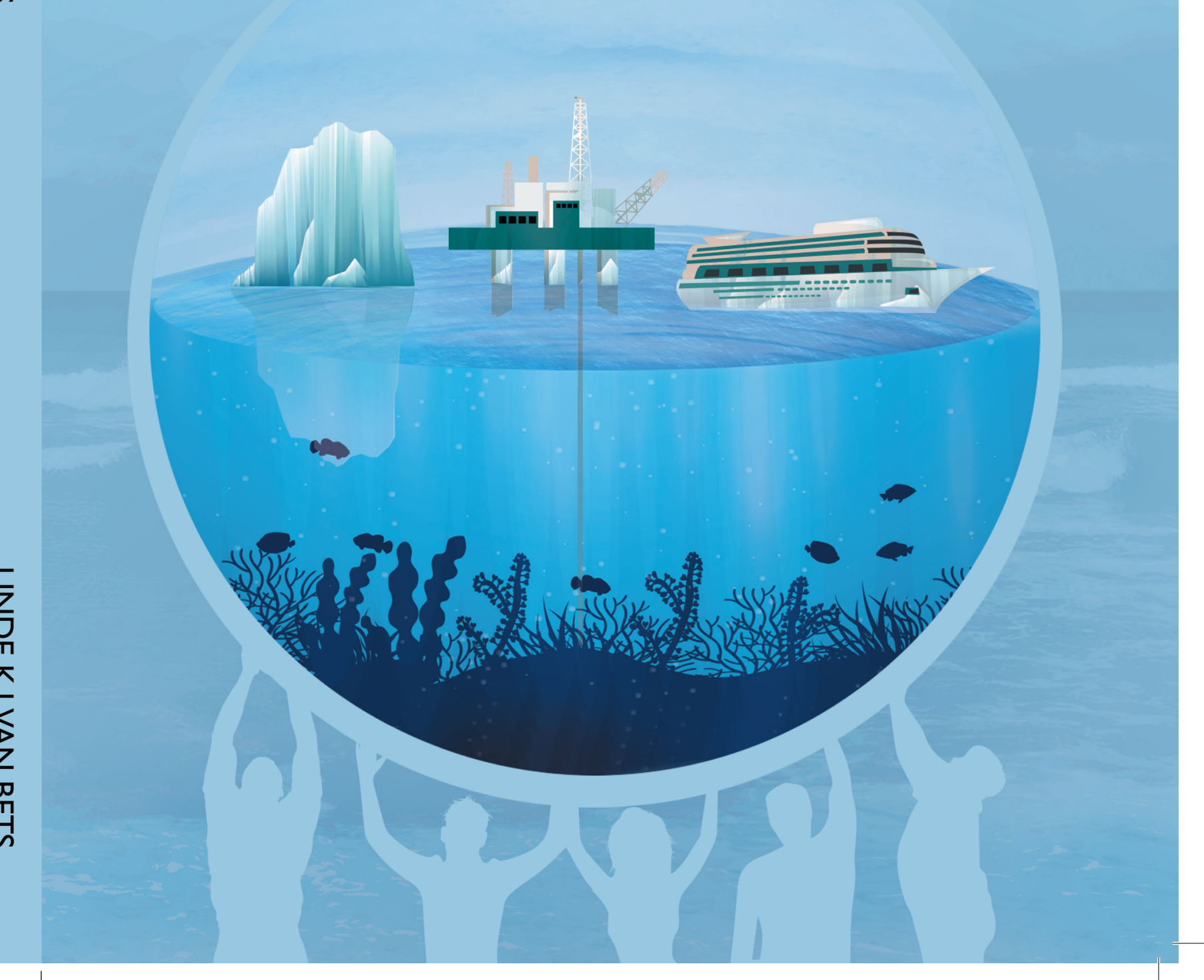




\section{Propositions}

1. To understand environmental governance of maritime activities, the ecological definition of marine community should be complemented with a sociological definition.

(this thesis)

2. The user community is gaining influence in environmental governance of maritime activities compared to the policy community.

(this thesis)

3. Tracking down actors involved in mobile activities, like cruise tourism, for an interview makes the fine line between voluntary recruitment and stalking blurry.

4. While open access is the norm in science, getting access as social scientist to an established natural science community is challenging.

5. Naming offshore oil and gas fields according to fairy tales (Snow White, Boots and Cinderella) depoliticises oil and gas activities.

6. Generating impact for science is as important as ensuring science for impact (cf. Netherlands Scientific Expedition Edgeøya Spitsbergen)

Propositions belonging to the thesis, entitled:

Marine communities, Governing oil \& gas activities and cruise tourism in the Arctic and the Caribbean

Linde van Bets

Wageningen, 22 September 2017 


\title{
Marine communities
}

Governing oil \& gas activities and cruise tourism in the Arctic and the Caribbean

\author{
Linde K.J. van Bets
}




\section{Thesis committee}

\section{Promotors}

Prof. Dr J.P.M. van Tatenhove

Personal chair at the Environmental Policy Group

Wageningen University \& Research

Prof. Dr A.P.J. Mol

Professor of Environmental Policy

Wageningen University \& Research

\section{Co-promotor}

Dr M.A.J. Lamers

Associate professor, Environmental Policy Group

Wageningen University \& Research

\section{Other members}

Prof. Dr V.R. van der Duim, Wageningen University \& Research

Prof. Dr C.J. Bastmeijer, Tilburg University

Dr K. Soma, Wageningen University \& Research

Dr M. Knol, University of Tromsø, Norway

This research was conducted under the auspices of the Wageningen School of Social Sciences (WASS). 


\section{Marine communities}

Governing oil \& gas activities and cruise tourism in the Arctic and the Caribbean

Linde K.J. van Bets

Thesis

submitted in fulfilment of the requirements for the degree of doctor at Wageningen University by the authority of the Rector Magnificus

Prof. Dr A.P.J. Mol,

in the presence of the

Thesis Committee appointed by the Academic Board

to be defended in public

on Friday 22 September 2017

at 1.30 p.m. in the Aula. 
Linde K.J. van Bets

Marine communities

Governing oil \& gas activities and cruise tourism in the Arctic and the Caribbean 218 pages.

PhD thesis, Wageningen University, Wageningen, the Netherlands (2017)

With references, with summaries in English and Dutch

ISBN 978-94-6343-657-1

DOI $10.18174 / 420861$ 


\section{Table of content}

List of figures $\quad$ VIII

List of tables IX

List of abbreviations $\quad \mathrm{X}$

1. Introducing marine communities 1

1.1 Introduction 3

$\begin{array}{lll}1.2 & \text { Conceptualising marine community } & 7\end{array}$

$\begin{array}{lll}\text { 1.2.1 A review of the community literature } & 7\end{array}$

1.2.2 The conceptual framework of marine community 8

1.2.3 Marine community as a governance arrangement $\quad 12$

$\begin{array}{lll}1.3 & \text { Research objective and research questions } & 13\end{array}$

$\begin{array}{lll}1.4 & \text { Research methodology } & 14\end{array}$

1.4.1 Ontological and epistemological stance 14

$\begin{array}{lll}1.4 .2 & \text { Case study design } & 14\end{array}$

1.4.3 Cross-case comparative analysis $\quad 22$

$\begin{array}{lll}1.4 .4 & \text { Data collection } & 22\end{array}$

$\begin{array}{lll}1.4 .5 & \text { Data analysis } & 24\end{array}$

$\begin{array}{lll}1.4 .6 & \text { Research validity } & 26\end{array}$

1.5 Outline of the thesis 28

2. Liquefied natural gas production at Hammerfest: a transforming 31 marine community

2.1 Introduction $\quad 35$

2.2 Theoretical framework 37

$\begin{array}{lll}2.3 \text { Methodology } & 39\end{array}$

2.4 A transforming marine community on LNG production in 40 Hammerfest

2.4.1 Institutional coalition $\quad 43$

2.4.2 Strategic coalitions 44

2.4.2.1 Strategic coalition: Statoil and fisheries 45

2.4.2.2 Strategic coalition: Statoil, inhabitants and the $\quad 47$ municipality

$\begin{array}{lll}\text { 2.4.3 Oppositional coalition } & 48\end{array}$

\begin{tabular}{ll}
2.4 .4 & Marine community \\
\hline
\end{tabular}

2.5 Discussion $\quad 52$

2.6 Conclusions and recommendations 54 
3. A power analysis of a transforming marine community around $\quad 57$ oil transhipment at St. Eustatius

3.1 Introduction $\quad 61$

$\begin{array}{lll}3.2 & \text { Theoretical framework } & 62\end{array}$

$\begin{array}{lll}3.3 & \text { Methodology } & 65\end{array}$

3.4 A transforming marine community around oil transhipment in 66 Statia

3.4.1 A new power architecture 69

3.4.1.1 Before the dissolution of the Dutch Antilles in $\quad 70$ 2010

3.4.1.2 After the dissolution of the Dutch Antilles in 71 2010

3.4.1.3 After April 1, 2015

$\begin{array}{lll}3.5 & \text { Discussion } & 80\end{array}$

3.6 Conclusion 82

4. Governing cruise tourism at Bonaire: a networks and flows 85 approach

$\begin{array}{lll}4.1 & \text { Introduction } & 89\end{array}$

4.2 Theoretical framework 92

$\begin{array}{lll}4.3 & \text { Methodology } & 94\end{array}$

$\begin{array}{ll}4.4 \text { Findings } & 96\end{array}$

$\begin{array}{lll}\text { 4.4.1 } & \text { Flow of cruise ships } & 97\end{array}$

4.4.2 Flow of cruise passengers 101

$\begin{array}{ll}4.4 .3 \text { Marine community } & 105\end{array}$

$\begin{array}{llr}4.5 & \text { Conclusions } & 109\end{array}$

5. Collective self-governance in a marine community: expedition 111 cruise tourism at Svalbard

$\begin{array}{ll}5.1 & \text { Introduction } \\ 5.2 & 115\end{array}$

$\begin{array}{lll}5.2 & \text { Theoretical framework } & 118\end{array}$

$\begin{array}{ll}5.3 \text { Methodology and methods } & 121\end{array}$

$\begin{array}{lll}5.4 & \text { Findings } & 124\end{array}$

$\begin{array}{lll}\text { 5.4.1 State governance } & 124\end{array}$

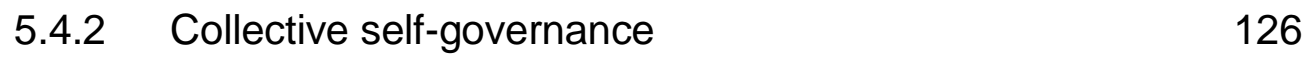

5.4.3 Internal relationship: within the cruise user community 127

5.4.4 External relationship: user versus policy community 130

5.4.5 External relationship: between cruise and research 132 user communities

5.5 Conclusion 
6. Marine communities: a conclusion 137

6.1 Introduction 139

6.2 Tracking changes in governance by marine communities 140

6.2.1 Comparing environmental governance in marine 140 regions

6.2.1.1 Caribbean Netherlands $\quad 140$

6.2.1.2 The European Arctic 142

6.2.2 Comparing environmental governance of maritime 144 activities

6.2.2.1 Cruise tourism 144

6.2.2.2 Oil and gas activities $\quad 145$

6.3 Marine community as a temporary governance arrangement 146

6.3.1 Tracking changes in governance modes and shifts $\quad 146$

6.3.2 Tracking changes in governance styles 148

6.3.3 Tracking changes in governance processes 151

6.4 Methodological reflection 156

6.5 Future research 159

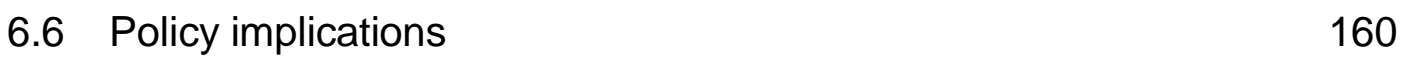

References 163

Appendices $\quad 179$

$\begin{array}{ll}\text { Summary } & 195\end{array}$

Samenvatting 199

WASS Education Certificate 203

About the author 205

List of publications 205

Acknowledgements 206 


\section{List of figures}

Figure 1.1. The relationship between user and policy communities within a marine community

Figure 1.2. The location of the case studies in the Caribbean

Figure 1.3. The location of the case studies in the Arctic

Figure 2.1. Graphical abstract Hammerfest 33

Figure 2.2. The relationship between user and policy communities $\quad 37$ within a marine community

Figure 2.3. The location of Hammerfest in the Arctic

Figure 2.4. Overview of the operations of the LNG plant 42

Figure 2.5. Overview of the coalitions within the marine community of 51 LNG production in Hammerfest

Figure 2.6. Overview of the coalitions in relation to the dimension of sustainable development

Figure 3.1. Graphical abstract St. Eustatius

Figure 3.2. The relationship between user and policy communities within a marine community

Figure 3.3. The location of Statia in the Caribbean

Figure 3.4. Existing NuStar facility

Figure 3.5. Transforming marine community because of new power $\quad 70$ dynamics

Figure 3.6. St. Eustatius national marine park

Figure 4.1. Graphical abstract Bonaire

Figure 4.2. The flow of cruise ships to Bonaire

Figure 4.3. The flow of cruise passengers in Bonaire

Figure 4.4. The conceptual framework combining the networks and flows approach and marine communities

Figure 4.5. Space of flows and space of places interacting within the 107 marine community of cruise tourism in Bonaire

Figure 5.1. Graphical abstract Svalbard

Figure 5.2. Expedition and overseas cruise tourists 2001-2014 117

$\begin{array}{lll}\text { Figure 5.3. The relationship between user and policy communities } & 120\end{array}$ within a marine community

Figure 5.4. The location of Svalbard in the Arctic

Figure 6.1. Governance shifts and modes for the four case studies 


\section{List of tables}

Table 1.1. Overview of the case studies 23

Table 1.2. Number of interviews 25

Table 6.1. Structuring the complexity of governance 153 


\section{List of abbreviations}

$\begin{array}{ll}\text { AECO } & \text { Association of Arctic Expedition Cruise Operators } \\ \text { BES islands } & \text { Islands of Bonaire, St. Eustatius and Saba } \\ \text { EU } & \text { European Union } \\ \text { FCCA } & \text { Florida Caribbean Cruise Association } \\ \text { IAATO } & \text { International Association of Antarctica Tour Operators } \\ \text { ICT } & \text { Information and Communication Technology } \\ \text { IMO } & \text { International Maritime Organization } \\ \text { LNG } & \text { Liquefied Natural Gas } \\ \text { Ministry of I\&E } & \text { Dutch Ministry of Infrastructure and Environment } \\ \text { MPA } & \text { Marine Protected Area } \\ \text { NGO } & \text { Non-Governmental Organisation } \\ \text { PDO } & \text { Plan for Development and Operation } \\ \text { SIDS } & \text { Small Island Developing States } \\ \text { SLO } & \text { Social License to Operate } \\ \text { SS\&S } & \text { Statia Safe \& Sound } \\ \text { Statia } & \text { St. Eustatius } \\ \text { STENAPA } & \text { St. Eustatius National Parks } \\ \text { STINAPA Bonaire } & \text { Stichting Nationale Parken Bonaire } \\ \text { TCB } & \text { Tourism Corporation Bonaire } \\ \text { USA } & \text { United States of America } \\ \text { WWF } & \text { World Wildlife Fund }\end{array}$




\section{1. \\ Introducing marine communities}





\subsection{Introduction}

Oceans and seas are among the most ecologically vital and socio-economically important systems on the planet (Harley et al., 2006). Marine environments cover approximately $70 \%$ of the earth and host unique ecosystems such as polar oceans, temperate continental shelves and tropical seas. These ecosystems contain diverse habitats ranging from coral reefs, sea grass beds, and estuaries in coastal areas to hydrothermal vents, seamounts and soft sediments on the ocean floor. Such habitats are crucial in supporting an abundance of marine life (Convention on Biological Diversity, 2017).

Despite the increased awareness of the importance of the marine environment, the scarce space still available for human activities on the densely populated and economically exploited terrestrial environment has fuelled a growing interest in exploring the sea for human use. This is being accelerated by the food and energy needs of the growing world population and facilitated by technological innovation. As such, more and new activities are being translocated to the sea: the production of electricity by offshore wind turbines, the large-scale resource extraction of sand, oil and gas, deep sea mining or gene mining of marine organisms such as corals and sponges, and offshore aquaculture and sea farming, for example, the production of seaweed for food, feed or energy. Next to provisional ecosystem services, oceans have always provided important regulating ecosystem services, such as (toxic) waste processing, erosion control, and biological regulation of water quality and climate, flood and storm protection through buffers such as coral reefs and marsh plants. Finally, the beautiful landscape and underwater world of oceans provide cultural ecosystem services such as recreational, aesthetic and spiritual benefits originating from nature. Coastal tourism, including scuba-diving and other nature-based tourism, for example coral reefs, is an important sector within the global tourism industry and a major part of the economies of many small islands (Murk and Klostermann, 2011).

The increase in activities at sea has resulted in governance challenges to address the claims and interests of different maritime sectors in the marine environment. As a result, the intensified use of the sea has led to a spectrum of governance initiatives to address the resulting environmental effects and risks to the marine environment. The following three examples will illustrate the range of the governance spectrum.

The importance of fisheries continues to rise as coastal populations are increasing, and rapidly growing economies are driving up the demand for fish. Although the contribution of aquaculture is growing, wild-capture fisheries remain 
critically important for supplying the increasing demand. Mangrove forests are crucial in this context because these highly productive ecosystems enhance abundant fish populations through the provision of food and shelter. Small-scale fishing communities acknowledge the benefits of adjacent mangroves for thriving fishing populations. Tenure and user rights for fishing in particular areas are organised at the local level and passed down within families. Regulatory frameworks enforce these fishing rights. Such limited access helps to prevent overfishing (Hutchison, Spalding, and Zu Ermgassen, 2014).

A second example concerns shipping. More than $80 \%$ of the global trade is shipped across the world (International Maritime Organization, 2016). This poses severe environmental risks in terms of resource depletion (energy and end-of-life cycle materials), water pollution (through waste and waste water discharge, oil leakage, and the introduction of invasive species through ballast water), air pollution (greenhouse gases, sulphur dioxide and nitrogen oxides), and the disturbance of natural habitats related to, among others, marine protected areas (MPAs) and coastal protected areas (Lai, Lun, Wong, and Cheng, 2011; Yang, Lu, Haider, and Marlow, 2013). The transboundary nature of the activity and the environmental problems it causes explain why shipping is governed by international decision-making. This is embodied in the International Maritime Organization (IMO), the specialised United Nations agency with the responsibility for the safety and security of shipping and the prevention of marine pollution by ships. The governance of shipping is steered by the IMO through more than 20 international conventions. Decision-making within the IMO is time-consuming and inefficient because of the lengthy ratification and enforcement procedures by the 172 Member States (DeSombre, 2006; Wuisan, Van Leeuwen, and Van Koppen, 2012). In response, various private and public-private initiatives have emerged to steer environmental governance of shipping through non-state and often voluntary systems such as performance indices, labelling systems, certification systems and management systems based on second- and third-party verification. Implementation of this diverse field of voluntary standards is also not straightforward. Confusion, incomparability and unfamiliarity with each of the systems, high administrative burdens, and lack of harmonisation and integration are often-mentioned reasons for the meagre proliferation and implementation of these governance instruments (Toonen and Mol, 2016).

The third maritime activity, cruise tourism, illustrates a highly complex, mobile and transnational system, similar to shipping. Despite the economic interests of many sea-front destinations, the increasing flows of cruise ships and passengers also result in various environmental impacts. Offshore, onshore and global 
environmental impacts of cruise tourism, such as sewage and grey water discharge, the dumping of solid waste, the biosecurity risks of hull fouling and ballast water discharge, air pollution and greenhouse gas emissions, infrastructural developments and visitation peaks at natural attractions, have been reported (Amelung and Lamers, 2007; Johnson, 2002; Klein, 2007; Lester and Weeden, 2004; Wood, 2002). From a state-centred perspective, cruise shipping is considered an under-regulated activity (DeSombre, 2006; Johnson, 2002; Timothy, 2006). For example, through the 'flags of convenience' system, companies can choose to register ships in states where social or environmental regulations are most convenient. Competition between ports also results in regulatory laxity while extending the rules of individual ports or states may shift impacts to areas that lack equivalent rules or proper enforcement (Dobson and Gill, 2006). However, these institutional voids are increasingly being tackled by international (e.g., IMO) and supranational (e.g., European Union (EU)) authorities and non-state actors, such as industry associations and environmental organisations (Haase, Lamers, and Amelung, 2009; Klein, 2007; Lamers, Haase, and Amelung, 2008).

These examples show that the governance of maritime activities operates at quite different scales. In small-scale fisheries in mangroves the community is local, defined by the small territory it shares. In addition, this community is characterised by its high dependency on fisheries for subsistence and income. Apart from the small territory, it also shares fishing as an occupation and a way of living. The community could therefore also be understood as a rather homogeneous social structure because the entire community is involved in a single economic activity, fisheries.

The communities involved in governing shipping and cruise tourism are more complex and larger. Under the influence of globalisation, those activities operate worldwide, with ships, goods and tourist flows literally spanning the globe. Hence, these maritime activities are unique because of their relative freedom from territory-bound regulation by state actors. This governance challenge is addressed by different actors. The examples above illustrate that policy makers try to steer users or that sometimes users regulate themselves. Unlike small-scale fisheries in mangrove areas, such communities cannot be defined by a small spatial unit or a homogeneous social structure. They have a transnational, multi-actor and multilevel character in which different networks meet.

The actors involved in governing maritime activities are not necessarily located in the same geographical place and may not even be in direct contact; they increasingly interact through global and transnational institutions or networks and 
are influenced by globalisation. Globalisation is perhaps even more prominent in the marine environment, a fluid transboundary environment where nation-state sovereignty tends to decrease the farther one moves offshore (Burn, Tyler, Zadkovich, and Loftis, 2015; Suárez-de Vivero, 2013). As a result of globalisation, numerous sustainability questions are emerging, and local communities are often among the first to face the consequences of rather global and distant environmental problems. This phenomenon is clearly demonstrated by small islands. It is often said that small islands remain at the frontline of climate change because they are likely to suffer the most serious from climate change. The rise in sea temperature threatens the marine ecosystem on which small island populations often strongly depend for their livelihood and economic activity (Águeda Corneloup and Mol, 2014). The fragile marine environment, coastal zones and island ecosystems are susceptible not only to natural hazards but also to impacts from the continual physical change brought by globalisation and international economic growth, leading to external global impacts from climate change and sea level rise (Douglas, 2006). Sites of power and the subjects of power may be literally, as well as metaphorically, oceans apart (Held, Goldblatt, McGrew, and Perraton, 1999). Globalisation thus results in communities characterised by an interplay between territorially (e.g., national states, port agencies and island communities) and less territorially defined actors (e.g., mobile and transnational industries) to govern maritime activities in a sustainable manner.

This complicates environmental governance of maritime activities. Governance refers to "sustaining co-ordination and coherence among a wide variety of actors with different purposes and objectives such as political actors and institutions, corporate interests and civil society" (Pierre, 2000, pp. 3-4). Environmental governance strives for sustainability as the supreme consideration for managing all human activities, being it political, social and economic. Environmental governance is already defined by its vertical, multi-level and horizontal, multi-actor dimensions, but it does not sufficiently capture the interplay between territorially and less territorially defined actors and institutions involved. Maritime activities, illustrated by small-scale fisheries in mangrove areas, can be seen as local, bounded by time and space through the specifics of the marine ecosystem in which they occur; the possibilities and limitations of the available physical, social and institutional infrastructures; and the particular manners of developing the maritime activity at stake. Maritime activities such as shipping and cruise tourism, at the same time, may be seen as global, connected across time and space often at large distances through information and communication technology (ICT), trade and transport, science and technology. 
In conclusion, the future use of marine and coastal areas poses serious dilemmas, but it also challenges society to develop innovative approaches to achieve environmental governance of marine resources. Analysing the governance of maritime activities cannot be delimited by geography alone as maritime activities stretch across the globe. It requires a new governance arrangement that accounts for the simultaneous and equally important influences by various territorially and less territorially defined institutions and actors. For this purpose, this thesis presents the marine community concept as a new analytical lens for studying environmental governance of maritime activities. A marine community is a community of users and policy makers involved in the governance of a certain maritime activity. This thesis will construct the marine community concept that can be used in research, rectified and transformed by operationalising it in various settings: different environment problems, marine regions and maritime activities. A comparison of marine communities across different settings will provide a better understanding of territorially and less territorially defined interactions among the various actors involved in environmental governance of maritime activities in a globalising world.

\subsection{Conceptualising marine community}

This section will provide a short review of the community literature and argue how the marine community concept is positioned in the literature. In addition, it will identify deficiencies in the literature in studying the marine community in relation to territorially and less territorially interactions in the governance of maritime activities.

\subsubsection{A review of the community literature}

The majority of the literature envisions a community in at least one or a combination of the following three conceptualisations: a small spatial unit, a homogeneous social structure or a set of shared norms (Agrawal and Gibson, 1999; Crow and Allan, 1994; Lee and Newby, 1983; Smith, 2001; Willmott, 1986).

(1) Community as a small spatial unit

A small spatial unit as a community can be seen where people have something in common, and this shared element is understood geographically. Other ways of naming this community are territorial community, place community or locality. The smallness and territorial attachment of this type of community (Tonnies, 1887) is a popular conceptualisation in community-based natural resource management which owes its success to the decentralisation of authority, participation and the 
cultural autonomy of community members (Chambers and McBeth, 1992; Chitere, 1994; Etzioni, 1996; Ostrom, Burger, Field, Norgaard, and Policansky, 1999).

(2) Community as a homogeneous social structure

Another conceptualisation of community, which builds on the previous one, addresses the social structure of the community. The social structure is perceived to be homogeneous as members share another characteristic other than place, be it the same religion, sexual orientation, occupation or ethnic origin. This conceptualisation appears to be a self-fulfilling prophecy as the abovementioned shared interests are also presumed to shape a community. This type of community is particularly studied in anthropology. Resource management in this community is enhanced by the homogeneity which furthers cooperation and reduces hierarchy and conflicts (Agrawal and Gibson, 1999). Another name for this conceptualisation is a community of interest. Interest can, but does not have to be, place-bound (Hoggett, 1997, p. 7). Cyber-communities, for example, also fall within this conceptualisation and symbolise non-place-based communities of interest.

\section{(3) Community as shared norms}

The third traditional conceptualisation builds on the idea that a community exists among individuals who share "common interests and common identification ... growing out of shared characteristics" (Ascher, 1995, p. 83). This community is also called a community of communion, which refers to a sense of attachment to a place, group or idea, creating a spirit of community. In relation to resource management, common and shared rather than individual and selfish are likely to be more successful attributes (Agrawal and Gibson, 1999).

\subsubsection{The conceptual framework of marine community}

The marine community originates from ecological sciences, where it refers to a group of interacting living organisms sharing a populated marine environment (Bertness, Gaines, and Hay, 2000), resembling the small-spatial-unit conceptualisation of community. In this thesis, a marine community is based on social science definitions and insights, emphasising social, economic and political dynamics. The community literature provides a good reference point but not a proper conceptualisation for studying the territorially and less territorially defined interactions in environmental governance of maritime activities.

Influenced by globalisation, there is a tendency to diverge from a small-spatialunit community (Agrawal and Gibson, 1999). This is particularly valid for the fluid marine environment, where resources are fugitive and maritime activities have a 
highly mobile, footloose character and often do not operate within national boundaries. Environmental governance by a small-spatial-unit community is furthermore challenged because many of the resources within the marine environment are considered common pool resources, implying they are a common good and that their use is sub-tractable by and nonexclusive for various actors (Ostrom, 1990). With these competing claims and the increasing pressure on the marine ecosystem, environmental issues and nature protection moved up the public and political agendas of nation-states, international organisations, civil society and lately even economic actors (e.g., World Ocean Council, 2014a, 2014b). Although environmental problems in the marine environment have become prominent at the local level, they are increasingly being governed at the national, regional and global level by rather footloose actors, institutions and networks. As such, the community cannot only be geographically delimited to a small unit but rather needs to account for the interplay between the territorially and less territorially defined actors and networks involved in the governance of maritime activities. Nevertheless, this does not imply that the small-spatial-unit community should be disregarded. In fact, the local-global interplay is at the heart of the marine community concept. Diverging from a small-spatial-unit community also has implications for the other conceptualisations of community.

Although it is hard to believe that a community can be entirely homogeneous, the most striking assumption of the second conceptualisation of community is the extent to which it downplays the individual's agency. Even if a community is similar in some respects, it does not automatically lead to an overall homogeneous community structure because of individual preferences and the capacity of individuals to act independently. The marine community presumes a heterogeneous social structure as it embraces both users and policy makers, each with a distinct logic, rationality and purpose. Furthermore, it focuses on the agency of users and policy makers to acknowledge existing conflicts and to interact to overcome incompatible use between maritime activities and marine ecosystems.

In relation to the third conceptualisation, a community as shared norms, actors in the marine community indeed have a shared understanding that resources in the marine ecosystem are limited and that the maritime activity should be governed sustainably. However, the interests and norms for how to achieve this or the extent to which actors allow the governance of maritime activities to affect their individual interests or norms might differ significantly. Furthermore, these interests and norms are not set in stone and are likely to change over time. The marine community concept acknowledges different interests and norms among users and policy makers to come to a shared understanding of a sustainably governed 
maritime activity in relation to the marine ecosystem. This implies that actors can join the community given that they pursue the same shared understanding. Feeling connected to this shared understanding generates the community identity and represents a collective intention to strive for sustainably governed maritime activities. Although in a network the connection to other participants, relationships and personal interactions are crucial, in a community the connection to the goal or shared identity is what attracts people to become part of the community. The connection to the goal is therefore prioritised over the connection to other actors in the marine community. Therefore, it is a marine community and not a marine network.

The marine community embraces parts of the three traditional conceptualisations of community, but it cannot be conceptualised according to this community typology because of the diminishing importance of territory, its heterogeneous character and the diverging norms among actors in the marine community for achieving environmental governance of maritime activities. A marine community is a community of socio-economic and policy actors and institutions organised around a certain maritime activity that influences or will be affected by the (marine) ecosystem in which the activity occurs. Analytically, in a marine community two interdependent communities can be distinguished: a user community and a policy community as shown in Figure 1.1. User and policy communities have a distinct logic, rationality and purpose. Nevertheless, actors and to a lesser extent institutions can be part of both a user and a policy community. Over time, their role can change from being part of a user community to a policy community or vice versa. As such, a marine community allows for a dynamic view on community-environment interactions.

According to Crow and Allan (1994) and Smith (2001), a user community refers to interdependent actors that execute, and are affected by, the maritime activity and that make use of the goods and services provided by the marine ecosystem. This originates from community-based natural resource management as a bottomup approach of organisation by users who participate in the planning, research, development, management and policy-making for the entire community (Balint and Mashinya, 2006; Senyk, 2005). Decentralisation of management enables users to handle the unique social, political and ecological problems that their community faces and to find solutions ideal to their situation (Hackel, 1999; Senyk, 2005; Tacconi, 2007). It is important to note that the user community in the marine community is not as localised as the user community in community-based management because of the mobile nature of maritime activities combined with globalisation. 
A policy community, on the other hand, comprises actors who are part of (in)formal institutions and governance arrangements that regulate the maritime activity to achieve sustainable use and management of marine ecosystems (Atkinson and Coleman, 1992; Sørenson and Torfing, 2005; Walker, 1989). In political sciences and sociology different types of policy communities exist. In political sciences policy communities are often linked to corporatist and network theory and are defined as relatively slowly changing networks determining the context of policymaking in specific policy segments (Thatcher, 1998). The boundaries of the policy community are quite stable, clearly defined and driven by strong relational ties between bureaucrats, politicians and interest groups. The policy community in this thesis is a more open and sociological policy community.

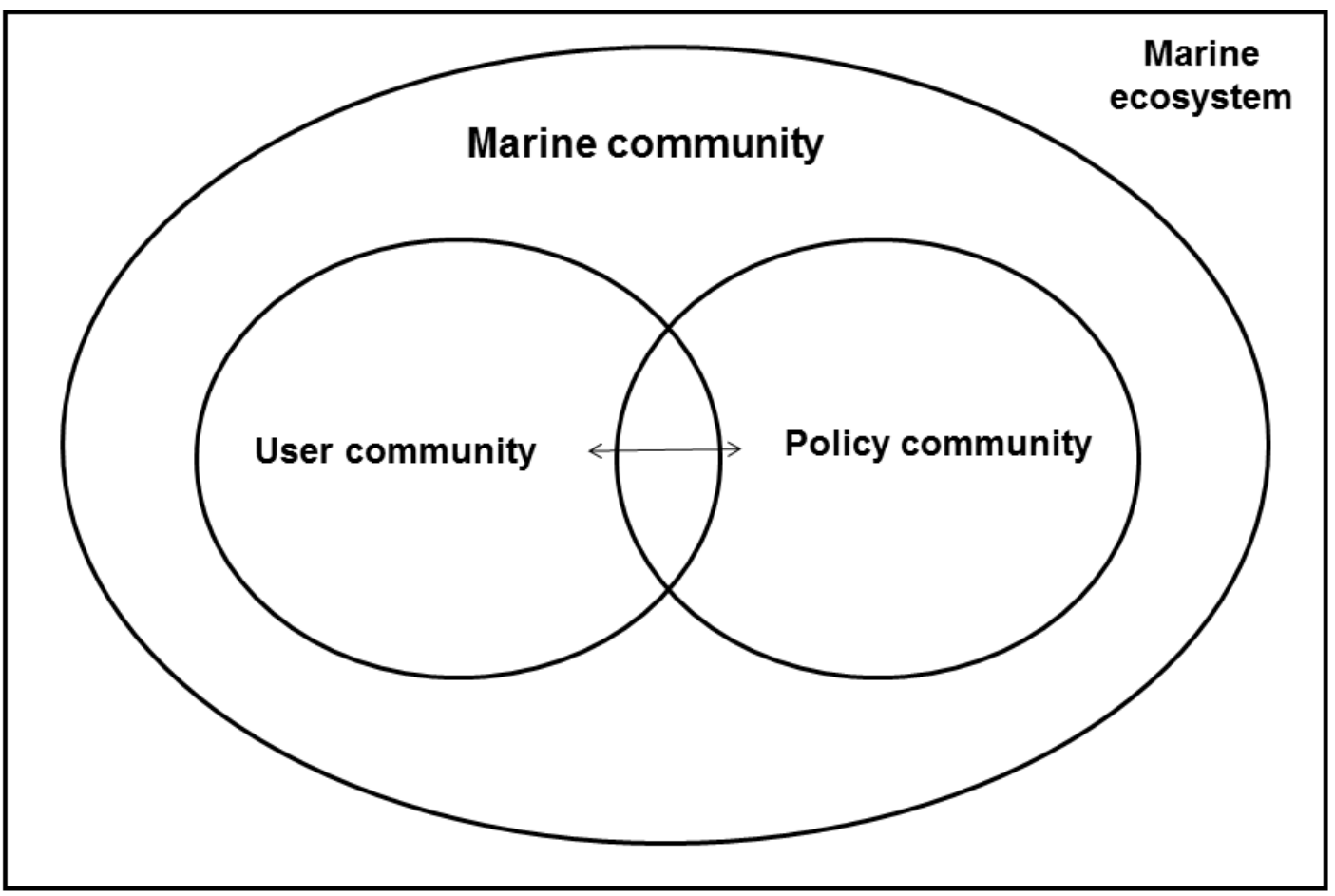

Figure 1.1. The relationship between user and policy communities within a marine community

Consistent with the shift in governance from sector-based policies to shared efforts and responsibilities of governments, market parties and non-governmental organisations (NGOs), more actors became involved in policy-making. Policy communities differ in the horizontal (multi-actor setting of governance) and vertical relationships between different layers (multi-level setting of governance) (Hooghe and Marks, 2003; Van der Zouwen, 2006; Van Tatenhove, 2012). This is also reflected in the policy community in this thesis. Actors engage in policy community to work out alternatives to policy problems of a specific field, i.e., the maritime activity. Actors depend on each other and collaborate to exchange resources. 


\subsubsection{Marine community as a governance arrangement}

The extent to which governmental and/or non-governmental actors are involved in governing, vis-à-vis each other, is the essence of the governance debate, which emerged in the 1990s. As a result, governance has become a widespread subject of study across different disciplines, and different conceptualisations of governance have been developed.

This thesis argues that user communities and policy communities are increasingly interdependent and interwoven in the marine community as both are dependent on and co-govern ecosystem goods and services. The marine community could therefore be considered as a governance arrangement, i.e., a temporary stabilisation of the content and organisation of a policy domain. In this governance arrangement different and more or less stable coalitions of policy makers and users try to influence the governance of maritime activities by designing legitimate initiatives based on shared discourses for managing resources and defining the rules of the game (on different levels) (Van Tatenhove, 2013). This is further investigated in this thesis by examining different modes and shifts the marine community uses to steer governance using the typology of Arnouts et al., which builds on Kooiman's work (Arnouts, Van der Zouwen, and Arts, 2012; Kooiman, 2003). In this typology, a governance mode is defined as "the totality of interactions, in which public as well as private actors participate, aimed at solving societal problems or creating societal opportunities" (Kooiman, 2003, p. 4). Arnouts et al. developed a continuum of governance modes with hierarchical governance on the one end and self-governance on the other and cogovernance situated in between. Hierarchical governance refers to the governance domain being mainly owned by the government, with non-governmental actors in a subservient role. Self-governance is the opposite governance mode, dominated by non-governmental actors, with government maintaining a distance. Co-governance is located in between and reflects both governmental and non-governmental actors working together in governance. Unlike Kooiman's work, Arnouts et al. make an additional distinction within co-governance. While closed co-governance depends more on restricted, structured and fixed forms of governmental/nongovernmental co-governing that closely resembles neo-corporatist models of government (Liefferink, 2006), open co-governance implies a more flexible and autonomous alternative that is related to network governance (Rhodes, 2000) and liberal pluralism (Liefferink, 2006). Governance modes can differ per policy issue within one country. For this reason the governance modes of Arnouts et al. are preferred as analytical tools over general categories such as neo-corporatism, network governance or liberal pluralism which study countries as a whole. 
Another useful concept is governance shift: the changes in governance that occur over time which prescribe a chronology of the abovementioned governance modes. In general, hierarchical and closed co-governance are considered more traditional modes of governance (Lijphart, 1968; Van Waarden, 1992) in line with the first stage of political modernity in the 1960s and 1970s (Van Tatenhove, Arts, and Leroy, 2000). Open co-governance and self-governance, on the other hand, are more contemporary modes of governance, characteristic of the stage of late modernity in which we live currently (Van Tatenhove et al., 2000). A governance shift, in line with evolving modernity in society, would then depart from a more traditional governance mode (hierarchical or closed co-governance) towards one of the contemporary governance modes (open co-governance or self-governance). In each marine community, multiple governance modes can coexist, and governance modes can shift over time. By relying on different governance modes and shifts, user and policy makers in the marine community negotiate to find integrated solutions for problems caused by conflicts concerning incompatible use among sectors, maritime activities and marine ecosystems. This thesis will further operationalise the marine community concept.

\subsection{Research objective and research questions}

\section{Research Objective}

The aim of this $\mathrm{PhD}$ thesis is twofold: first, to understand environmental governance of maritime activities by different marine communities and, second, to understand how different governance modes, shifts, styles and processes affect the role of the user and policy community in the marine community.

\section{Research questions}

How can the marine community concept enrich our understanding of environmental governance of maritime activities in distinct maritime settings?

1. How are marine communities organised to govern environmental problems in different sectoral and geographical settings?

2. How do marine communities develop in relation to various institutional settings, and how do different governance modes, shifts, styles and processes affect the role of the user and policy community in the marine community? 


\subsection{Research methodology}

\subsubsection{Ontological and epistemological stance}

The marine community concept is used as an analytical lens to look at reality. This reflects a critical realist ontological stance, which stresses science as an ongoing process in which scientists continuously improve the concepts they use to understand the mechanisms that they study (Bryman, 2004). Nevertheless, reality exists without human interpretation and interaction in the form of material components related to maritime activities, such as cruise ships and oil and gas platforms, reflecting a realist ontological stance. However, the accounts of facts or reality, such as the marine community in this thesis, are socially constructed.

Marine community is, in addition, a new concept that will gain more content and depth by its application in this thesis. Based on the data in the empirical case studies, relevant theories are selected to provide an in-depth understanding of the multiple interests and actors within user and policy communities and how these actors and the institutions they belong to influence and shape the marine community. As such, an inductive approach is taken to translate these observations into theoretical insights about marine communities and governance processes. This is consistent with a critical realist ontological stance, which stresses that the concepts to study empirical reality are always in the making.

\subsubsection{Case study design}

To understand the relationships and complexities between marine communities in different marine ecosystems and institutional settings, a case study design and a cross-case comparative analysis are applied. The outcomes of these analyses will be the building blocks for marine communities as a governance arrangement.

In this project, a case study methodology is applied (Yin, 2003). A case study methodology allows the researcher to derive a comprehensive understanding of the research object because of the in-depth focus. This methodology presents the opportunity to examine a range of different factors, to consider various causal connections and to account for the changes in these connections over time. This methodology is also suited to address actors' motives, interpretations, constructions of reality and behaviour (De Vaus, 2001; Swanborn, 2010; Yin, 2003).

To obtain an in-depth analysis of the marine community concept, four distinct cases were selected. In this multi-case design, the case studies function as exemplifying cases that provide a suitable setting for studying the marine community thoroughly in different settings (Bryman, 2004, p. 51). To capture a high diversity in environmental problems, governance processes and the 
compositions of marine communities, the selection of cases is based on two marine regions and two maritime activities that occur in marine regions. The different case studies further illustrate different multi-actor and multi-level governance settings in the policy communities (local; national and EU; global), different current and future activities and users in the user communities and different governance contexts in which the marine community exists. Consistently focusing on the marine community as a unit of analysis in each of the case studies allows for a cross-case comparative analysis across marine regions and maritime activities. Below, the selection of marine regions and maritime activities will be explained.

The case study design was initially driven by the selection of two different marine regions: the Caribbean Netherlands and the European Arctic. Both marine regions provide great potential to analyse the transnational character of the marine community as stressed in the introduction. The differences between the marine regions are expected to lead to different governance processes by marine communities.

Tropical coasts and seas are especially known for their marine biodiversity, on which many coastal and island communities highly depend for the main provision of protein and as a source of income via recreation and tourism (Murk and Klostermann, 2011). Within this region the Caribbean Netherlands was selected; it consists of the three islands of Bonaire, St. Eustatius and Saba. They are collectively called the BES islands and became tropical overseas municipalities of the Netherlands in 2010. Small islands in the Caribbean are a good example of local communities that experience environmental problems largely driven by globalisation processes. In addition, they are labelled as 'small island developing states (SIDS)' because of their intrinsic characteristics: small territories and populations with restricted economies that are highly dependent on limited natural resources and the import of goods (Águeda Corneloup and Mol, 2014). Policymaking in small islands is, therefore, often characterised by a strong reliance on intensive and personal interactions and networks. It will be interesting to see how governance with a strong role for local island communities is affected by global economic, social, political and environmental changes and how this influences the composition of marine communities in the Caribbean Netherlands. The case studies in this thesis take place in Bonaire and St. Eustatius (Statia). Bonaire and Statia are part of the Lesser Antilles, a group of islands in the Caribbean which form a long, partly volcanic island arc between the Greater Antilles to the northwest and the continent of South America (Merriam-Webster, 2001). While Bonaire is situated next to Aruba and Curaçao along the south-eastern fringe of the 
Caribbean Sea just north of the Venezuelan coast of the South American mainland (Levander et al., 2006), Statia is part of the northern part of the Lesser Antilles chain as shown in Figure 1.2. Bonaire has an arid climate, which is beneficial for tourism in relation to Bonaire's coral reefs. Unlike Statia, Bonaire lies outside the hurricane belt. It will be interesting to see whether the representation of different areas in the Caribbean will also influence governance processes differently.

Bonaire was selected as case study because it features strong interdependency between nature and economic development and tension between short-term and long-term visions in the Caribbean in relation to cruise tourism development. An increase in cruise passengers and infrastructure and facilities to accommodate them will likely put extra pressure on the island's marine ecosystem, which functions as the main tourist attraction at Bonaire. Although increased cruise tourism may be beneficial to the island's economy in the short term, the question is how sustainable this development will be (Schep, Beukering, van, Brander, and Wolfs, 2012).

Statia has a strong history of trade because of the geographical location of the island which made it a free port in the $18^{\text {th }}$ century. During the island's colonisation, the island's authority switched 22 times between the British and the Dutch. The local economy of the island flourished, particularly under the Dutch West India Company In these times the island was called The Golden Rock. Statia was selected as a case study for the following two reasons. First, its strong historical trade roots made it an attractive business environment for oil transhipment. The strong dependence on the import and export of oil in the Caribbean for the local economies of islands has often resulted in unequal relationships between market parties and small islands, especially when it comes to environmental management (Mol, Mol, and Van Vliet, 2004). The second reason is the changed constitutional status of the island to a special municipality of the Netherlands in 2010. Although this argument is also applicable to Bonaire, cruise tourism in Bonaire is still the responsibility of the island, whereas the conventional status at Statia has significantly changed the responsibilities for environmental management in relation to the oil transhipment terminal: from the island government to the Dutch Ministry of Infrastructure and Environment (Ministry of I\&E). It will be interesting to see whether the changing political situation and the intervention of the Dutch Ministry will affect the dynamics and relationships within the marine community, which used to be a small island community.

Recently, the Arctic has been opening up because of climate change. Largescale changes can be expected from the regression of sea ice coverage which is 
making natural resources and potential shipping corridors between Europe and the Far East and between America's East and West coasts increasingly accessible. The development of the Arctic region is, therefore, a major and promising economic and geopolitical issue (Lamers, Pristupa, Amelung, and Knol, 2016). The accessibility for new human activities (fisheries, transport and oil \& gas activities) will increasingly pressure marine biological resources (Knol, 2010; Lamers et al., 2016). It is yet unknown how the marine ecosystem will respond to the combination of changing environmental conditions as well as human impacts. Not only is the ecosystem response unknown, but also how local communities will adapt to new activities is unclear. Isolated (and often indigenous) communities already exposed to a changing Arctic environment are, in addition, affected by new socio-economic developments and the growing tension between these communities, the state and economic actors in governance processes. To investigate this local-global interplay in the development of the Arctic, the European Arctic and Norway more specifically, as one of the Arctic coastal states, were selected as a marine region in relation to the occurrence of interesting maritime activities such as expedition cruise tourism and offshore liquefied natural gas (LNG) production. In addition, there are existing research collaborations between Wageningen University \& Research and the Association of Arctic Expedition Cruise Operators (AECO) and with the oil and gas company Statoil, from which this research could benefit. Expedition cruise tourism and offshore LNG production occur on Norwegian territory in Svalbard and Hammerfest, respectively (shown in Figure 1.3.).

Svalbard, an archipelago halfway between the Norwegian mainland and the North Pole, was no-man's land until the beginning of the 1900s, when Norway claimed sovereignty over the islands. This was granted through the Spitsbergen Treaty (1920), which also allows treaty parties to engage in economic activities at Svalbard (Government of the French Republic, 1925). Svalbard's economy used to thrive on whaling, fishing and coal mining, but it is currently based on the pillars of research, tourism and mining. The Svalbard case, although hosting an island community, is different from the traditional local community because it has no indigenous population. The current population comprises Norwegian, Russian, Ukrainian, Polish and other non-Norwegian inhabitants, but none of them are permanent settlers. In this sense the transnational character of the marine community, even without the influence of a global maritime activity such as expedition cruise tourism, is already quite apparent.

The other case study in the European Arctic takes place in a fishing village called Hammerfest situated in Northern Norway near the Barents Sea and close to 


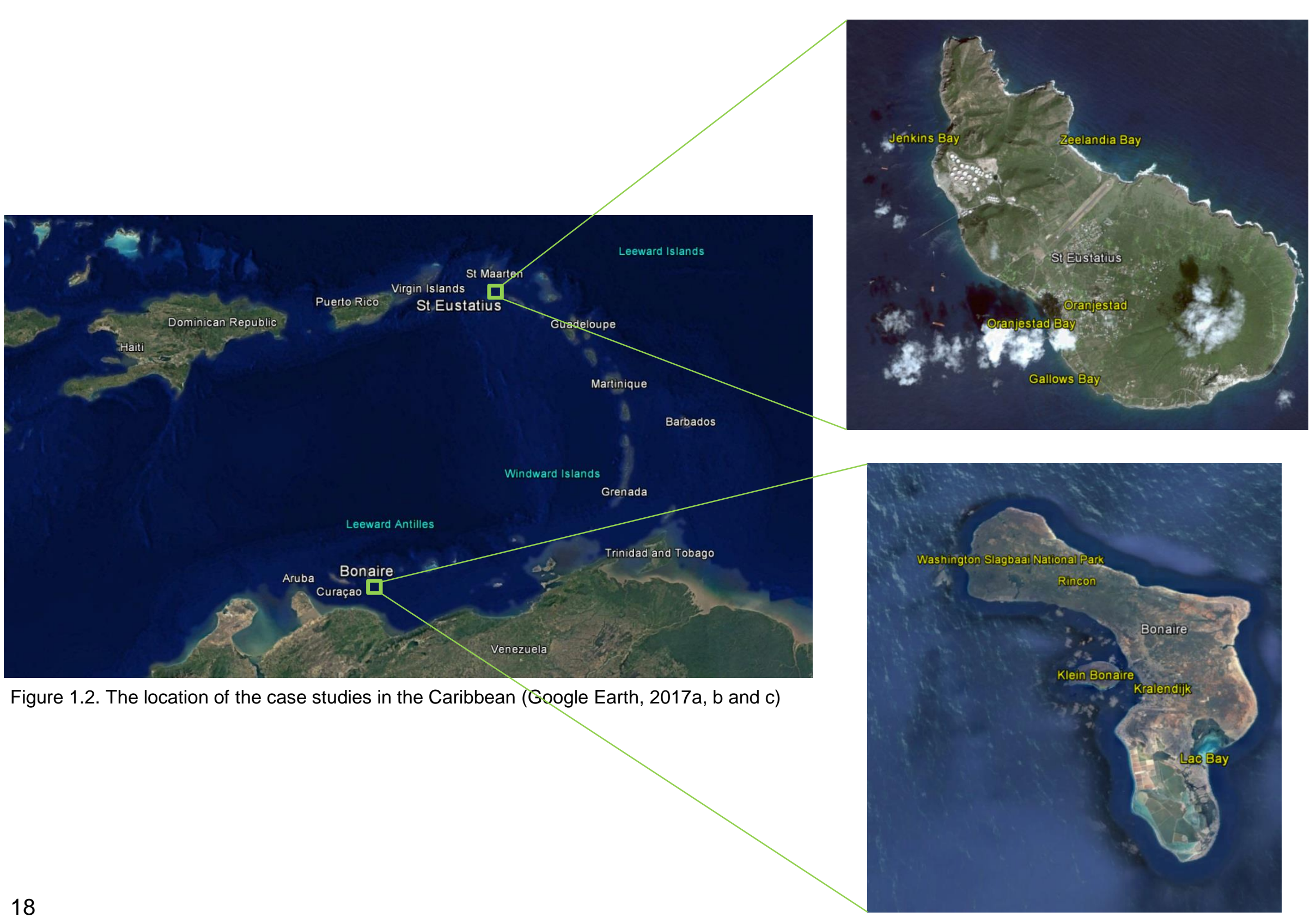


the border with neighbouring Russia. Finnmark, the area in which Hammerfest's local fisheries community is located, used to be known for out-migration and declining fisheries (Arbo and Hersoug, 1997). It has since transformed into an international centre of oil and gas activities in the Barents Sea pioneered by the offshore LNG plant of Statoil (Angell and Stokke, 2014). As such, this marine community transformed because of a new maritime activity and reflects the interplay between a local community and global activity very well.

The case study design was, in the second place, driven by the selection of different maritime activities which occur in both marine regions. This enables cross-case comparisons across maritime activities within the same marine region and across maritime activities in different marine regions. The maritime activities of cruise tourism and oil and gas were deliberately chosen for their transnational scope in relation to the marine community concept. Shipping was not selected because it is still under development in the Arctic. Fisheries, an important maritime activity, is left out because it is already intensively researched in the context of adaptive co-management (Sen and Nielsen, 1996). While cruise tourism is a very mobile and footloose activity, oil and gas activities are more static and placebased. It will be interesting to see whether the different nature of the maritime activity provokes changes in the compositions of marine communities and their governance processes.

The cruise industry is the fastest-growing segment of the global tourism business, with more than 14 million passengers in 2009 and an annual growth rate of approximately 7\% (Cruise Lines International Association, 2010). Cruise companies operate worldwide, with cruise ships and tourist flows literally spanning the globe, including the most remote and vulnerable regions (Haase et al., 2009). The market has traditionally been dominated by North America, but European and Asian clientele and destinations are recently witnessing the largest growth rates. The cruise market is highly differentiated, from small-scale adventure cruises to luxury large-scale cruises with vessels equivalent to floating destinations (Greenwood and Barron, 2006; Wood, 2000). The mobile nature of cruise tourism challenges governance by place-based and sovereign state actors, such as ports or environmental agencies (Lamers, Eijgelaar, and Amelung, 2015; Papathanassis and Beckmann, 2011). This governance challenge, nevertheless, is increasingly being targeted by intergovernmental policy processes, industry self-regulation, civil society initiatives, and other non-state governance arrangements. This is expected to be reflected in the composition of the marine community, which is presumed to be less place-based compared with oil and gas activities.

The case studies in Svalbard and Bonaire address different types of cruise 
tourism, small-scale expedition cruise tourism (approximately 500 passengers/cruise) and large-scale cruise tourism (approximately 3,000 passengers/cruise), respectively. Svalbard is therefore often the only destination during a ten-day cruise around the archipelago, whereas Bonaire is one of several Caribbean island destinations visited for only a day during a longer cruise journey. In that sense the interaction between local islands as cruise destinations and global and transnational cruise lines is crucial in the competitive Caribbean cruise market. Cruise tourism in Bonaire was selected as a case study because its cruise season is expanding from six months to all year round. This increase in cruise tourism is the result of Bonaire's increased embeddedness in the transnational cruise network of the Florida Caribbean Cruise Association (FCCA). The Bonaire case clearly portrays the local-transnational interaction in the marine community in relation to cruise tourism. Expedition cruise tourism at Svalbard was selected as a case study because it presents a clear case of the coexistence of state governance and collective self-governance, driven by the establishment of AECO, in one cruise destination. Tourism in Svalbard increased rapidly in the 1990s, which made the need for regulations urgent (Viken, 2011). Until that time, people referred to Svalbard as the Wild West, where cruise operators and visitors could behave like cowboys and take human bones, polar bear skulls, flora and fauna and fossils without any re strictions. While Svalbard used to be governed by Norwegian Ministries without significant local influence, the 1990s were marked as an era of emerging network governance involving private industry, the World Wildlife Fund (WWF), and local authorities, with blurring borders and power relations between them (Viken, 2006). The analysis is expected to be influenced by the different type of cruise tourism in the two case studies.

Oil and gas production is more static compared with cruise tourism. Platforms and terminals stay in one place, and only the ships transporting oil and gas products move across the globe. Oil and gas fields, as well as platforms and terminals, are within national boundaries or, in the case of offshore activities, in the territorial seas or exclusive economic zones established by coastal states. The governance of oil and gas activities is therefore more nationally organised, often by state actors. The cases of Statia and Hammerfest address different processes of the industry, oil storage and transhipment on land and offshore natural gas extraction and conversion to LNG, respectively. The terminal in Statia is a for-hire bulk liquid terminal engaged in third-party storage and handling for oil being transported in single-hulled tankers from the Middle-East and Venezuela to double-hulled tankers, which are allowed in the United States of America (USA). After the new constitutional status of Statia in 2010, the Netherlands realised that 


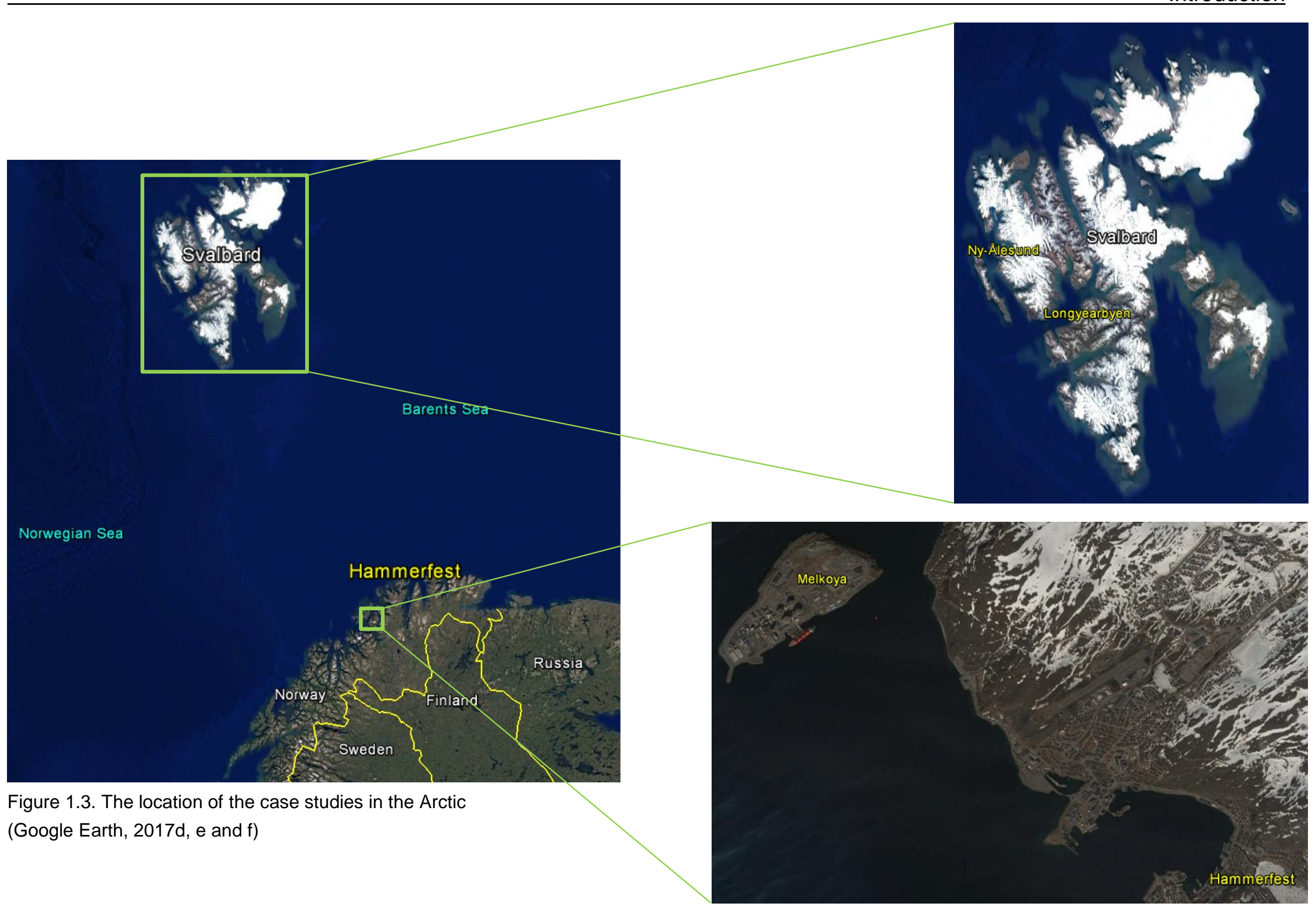


the local island community did not have the capacity to handle a large oil terminal given the pressing environmental problems it has caused over the years. In response, they took over the enforcement of environmental management of the terminal. This change in governance from the local to the national level triggered the selection of this case. Hammerfest hosts a LNG plant that converts natural gas extracted from three offshore gas fields which is transported through a $160 \mathrm{~km}$ pipeline to the conversion plant. It is a remarkable case study because of the large-scale and difficult technology it applies in the vulnerable Arctic environment as it extracts gas through subsea facilities.

Table 1.1. provides a general overview of the case studies based on the characteristics of the marine regions in the European Arctic and the Caribbean Netherlands, the activities taking place and the multiple actors and levels involved in the marine community.

\subsubsection{Cross-case comparative analysis}

After an in-depth analysis of each case study, a cross-case comparative analysis of the four marine communities and their governance processes will be presented in the conclusion. The aspects for comparing the cases include the following:

1. Marine communities around different maritime activities

2. Marine communities in different marine regions

3. Governance modes, shifts, styles and processes by marine communities

The first two aspects relate to sub-research question 1 and the third aspect to subresearch question 2.

\subsubsection{Data collection}

This thesis draws on a qualitative research approach based on the collection of primary and secondary data. The primary data concern semi-structured, in-depth interviews and (participatory) observations conducted by the researcher while the secondary data concern literature, policy documents, newspapers and social media.

Before the data collection started, interviews with an expert for each marine region were conducted to gain a better understanding of the past, current and future changes in the marine region and the communities living in the Caribbean Netherlands and the European Arctic. The interviews conducted in this thesis are characterised as semi-structured, in-depth interviews because they are loosely structured interviews guided by a topic list (see Appendix 1). This type of interview gives the interviewee more freedom to talk about issues that are not always listed in the topic list but still relevant to the research (Bryman, 2004). 
Table 1.1. Overview of the case studies

\begin{tabular}{|c|c|c|c|c|c|c|}
\hline & & & Svalbard & Hammerfest & Bonaire & Statia \\
\hline \multicolumn{2}{|c|}{ Marine region } & \multicolumn{3}{|c|}{ European Arctic } & \multicolumn{2}{|c|}{ Caribbean Netherlands } \\
\hline \multicolumn{2}{|c|}{ Economic activities } & & $\begin{array}{l}\text { science } \\
\text { tourism } \\
\text { mining }\end{array}$ & $\begin{array}{l}-\quad \text { oil and gas } \\
\text { production } \\
\text { - } \text { fishing }\end{array}$ & $\begin{array}{ll}- & \text { tourism } \\
- & \text { oil transhipment } \\
- & \text { salt production }\end{array}$ & $\begin{array}{ll}- & \text { oil transhipment } \\
- & \text { tourism fishing }\end{array}$ \\
\hline \multirow{3}{*}{$\begin{array}{c}\text { Marine } \\
\text { Community }\end{array}$} & $\begin{array}{l}\text { Maritime } \\
\text { activity }\end{array}$ & - & $\begin{array}{l}\text { expedition cruise } \\
\text { tourism }\end{array}$ & $\begin{array}{ll}- & \text { offshore LNG } \\
& \text { production } \\
\end{array}$ & - cruise tourism & - oil transhipment \\
\hline & $\begin{array}{l}\text { User } \\
\text { community }\end{array}$ & $\begin{array}{l}- \\
- \\
- \\
-\end{array}$ & $\begin{array}{l}\text { industry association } \\
\text { foreign tour } \\
\text { operators } \\
\text { researchers } \\
\text { local inhabitants }\end{array}$ & $\begin{array}{l}\text { - Statoil } \\
-\quad \text { Sámi } \\
-\quad \text { fishermen } \\
\text { - local inhabitants }\end{array}$ & $\begin{array}{ll}\text { - } & \text { transnational cruise } \\
& \text { industry association } \\
- & \text { local tour operators } \\
\text { - } & \text { local inhabitants }\end{array}$ & $\begin{array}{ll}- & \text { NuStar } \\
- & \text { fishermen } \\
- & \text { local inhabitants }\end{array}$ \\
\hline & $\begin{array}{l}\text { Policy } \\
\text { community }\end{array}$ & - & $\begin{array}{l}\text { national Norwegian } \\
\text { authorities } \\
\text { local authorities }\end{array}$ & $\begin{array}{ll}- & \text { national Norwegian } \\
& \text { authorities } \\
\text { - } & \text { national NGOs }\end{array}$ & $\begin{array}{ll}- & \text { island government } \\
- & \text { local NGOs }\end{array}$ & $\begin{array}{ll}\text { - } & \text { national Dutch } \\
& \text { authorities } \\
- & \text { island government } \\
\text { - } & \text { local NGOs }\end{array}$ \\
\hline
\end{tabular}


All semi-structured interviews were conducted using the same topic list, covering questions on contacts and interactions in the community, access to knowledge and information, rule compliance, conflict resolution and their perceptions on the governance of the maritime activity and environmental problems at stake. These topics were inspired by the community literature and used to analyse the organisation of the marine community and their governance processes. However, the topic list was slightly modified for each case study.

Before the semi-structured interviews occurred, test interviews were conducted to verify and improve the topic list. In total, 106 interviews were conducted by the author of this thesis (see Table 1.2.). The interviews were mainly conducted face to face during fieldwork but also sometimes by phone, Skype or videoconferencing. The interviews lasted between 25 and 90 minutes. Interviews were conducted with key informants who represent the main actor groups in the case studies, such as national and local governmental authorities, oil and gas companies, cruise operators, branch organisations, tourism organisations, fisheries, port authorities, NGOs, local inhabitants and researchers (see Appendix 2). Before the fieldwork started, interview appointments were already scheduled with relevant key informants found in policy documents, research reports, websites and newspapers. Other interviewees resulted from snowball sampling influenced by the preselected interviewees (Creswell, 2014). Additional primary data was gathered through participant observation during fieldwork, several meetings and conferences. Regarding secondary data, different sources were used. First, scientific and academic publications about the subject of the research were read and analysed. Scientific publications about each of the case studies were not always sufficiently available. Therefore, scientific publications were supplemented with data from policy briefs, minutes of meetings, monitoring reports, legislation, newspapers and social media.

\subsubsection{Data analysis}

Almost all interviews were recorded with a voice recorder; in some cases (8) the circumstances (noisy environment (3), bad Skype or phone connection (3), a guided tour (1) or dead battery (1)) did not allow for this. The interviews were transcribed verbally as soon as possible after the interview took place, preferably the same day or the next day. At that time the interview was still fresh in the interviewer's mind. This greatly reduces the amount of fast-forwarding and rewinding during transcription. In addition, going through the interview again provided an opportunity for the interviewer to reflect on the information. Interesting or important findings could already be verified or cross-checked in upcoming interviews during fieldwork. As such, this enabled efficient data collection. The 
anonymity of the interviewees was guaranteed by means of a coding system used for referencing interviews in this thesis. Although the interviewees were categorised as governmental, market, civil society or research actors, some of them have or had multiple roles. In those cases, the most dominant category was chosen.

Table 1.2. Number of interviews $(n=106)$

\begin{tabular}{|l|c|c|c|c|c|}
\hline & $\begin{array}{c}\text { Hammer- } \\
\text { fest }\end{array}$ & Svalbard & Bonaire & Statia & Total \\
\hline Market actors & 5 & 19 & 21 & 7 & 52 \\
\hline $\begin{array}{l}\text { Governmental } \\
\text { actors }\end{array}$ & 3 & 4 & 8 & 8 & 23 \\
\hline Civil society actors & 2 & 1 & 5 & 5 & 13 \\
\hline Researchers & 4 & 7 & 2 & 4 & 17 \\
\hline \hline Total & 14 & 31 & 36 & 25 & 106 \\
\hline
\end{tabular}

The data were structured through coding with ATLAS.ti (see Appendix 3-6). Several rounds of coding occurred. The first round applied top-down coding in relation to the marine community and how it governs environmental problems caused by maritime activities. The categories for top-down coding were based on the interview topic list: actors in the user and policy communities, contact and interactions in the communities, means they use to interact, access to knowledge and information, how rule compliance and conflict resolution is ensured and their perceptions on the governance of the maritime activity and environmental problems. During top-down coding new coding categories were revealed in the analysis and used for bottom-up coding based on the additional theoretical framework chosen to deepen the understanding of the marine community. This also reflects the inductive approach of this thesis, driven by the empirical findings and additional theoretical frameworks that reflect the reality in the empirical findings. The interactions among actors in the marine community and the means they use to interact were visualised through mind mapping, which resulted in the community composition.

In case study design, triangulation is used to reduce bias and to strengthen the reliability of the research findings (Bryman, 2004; Mason, 2002; Yin, 2003). Triangulation makes use of "multiple sources of evidence" (Yin, 2003, p. 114) to identify and compare different perspectives on the same problem or research question. Data triangulation started with double checking by asking different 
interviewees the same information or by consulting key interviewees on more than one occasion. Afterwards, the information was also cross-referenced with policy documents, scientific publications, observations and news items (Bryman, 2004). In the end, triangulation is determined by an iterative process; thus, multiple rounds of structuring and cross-referencing occurred (Bogdan and Biklen, 2006; O’Donoghue and Punch, 2003).

\subsubsection{Research validity}

The qualitative research methodology taken in this thesis poses some questions about the validity and reliability of the research conducted. Validity refers to the accuracy of the findings and can be enhanced in different ways (Creswell, 2014). A distinction is made between internal validity and external validity.

Internal validity relates to the integrity between empirical and theoretical work. Triangulation of the data sources, as explained above, is one of the approaches used in this thesis to enhance internal validity (Bryman, 2004; Yin, 2003).

A second approach is the use of semi-structured interviews with large numbers of interviewees representing different actor groups. Additional interviews were still conducted even if the point of data saturation was already seemingly achieved to benefit the most from the time spent in the field.

This leads to the third approach to enhancing the internal validity in this thesis. Semi-prolonged periods of exposure to the research object during fieldwork enriches the researcher's in-depth understanding (Creswell, 2014). Data for the Svalbard case was collected during a month-long stay in the summer of 2014 in Svalbard: two weeks in Longyearbyen, the departure and arrival port for expedition cruises around Svalbard and two weeks in Ny-Ålesund, the international research community that has become a tourist attraction for expedition cruises and a few days in Oslo for interviews with NGOs and policy makers. Additional data were collected later on in August 2015 for two weeks during the Netherlands Scientific Expedition Edgeøya Spitsbergen. The Hammerfest case relies on data from a tenday stay at Hammerfest in October 2014 covering interviews with oil and gas companies, the supply industry, Hammerfest municipality and local inhabitants and a week in Oslo for interviews with Norwegian authorities and NGOs. The fieldwork period in the Caribbean Netherlands from March-April 2015 consisted of a threeweek stay in Bonaire and ten days in Statia. Any developments in relation to the case studies after fieldwork received follow-up as well.

Later in the writing process, internal validity was further guaranteed by verifying questions or new insights with interviewees. Preliminary results and draft versions of the chapters were discussed with supervisors, co-authors, colleagues and presented and discussed with a wider (scientific) audience at various international 
conferences, project and department meetings, master classes and workshops. The chapters benefitted greatly from these opportunities for peer debriefing and feedback. This helped to reduce the bias of the researcher in interpreting the empirical findings. The researcher and the research results are continuously influencing one another. Reflecting on and mirroring the results to a critical audience is rewarding and makes the researcher more aware of his/her own assumptions or bias. The final, but not less important, means for improving the internal validity of this $\mathrm{PhD}$ thesis originates from the peer review process for the research proposal and each of the four empirical chapters in respected academic journals. Once a chapter was published in the respected academic journal, a copy of the chapter was sent to the interviewees for the case study at stake. Interviewees read the chapter with great interest and thanked the author for the correct and detailed analysis.

External validity questions the generalisation and integrity of the conclusions drawn in the research. The main problem with qualitative research is that it is largely context-dependent. This implies that generalisations cannot be applied directly one-on-one to a different context but rather should be framed as generalisations based on the theoretical or analytical stance taken (Boeije, 2010; Bryman, 2004; Yin, 2003). In this thesis, the general limited external validity of case studies (Creswell, 2014; Yin, 2009) is strengthened by the cross-case comparative analysis which will be presented in the conclusion. As explained in the previous section, the cases are selected as exemplifying cases not only in relation to the marine community concept but also for the socio-economic developments that take place in the marine regions and the maritime activities they host. Consistently focusing on the marine community as a unit of analysis in the four case studies enables a profound understanding of marine communities across various governance contexts, distinct marine regions and different maritime activities. These findings will be further discussed in relation to the literature. $A$ major challenge is that marine community is a new concept that diverges from traditional conceptualisations in the community literature. Nevertheless, the community literature will be valuable for identifying what the marine community and traditional conceptualisations of community have in common and for emphasising the added value of the marine community concept. To relate the findings on marine communities to contemporary trends in the governance of maritime activities in a globalising world, other bodies of literature are needed. Globalisation and less place-based forms of governance hint towards the literature on the global network society and mobility studies. However, "often what a case study exemplifies will only become apparent after the case study has been carried 
out" (Bryman, 2004, p. 52). The extended generalisability will therefore be further discussed in relation to the relevant literature in the methodological reflection at the end, building on the findings in the individual case studies and the cross-case comparative analysis.

\subsection{Outline of the thesis}

After setting the stage for the thesis in this introduction, this section will provide the outline of this thesis. Chapters 2 through 5 will provide a sequential case study analysis of the four cases. These four chapters have been published in respected academic journals, but minor changes have been made in the chapters in order to create a coherent thesis.

Chapter 2 presents the case study on LNG production in Hammerfest. Hammerfest, a village in Northern Norway, used to be a small-scale local fisheries community which has transformed into an international oil and gas marine community because of a new LNG production plant. The chapter analyses how the marine community is being shaped by institutional, strategic and oppositional coalitions striving for economic growth, environmental and community development, respectively.

In Chapter 3 the case study on oil transhipment in Statia is analysed. In 2010, Statia became part of the Netherlands, significantly changing the responsibilities related to environmental management of the oil terminal. This is investigated by looking into the new power dynamics within and between the user and policy community in the marine community and how this affects governance.

Chapter 4 analyses the governance of cruise tourism in Bonaire. In this case study the marine community is studied from a networks and flows perspective as cruise tourism in Bonaire, and in the wider Caribbean, is increasingly governed by an interplay between local and transnational cruise networks and flows. Moreover, this chapter examines how unequal relationships have emerged between cruise lines and destinations and how they affect sustainable cruise tourism in Bonaire.

In Chapter 5 the fourth case study is presented: expedition cruise tourism, a relatively small-scale, nature-based type of cruise tourism, in Svalbard. The marine community features the coexistence of state governance and collective self-governance driven by the branch organisation AECO. This chapter looks into the contribution of collective self-governance and its reliance on information systems, next to already-existing state governance, to govern tourism sustainably.

Chapter 6 will present the conclusions of this thesis. Based on the in-depth analysis of each of the cases in the preceding chapters, a cross-case comparative analysis of marine communities between governance in distinct marine regions 
and of different maritime activities will be presented. Based on the findings in the cross-case comparative analysis, theoretical conclusions will be drawn about marine communities as a contemporary governance arrangement in discussion with relevant theory. Afterwards, a reflection on methodology will be given before providing recommendations for future research and policy implications. 



\section{2.}

\section{Liquefied natural gas production at Hammerfest: a transforming marine community}

This chapter has been published as

L.K.J. van Bets, J.P.M. van Tatenhove, and A.P.J. Mol (2016)

Liquefied natural gas production at Hammerfest: a transforming marine community Marine Policy 69: 52-61 


\begin{abstract}
Global energy demand and scarce petroleum resources require communities to adapt to a rapidly changing Arctic environment, but as well to a transforming socioeconomic environment instigated by oil and gas development. This is illustrated by liquefied natural gas production by Statoil at Hammerfest, which opened up the Barents Sea for oil and gas drilling. Although environmental organisations, Sámi indigenous people, fisheries and local inhabitants of Hammerfest strive for environmental and community development in relation to liquefied natural gas production by engaging in negotiations with Statoil and the Norwegian government, they are overshadowed by economic growth, implemented by a strong coalition between Statoil and the Norwegian State. Sustainable development of liquefied natural gas production is therefore constrained by centralised decision-making by the institutional coalition. Statoil's concessions on environmental and community development were rather based on cost-efficient and short-term means. This is strengthened by the fact that contact with stakeholders faded away once the social license to operate was achieved. This chapter will analyse why current governance of liquefied natural gas production in Hammerfest did not move beyond economic development.
\end{abstract}

Key words: Coalitions, Hammerfest, Marine community, Small island developing state, Sustainable development 


\section{Vammerfest offshore oil \& gas}

A transforming marine community!

Global energy demand and scarce petroleum resources require local communities to adapt to a changing Arctic environment, but as well to a transforming socio-economic envi-ronment instigated by oil and gas.
This is illustrated by Hammerfest which transformed from a local fisheries community to a centre of oil and gas activities, pioneered by liquefied natural gas production by Statoil.

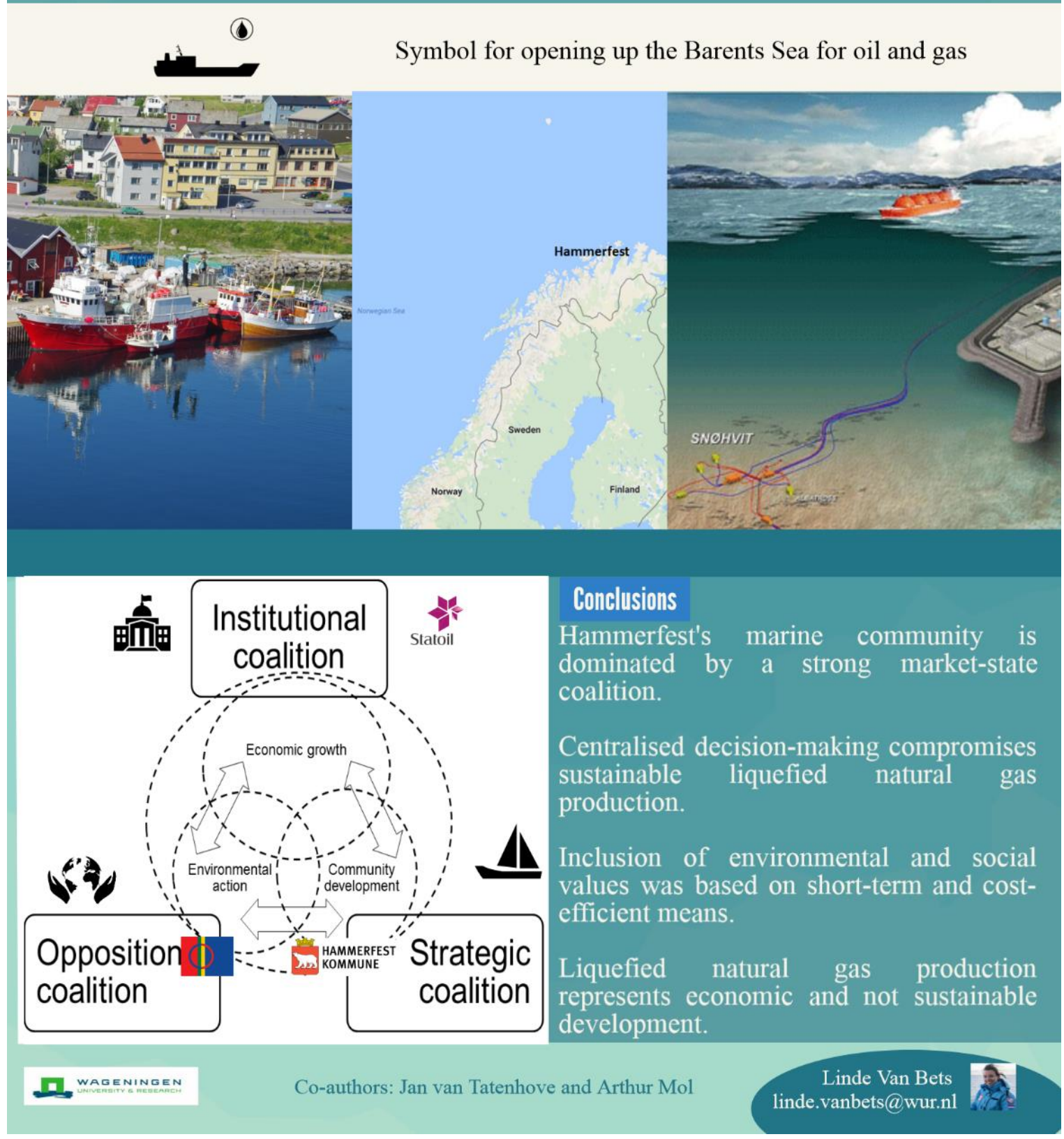

Figure 2.1. Graphical abstract Hammerfest 



\subsection{Introduction}

The convergence of rapidly increasing global energy demands and climate change in the Arctic opens up possibilities for oil and gas companies. At the same time, they face unique challenges. The Arctic, despite moderating temperatures and retreating sea ice, remains a harsh environment. Human and environmental safety is difficult to ensure. The Arctic environment is fragile and recovers slowly after ecosystem damage (Patin, 1999; Short, 2007). Another challenge is that small, isolated (indigenous) communities, in for example Alaska, Canada, Russia, the Shetland Islands (United Kingdom) and Norway, which are often highly dependent on marine resources for subsistence, are confronted with large oil and gas companies. These communities, already exposed to a changing Arctic environment, are now affected by an external labour force, industrial development, energy politics and sudden wealth (Klick, 2009; The Arctic Council, 2007), but also with the growing tension between these communities, the state and the oil and gas industry.

In Northern Alaska there is for over thirty years a structural conflict over offshore oil and gas development in the Chukchi and Beaufort Seas, between surface users (Inupiat subsistence hunters), subsurface owners (the state and federal governments that own the oil and gas rights), and the oil industry. While there are many opportunities for local involvement in offshore decision-making, cultural factors, local capacity and competing interests compromise effective use of such opportunities (Haley et al., 2009, 2011). Another example concerns oil and gas exploitation in Nunavut (Canada). Although Nunavut does not have any offshore jurisdiction, Inuit indigenous people rights are protected through various rules and organisations, such as the Inuit Circumpolar Council, the Canadian Constitution and settled land claim agreements which are treaty based like the Nunavut Land Claims Agreement (Pelaudeix, 2015). Both in Alaska and Canada the exploitation of oil and gas reserves has led to the settlement of indigenous ownership claims. In Russia, on the other hand, resources have been extracted disregarding local land claims and involvement. However, the examples of the Yama-Nenets Autonomous Okrug and the neighbouring union Yerv symbolise a growing empowerment of indigenous communities in relation to oil and gas companies (The Arctic Council, 2007). Finally, in 1975 Sullom Voe (Shetland Islands, UK) was identified as a location for a pipeline terminal and support facilities for offshore oil and gas in the North Sea. After 30 years of experience, Sullom Voe became a pioneer model of integrated coastal zone management based on adaptability and independence from government, industry and interest groups (Ritchie, 2004). 
This chapter will look into one of such communities, Hammerfest's fishing community, near the Barents Sea, off the northernmost tip of Norway and neighbouring Russia. Hammerfest became the capital of Norway's new 'Arctic Energy Province' because of oil and gas discoveries pioneered by Statoil's LNG plant. During this development, Statoil faced, on the one hand, technological hurdles and opposition from environmentalists, sceptical fishermen and a wary local population. The plant introduced, on the other hand, socio-economic changes which were welcomed by Hammerfest's community. Finnmark County, where Hammerfest is located, is highly dependent on resources of the Barents Sea. Until recently this area was known best for out-migration and a declining fishing industry because of its isolated location and globalisation of fisheries (Arbo and Hersoug, 1997). Because of the construction and putting into operation (in 2007) of the LNG plant, Hammerfest experienced a population growth and a thriving economy (Klick, 2009). Hence Hammerfest's community needs to adapt to a rapidly changing Arctic environment, but also to a new socio-economic environment instigated by oil and gas developments. To adapt to such changes is particularly challenging for Hammerfest's community, which resembles characteristics of what is labelled a 'small island developing state': a rather isolated territory with abundant natural resources and limited governance capacity in terms of human, financial, information and other resources (Águeda Corneloup and Mol, 2014). Such areas face challenges in resource management such as lack of knowledge, lack of resources and a scale mismatch between actors impacting natural resources and actors preventing/governing such impacts. Effective governance is crucial for maximising benefits and minimising negative impacts.

The aim of this chapter is to analyse the introduction of LNG production in the community of Hammerfest and the enabling and constraining conditions of this community to govern environmental consequences of LNG production in Hammerfest. The central research question is: How is Hammerfest, as an example of a SIDS type of community, affected by the introduction of a new activity, such as a new LNG plant? And in what way is such a community capable of preserving its vulnerable marine ecosystem in relation to environmental consequences of this new activity?

Section two will introduce the theoretical framework. Core concepts are marine community and the policy arrangements approach. Section three describes the methodology, while section four analyse and explains the transformation of Hammerfest's community around LNG production, based on empirical data from interviews. This section starts with the reconstruction of the marine community followed by the implications for sustainable development of 
LNG production in Hammerfest. Section five presents the discussion and section six the conclusions and recommendations.

\subsection{Theoretical framework}

To analyse socio-economic and political dynamics around LNG production in Hammerfest in relation to a rapidly changing Arctic environment, the concept of marine community is introduced. A marine community is a community of socioeconomic and policy actors and institutions organised around a certain maritime activity which influences or will be affected by the (marine) ecosystem in which the activity occurs. Analytically, in a marine community two interdependent communities can be distinguished: a user and a policy community, shown in Figure 2.2. Both communities have a distinctive logic, rationality, purpose and institutional rules. A user community is a community of interdependent actors that executes and is affected by the maritime activity and which makes use of the goods and services marine ecosystems provide (Crow and Allan, 1994; Smith, 2001). A policy community comprises actors that are part of (in) formal institutions and governance arrangements that regulate maritime activities to achieve sustainable use and management of marine ecosystems (Atkinson and Coleman, 1992; Sørenson and Torfing, 2005; Walker, 1989).

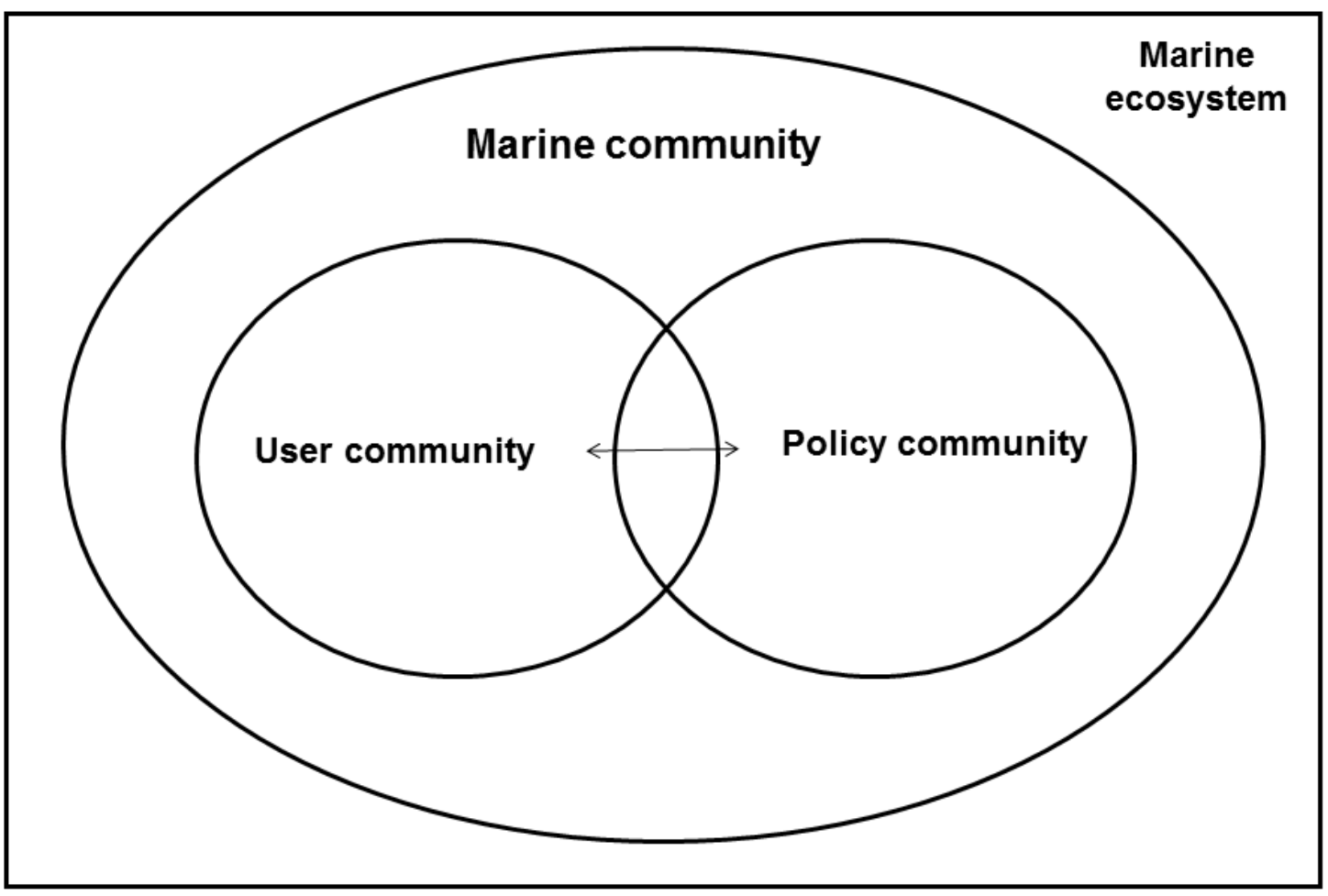

Figure 2.2. The relationship between user and policy communities within a marine community 
To analyse the functioning and development of marine communities the dimensions of the policy arrangement approach are applied, such as actors and their coalitions, resources, rules of the game and discourses (Arts and Van Tatenhove, 2004). This chapter focuses on the development and institutionalisation of coalitions and how they make use of the other dimensions of the policy arrangement approach, in order to understand the enabling and constraining conditions for sustainable development of the marine community in Hammerfest.

The formation of policy coalitions is analysed from both a strategic and an institutional perspective. In general, marine communities consist of interdependent state, market, civil society and scientific actors (from different levels) who interact with each other in user and policy communities. The interdependency between actors is determined by their ability to possess, choose to share and mobilise resources, and to define and to apply rules of the user and policy community, based on their perceptions and discourses. Resources can vary from tangible resources such as regulations, financial means and databases to less tangible, but equally important, resources such as power, status, legitimacy, knowledge and information. Rules refer "to the rules of the game currently in operation, in terms of formal procedures of decision-making and implementation, as well as informal rules and routines of interaction" (Liefferink, 2006, p. 47). Rules thus determine how decision-making takes place, who is involved and who has access to certain resources. Perceptions are definitions or images of reality used by actors to interpret and to evaluate their actions and those of others (Arts and Buizer, 2009; Rein and Schon, 1986; Van Twist and Termeer, 1991; Weick, 1979). Based on these perceptions, "ensembles of ideas, concepts and categorisations are produced, reproduced and transformed in a particular set of practices and through which meaning is given to physical and social realities, the so called policy discourses" (Hajer, 1995). Guided by policy discourses, actors will decide with whom they will form a policy coalition in which they share resources and strategies. As such these policy coalitions will identify similar goals and therefore engage in policy processes to achieve them. In this policy process some coalitions might support the dominant policy discourse or rules of the games, while others will challenge these (Arts and Van Tatenhove, 2004).

To integrate LNG production in Hammerfest's marine community in a sustainable way, forms of governance need to be tailored and adapted to the (changing) characteristics of the marine community and marine ecosystem. Therefore this chapter will analyse how the transformation of the marine community has enabled or constrained the governance of LNG production in Hammerfest. 


\subsection{Methodology}

To understand relationships, complexities and institutional settings within a marine community, a case study design was chosen. A case study allows the researcher to derive an in-depth understanding of the research object by examining a range of factors, potential causal connections as well as how they change over time. In addition, this methodology is useful to address actors' motives, interpretations, constructions of reality and behaviour (Swanborn, 2010; Yin, 2003). Hammerfest was selected as a case study because it is a symbolic push for Arctic oil and gas development as Statoil's LNG plant reversed the long-standing closure of the Barents Sea for oil and gas drilling (Klick, 2009). Another interesting characteristic is the coexistence with local fisheries and Sámi indigenous people. Furthermore Hammerfest shows different forms of cooperation between a large oil and gas company and a local municipality. Cooperation is for example initiated from Statoil's Corporate Social Responsibility strategy (Statoil, 2013) which encompasses the idea that businesses have not only economic and legal obligations, but also ethical and philanthropic responsibilities to society which go beyond making profit for their shareholders (Carroll, 1991). This chapter will investigate how cooperation between different coalitions affects possibilities for sustainable development in Hammerfest.

The semi-structured interviews with key informants served for mapping the marine community structure and for identifying how actors positioned themselves in coalitions in this community and which resources, rules, perceptions and discourses they used. All the semi-structured interviews were conducted using the same topic list (see Appendix 1), covering questions on stakeholders' contacts and interactions in the community, access to knowledge and information, rule compliance, conflict resolution and their perceptions, distracted from the theoretical framework. Key informants represented national and local governmental authorities, oil and gas companies and their supply industry, NGOs, researchers and fishermen (see Appendix 2). Fieldwork at Hammerfest was conducted for two weeks in October 2014. 14 interviews were conducted in total, of which nine with a single interviewee and five with multiple interviewees. Nine interviews were conducted face-to-face, four by Skype and two by videoconferencing. Before the field work started seven appointments were already made with a selection of interviewees, based on their role in the marine community. Remaining interviewees resulted from a snowball sampling method influenced by the preselected interviewees. Information provided by interviewees was double checked by asking different interviewees the same information. All the interviews were recorded with a voice recorder. The interviews were transcribed 
as soon as possible after the interview took place. Anonymity of the interviewees was guaranteed; therefore a coding system is used for referencing the interviews (see Appendix 2). Data analysis was based on triangulation of data from the semistructured interviews, literature, policy documents and (participatory) observations by the researcher through coding with ATLAS.ti (see Appendix 3).

\subsection{A transforming marine community on LNG production in Hammerfest}

Hammerfest is located in Finnmark (see Figure 2.3.), Norway's most fisherydependent county, because of its high adjacency to resources in the Barents Sea, such as Atlantic cod and herring, and the significant amount of Russian landings of cod it receives. Traditionally, fishing villages in Finnmark are characterised by their scattered location, limited industrial base and great distances between populated areas. Large investments by the Norwegian government transformed the marine community in Finnmark from a fishing to a fish processing community in the 1970s.

Afterwards governmental interventions introduced a welfare policy in Finnmark which resulted in the public sector, followed by tourism. Nevertheless fisheries still faced resource and market crises in the 1980s and 1990s (Arbo and Hersoug, 1997). Currently local fishermen feel threatened by globalisation of fisheries; in particular by industrial fisheries in southern Norway and Russia. As a result Hammerfest's population declined. Especially young people left because of lack of future perspectives as fishing fared poorly and new business opportunities were stagnant (Klick, 2009, I-G-3). Until 2002 Hammerfest's marine community was highly dependent on fisheries for its livelihood and local economy and consisted of a local user community of fishermen, local inhabitants and Sámi indigenous people and a local policy community with the municipality as central actor. This marine community resembles a one-sided, subsistence-driven economy of SIDS (Mol et al., 2004).

Because of the exploitation of oil and gas in the Barents Sea and the development of the LNG plant at Melkøya, Hammerfest has transformed from a local marine fisheries community to a national (and even international) marine community, with the international petroleum industry at its centre. Melkøya is an island, just west of Hammerfest, which is connected to the mainland through a tunnel. The LNG plant processes gas from three offshore natural gas fields Snøhvit, Albatross and Askeladden in the Barents Sea, situated $140 \mathrm{~km}$ from Hammerfest. Those gas reserves were discovered between 1981 and 1984 . Natural gas is distributed through a pipeline to the processing plant at Melkøya, 


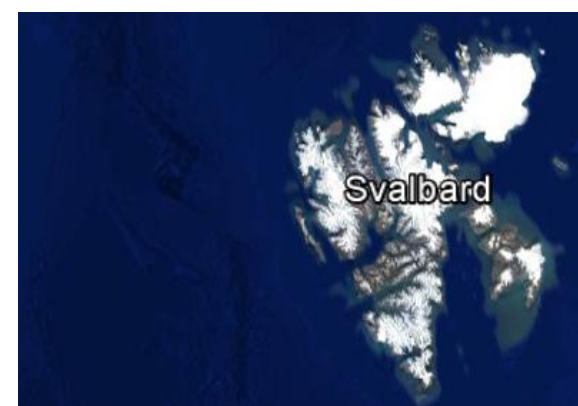

Barents Sea

Norwegian Sea

Figure 2.3. The location of Hammerfest in the Arctic (Google Earth, 2017d and f)
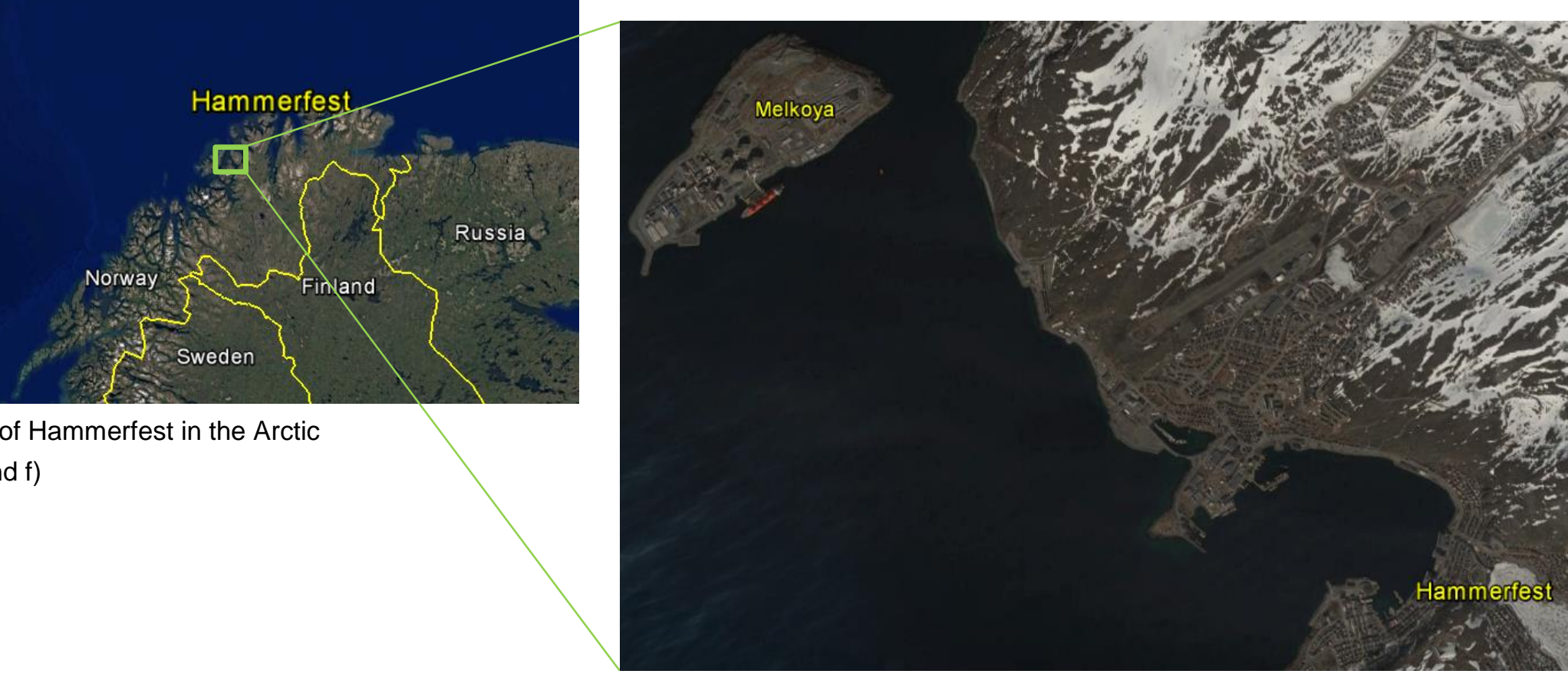
where it is converted to LNG (shown in Figure 2.4.). In 2002 the construction was approved by the Norwegian government. Since August 2007 the plant is operational. Initially LNG would be shipped to the USA. However, discoveries of huge amounts of shale gas transformed the USA from being dependent on the import of oil and gas, to a self-producing country. Currently most LNG is transhipped to Europe, but the Asian demand is increasing rapidly (Carroll, 1991, I-R-4). This LNG plant is quite remarkable because of its scale and the technology it applies in the vulnerable Arctic environment. Gas extraction occurs without surface installations, because conversion takes place on shore. Instead of fixed or floating units, subsea production facilities stand at water depths of 250-345 m on the seabed. Seabed facilities are designed to be overtrawlable, so that both oil and gas industry and fisheries do not suffer from any damage by touching the seabed. To reduce emissions, the plant is designed to capture $\mathrm{CO}_{2}$ which is re-injected in the field (Statoil, 2007). Statoil's LNG plant brought new economic perspectives to the region, and transformed the marine community. The next section will explain the changes in Hammerfest's marine community by analysing how institutional, strategic and oppositional coalitions affected the resources, rules and discourses of the user and policy community.

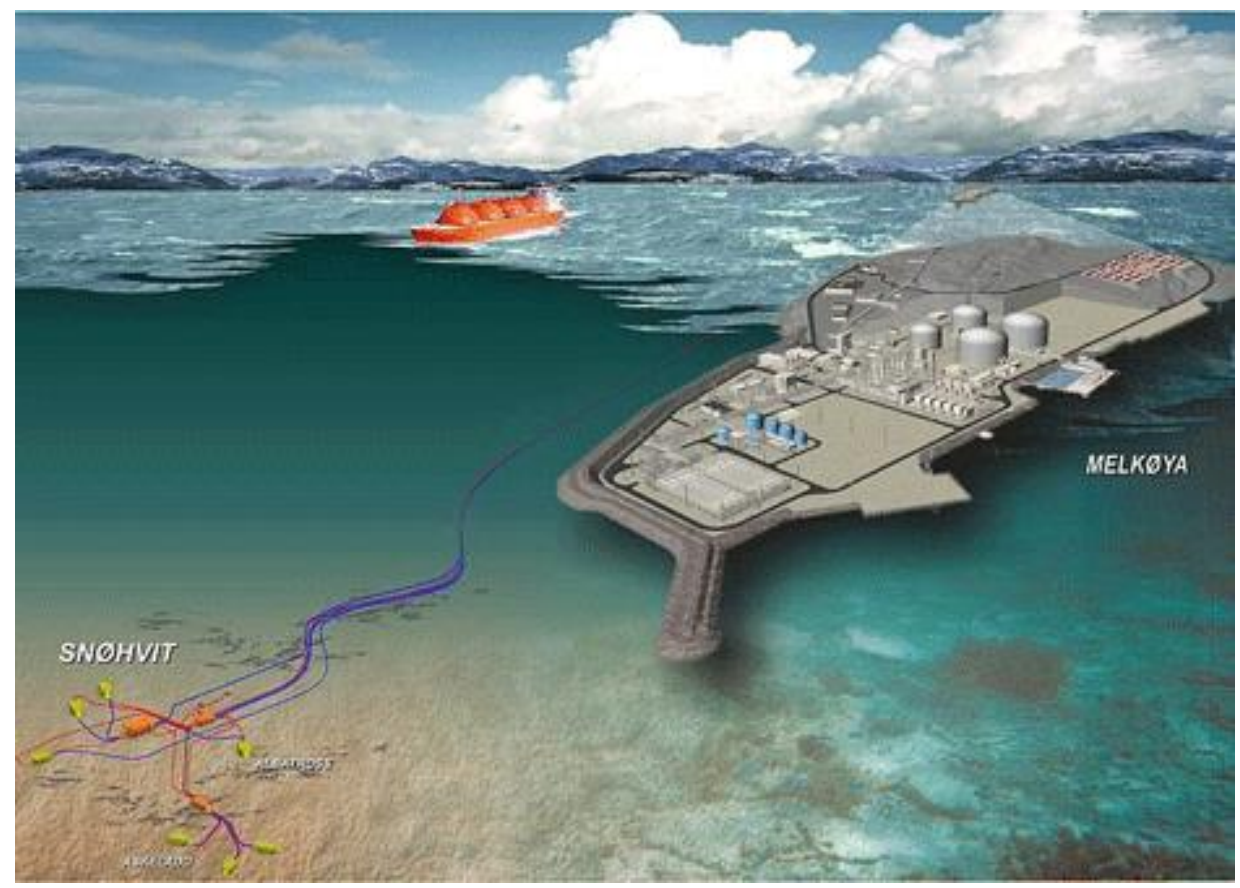

Figure 2.4. Overview of the operations of the LNG plant (Nilsen, 2012) 


\subsubsection{Institutional coalition}

Since the establishment of Statoil as a state-owned company in 1972, the relation between the Norwegian State and Statoil can be characterised as an institutional coalition; i.e. a structural relationship based on formal rules that formalises its interdependency through sharing of resources and discourses. Characteristic of this institutional coalition are its two faces: the first face is the state participant/user relation, the second face is the regulator/user relation.

Despite changes, such as increased state participation in the 1980s and semiprivatisation in the 2000s (Klick, 2009), the state participant/user relation between the Norwegian state and Statoil became institutionalised during the last decades. ${ }^{1}$ This relation was further strengthened by initiatives of the Norwegian government, such as Norwegianisation of the oil and gas industry, by giving preference to domestic oil companies and suppliers (Norwegian Petroleum Directorate, 2012), the 'High North Strategy' of the Stoltenberg administration with a renewed interest in Finnmark's economic development, coupled with offshore oil and gas activities and cooperation with Russia (Klick, 2009) and Norway's tax efficient system which incentivises oil and gas exploration. ${ }^{2}$

The second face of the institutional coalition represents the regulator/user relation. Besides participating in oil and gas activities, the Norwegian State is also responsible for regulating these activities. Since the 1970s Norway has moved towards a performance-based approach to supervise oil and gas activities, in which the state defines the performance that needs to be achieved, while the industry is free to decide how this will be done (Petroleum Safety Authority Norway, 2010). The Petroleum Act (1996) governs petroleum activities, under jurisdiction of the Ministry of Petroleum and Energy and its Petroleum Directorate. Before an area is opened up for oil and gas drilling, a strategic impact assessment is made and the public is consulted (Ministry of Petroleum and Energy, 1996). This is an important moment for other actors (such as research institutes and NGOs) to question the nature and extent of proposed oil and gas activities in relation to social, economic and environmental effects (I-R-2, I-CS-1).

The two faces of the Norwegian state (as state participant and as regulator of oil and gas) could conflict. According to an NGO, their input is not considered and even overruled by the Norwegian government's face as state participant:

\footnotetext{
${ }^{1}$ Currently the Norwegian State has a direct ownership of $67 \%$ within Statoil, managed by the Ministry of Petroleum and Energy. State participation in Statoil's LNG project is even more prominent by the 30\% share of the state-owned company Petoro (Statoil, 2011a).

$278 \%$ of the costs are reimbursed in the subsequent year (Statoil, 2011b).
} 
"The Norwegian Polar Institute and the Environment Agency provide the same input as we do; it is not taken into account. In Norway the situation is, issuing a consequence analysis equals opening up the area for oil and gas activities." (I-CS2)

Once the area is opened, the most important resource for developing any oil and gas discovery is the Plan for Development and Operation (PDO) licensees have to submit. A PDO contains an account of economic, resource, technical, safety, commercial and environmental aspects, as well as information as to how a facility may be decommissioned and disposed of when the petroleum activities have ceased. The Ministry of Petroleum and Energy is authorised to approve a PDO. Because of the scale of Statoil's LNG plant approval of the Norwegian State was required (Norwegian Petroleum Directorate, 2012, I-R-4). In 2007 the LNG plant started to operate. The Environment Agency and the Petroleum Safety Authority monitor the environmental impact and safety of the plant. Statoil reports on compliance with the permits based on the 'internal control principle' (I-CS-1). As Statoil is in charge, they consult national research institutes to monitor the effects of the LNG plant on different parts of the environment (I-R-3). In case of noncompliance, Statoil has a notification duty. Afterwards agencies will set a deadline by which non-compliance should be solved. Results about monitoring and rule compliance are made publicly available by the agencies at stake (I-G-1, I-G-2, I-M2 , I-CS-1, I-R-1). These state agencies represent independently both faces of the Norwegian State in the institutional coalition. While the Ministry of Petroleum and its Petroleum Directorate represent state participation in Statoil's LNG plant, the Environment Agency and the Petroleum Safety Authority regulate this industry.

\subsubsection{Strategic coalitions}

The strong institutional coalition between the Norwegian State and Statoil changed the relations between the user and policy community in Hammerfest. Characteristic of Hammerfest's marine (fisheries) community is its isolation and lack of resources and knowledge to counterbalance the power of a multinational company such as Statoil.

"Oil and gas companies and the Ministries are the same people, they have the same interest; they have the license to operate." (I-M-3)

The lack of trust in the Norwegian State's regulatory face versus its state participant face and the lack of an institutional coalition between Hammerfest municipality and the Norwegian State, forced local actors to define their position in 
relation to the institutional coalition. Two strategic coalitions emerged: one between Statoil and fisheries and one between Statoil, Hammerfest municipality and local inhabitants. Each of these strategic coalitions has its own resources, rules and discourses to achieve its objectives. Compared with the institutional coalition, these coalitions have a short-term and strategic character because actors attempt to pursue their interest by looking for actors with whom policy interpretations are shared and acceptable consensus can be reached, while disregarding actors with conflicting policy interpretations (Arts and Van Tatenhove, 2004).

The formation of these coalitions is essential for acquiring a social license to operate (SLO) for the LNG plant. The concept of a SLO emerged in the late 1990s, predominantly in the mining industry (Boutilier, 2014). Currently the concept is used in a variety of contexts ranging from business, academia, and consultants to media. A SLO is "the ongoing acceptance and approval of the activities of an industry by local communities and other stakeholders" (Smits, Justinussen, and Bertelsen, 2016). Although it is difficult to measure whether or not a SLO has been granted, Thomson and Boutilier (2011) introduce four concepts to understand how a company such as Statoil can obtain and maintain its SLO. First, economic legitimacy is determined by the level of local benefits provided by the activity at stake. Second, interactional trust is based on "the perception that the company listens, responds, keeps promise, engages in mutual dialogue and exhibits reciprocity in its interactions" (Thomson and Boutilier, 2011). Thirdly, institutionalised trust requires stakeholders to perceive that the relationships between their institutions and the company are based on mutual trust with respect for each other's interests. Fourth, socio-political legitimacy is required, and is characterised by fairness, meeting expectations and contributing to the wellbeing of a region or a country (Thomson and Boutilier, 2011).

\subsubsection{Strategic coalition: Statoil and fisheries}

Interaction between Statoil and fishermen was triggered by fishermen's scepticism about the pipeline path connecting offshore gas fields to the LNG plant, released in the construction plan in 2002. The pipeline crossed important fishing grounds; amongst others spawning areas for Atlantic cod. As a result the fishing community in Hammerfest was sceptical. However, they choose to be open-minded to grasp the possibility to influence the outcome in their favour, instead of resisting this LNG development. If they would be successful, they could not only guarantee their livelihood, but their families could also benefit from a more diversified economy in times of severe community decline and depression. In other areas of Norway direct conflicts between fisheries and oil \& gas activities are more 
likely; the narrow continental shelf of the Lofoten and Vesterålen forces both activities to operate close to each other, while in the North Sea fixed or floating, instead of subsea, oil drilling installations claim large restricted areas for fisheries (Pedersen, 2010). As a result fishermen in the North Sea refuse to engage in dialogue with Statoil (I-M-3), or unite with NGOs in the Lofoten and Vesterålen to successfully halt oil and gas developments (I-CS-2). A strategic coalition started to develop through semi-formal meetings between Statoil and fisheries to defuse the emerging conflict about resource overlap (I-R-4).

Fisheries are, next to oil and gas, an important resource on Norway's continental shelf. Local fishermen of Hammerfest strengthened their position in this strategic coalition through representation by the national fishermen organisation Norges Fiskarlag and the national Directorate of Fisheries. Based on resources, such as local knowledge and historic use, fishermen made clear demands on which a SLO could be granted. After four years of negotiations, Statoil and fishermen agreed to construct the pipeline outside important fishing grounds. The actual construction of the pipeline was determined by the Ministry of Petroleum and Energy and deviated partly from the agreement for economic reasons. This created distrust between fishermen on the one hand and Statoil and the Ministry of Petroleum and Energy on the other hand. This feeling of distrust dissolved afterwards because the pipeline was constructed under the seabed and covered with rocks and sand, in order for it to be overtrawlable (I-M-3). Remarkably the same situation was repeated when the construction of the electrical cable path deviated from the agreement between fishermen and ENI Norge, which just started oil production in 2016 from their offshore Goliat platform (I-M-1).

In the end fishermen are not compromised by the LNG plant and benefit from Hammerfest's improved quality of life, while Statoil involved fishermen early in the process to gain their SLO. Fishermen, nevertheless, emphasise the asymmetric power play during negotiations. Although fishermen felt involved by Statoil, in the end economic interest is the company's first priority. Moreover fishermen have to sacrifice fishing time at sea to engage in talks with Statoil to save their livelihood, while organising stakeholder involvement is part of Statoil's corporate business (I$\mathrm{M}-3)$. One fisherman summarised the asymmetric power play even as follows:

"Ultimately it is not a decision between fishermen and Statoil, but by the Ministry of Petroleum and Energy. The national level decides and the local and regional levels have to play with." (I-M-3, I-R-2) 


\subsubsection{Strategic coalition: Statoil, inhabitants and the municipality}

The strategic coalition between Statoil, local inhabitants and Hammerfest municipality emerged during public meetings in which Statoil informed local inhabitants about the state of affairs of the LNG plant and potential incidents (IM-2, I-G-3). Initially local inhabitants were enthusiastic about the LNG plant as it might boost their economy. However, during construction, local inhabitants faced some unexpected consequences, because Hammerfest became invaded by a mobile work force of 3,500 employees, which increased the population with one third. One consequence of this population increase was the occupation of tourist accommodations which harmed the tourism industry (Interview with Hammerfest Turist in (Klick, 2009)). Moreover local inhabitants were overwhelmed and diminished visiting bars and restaurants. This tendency can still be noticed today (I-G-3).

When the LNG plant started to operate, Statoil faced technical hurdles (I-G-1, IG-2, I-G-3, I-M-2, I-R-4) and the public started to raise concerns about health, safety and the environment. An example was an unannounced flaring incident, which resulted in a flame of $130 \mathrm{~m}$ height which lightened up the whole city and which released more $\mathrm{CO}_{2}$ emissions than what had been permitted for the entire year (I-G-3, I-M-3). During these public meetings, Hammerfest municipality, the so-called Hammerfest Kommune, facilitated between Statoil and local inhabitants. They actively engaged in dialogue with Statoil to assure Hammerfest would benefit directly from this latter development. One major risk would be a flow of money out of the community to corporate headquarters in southern Norway. The commitment from active local organisations and Hammerfest Kommune, but also contributions from Statoil to local organisations keen on local capacity building and education such as Petro Arctic, Pro Barents AS and Energi Campus Nord secured a sixfold of intended contracts with local suppliers, as estimated in 2002 (Klick, 2009).

The most important resource for this strategic coalition is the annual property tax of approximately $€ 19$ million paid by Statoil. Hammerfest Kommune invests this tax revenue in schools, kindergarten, health care and the Arctic Culture Centre (I-G-3). Without the property tax, the situation might have been completely different (I-G-3).

Despite, the revived local economy and increased quality of life, there are some economic setbacks. Initially the LNG plant would provide 2,000 jobs (Klick, 2009), while currently only 1,300 are in place (Hammerfest Kommune, 2012). Recently Statoil even tightened up contracts with the supply industry because they are able to do it cheaper themselves (I-G-1, I-G-3, I-M-4). Hammerfest Kommune is 
worried about employment prospects for the youth in the oil and gas industry. The local community is dependent on Statoil's financial contributions and property taxes. But, merely a transfer of money to the community by Statoil does not stimulate growth or community development, which is delegated to Hammerfest Kommune (Interview with Statoil in Klick, 2009). Although Hammerfest Kommune is eager to implement community development and negotiated therefore with Statoil, it is dependent on Norway's regulatory framework and decision-making power of Statoil, which is illustrated by the property tax and the setback in employment (I-G-3).

\subsubsection{Oppositional coalition}

Sámi and NGOs are critical about Statoil's LNG plant. Sámi's main concern is indirect. They are afraid that increased area development and infrastructure in Hammerfest, as Arctic Energy capital, might claim areas now used for reindeer herding (Klick, 2009, I-G-3). Since the Finnmark Act (2005) Sámi have acquired ownership and rights to use land and waters in Finnmark County. Property disputes and conflicts with other users are managed by the Finnmark Estate Agency, which consists of members from the Sámi Parliament and Finnmark County Council (Norwegian Parliament, 2005). However, there is no legislation that provides Sámi with any rights to demand compensation or royalties for property claimed by development of offshore resources such as oil and gas in the Barents Sea (Boutilier, 2014; Klick, 2009). In addition, Sámi, unlike fisheries, are not well-integrated within Hammerfest's community, which disadvantaged them to engage in a policy coalition with local inhabitants of Hammerfest. In the past, the Alta Controversy (1978-1982), in which Sámi protested against the building of a dam that could harm reindeer migration, created tension in Finnmark. This controversy granted Sámi power through resources such as state protection and property rights under the abovementioned Finnmark Act, but Norwegians questioned the legitimacy of empowerment of Sámi which aggravated the existing tension. This figurative distance between Hammerfest's community and Sámi is strengthened by a physical distance caused by reindeer migration which urges Sámi to pursue a nomadic culture outside Hammerfest (Klick, 2009). For these reasons Statoil did not perceive Sámi as primary stakeholders (I-M-2).

Although NGOs Natur og Ungdom, WWF Norway and Bellona were sceptical about the environmental performance of the LNG plant (Pedersen, 2010), Statoil got some credibility based on past negotiations. Statoil and these NGOs were already in dialogue about the Integrated Management Plan for the Barents Sea and the Lofoten Islands. This experience and the pressure of the NGOs resulted in the implementation of environmental best practices, such as carbon capture \& storage 
and reduced emissions of toxic drilling fluids in the LNG plant (Klick, 2009). Although NGOs furthermore lobbied the Ministry of Petroleum and Energy and the Ministry of Climate and Environment and their agencies and organised protests in Hammerfest, in the end they were rather absent in decision-making regarding the LNG plant for three reasons. First, NGOs are willing to accept a SLO for natural gas extraction, but not for oil. Second, because oil and gas are national resources and managed at the national level, NGOs lobbied the national rather than the local level. Third, the timing for the LNG plant (in tough economic times) in Hammerfest made locals feel that NGOs which strive for intangible, long-term, macroenvironmental interests interfered with their right to direct economic development. As a result Statoil's discourse of economic revitalisation in the North coupled with oil and gas developments, prioritised at both the national and local level, together with the absence of a locally-based environmental agenda, hampered national NGOs to introduce a strong sustainability discourse to influence this development at any level. However, Greenpeace Norway keeps an eye on Statoil, as they own four shares in Statoil's company which grants them access to annual meetings of Statoil.

\subsubsection{Marine community}

The emergence of these coalitions has affected Hammerfest's marine community significantly. Before the exploitation of LNG the marine community of Hammerfest was a local, small-scale community, consisting of a fisheries user community, while Hammerfest municipality formed the policy community. The start of LNG production by Statoil transformed the marine community dramatically. Not only became Statoil the core actor, the institutional coalition between the Norwegian State and Statoil became the most dominant coalition in this marine community. The formation of coalitions in this marine community is in the first place driven by matching discourses about revitalisation of the North by the Norwegian government coupled with offshore oil and gas exploration in the Arctic by Statoil. This is further implemented through national rules such as the High North Strategy and Norwegianisation of oil and gas and through resources such as state participation and the Norwegian regulatory system; i.e. a tax efficient system which incentivises oil exploration and performance-based supervision of oil and gas activities which gives Statoil much operational freedom. This coalition is powerful because both Statoil and the Norwegian State are at the same time part of the user and policy community. Statoil and the Norwegian State, in fact, use discourses, rules and resources of the policy community to strengthen their position as user in the marine community.

Statoil wanted to address local concerns, on the other hand, and engaged 
therefore in two strategic coalitions to acquire their SLO. As such Statoil became the core actor of the marine community. Local actors, from their point of view, engaged in these strategic coalitions with Statoil to ensure they would benefit from the LNG plant. By addressing concerns of fishermen and local inhabitants on resource overlap and health, safety and environmental issues, Statoil received a SLO for its LNG plant. Crucial for the strategic coalition is the matching discourse of joint economic development of the community and the company. This is realised through the property tax, implemented by Norway's regulatory framework, which stimulated the local economy of Hammerfest.

The oppositional coalition did not become part of the marine community because of a mismatch in discourses regarding economic revitalisation of the North coupled with oil and gas development, on the one hand, and sustainable development, based on intangible, long-term and indirect environmental concerns, on the other hand. This was further strengthened by the absence of local NGOs with whom Sámi and nationally-based NGOs could form a coalition to mobilise resources and to introduce a sustainability discourse.

Statoil's position at the core of the marine community and at the core of two of the three coalitions (see Figure 2.5.), provokes the interpretation of a very dense and concentrated marine community. However, this is not correct. The strong institutional coalition, on which the strategic and oppositional coalitions depend, is responsible for the scale mismatch between the local user and national policy community. This scale mismatch is mainly shaped by the coalitions, but also reinforced by Hammerfest's resemblance with SIDS for the following three reasons.

First, lack of resources and knowledge constrain governance capacity of the local user community to withstand the power play of the institutional coalition. As such fishermen were the only actor in the user community which had valuable resources such as historic use and local knowledge, backed-up by representation of the national fisheries organisation, to influence decision-making in the policy community to a certain extent.

Second, Hammerfest's eagerness for employment, government revenues and the transfer of knowledge and technology, has put Statoil in a powerful position to negotiate on taxes, concessions on natural resources and investment locations. This resulted in a disproportional relationship with the local user community, as local concerns for community development were overshadowed by economic growth.

Third, Hammerfest's isolated location from the Norwegian State in Oslo and the headquarters of Statoil in Stavanger reinforced the scale mismatch. Although 
Oslo-based NGOs tried to lobby the national policy community and to influence mismatching discourses of economic and sustainable development, the absence of local NGOs or a strong environmental department of Hammerfest Kommune made this unsuccessful (Klick, 2009). Sámi are the closest example of a local environmental user community perspective, but they are not well integrated into Hammerfest's community. Therefore a push for environmental concerns from a local user community is largely absent. The local user community, vice versa, did not manage to get connected to the national policy community, because there is no strong cooperation between Hammerfest Kommune and the national policy community. This probably results from Hammerfest's history as small-scale marine fisheries community. Economic growth is therefore the dominant discourse in this marine community because it is pursued by both the national policy community and local user community, while community development is mainly addressed by the local user community and lacks support from the national policy community. Environmental action is not well represented by both the user and policy community and is excluded from the core of this marine community.

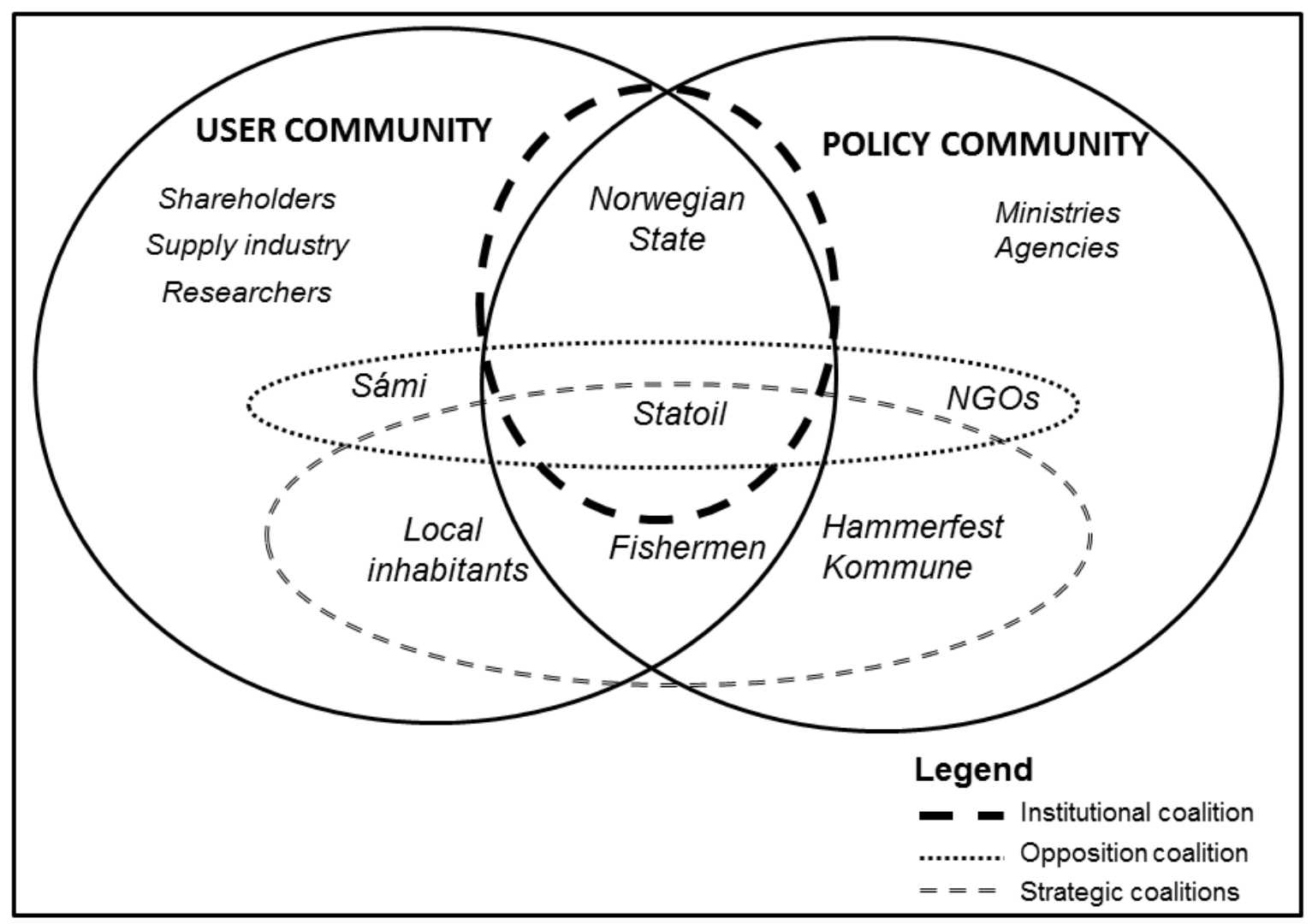

Figure 2.5. Overview of the coalitions within the marine community of LNG production in Hammerfest 


\subsection{Discussion}

How does the change from a local marine (fisheries) community to a multi-level marine (oil and gas) community affect possibilities to govern developments in a sustainable way? Despite investments in environmental best practices and early and frequent stakeholder dialogue, the dominant discourse of Statoil is economic growth, which is largely pursued by the institutional coalition (see Figure 2.6.). This institutional coalition provides a SLO for Statoil, mainly based on economic legitimacy and the institutionalised trust relationship between Statoil and the Norwegian State.

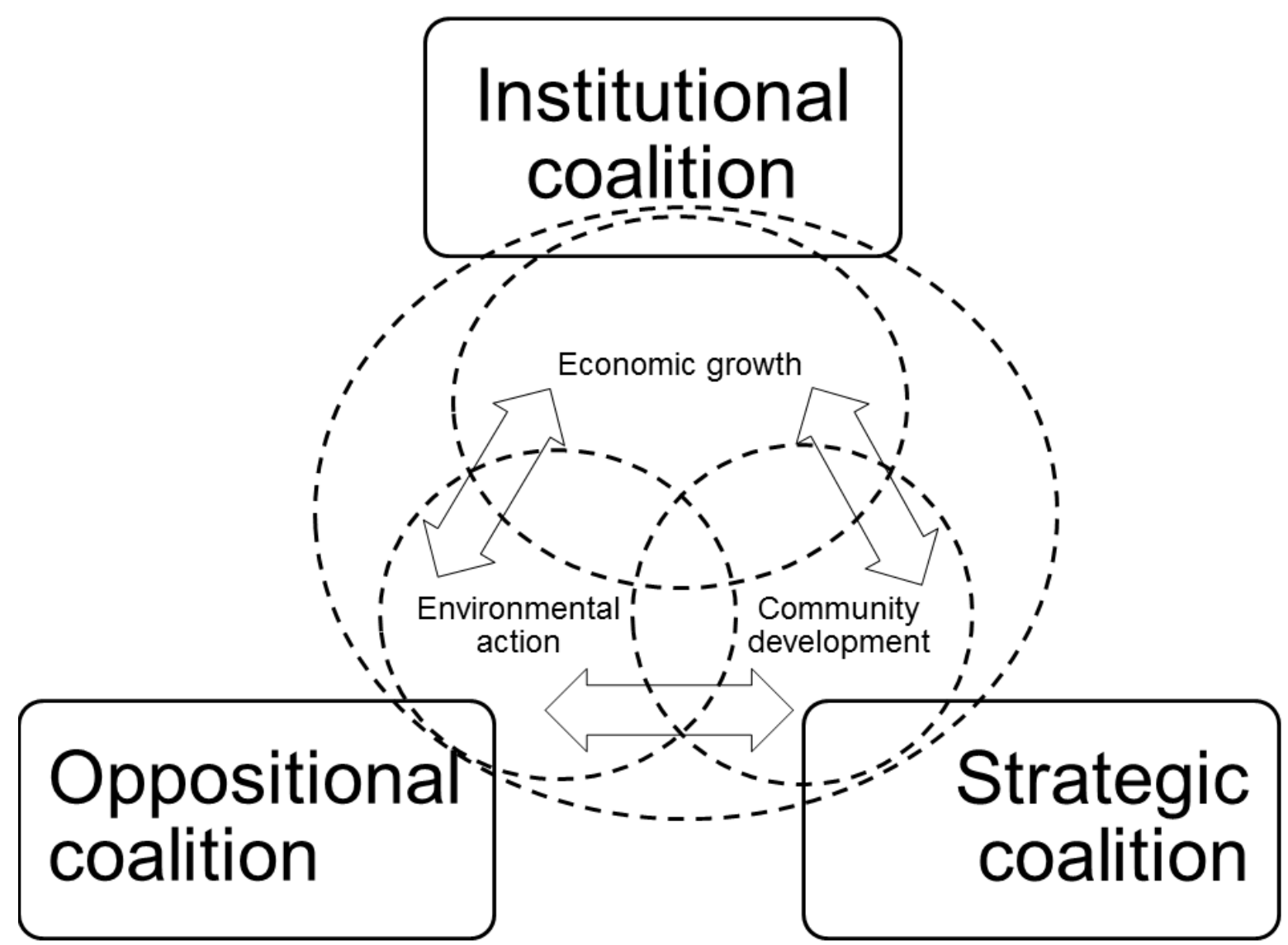

Figure 2.6. Overview of coalitions in relation to the dimensions of sustainable development

The inclusion of environmental soundness and community development in the governance of the LNG plant, strived for by the oppositional coalition and the strategic coalition, respectively, are however compromised by Statoil's reliance on cost-efficient and short-term conflict resolution mechanisms. Local actors perceive this as ticking the boxes rather than a long-term investment towards a SLO, based also on institutionalised trust and socio-political legitimacy. This can be observed as contacts with fishermen, local inhabitants and NGOs faded away once an economic legitimate and interactional trust-based SLO was achieved (Boutilier, 
2014, I-M-3). Sustainable development of LNG production in Hammerfest presupposes that environmental action and community development should be addressed equally important as economic growth in both the user and policy community. This will have consequences for possibilities for environmental governance by Hammerfest's marine community. Decision-making by Hammerfest's marine community should incorporate also other actors, even beyond the existing strategic and oppositional coalitions, for environmental action and community development, which might lead to a more sustainable outcome.

Policy-making on behalf of the institutional coalition results in centralised decision-making regarding weighing environmental consequences and environmental monitoring. Although Norway's performance-based supervision of oil and gas activities provides opportunities for exploring different environmental scenarios to reach the predefined performance by the Norwegian State, so far this does not occur. Environmental scenarios or approaches to achieve a certain performance could be weighed differently by different stakeholders, but are currently mainly valued by the institutional coalition. Environmental consequences estimated by other stakeholders, especially those outside the policy arena, are less likely to be taken into account (I-CS-2).

"NGOs state that there is a big gap between environmental risk assessments performed by a consultancy hired by Statoil and one conducted by them, especially regarding the worst case scenario described in the risk assessment." (ICS-2)

A similar argumentation applies to environmental monitoring of the LNG plant. Performance-based supervision allows Statoil to consult national research institutes of their own choice to monitor different parts of the environment, which are not allowed to advise Statoil in policy-making (I-CS-2). Monitoring results are submitted by Statoil and discussed one-on-one with the state agency at stake. As a result research is broken up across different research institutes and state agencies with different scopes and little communication between them (I-G-2, I$\mathrm{CS}-2)$. In the end knowledge in this marine community is concentrated in the national policy community which compromised access to this knowledge for all stakeholders (I-G-3). In fact Statoil becomes rather powerful because of this monitoring system because it is the only actor who has a proper overview of all available knowledge.

To reduce tension between eagerness for community development in Hammerfest and centralised decision-making, Hammerfest Kommune should 
function more as a bridging organisation, i.e. an organisation designed to facilitate collaboration and knowledge coproduction among resource users, researchers and resource managers to create continuous learning (Berkes, 2009; Carr and Wilkinson, 2005; Schultz, Folke, and Olsson, 2007). They can make the national policy community more aware of local concerns. In relation to the local user community, Hammerfest Kommune could assume Statoil's role as organiser of stakeholder outreach by organising public meetings. As a result Statoil, distracted and fatigued by different stakeholder demands (Klick, 2009), can delegate the responsibility for community development to Hammerfest Kommune. Hammerfest Kommune can build on successes and errors experienced in public meetings organised by Statoil to address current issues, but also to be better prepared for the rather uncertain future, because decreasing oil prices have frozen Arctic oil and gas projects (International Energy Agency, 2015). Although this would benefit bridging the local to national level, it does not yet address asymmetries in power and interests. The national policy community should be responsible to address this. However in the current Norwegian regulatory framework, a dedicated institution concerned with protecting stakeholders affected by oil and gas activities is absent (Klick, 2009).

\subsection{Conclusions and recommendations}

This chapter has shown that governance of LNG production by Hammerfest's marine community rather represents economic than environmental and community development. The framework of marine communities and coalitions provides a better understanding why current governance of LNG production in Hammerfest did not move beyond economic development.

The marine community concept enlightens which actors and levels dominate the user and/or policy community, for what reasons and if and how they interact with each other. Hammerfest's marine community (both the policy and user community) on LNG production is dominated by the institutional coalition (Statoil and the Norwegian State). This powerful coalition is, apart from its actors and their coalitions, self-reinforced through the other dimensions of the policy arrangements approach, namely matching economic discourses and its implementation through resources and rules. As a result policy-making is largely dominated by this institutional coalition, which impedes strategic and oppositional coalitions to influence this process. This is strengthened by Hammerfest's similarities with SIDS. Although the local user community attempts to protect their high resource dependency by engaging in two strategic coalitions with Statoil, they lack resources and rules to influence policy-making. In the end the outcomes of both 
strategic coalitions are determined by resources, rules and discourses of the institutional coalition. The oppositional coalition is less successful, because their long-term environmental discourse is not pursued by other actors in the marine community. As such they cannot rely on any dimension of the policy arrangement for forming a policy coalition such as sharing resources and strategies or pursuing similar discourses.

Hammerfest's marine community is characterised by the tension between economic and sustainable development and asymmetric power relations between the institutional coalition and the strategic and oppositional coalitions. Centralised decision-making power by the institutional coalition constrains knowledge sharing between actors of the institutional, strategic and oppositional coalitions and hampers effective and long-term conflict resolution in Hammerfest's marine community. To address environmental and community interests, within the context of centralised decision-making, the countervailing power between the institutional coalition on the one hand and the strategic and oppositional coalitions on the other, should be brought more in balance. An example of bringing both coalitions more in balance is to develop forms of ecosystem-based monitoring in which state agencies, Statoil and research institutes on the one hand and local actors on the other hand exchange knowledge and learn from each other emphasising sustainable development. Continued public meetings, facilitated by Hammerfest Kommune, will increase attention for community development in Hammerfest, beyond the transfer of financial means by Statoil. To balance power relations, the Norwegian State, should, next to its face as state participant, strengthen its face as regulator, especially to protect local communities affected by oil and gas activities, which is currently absent in Norway's regulatory framework (Klick, 2009). 



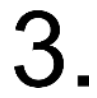

\section{A power analysis of a transforming marine community around oil transhipment at St. Eustatius}

This chapter has been published as

L.K.J. van Bets, J.P.M. van Tatenhove, and M.A.J. Lamers (2016) A power analysis of a transforming marine community around oil transhipment at St. Eustatius Ocean \& Coastal Management, 132: 59-69 


\section{Abstract}

The strategic location of small islands in the Caribbean, close to the USA, and their historical trade roots as former colonies of Europe make them an interesting business environment. Small islands' eagerness for economic development and their limited governance capacity has often resulted in an unequal relationship between multinational private parties and small islands' policy actors, especially in regard to environmental management. This is also observed at St. Eustatius, a small Caribbean island that hosts a crucial oil storage and transhipment terminal that compromises the environmental state of the small island. However, in 2010, St. Eustatius became part of the Netherlands, significantly changing the responsibilities related to environmental management. Bringing the environmental state back in reversed existing power relations. To analyse these changing power dynamics, the new social scientific concept of marine community will be applied, which encompasses a user community and a policy community and shows the different interests and power dynamics within and between them. While the governance of the oil terminal used to be determined by structural power in the user community on behalf of NuStar, it currently relies on the structural power of the Dutch Ministry of Infrastructure and Environment in the policy community. In theory, structural power to bring the environmental state back in would be beneficial for governance. In practice, however, this is challenging because a small island environmental state is different from the environmental state in countries in Western societies. Although the Dutch Ministry has structural power, the way it relates to others (dispositional power) and uses resources (relational power) should be better adapted to the needs and characteristics of small island environmental states such as St. Eustatius.

Key words: Governance, Marine community, Power, Small island developing state, St. Eustatius 


\section{Oil transhipment at St. Eustatius: A power analysis}

The environmental state of St. Eustatius, a small Caribbean island, is compromised by a us virgin crucial oil transhipment terminal. However, in 2010 St. Eustatius became part of the Netherlands which changed responsibilities for environmental management significantly. Bringing the environmental state back in reversed existing power relations.

To analyse these changing power dynamics, we apply the new concept of marine community, which encompasses a user and a policy community and shows the different interests and power dynamics within and between them.
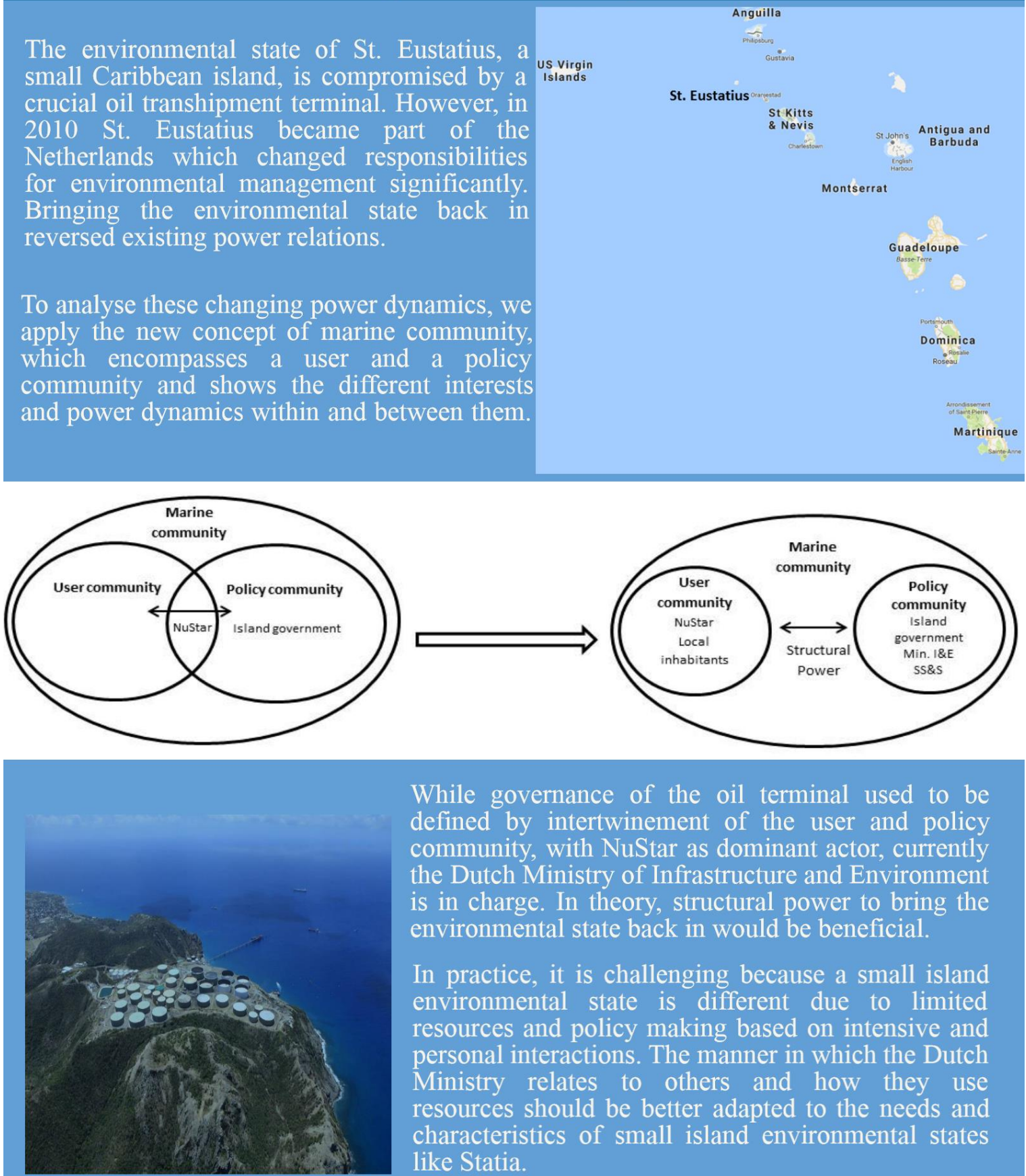

While governance of the oil terminal used to be defined by intertwinement of the user and policy community, with NuStar as dominant actor, currently the Dutch Ministry of Infrastructure and Environment is in charge. In theory, structural power to bring the environmental state back in would be beneficial.

In practice, it is challenging because a small island environmental state is different due to limited resources and policy making based on intensive and personal interactions. The manner in which the Dutch Ministry relates to others and how they use resources should be better adapted to the needs and characteristics of small island environmental states like Statia.

D. WAGENINGEN Co-authors: Jan van Tatenhove and Machiel Lamers

Figure 3.1. Graphical abstract St. Eustatius 



\subsection{Introduction}

Small islands in the Caribbean region are highly dependent on their unique natural resources and linkages with other islands and markets. In the literature, they are often labelled as SIDS because of their intrinsic characteristics: small territories and populations with restricted economies that are highly dependent on limited natural resources and imports of goods (Águeda Corneloup and Mol, 2014). The strategic location of Caribbean islands close to the USA and their historical trade roots as former colonies of Europe make hem an attractive business environment (Mol and Van Vliet, 1997). Small islands are eager for employment, foreign currency, government revenues and transfer of knowledge and technology, which puts multinational companies in a powerful position to negotiate on tax exemptions, reduced import and export fees, concessions on natural resources and investment locations. This has often resulted in an unequal relationship between market parties and small islands (Mol et al., 2004), especially in regard to environmental management. This is strengthened by limited governance capacity on small islands, i.e., a lack of human, financial, informational and other resources (Águeda Corneloup and Mol, 2014).

The Caribbean economy has always relied on exports, of which oil is an important example (Mol et al., 2004). The Caribbean basin is one of the world's major oil-producing regions, with Venezuela boasting the Western Hemisphere's largest reserves, followed by Mexico, Columbia and the Gulf Coast of the USA. While most of the oil is shipped - regionally predominantly to the USA - there is a deficit of deep water ports there, making Caribbean refining and transfer points critical (Royal Haskoning, 2011).

Statia is situated at the axis of these major shipping routes between Brazil and the USA and between West Africa and the Gulf of Mexico (Royal Haskoning, 2011). Therefore, a large oil transhipment terminal was established in 1982 at Statia. Although its economy is largely dependent on oil transhipment, oil spills have threatened Statia's terrestrial and marine ecosystems frequently over the last two decades (Klok, Debrot, Meesters, Stapel, and Slijkerman, 2011). As such, the oil terminal affects not only Statia's pristine nature but also its fishery and (dive) tourism sectors that thrive on this nature. The unequal power balance between Statia and the oil terminal has been challenged since October 2010, when Statia became a special municipality of the Netherlands. New legislation and responsibilities were implemented for improving environmental policy-making and management at Statia, which led the Ministry of I\&E to become entirely responsible for the oil terminal in April 2015. This transformed power dynamics. 
To analyse this unequal power distribution at Statia, this chapter introduces the social-scientific concept of a marine community, which takes into account the scope, scale and speed of change in coastal-marine settings of small islands (Harley et al., 2006). These changes affect the interactions and interdependencies among governmental, market and civil society actors on the island and their interaction with the marine biophysical dynamics (Galaz, Olsson and et al., 2008). A marine community consisting of a user and a policy community shows different interests and power dynamics within and between them.

The aim of this chapter is to analyse the power dynamics within the marine community of oil transhipment in Statia and the consequences of this changing power architecture for the marine community to govern oil transhipment in Statia in a sustainable way.

Section 2 introduces the theoretical framework. The core concepts are marine community and power. Section 3 describes the methodology, while Section 4 analyses and explains the transforming of the marine community of oil transhipment in Statia and its changing power dynamics. This section starts with the reconstruction of the changing power architecture within the marine community, followed by the implications for sustainable oil transhipment in Statia. Section 5 presents the conclusions and recommendations.

\subsection{Theoretical framework}

To analyse the recent changes in the governance of oil transhipment in Statia in relation to the marine ecosystem, this chapter presents the concept of marine community (Van Bets, Van Tatenhove, and Mol, 2016), which enables us to study the transformation of a SIDS into an environmental state in the context of the three-layered power concept of Arts and Van Tatenhove (2004).

Whereas in ecological sciences, the concept refers to a group of interacting living organisms sharing a populated marine environment (Bertness et al., 2000), in this thesis, a marine community is based on social science definitions and insights, emphasising social and political dynamics. A marine community is a community of socio-economic and policy actors and institutions organised around a certain maritime activity that influences or will be affected by the (marine) ecosystem in which the activity occurs (Van Bets, Van Tatenhove, and Mol, 2016). Analytically, in a marine community, two interdependent communities can be distinguished: a user community and a policy community, as shown in Figure 3.2.

Actors, and their institutions, can be part of both user and policy communities, but each community has a distinct logic, rationality and purpose. According to Crow and Allan (1994) and Smith (2001), a user community refers to a network of 
interdependent actors that executes, and is affected by, the maritime activity and which makes use of the goods and services provided by the marine ecosystem.

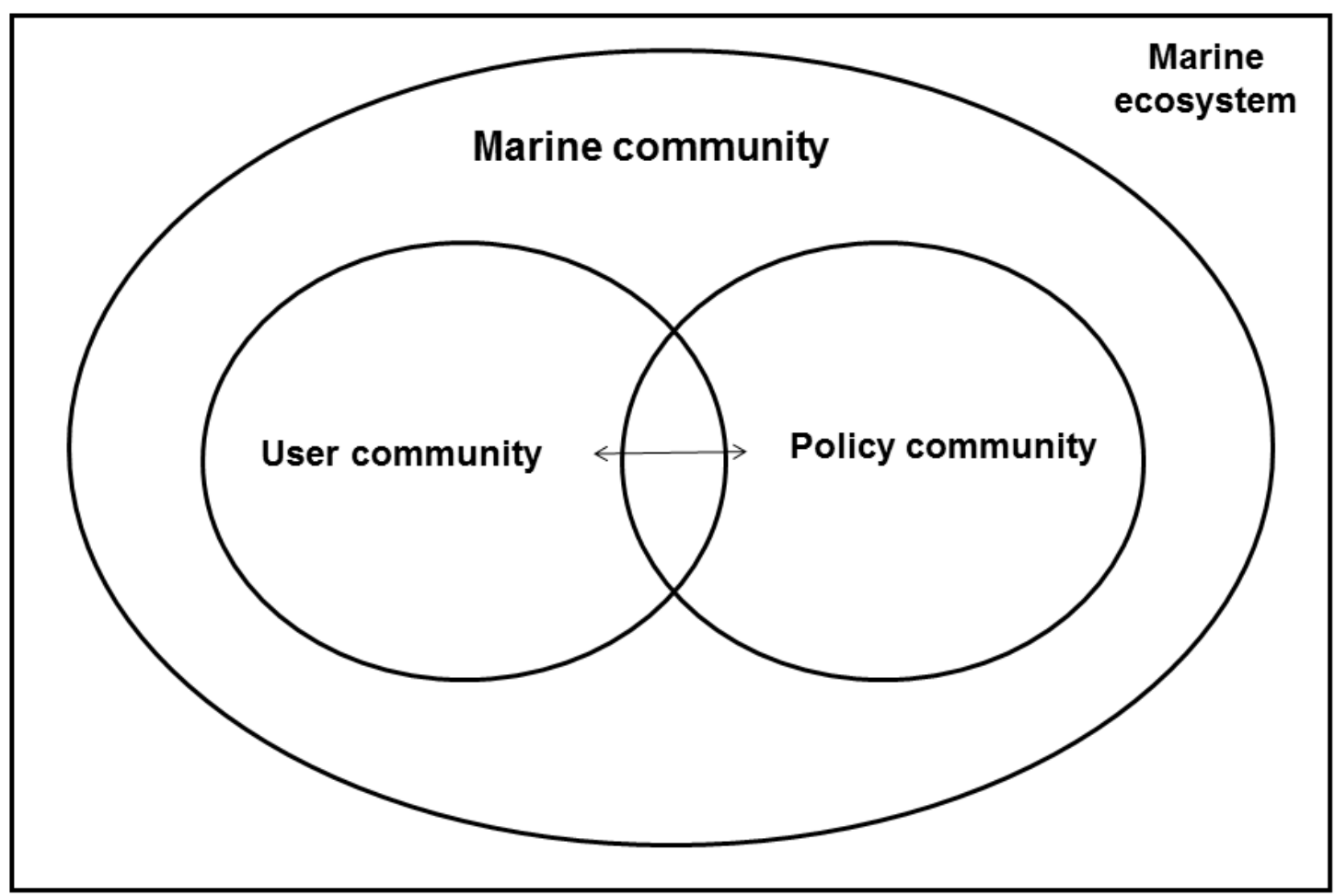

Figure 3.2. The relationship between user and policy communities within a marine community

A policy community comprises actors who are part of (in)formal institutions and governance arrangements that regulate the maritime activity to achieve sustainable use and management of marine ecosystems (Atkinson and Coleman, 1992; Sørenson and Torfing, 2005; Walker, 1989). The marine community concept is different from a social-ecological system for the following reasons. First, the marine ecosystem is problematized and taken into consideration only when maritime activities are performed. Although it is acknowledged that the marine ecosystem is affected by the maritime activity, the focus is on how the marine community governs these environmental changes. Second, the marine community does not adopt the systemic perspective of a social-ecological system; rather, it focuses on the agency of users and policy makers and how they interact with each other to address environmental issues.

Marine communities consist of interdependent state, market, civil society and scientific actors (operational at different levels) who interact with each other in user and/or policy communities. Bringing the environmental state back in provokes the existing power relationships between actors in the marine community to influence policy-making and decision-making. To study the power dynamics within marine communities in detail, the three-layered power concept of Arts and Van Tatenhove 
(2004) will be applied. They define power as "the organisational and discursive capacity of agencies, either in competition with one other or jointly, to achieve outcomes in social practices, a capacity which is however co-determined by the structural power of those social institutions in which these agencies are embedded" (Arts and Van Tatenhove, 2004, p. 347). Inspired by Clegg's three circuits of power (Clegg, 1989), they distinguish between relational, dispositional and structural power.

Relational power refers to the capability of actors to achieve outcomes through interactions. This form of power posits actors, resources, outcomes and interactions as the constitutive elements of power. However, the capacities of actors to realise or to influence outcomes in interaction are unequally distributed because of unequal access to certain resources.

Dispositional power shapes the "agency's capacity to act" (Clegg, 1989, p. 84). Institutional rules and the unequal distribution of resources define and position actors vis-à-vis each other within the user and policy community and between the user and policy community. Rules determine whether it is legitimate for an agent to claim a certain position, while the (uneven) distribution of resources determines the (relative) autonomy and dependency of an agent in a certain position. These positions co-determine what agents may achieve in terms of relational power in a marine community. The unequal distribution of resources, how resources are applied, and the positioning of actors in the user and policy community in relation to the marine activity are all factors that are the result of structural power.

Structural power refers to the way macro-societal and political structures shape the nature and conduct of agents, being both individuals and organisations. Structural power works through orders of signification, legitimisation and domination, which 'materialise' in discourses as well as in political, legal and economic institutions in societies (Giddens, 1984). "Mediated by these discourses and institutions, (collective) agents give meaning to the social world, consider some acts and thoughts legitimate and others not, and are enabled and constrained to mobilise resources to achieve certain outcomes in social relationships" (Arts and Van Tatenhove, 2004, p. 351). By applying this multilayered power model to understand the governance dynamics of marine communities, power is not restricted to the ability of actors in the user and policy community to mobilise resources or to realise outcomes; it also includes the way actors are positioned vis-à-vis each other and the unequal division of resources as a result of structural power. 


\subsection{Methodology}

To gain insights into the relationships, complexities and institutional settings within a marine community, a case study design was chosen. Case studies allow researchers to derive an in-depth understanding of a research object by examining a range of factors and potential causal connections and how they change over time. In addition, this methodology is useful to address actors' motives, interpretations, constructions of reality and behaviour (Swanborn, 2010; Yin, 2003). Statia was selected as a case study because of its maritime activity, an oil transhipment and oil storage terminal, operational since 1982 and managed by the American company NuStar Terminals N.V. since 2005 and because of the institutional changes when Statia became a special municipality of the Netherlands.

The semi-structured interviews with key informants served for mapping the marine community structure and for identifying how each actor is positioned in this community. All the semi-structured interviews were conducted using the same topic list, covering questions on stakeholders' contacts and interactions in the community, access to knowledge and information, rule compliance, conflict resolution and their perceptions, distracted from the theoretical framework (see Appendix 1). Key informants represent the main stakeholder groups, such as national and local governmental authorities, NuStar, fisheries, port authorities, NGOs, dive shops, local inhabitants and researchers. In total, 25 interviews were conducted in total, of which 20 were conducted with a single interviewee and four with multiple interviewees. Some key interviewees were interviewed on more than one occasion. The limited population size at Statia enabled the selection of relevant and sufficient interviewees. Twenty-four interviews were conducted faceto-face, 23 in Statia and one in the Netherlands. Most of the interviews were conducted in interviewees' offices, and some were conducted out in the field; for example when interviewing a dive shop owner on the beach. The interviews lasted between 25 and $90 \mathrm{~min}$. Before the fieldwork started, eight interview appointments were already scheduled with selected stakeholders. Other interviewees resulted from a snowball sampling method influenced by the preselected interviewees.

Almost all the interviews were recorded with a voice recorder; in some cases, the circumstances did not allow for this. The interviews were transcribed verbally as soon as possible after the interview took place, preferably the same day or the next day. The anonymity of the interviewees was guaranteed by means of a coding system used for referencing the interviews in this chapter (see Appendix 2). Although the interviewees are categorised in governmental, market, civil society and research actors, some of them have or had multiple roles. In those cases, the 
most dominant category was chosen.

The data were structured through coding with ATLAS.ti. Several rounds of coding occurred, including top-down coding, based on the interview topic list, the distinct actors in the user and policy community and the three different layers of power, and bottom-up coding in the three different phases, i.e., before 2010, 20102015 and after April 2015, which the analysis revealed (see Appendix 4).

The interactions among actors in the marine community and the means they use to interact were visualised through mind mapping, which resulted in the community composition shift presented in Figure 3.5. Data triangulation started with double checking by asking different interviewees the same information or by consulting key interviewees on more than one occasion. Afterwards, the information was also cross-referenced with policy documents, literature, (participatory) observations and news items. In the end, triangulation is determined by an iterative process; thus multiple rounds of structuring and cross-referencing occurred (Bogdan and Biklen, 2006; O'Donoghue and Punch, 2003). Fieldwork at Statia was conducted for two weeks in April 2015. At the end of the field work, the validity of the information was tested by means of a presentation at the science cafe, of the Caribbean Netherlands Science Institute, to which all interviewees and also local inhabitants of Statia were invited.

\subsection{A transforming marine community around oil transhipment in Statia}

Statia is a small island $\left(21 \mathrm{~km}^{2}\right)$ in the Caribbean (Figure 3.3.), home to approximately 4,000 inhabitants. Statia's capital town is Oranjestad, which is divided into two main sections. Lower Town is a stretch along the waterfront, hosting dive shops, colonial-era ruins and the harbour, while Upper Town has a restored historic core and is also the island's main commercial and residential centre. Although fisheries, agriculture and tourism contribute to a certain extent to Statia's economy, it is largely dependent on oil transhipment. The terminal is a forhire bulk liquid terminal engaged in third-party storage and handling for oil being transported in single-hulled tankers from the Middle East and Venezuela as well, to double-hulled tankers, which are allowed in the USA. Since 1982, several companies have run this facility and expanded the property; NuStar Terminals N.V. has run the company since 2005. Currently, the facility consists of approximately 72 tanks, as shown in Figure 3.4., with a capacity of 13 million barrels for crude oil and petroleum products. This terminal is the largest one owned by NuStar, accounting for $25 \%$ of NuStar's capacity, according to their 2010 annual report (NuStar Energy L.P., 2010). The terminal, located on the north- 

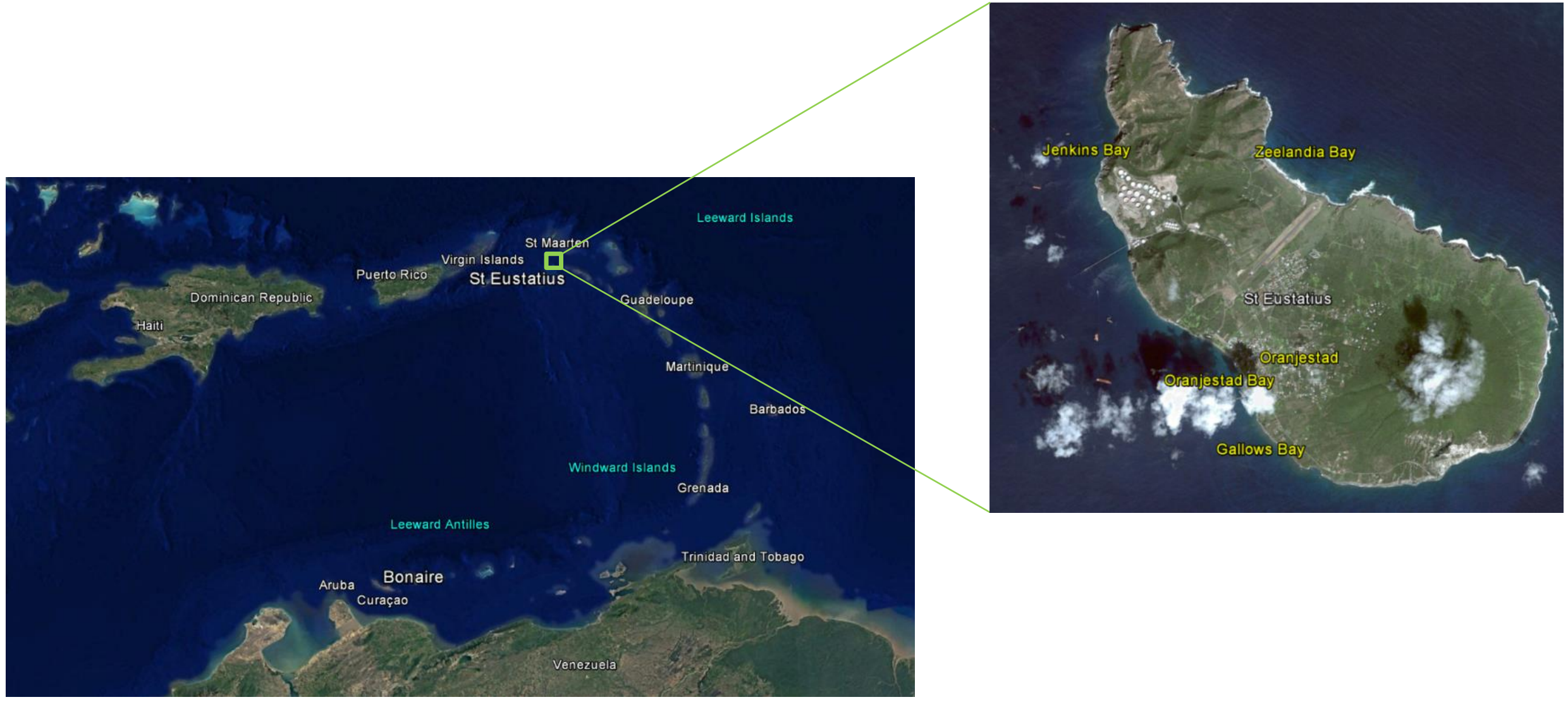

Figure 3.3. The location of Statia in the Caribbean (Google Earth, 2017a and b) 
ern side of the island, has a jetty for smaller tankers, a floating hose station, a floating dock and a single point mooring for larger tankers. There are three designated anchorage zones for bunker vessels, situated in Oranje Baai between the City Pier and the oil terminal jetty. Since 1996, the marine surroundings of Statia, which host pristine coral reefs, sea grass, reef fish and sea turtles (Debrot and Bugter, 2010), are protected as St. Eustatius National Marine Park from the high water line to $30 \mathrm{~m}$ depth. The majority of the designated anchorage zones fall within the marine park (White, Esteban, and MacRae, 2007).

Although Statia was part of the Dutch Antilles until 2010, the island government did not receive much support from the Dutch Antilles government regarding the governance of the oil terminal. This is reflected in the tax agreement regarding the oil terminal. The Dutch Antilles government was supposed to collect this tax, but it could not provide the necessary support and therefore allowed the island government to collect the tax instead (I-G-9). The former Dutch Ministry of Spatial Planning, Housing and the Environment and the Directorate-General for Public Works and Water Management were occasionally consulted by the island government regarding permits for the oil terminal (I-G-4, I-G-7). In the absence of a strong governmental influence, NuStar's role as the largest (private) employer enabled it to become the dominant actor at Statia through means of employment, taxes and corporate social responsibility.

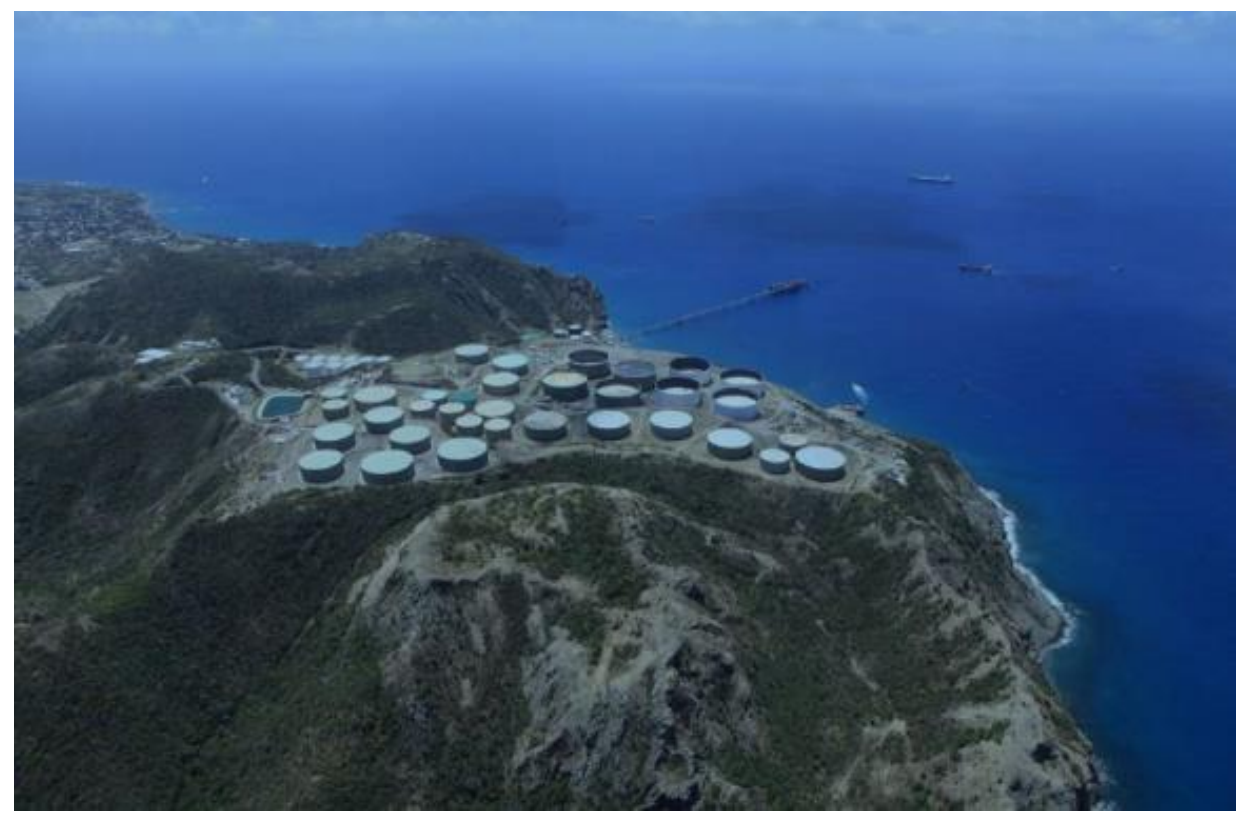

Figure 3.4. Existing Nustar facility (Royal Haskoning, 2011)

In October 2010, the Dutch Antilles dissolved, and Bonaire, St. Eustatius and Saba became special municipalities of the Netherlands. The Ministry of I\&E became more involved in environmental management by large companies, such 
as NuStar. ${ }^{3}$ Not much later, in 2011, NuStar announced the need for a second oil terminal, which created dispute among local inhabitants. Inspections since 2010 revealed that NuStar's operations were outdated and did not meet the required Dutch and European standards. In April 2015, those inspections and recent incidents urged the Ministry, instead of the island government, to become entirely responsible for permitting, supervising and enforcing environmental regulations regarding the oil terminal.

\subsubsection{A new power architecture}

The transformation of the marine community of oil transhipment in Statia will be explained through interactions between and within the user and policy community during three different phases in terms of power, as mentioned above: before and after the dissolution of the Dutch Antilles in 2010 and after 2015, when the Ministry of I\&E became responsible for the oil terminal. Figure 3.5. illustrates the findings; how structural power made the user and policy community drift apart.

The upper part of Figure 3.5. illustrates the intertwinement of the user and policy community in the first phase, with NuStar acting as both a user and a policy actor. This is stereotypical of policy-making in small islands, which rely on intensive and personal interactions and networks. Because of the new structural power architecture, introduced by the constitutional change in 2010 and amplified in 2015 by making the Ministry of I\&E entirely responsible for the supervision of NuStar, the policy community became disentangled from the local marine community. This created distance not only between the Ministry and the island but also between the island government and NuStar, as shown on the lower part of Figure 3.5. While NuStar and the island government had made compromises in the past, they now found themselves on opposite sides because of competing claims to restore their loss of power. As such, NuStar was repositioned back to only the user community.

\footnotetext{
3 The Law Maritime Management BES (in Dutch: Wet Maritiem Beheer BES) made the Dutch Ministry of Infrastructure and Environment responsible for the management of the sea around the Caribbean Netherlands (Koninkrijk der Nederlanden, 2010a); the Law on Public Housing, Urban Planning and Environmental Management BES (in Dutch: Wet Volkshuisvestiging, Ruimtelijke Ordening en Milieubeheer BES) urged for sustainable environmental policy on these islands (Koninkrijk der Nederlanden, 2012); and the Maritime Disaster Management Caribbean Netherlands (in Dutch: Maritieme Rampenbestrijding Caribisch Nederland) was established as the joint responsibility of the Dutch Ministry of Infrastructure and Environment and the Island Governors.
} 


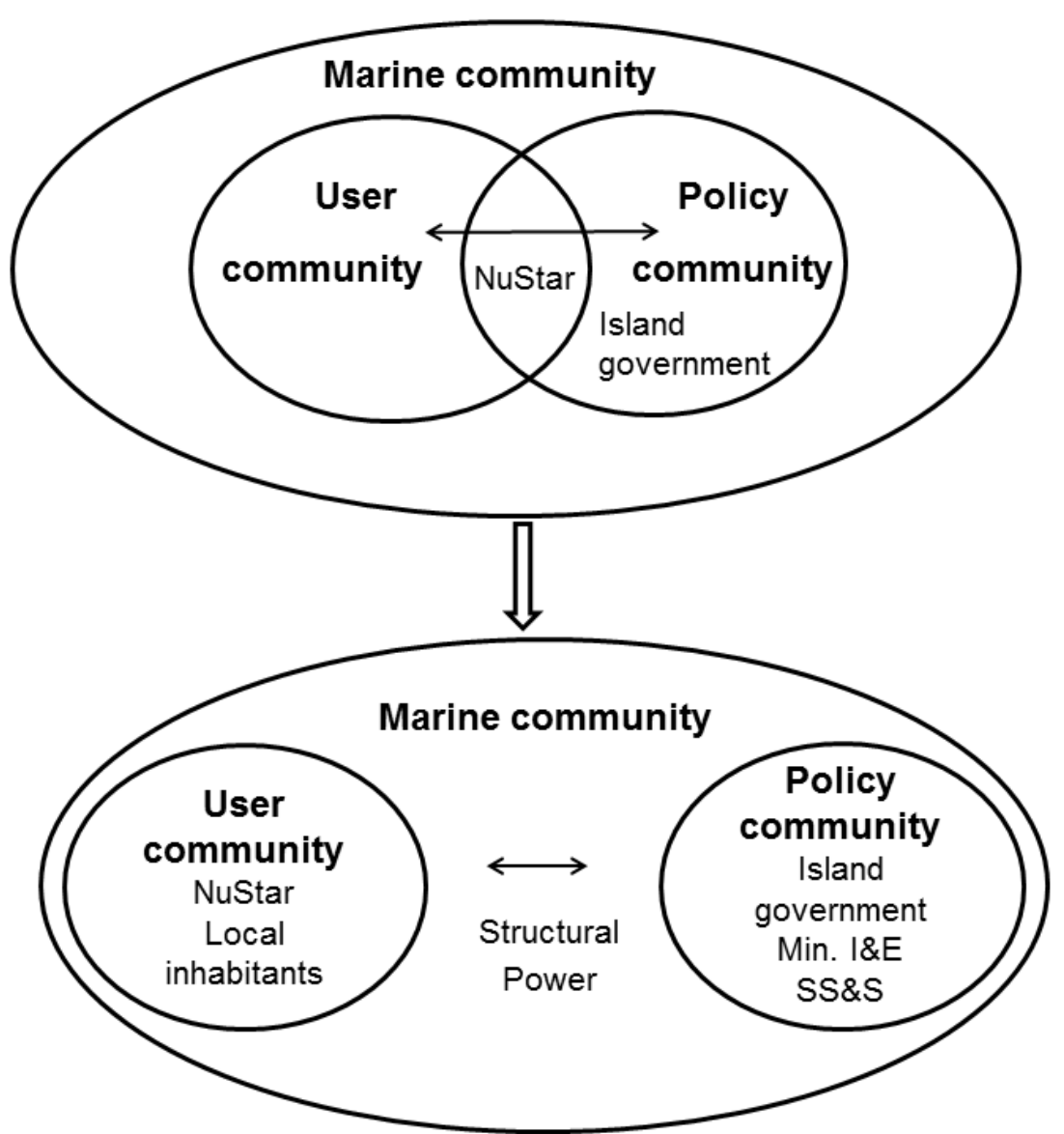

Figure 3.5. Transforming marine community because of new power dynamics

\subsubsection{Before the dissolution of the Dutch Antilles in 2010}

Before 2010, the unequal positioning of the island government's relationship with the Dutch Antilles government vis-à-vis NuStar was the result of the specific order of domination at Statia. The small island government of Statia, with a lack of knowledge and money, was dependent on NuStar as the largest employer and tax payer. This unequal power position was further amplified by NuStar providing houses, a private school and cars for its employees. Statia's economy was highly dependent on NuStar, including the spending of the company's international employees on accommodations, restaurants and rental cars (I-G-4, I-R-5,Koek, 2015) and NuStar's financial support to the community, based on its corporate social responsibility strategy (I-M-6, I-M-9). By dictating the terms of engagement, NuStar presented itself as a benefactor, buying the goodwill of Statia's local population (I-G-4) and initiating initiatives to strengthen community development. An example is the charity fund 'Statia Way Foundation', dedicated to the advancement of children, to which NuStar employees can donate a percentage of their salary or volunteer hours. This foundation is used to renovate or maintain schools, botanical gardens, gyms, auxiliary homes and playgrounds but also to 
support St. Eustatius National Parks (STENAPA) with the sea turtle program or assist the marines in their hurricane drill exercise (I-M-6, I-M-9, I-CS-3, I-CS-4, I-R8). Furthermore, NuStar steps in when the island's provisioning of water and electricity is lacking (I-M-6, I-M-9), employ local research institutes and hire interns from local schools (I-M-6). NuStar decides how much and in what activities to invest, while the island government lacks resources to control or influence NuStar to implement and comply with environmental regulations to prevent oil contamination (Klok et al., 2011).

In conclusion, the 'structured asymmetries of resources' of small island communities, such as Statia (i.e., structural power), resulted in an advantageous positioning of NuStar vis-à-vis the island government of Statia (i.e., dispositional power). Because of this positioning and the unequal distribution of resources, the island government lacked resources and capacity to govern NuStar adequately. The result was a strong user community dominated by NuStar, in which a weak policy community was intertwined. In these times, Statia aimed for increased economic growth based on oil transhipment by NuStar. Failed environmental management took form in this phase based on the fact that NuStar had operated without an environmental permit since 2002 , which was only discovered in the next phase.

\subsubsection{After the dissolution of the Dutch Antilles in 2010}

A changing power architecture of the policy community.

The dissolution of the Dutch Antilles in 2010 reversed the structural power architecture dramatically. The intervention of the Dutch Min. I\&E into the policy arena changed the balance between the user and policy community.

The Ministry of I\&E positioned itself as an important regulator in this marine community through a strong Dutch culture of law enforcement based on strict rules for the oil terminal. This shift in responsibilities was needed to bring the environmental state back in. Inspections, based on the new Law Maritime Management BES, revealed that NuStar had been operating without an environmental permit since February 2002 (Bestuurscollege St. Eustatius, 2013). Although NuStar claimed the old permit (1997) was tacitly extended (I-M-6), this did not appear to be true (I-G-4, I-G-10, I-CS-7). In the absence of any permit, no authority was checking whether operations were compliant with safety and environmental regulations. During those inspections, it also came to light that NuStar's operations were terribly outdated (I-G-4, I-G-10, I-CS-7). Many changes had to be implemented; additional investments were calculated to be approximately $\$ 80$ million (I-G-10). However, the Ministry of I\&E respected NuStar, certainly because the new constitutional structure brought many changes and 
uncertainties. The Ministry of I\&E and NuStar relied on the negotiation culture for which the Netherlands is known by bargaining about a delay in the implementation of certain deadlines in the new environmental permit (2013). Successful negotiations resulted in the postponement of deadlines by seven and a half, 15 or even 20 years (I-G-4, I-CS-7). Additionally, the obligation to install vapour extraction units to prevent emissions of harmful substances into the air was dropped (I-CS-7).

NuStar, however, resisted the Ministry's dispositional and relational power by not acknowledging the standards in the permit because it relied on safety and environmental standards for oil terminals in Europe. The limited resources and capacity at Statia made it impossible to comply with European standards. A clear example of a European standard that was rejected by NuStar was a baseline survey that established the current chemical composition of the soil on the existing terminal location (Bestuurscollege St. Eustatius, 2013). NuStar was afraid it might be liable for soil contamination because of this baseline survey. For these reasons, stereotypically for an American company, NuStar was eager to go to court (I-G-4) to further resist the dispositional power of the Ministry. NuStar and the Ministry are still in court over this environmental permit. This is not the first time the Netherlands has encountered a legal conflict with NuStar. Because of the new constitutional structure, the Dutch Ministry of Finance contends that NuStar is subject to real estate tax rather than profit tax, which implies a doubling of the taxes. In the past, NuStar has been on Statia for little money, as reflected in the Free Zone and Profit Tax Agreement (1989-2000) and an annual minimum profit tax of 1.0 million Netherlands Antilles guilders (approximately $\$ 0.6$ million), according to the 2005 Tax and Maritime Agreement between the governments of Statia and the Netherlands Antilles and NuStar. NuStar has rejected this new asymmetric distribution of resources by means of several court cases against the Dutch Ministry of Finance (I-G-4).

NuStar's expansion plan triggered the emergence of another actor in the policy community, Statia Safe \& Sound (SS\&S), an NGO established to keep Statia a safe place for everyone to live and to contribute to ensuring that the long-term economic and social future of its people was based on sound decisions and solutions (I-CS-7). This NGO has also a court case against the Ministry of I\&E, this time regarding the weakening or exclusion of European standards in the same environmental permit. SS\&S argues that NuStar has self-inflicted this situation by operating outside of governmental control for over ten years. Because of the lack of supervision and low taxes, NuStar has sufficient means available to comply with the new permit. SS\&S wants the Ministry of I\&E to apply the same standards for 
NuStar as for oil terminals in Europe because Statia deserves the same level of protection. To strengthen their reasoning, they rely on the Odfjell terminals in Rotterdam and the Chemie-Pack in Moerdijk, which were, closed and burned down, respectively, because of the lax and lenient supervision of the Ministry. Through the means of this court case, similarly to NuStar, they rely on legal resources to counterbalance the dispositional and relational power of the Ministry of I\&E (I-CS-7). Recently, standards set by the Ministry have been judged fair, but NuStar is appealing (I-G-4).

The legitimacy of the Minister's regulatory role has been further questioned by a lack of guidance. The new permit requires NuStar to monitor the oil terminal in relation to Statia's nature. Although there is a generic ecological assessment framework for coastal systems in the Caribbean Netherlands (Becking and Slijkerman, 2012), there is not yet a protocol to determine how the local monitoring of the operations of NuStar in relation to Statia's nature should be conducted. The Ministry of I\&E is therefore dependent on the Ministry of Economic Affairs, as dedicated institution (I-G-4). Although the Law on Public Housing, Urban Planning and Environmental Management BES stresses the urgency of such a nature policy plan (Koninkrijk der Nederlanden, 2012), it is currently unclear when the Ministry of Economic Affairs will develop this plan. In the absence of such a protocol, NuStar does not consider the Ministry of I\&E to be a legitimate actor because it imposes new regulations without proper guidance on a small island with limited resources and capacity.

The new constitutional structure introduced a new order of domination (structural power), materialised in a new actor in the policy community, the Ministry of I\&E. The Ministry positioned itself against NuStar through new institutional rules and against the island government through an unequal distribution of resources, i.e., the new real estate tax (dispositional and relational power). In doing so, the Ministry of I\&E broke path-dependent behaviour (i.e., how current decision-making is largely influenced by decisions made in the past, which makes it difficult to reserve the course once this particular path is taken) (Hall and Taylor, 1996) between the island government and NuStar, reflected in the previous phase by the intertwinement of the user and policy community. This resulted in a strong policy community around the Min. of I\&E in relation to a subjected NuStar, which was displaced from its position of power in the policy community back to the user community because of the risk of the enforcement and prosecution by the new competent authority. However, relying on European standards for a small island such as Statia made NuStar and SS\&S question the Ministry of I\&E's legitimacy as a regulator. Thus, the new positioning of I\&E in the policy community vis-à-vis the 
island made both NuStar and SS\&S rely on court cases to counterbalance the dispositional power of the Ministry of I\&E.

\section{A changing power architecture of the user community.}

The emergence of SS\&S as new actor in the policy community empowered the user community, as will be explained below.

In the summer of 2011, NuStar announced the need for a second oil terminal to provide additional storage capacity for a new customer. The existing terminal is situated in the north, behind Signal Hill, which mitigates the presence and view of the tanks, whereas the new terminal, consisting of approximately 30 tanks for various hydrocarbon products and a new jetty, would be built close to Oranjestad and the airport. Through this expansion, NuStar would almost double its storage capacity from 13.8 to 26.5 million barrels (Royal Haskoning, 2011). The island government decided to collaborate with NuStar and therefore prioritised oil over tourism, which was the initial aim, according to Statia's strategic development plan (Van der Velde, Hoogenboezem-Lanslots, and Schenau, 2011). This decision still reflects intertwinement between NuStar and the island government in this marine community. In these times, the island government and the Ministry of I\&E were responsible, for environmental permits for the terrestrial and marine parts of the terminal, respectively. However, the island government asked for assistance; in the end, the Ministry of I\&E consulted various stakeholders and research institutes and drafted both permits (Bestuurscollege St. Eustatius, 2013).

Although the proposed facility site was designated for business and storage, Statia's Spatial Development plan allowed this zone to be amended. Normally, the Island Council would be the dedicated institution; however, it gave away the responsibility for an amendment to the Executive Council. This implied that an amendment could now be completed within two weeks (Van der Velde et al., 2011), while the original procedure would have taken ten weeks. St. Eustatius Monuments Foundation felt that this change in procedures would speed up the amendment process, such as the one by NuStar. As such, the Monuments Foundation established the NGO SS\&S (I-CS-7). This became an important new actor in the policy community as it kept a close eye on NuStar. Before the implementation of Statia's spatial development plan, NuStar had no expansion plans. However, once the spatial development plan was implemented, NuStar suddenly applied for an amendment of the zoning in February 2012 (Adviesbureau RBOI-Buro Vijn, 2012) and asked for a thorough handling of this process to be compliant with all applicable laws. Only two weeks were needed to complete the process (Adviesbureau RBOI-Buro Vijn, 2012). SS\&S saw this coming and was 
therefore well-prepared (I-CS-7).

Statia's population was divided sharply on the expansion. Together with St. Eustatius Awareness and Development movement and Statia Roots Foundation, SS\&S started to inform the local inhabitants about the potential consequences of this expansion. The location of the second terminal was known to the locals as The Farm because of a historical plantation complex once situated there, and it is currently an archaeological site. This would affect Statia's tourism image of 'The Historical Gem'. The new terminal would operate on a property that was not only historically but also ecologically significant. The environment impact assessment, conducted by Royal Haskoning, demonstrated that the construction of the new jetty and vessel movements in the Northern Marine Reserve would affect the marine ecosystem. Regarding the terrestrial ecosystem, tanks would be built close to important habitat and nesting areas for rare and endemic species such as reptiles, the endangered red-bellied racer snake, the critically endangered Lesser Antillean iguana and several birds that breed in limited areas, including, amongst others, the red-billed tropicbird (Royal Haskoning, 2011, I-G-4).

Because of information provisioning and research assessments, the local inhabitants started to wonder about safety, health and environmental issues as well as how the terminal would pollute their view. The local inhabitants of Statia were not against the expansion because they were aware of NuStar's contribution to Statia's economy and community; they were in fact against an expansion on that location (I-CS-4). However, some people were against the expansion because it would triple NuStar's structural power over Statia as the terminal would become an even greater asset to the local economy (I-M-10) and therefore increase the structural asymmetries of resources at Statia. Although town hall meetings and information sessions were organised, there was widespread criticism on the island government because of limited information provisioning and a lack of public consultation. Through means of pictures and boat trips led by a dive shop, the local inhabitants could see whether the new terminal would be visible from their home and make an informed decision (I-M-10).

The local inhabitants informed and mobilised each other using the following resources to exercise relational power: letters to local newspapers, petitions, discussions in television programs and attempts to attract international media, which turned out to be successful, as reflected in a petition signed by inhabitants of Saba (I-G-4) and concerns raised by Dutch members of Parliament regarding the expansion (I-CS-6, I-CS-7). Grassroots opposition was shaped, at the expense of NuStar's expansion. The new dispositional power position of SS\&S made the local inhabitants aware of their right to stand up against a decision of the island 
government that would increase NuStar's structural power at Statia. They further strengthened their position by striving for a democratic outcome by filing 1,034 objections against the amendment of the spatial development plan (only 238 were valid objections because of identifiable signatures, names and addresses; (Public Entity St. Eustatius, 2012, I-G-4). This was significant considering the population size of Statia, i.e., 4,000. St. Eustatius Monuments Foundation's first objection against the island government, regarding the possibility of amending the spatial development plan, was set aside by the island government. The Monuments Foundation therefore started a court case against the island government to strive for good governance, made possible by more access to legal appeals because of the Dutch competent authority instead of decision-making based on unprofessional political and official relationships and the intertwinement of the economic and political elite. The judge ruled the case inadmissible because Statia could not be affected by the possibility of amending the spatial development plan but only if use was made of this possibility. The Monuments Foundation, however, appealed at the Joint Court of Aruba, Curaçao, St. Maarten and of Bonaire, St. Eustatius and Saba. The Monuments Foundation acted as its own lawyer and argued that the very amendment facility itself affected the state of the island's heritage and safety as it enabled a quick, low-profile procedure for the most impactful part of the entire Spatial Development Plan. Instead of a careful process with proper information sessions for the general public and opportunities for active involvement and participation, it required only the decision of the Executive Council to be available for public consultation for a period of 15 days. The verdict of the Joint Court acknowledged the Monuments Foundation's plea to be successful (I-CS-7,Pearl of the Caribbean, 2015).

The ultimate example of relational power within the user community was the protest march on March 16, 2012 by the local inhabitants to the acting Lieutenant Governor. Protesters handed him pictures illustrating the dangers brought about by the oil terminal. "It was a historical event. Never before local inhabitants of Statia had walked on the streets knowing they have the right to protest against the island government" (Paul Spanner in St. Eustatius Awareness \& Development Movement, 2012). They positioned themselves against the island government, reflecting dispositional power.

In the end, the expansion was withdrawn. Although the user community likes to believe the expansion was withdrawn because of the opposition they raised, adjustments to the plans and permits resulted in a threefold of the calculated investment. Consequently, the expansion became cost inefficient, and NuStar withdrew it (I-M-6). 
Through the establishment of SS\&S, new dispositional power changed the power architecture of the user community. By mobilising resources (information provisioning and research assessments) and legal appeals to strive for good governance because of the Dutch competent authority, the NGO empowered part of the user community contra NuStar's expansion through relational power. Loose ties between the local inhabitants became strengthened through protests against the potential expansion of the NuStar terminal; consequently, a user community within the marine community emerged, next to NuStar. Path-dependent behaviour within the user community was thus broken because this was the first time in history that the local inhabitants stood up against their island government. This user community further positioned itself against NuStar and the island government through means of filing objections against amending the spatial development plan in favour of NuStar and the protest march, reflecting dispositional power.

\subsubsection{After April 1, 2015}

In this phase, the new structural power architecture established in the previous phase was strengthened further, which resulted in new claims of power.

Inspections and recent incidents regarding the oil terminals of NuStar on Statia and BOPEC on Bonaire strengthened the Ministry of I\&E's concerns that those small islands did not have the capacity to handle large companies (I-G-4). In addition, they lacked a solid legal basis for environmental policy-making, although it was urgently needed considering recent environmental problems (VROM Inspectie, 2010). In 2010, the Facilities and Activities Ordinance BES ${ }^{4}$ measure was initiated to facilitate a proper environmental state on those islands in relation to large companies, such as NuStar. However, the implementation of this measure was delayed by local authorities and businesses aiming to determine the ambition and feasibility of environmental management. The Minister could no longer wait and urgently implemented the Large Facilities Environmental Management Ordinance BES ${ }^{5}$. On April 1, 2015, the Minister instead of the island government therefore became responsible for all permitting, supervision and enforcement duties regarding the oil terminals of NuStar and BOPEC and Curoil on Bonaire (Ministerie van Infrastructuur en Milieu, 2015).

Because of the transferred responsibility of the oil terminal to the Ministry of I\&E in 2010, NuStar's tax revenues are collected no longer by the island government but by the Netherlands. This reallocation of resources made the island government look for alternative ways to bring much needed revenue to the island. As such, a

\footnotetext{
${ }^{4}$ In Dutch: Inrichtingen- en Activiteitenbesluit Milieubeheer BES.

${ }^{5}$ In Dutch: Besluit Grote Inrichtingen BES.
} 
new Harbour Ordinance was drafted (Eilandsraad St. Eustatius, 2015b) as an attempt by the island government to regain structural power. This ordinance defined the boundaries of the harbour zone and the harbour fees and replaced the old Island Ordinance (1982). An important issue related to the NuStar terminal was the significant increase in harbour fees. Although NuStar understood that the harbour fees needed to increase, it did not agree with the exponential increase (an additional \$20 million per year), which was imposed on and not negotiated with the company (I-M-6). Because of island elections of March 15, 2015, the implementation of the ordinance was postponed until June 2015. NuStar wrote a letter to all its employees on March 6, 2015 and "urged them to contact the members of the Executive Council and Island Council and asked them to delay any consideration of these ordinances until a fair and responsible agreement can be reached by both parties" (Oliver, 2015, p. 2). Through this letter, the company made use of relational power to mobilise its employees to influence elections (I-M10). Afterwards, negotiations took place between the island government and NuStar regarding the increase in harbour fees. While NuStar and the island government managed to make compromises in the past, reflecting relational power, they now found themselves on opposite sides. NuStar therefore announced in September 2015 that it would start a court case against the island government regarding the $\$ 20$ million annual increase in harbour fees, which NuStar could not afford given the current oil market (Koek, 2015), reflecting structural power. Unequal distribution of resources, through a sudden increase in taxes and fees, subjected NuStar to structural and dispositional power by the Ministry of I\&E and the island government, respectively. As such, NuStar is currently reflecting on the future of its oil terminal at Statia. The company either has to leave Statia for cost-ineffective reasons or expand to become the largest oil transhipment terminal in the region (I-G-4).

The new Harbour Ordinance resulted not only in an increase in harbour fees but also in a designated harbour zone. Previously, there had not been a harbour zone because the marine park surrounds the entire island. The amended ordinance defined the area for the harbour but simultaneously reallocated the west side of the marine park to become harbour area (see Figure 3.6.). On top of that, the two marine reserves lost their legal protection and thus became a free for all (Eilandsraad St. Eustatius, 2015a). The island government was accused of noncompliance with requirements of proper governance because the marine park was reduced by approximately $27-40 \%$ (depending on whether the lost status of the marine reserves is included) based on a rapid, unmotivated decision without the consultation of relevant stakeholders (Koelega, 2015; World Wildlife Fund, 
2015a). Especially because St. Eustatius National Marine Park has been protected under the international Specially Protected Areas and Wildlife protocol since December 2014 (Koelega, 2015).

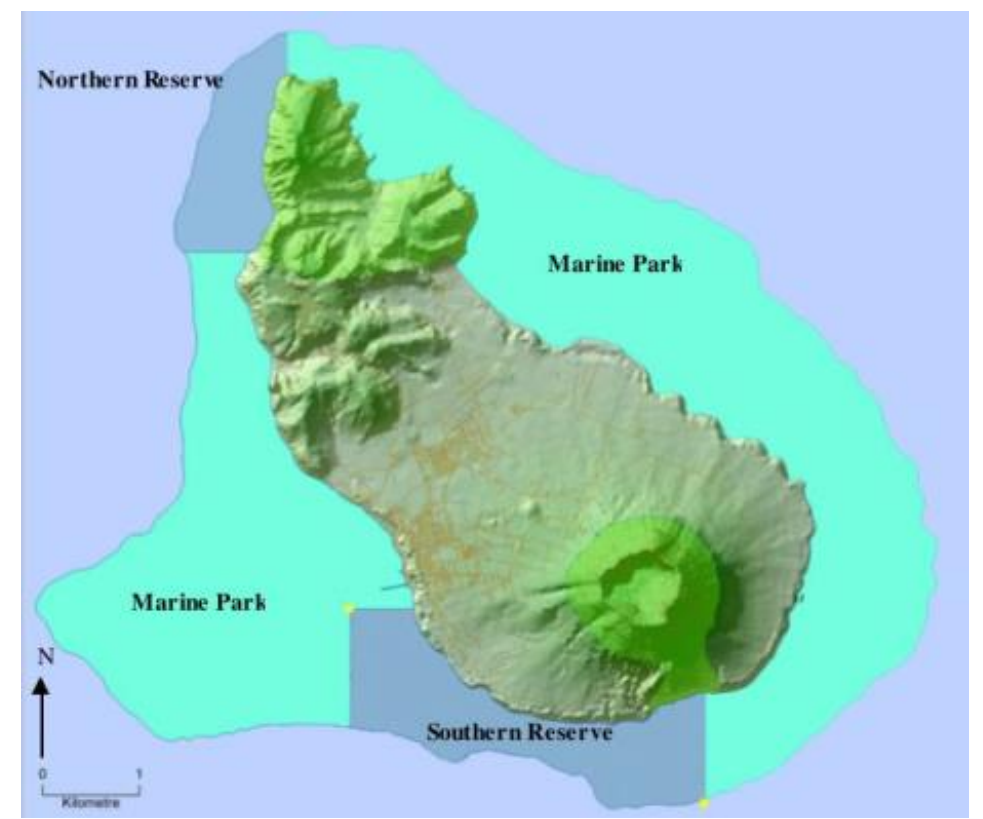

Figure 3.6. St. Eustatius national marine park. (White et al., 2007)

As such, the structural power struggle over the oil terminal also affects other sectors, such as nature conservation and dive tourism. Although the island government is responsible for the marine park, Statia's status as special municipality of the Netherlands requires the Ministry of Economic Affairs to oversee whether the island obeys Dutch legislation and international agreements regarding nature conservation. In the end, NuStar won the court case against the island government regarding the new Harbour Ordinance on October 30, 2015. The court concluded that the contested Harbour Ordinance had not been announced as prescribed by the Dutch Law on the public entities BES because only some government-selected stakeholders were informed about the draft ordinance, which prevented stakeholders from filing objections before it entered into force (Koninkrijk der Nederlanden, 2010b). Therefore, the Harbour Ordinance was rendered non-binding.

Tough negotiations among the island government and NuStar regarding increased harbour fees were among the issues discussed during the Dutch Caribbean Week in the Netherlands in June 2015. To induce good governance and to improve the financial management at Statia, the Dutch government decided to put Statia under enhanced surveillance by the Kingdom of the Netherlands (Spies, Soons, Thode, Verhey, and Weekers, 2015). The structural power of the Netherlands over Statia therefore increased even more, beyond the 
responsibilities of the Ministry of I\&E. Inhabitants of Statia were not happy with this decision because they preferred to aim for more autonomy than to be told by the Netherlands how to govern their island. This reminded Statia of its colonial history. Along with its enhanced surveillance, the Dutch government no longer visited Statia for work appointments (Van Kerkhof, 2015). On December 10, 2015, this governance boycott between the Kingdom of the Netherlands and Statia came to an end. Currently, they are back on speaking terms (Samson, 2015).

The structural power of the Ministry of I\&E resulted in an asymmetric distribution of resources since 2010 and strengthened the Ministry's beneficial position against the island government (dispositional power). Although the island government tried to turn around these structured asymmetries of resources through the new Harbour Ordinance vis-à-vis the Ministry and NuStar, the lack of a proper consultation process rendered its status non-binding. Tension between the island government and NuStar, among other things, resulted in even more structural power of the Netherlands over Statia. The national policy community thus became only stronger and more disentangled from the user community as well as the local policy community.

\subsection{Discussion}

To govern the environmental consequences of oil transhipment on a small island such as Statia, the power architecture of the marine community had to be transformed from a user-dominated to a policy-dominated marine community. Such a transformation of power dynamics and the application of new conceptions and practices of governance was part of more general processes of political modernisation (Arts and Van Tatenhove, 2004). In theory, environmental issues could be better addressed at Statia if the structural and dispositional power position of the policy community (public actors) increased compared with the power position of the user community (e.g., NuStar).

This case showed how the entrance of the Dutch government (including the European standards and legislation that accompanied it) in the policy community dramatically transformed the power balance of the marine community. The Ministry of I\&E forced the island government for improving the environmental management by NuStar and more generally for improving the environmental state of Statia. The environmental state refers to a specific form of statehood that follows an environmental rationale and refers to the ability of governmental actors embedded in specific regime complexes to govern activities causing environmental problems and spatial conflicts and to find solutions for these problems and conflicts (Van Tatenhove, 2015). In general, a decentralised 
approach for improving the environmental state on small islands in the Caribbean such as Suriname and Curaçao is not powerful enough to address environmental issues in relation to (multi-national) companies (Mol et al., 2004; Mol and Van Vliet, 1997). However, a more centralised approach could be in conflict with the limited resources and governance capacity of small island environmental states and policy-making characterised by unprofessional political and official relationships and the intertwinement of the economic and political elite ( $\mathrm{Mol}$ and Van Vliet, 1997).

This case showed clearly that the tension between a Dutch, or (Northern)European, conception of the environmental state and a small island environmental state in relation to oil transhipment in Statia provoked the abovementioned power struggle. Although the new structural power architecture of the Ministry of I\&E enabled the policy community to stand up against NuStar effectively for the first time, it put Statia in a paradoxical situation. While political transformations were required to strengthen the environmental state at Statia to govern the environmental consequences of the NuStar oil terminal, the structural power change simultaneously constrained trust relations between the Ministry of I\&E and Statia and thus questioned the Ministry of I\&E's legitimacy as new regulatory actor.

This resembles findings on the marine community of LNG production in Hammerfest (Van Bets, Van Tatenhove, and Mol, 2016). In that case, centralised decision-making between the Norwegian State and Statoil resulted in a similar scale mismatch between the national policy and the local user community within the marine community. This scale mismatch was, similar to Statia, amplified by Hammerfest's resemblance to SIDS, such as a lack of resources and governance capacity to withstand the power of the national policy community, eagerness for economic development, and isolation from the national policy community. The difference is that centralised decision-making by the national policy community emphasised economic growth in Hammerfest, while in Statia, the national policy community strives for a proper environmental state.

The findings of both cases argue for analysing power dynamics that are insufficiently addressed in the literature on small islands. An integrative literature review regarding the enhancement of sustainability on small islands foregrounds transparent and accountable decision-making through legal frameworks, supervision and monitoring as key conditions for stimulating good governance, community empowerment and resilience at small islands (Polido, João, and Ramos, 2014). Barnett and Campbell, in their study on small islands in the South Pacific, conclude that proactive adaptation should be facilitated as adaptation on 
small islands is often a response to a wider and pre-existing environmental problem, as is the case in Statia. Proactive adaptation will enable communities to be equipped to make decisions, to have access to resources and to act when needed (Barnett and Campbell, 2010). Although these studies presume that a structural change in decision-making will lead to sustainability and good governance at small islands, they neglect the changing power dynamics that such a structural change provokes, which counterbalance resilience and adaptive capacity, as reflected by Statia's marine community in relation to environmental governance of the oil terminal.

Adaptive capacity is determined, among other things, by the existence of power structures that are responsive and consider the needs of all stakeholders (Berkes, Colding, and Folke, 2003). The structural power change at Statia did not acknowledge the different needs of all stakeholders but rather imposed a new power architecture on them. As a result, Statia felt insufficiently heard by the Ministry, which relied on a Dutch-European conception of the environmental state, while the Ministry questioned the weak governance capacity at Statia, compromising the effectiveness of measures taken to achieve environmental management of oil transhipment in Statia. These feelings were strengthened by memories of Statia's colonial history. Imposing a Western society-dominated view of an environmental state does not acknowledge Statia's own capacity to act. This structural power change sharpened trust relations not only between Statia and the Netherlands but also within Statia's society. It thus compromised dispositional and relational power at Statia, which forms the foundation for Statia's adaptive capacity. This chapter therefore argues that changing power relations at small islands should be further explored because they might affect governance processes differently than in Western societies.

\subsection{Conclusion}

The governance of oil transhipment in Statia is challenged by recent developments. The marine community concept revealed that for improving the small island environmental state at Statia, new actors entered the policy arena; as a result, both the user and policy community matured within this marine community. The new composition of the marine community provoked a new structural power architecture; it transformed from a user-dominated to a policydominated marine community.

Although the new structural power position of the Dutch government improved the environmental state at Statia, the way the Ministry used its dispositional power and relational power (use of resources), based on its new structural power 
position, conflicted with the island's political culture, existing networks and interpersonal relations and the characteristics of Statia's civil society. For the years to come, it will be important for the structural power position of the Dutch government to become more aligned with the preferred environmental state of all actors in the user and policy community, such as the island government, NuStar, local inhabitants and NGOs. If not, exercising of merely structural power by the Ministry of I\&E and the island government might force NuStar to leave Statia as oil transhipment might no longer be profitable because of increased investments, taxes and fees.

To overcome this power struggle, the marine community should first invest in the layer of dispositional power. Dispositional power between the Ministry of I\&E and the island government can be mediated by the implementation of the Facilities and Activities Ordinance BES through which the island government can rely on a proper environmental state in relation to NuStar. Second, dispositional power between the Ministry of I\&E and NuStar can be restored by the development of Statia's nature policy plan by the Ministry of Economic Affairs, which will provide guidance for environmental monitoring by NuStar. Shaping the marine community's capacity to act through means of dispositional power co-determines what it can achieve in terms of relational power, by improving the willingness of actors to invest in Statia's small island environmental state regarding oil transhipment. 



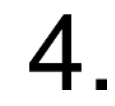

\section{Governing cruise tourism at Bonaire: a networks and flows approach}

This chapter has been published as L.K.J. van Bets, M.A.J. Lamers, and J.P.M. van Tatenhove (2016)

Governing cruise tourism at Bonaire: a networks and flows approach Mobilities

DOI: 10.1080/17450101.2016.1229972 


\section{Abstract}

Conceptual approaches to thoroughly study the governance of cruise tourism are lacking in the literature. Relying on Castells' network society, this chapter analyses how two interconnected flows of cruise ships and passengers are governed by a marine community of users and policy makers. Bonaire is used as a case study. Research shows that the transnational cruise ship flow increasingly determines the local passenger flow at Bonaire. Therefore, the marine community increasingly connects with and adapts to the requirements of the transnational cruise network. Moreover, unequal power relations between cruise networks and flows prioritise the economy over the environment in Bonaire.

Key words: Bonaire, Cruise tourism, Environmental governance, Flows, Marine community, Networks, Small island developing state 


\section{Cruise networks and flows @ Bonaire}

Cruise tourism is a complex and transnational mobility system governed by multiple levels and actors. Currently the literature lacks concepts that provide a thorough understanding of governance arrangements of cruise tourism mobility.

This chapter presents a conceptual framework to understand the development of a marine community around cruise tourism, based on the sociology of networks and flows. Governance arrangements of cruise tourism flows on and around the small Caribbean island of Bonaire serve as an in-depth case study.

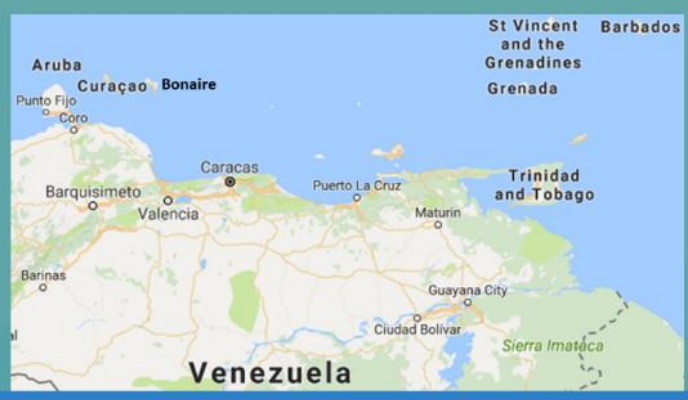

Gruise ships flow
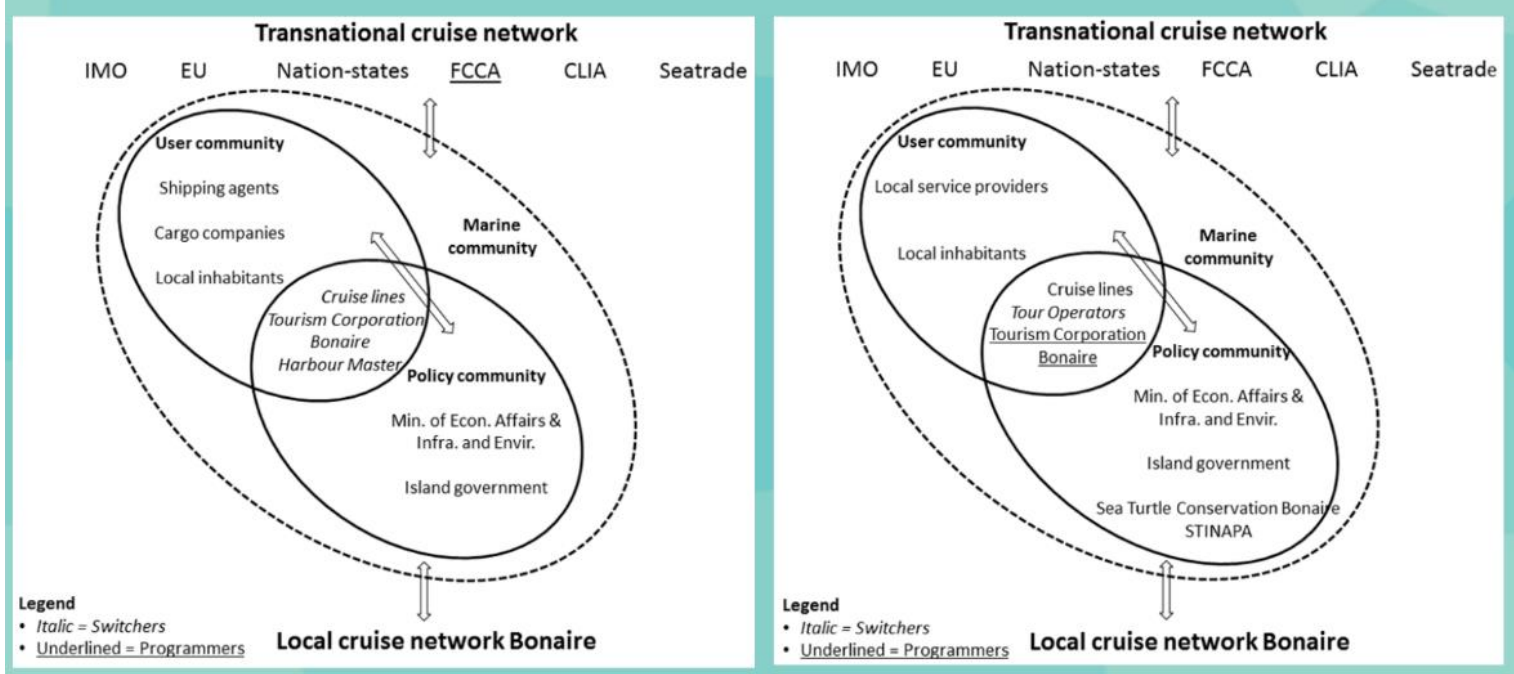

Conclusions

(\#1) The dominant transnational cruise ship flow determines the local passenger flow at Bonaire.

(12. The marine community increasingly connects and adapts activities to the requirements of the transnational cruise network.

(\#3) Unequal power relations between cruise networks and flows prioritise economy over environment.

Co- WAgeningen

Figure 4.1. Graphical abstract Bonaire 



\subsection{Introduction}

Cruise tourism has witnessed tremendous growth over recent decades. Although it began as a predominantly North American market, cruising has recently become more popular in European, Asian and Australian markets, and new destinations have been added to the portfolio (e.g. Brida and Zapata, 2010; Dowling, 2006; Weaver and Duval, 2008). Concurrently, the development of cruise tourism has stirred societal and academic debates about its environmental and socio-economic impacts at local, regional and global levels (e.g. Dobson and Gill, 2006; Johnson, 2002; Klein, 2007, 2011; Lamers, Eijgelaar, and Amelung, 2015; Lester and Weeden, 2004). In contrast to these widely shared environmental and socioeconomic concerns, the literature on cruise tourism regulation is more limited and fragmented. Cruise mobility is considered an under-regulated activity, particularly when viewed from a state agency perspective (e.g. Timothy, 2006; Weaver and Duval, 2008). Cruise tourism is clearly a complex and transnational mobility system governed by multiple levels and actors, including non-state actors (Lamers et al., 2015). However, the literature currently lacks useful conceptual approaches that provide a thorough understanding of the governance arrangements of cruise tourism mobility.

This chapter presents a new conceptual framework for understanding the development of a marine community involved in cruise tourism, based on the sociology of networks and flows. This framework provides an integrative approach to theorise governance of cruise tourism for three reasons. First, it shows how different flows of cruise tourism stretch from transnational to local cruise networks and how power relations emerge between transnational flows of cruise ships and place-based flows of passengers. Second, inspired by Manuel Castells' theory on power in the network society (Castells, 2009a), the framework identifies how a dynamic marine community consisting of users and policy makers involved in governing cruise tourism is formed and adapted under the influence of both local and transnational cruise networks. Finally, the framework provides insights into the governance implications of the interplay of transnational and local cruise flows and networks for sustainable cruise tourism. The governance arrangements of cruise tourism flows on and around the small Caribbean island of Bonaire serve as an indepth case study.

Bonaire is known for its rich coral reef ecosystem, which serves as the main attraction for scuba diving and snorkelling tourists. Bonaire's marine ecosystem is well preserved and has hosted the oldest MPA in the Caribbean since 1979 (STINAPA Bonaire, 2015a). In recent decades, however, various global and local, 
as well as human and natural developments have threatened this fragile ecosystem, jeopardizing the foundations of the island's economy (Van der Lely et al., 2013). One of these developments is cruise tourism. The island is home to 17,000 inhabitants and a relatively stable number of 70,000 stay-over tourists per year who visit Bonaire by airplane. Strikingly, visits by cruise ships have shown exponential growth, from approximately 40,000 cruise passengers in 2005 to 200,000 in 2010 (Schep et al., 2012).

Cruise tourism in Bonaire is largely influenced by the competitive character of the Caribbean cruise market, where the economic stakes are high and both cruise companies and coastal destinations advocate increasing flows of cruise ships and passengers. Competition is paramount for Bonaire as a cruise destination because it is located in the south of the Caribbean, far away from other popular cruise destinations such as St. Maarten and Barbados (Schep et al., 2012). Furthermore, Bonaire competes with its neighbouring islands Aruba and Curaçao, where the cruise tourism industry and infrastructure are well developed. Therefore, in the past, Bonaire was more likely to be excluded from cruise itineraries. However, Bonaire recently invested in marketing at the FCCA to highlight the island's potential as a popular cruise destination. This investment paid off, and in 20152016 Bonaire will further expand its cruise season from six months to all-yearround. As a result, more and larger cruise ships with different types of cruise passengers will visit Bonaire. To accommodate these increasing flows of cruise ships and passengers, more investments are required to provide appropriate infrastructure and sufficient facilities. An increase in the number of cruise passengers and investments in infrastructure and facilities will likely put extra pressure on the island's marine ecosystem, which functions as the main tourist attraction at Bonaire. Although increased cruise tourism may be beneficial to the island's economy, the question is how sustainable this development will be (Schep et al., 2012).

This chapter will show that the governance of cruise tourism flows on and to Bonaire, as well as more generally, is embedded in networks of state and nonstate actors and institutions. The interplay between the local tourism network of Bonaire and the larger transnational network of cruise tourism induces new dynamics and the coexistence of multiple levels and scales beyond Bonaire. Therefore, analysing cruise tourism in Bonaire can no longer be geographically limited just to Bonaire; such analysis needs to account for the interaction between the global cruise network and the locality of Bonaire's tourism industry. To understand the global-local interplay between the flow of cruise ships (Figure 4.2.) and the flow of cruise passengers in Bonaire (Figure 4.3.), the concept of a marine 


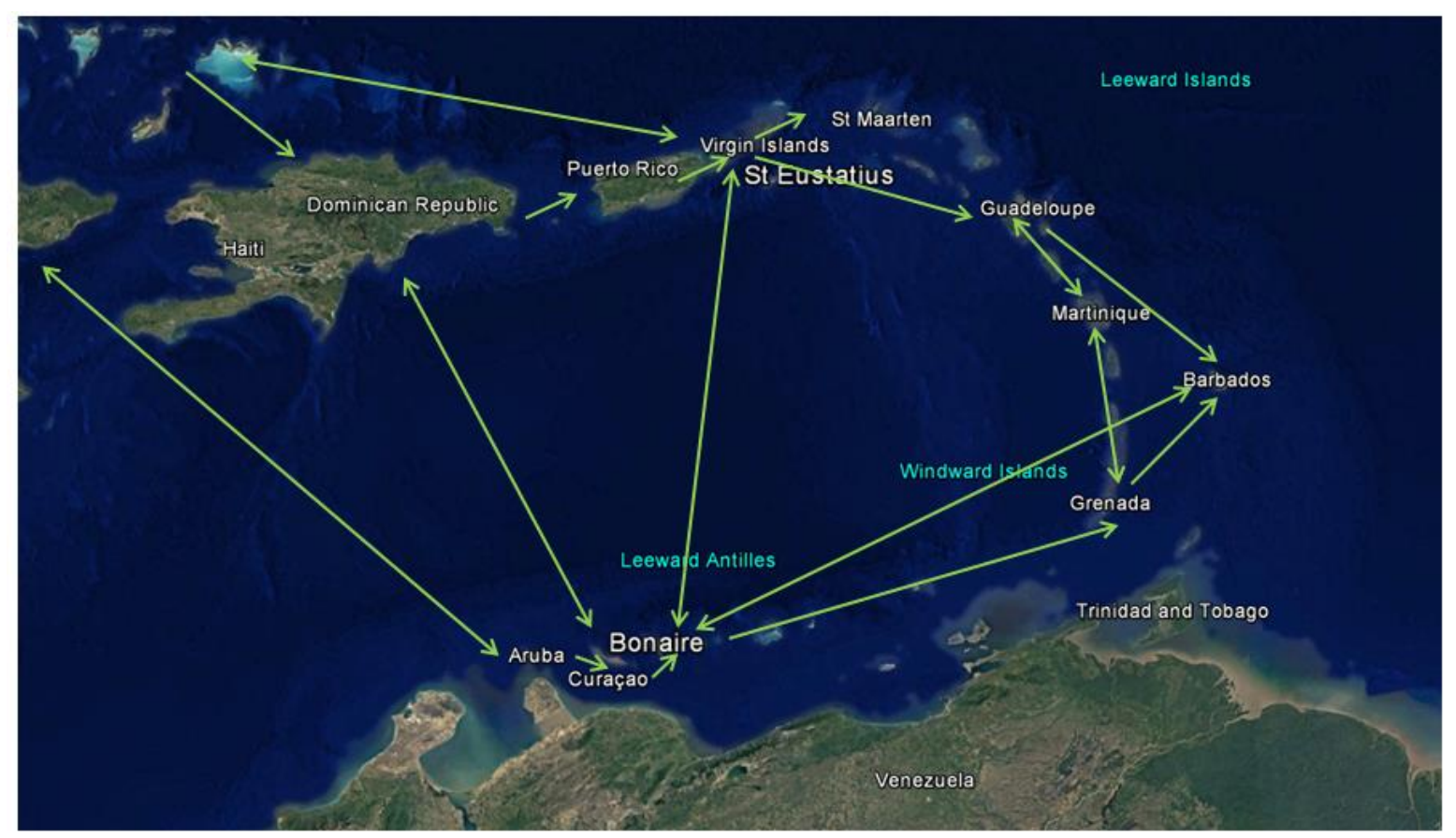

Figure 4.2. The flow of cruise ships to Bonaire (Google Earth, 2017a)
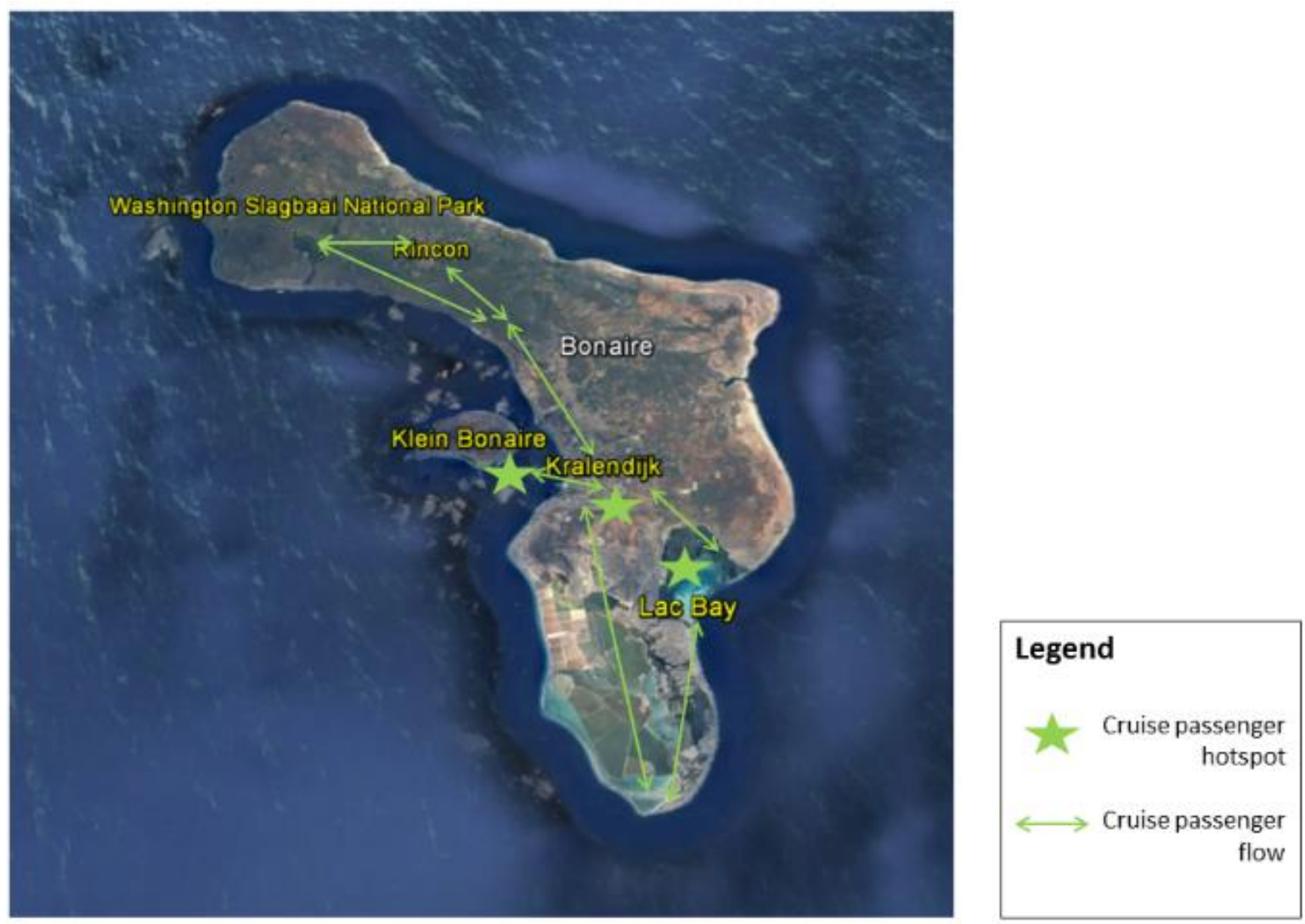

Figure 4.3. The flow of cruise passengers in Bonaire (Google Earth, 2017b) 
community was developed, which is a community of users and policy makers involved in the governance of a certain maritime activity (Van Bets, Van Tatenhove, and Mol, 2016).

The aims of this chapter are: to understand the marine community of cruise tourism in Bonaire in terms of networks and flows and to explore the governance implications for sustainable tourism for Bonaire's vulnerable marine ecosystem.

Section two will introduce the theoretical framework. Core concepts are marine community and networks and flows. Section three describes the methodology and section four analyses and explains the marine community of cruise tourism in Bonaire using the networks and flows approach, followed by a discussion of the governance implications for sustainable cruise tourism. Section five concludes the chapter.

\subsection{Theoretical framework}

To analyse increased cruise tourism in Bonaire, this chapter makes use of sociological theories on networks-and-flows and mobilities developed since the 1990s. This approach is promising for this case study because it diverges from a place- and nation-state-based concept of society as a central unit of analysis towards concepts of transnational networks and flows of people, capital, information, images, goods, and materials - as true architectures of global modernity. According to Castells, globalisation results from the rise of the network society, in which ICT increasingly determines the social structures and activities of this society. A key feature that distinguishes this global network society from previous network concepts of social organisation is the emergence of a 'space of flows', a timeless, boundless and transnational space in which flows travel between different nodes in a network, complementary to the ever existing placebounded activities in the 'space of places' (Castells, 2009a).

In the context of broader shifts towards a network society, cruise tourism development has faced similar changes. The cruise tourism market has grown and diversified significantly in recent decades, and now ranges from small-scale adventure and luxury to large-scale cruises with vessels equivalent to floating destinations in North America, Europe and Asia (Greenwood and Barron, 2006; Wood, 2000). As such, cruise tourism has become more deterritorialised, with cruise vessels and tourist flows literally spanning the globe, relatively free from place-bound (state) regulation and the usual place-based constraints of touristic space (Weaver and Duval, 2008; Wood, 2000). At the same time, cruise tourism also became reterritorialised, as European and Asian destinations and quite remote and vulnerable regions were added to the cruise itinerary portfolio 
(Lamers et al., 2015). Cruise tourism can therefore be characterised as a mobile placeless activity, with a particular intersection of travelling and belonging to both the space of flows, characterised by the global cruise sphere, and the space of places, i.e. the cruise destinations. Thus, the networks-and-flows and mobilities approach accounts for the variety of actors, institutions and organisations, operating at multiple levels (local, regional and global), that form the networks that aim to steer the different flows (on-shore visits, the journey itself and on-board activities) running in the cruise sphere (Lamers et al., 2015). This chapter focuses on the interrelation between cruise ship flows and cruise passenger flows.

To capture the multiple levels and actors involved in the interaction between the transnational cruise network and the local tourism network of Bonaire, the concept of the marine community is introduced in this chapter. While in ecological sciences the concept refers to a group of interacting living organisms sharing a populated marine environment (Bertness et al., 2000), in this thesis a marine community is based on social scientific definitions and insights, emphasising the following: the way socio-economic and policy actors and institutions are organised around a certain maritime activity, which influences or will be affected by the (marine) ecosystem in which the activity occurs (Van Bets, Van Tatenhove, and Mol, 2016). In principle, in a marine community two interdependent communities can be distinguished analytically: a user and a policy community (see Figure 4.4.). Actors, and to a lesser extent institutions, can be part of both user and policy communities, but each community has a distinct logic, rationality and purpose. According to Crow and Allan (1994) and Smith (2001); a user community refers to a community of interdependent actors that executes, and is affected by, the maritime activity, and who make use of the goods and services marine ecosystems provide. A policy community comprises actors that are part of (in)formal institutions and governance arrangements that regulate maritime activities to realise the sustainable use and management of marine ecosystems (Atkinson and Coleman, 1992; Sørenson and Torfing, 2005; Walker, 1989).

According to Castells, power in the network is exercised through means of networking power, i.e. "the power of the actors and organizations included in the networks that constitute the core of the global network society over human collectives and individuals who are not included in these global networks" (Castells, 2009b, p. 42). The paramount form of power in the network, however, is network-making power. This type of power is shaped by programmers and switchers. In the marine community, programmers are able to constitute the network and to (re-) program the flows running through the network to achieve their goals, e.g. increasing the flows of cruise ships and cruise passengers. The 
Switchers' strength, on the other hand, lies in their ability to connect and ensure cooperation across the local tourism network of Bonaire and the transnational cruise network by sharing a common understanding and by mobilising resources, while fending off competition from other cruise destinations in the Caribbean by establishing strategic cooperation. Switchers do not only connect the local cruise network of Bonaire to the transnational cruise network, they also switch between the user and policy community (see Figure 4.4.).

Applying these concepts, the marine community involved in cruise tourism in Bonaire is empowered by the fact that it links in various ways to transnational and local networks and flows steering cruise tourism. In other words, the marine community is intertwined in the space of flows, represented by global cruise tourism and programmed by different nodes, such as the IMO, the EU, nationstates, the Cruise Lines International Association, Seatrade Global Cruise and the FCCA, as well as in the space of places, shaped by the locality of the tourism industry on the small island of Bonaire, as reflected in Figure 4.4.

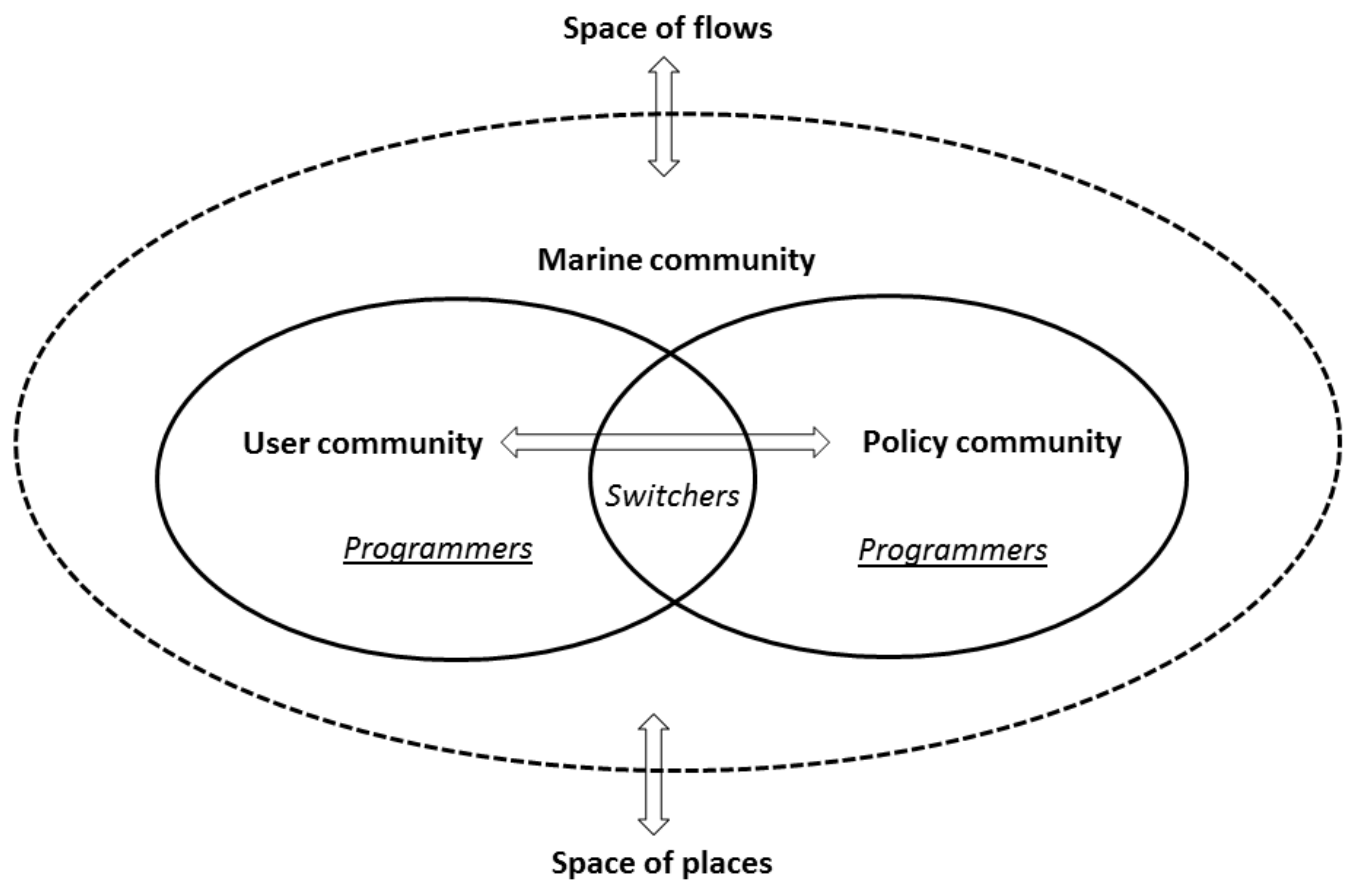

Figure 4.4. The conceptual framework combining the networks and flows approach and marine communities

\subsection{Methodology}

To gain insights into relationships, complexities and institutional settings within a marine community, a case study design was chosen. A case study allows the researcher to derive an in-depth understanding of the research object by examining a range of factors and potential causal connections as well as how 
they change over time. In addition, this methodology is useful to address actors' motives, interpretations, constructions of reality and behaviour (Swanborn, 2010; Yin, 2003). Bonaire was selected as a case study because it features strong interdependence between nature and economic development, which is affected by increasing flows of cruise tourism as the cruise season will expand beyond six months. These future plans raise questions about the environmental, economic and social impact of increased cruise tourism on Bonaire. Fieldwork at Bonaire was conducted for three weeks in March-April 2015. This chapter will provide insights into how these impacts are managed by the marine community involved in cruise tourism in Bonaire.

Bonaire is a small island $\left(294 \mathrm{~km}^{2}\right)$ in the Leeward Antilles in the Caribbean Sea, located off the north coast of South America. Bonaire's capital is Kralendijk, the largest town on the island. Bonaire used to be part of the Netherlands Antilles until the country's dissolution in 2010, when Bonaire, as well as St. Eustatius and Saba, became special municipalities within the Kingdom of the Netherlands. In contrast, the islands of Aruba, Curaçao and St. Maarten became independent states within the Kingdom of the Netherlands.

Bonaire's warm and dry climate enables the existence of large and diverse marine and terrestrial ecosystems, which provide a home for, among others, fringing coral reefs, sea grass, mangroves, reef fish, and sea turtles. This natural heritage at Bonaire is well preserved by the designation of five sites under the Convention on Wetlands (i.e. Ramsar Convention) and two national parks. This unique combination of protected ecosystems, both off and on land, attracts tourists to a variety of activities on the island, such as diving, snorkelling, kayaking, windsurfing, sailing, hiking and bird watching (Van der Lely et al., 2013). Therefore, Bonaire's economy is largely dependent on tourism; other industries include salt production, oil storage and shipment, and transportation (Central Bureau of Statistics, 2010). Having the intrinsic characteristics of a small territory and population, geographical isolation, and a restricted economy highly dependent on its natural resources, Bonaire can be defined as what is labelled elsewhere in the literature a SIDS (Mol et al., 2004).

The semi-structured interviews with key informants served for mapping the marine community structure and for identifying how each actor is positioned in this community, stretching from the transnational to the local cruise network, and which resources, rules and perceptions they use. All the semi-structured interviews were conducted using the same topic list, covering questions on stakeholders' contacts and interactions in the community, access to knowledge and information, rule compliance, conflict resolution and their perceptions, distracted from the 
theoretical framework (see Appendix 1). Key informants represent national and local governmental authorities, the cruise industry, tour operators, port authorities, NGOs, dive shops, local inhabitants and researchers. In total, 36 interviews were conducted, of which 32 were with a single interviewee and four were with multiple (two or three) interviewees. Of the interviews, 31 were conducted face-to-face in Bonaire, one was held face-to-face in the Netherlands, two were held by phone and one by Skype. Before fieldwork began, 12 interview appointments were already made with a selection of stakeholders, based on their expected roles and positions in the marine community. The remaining interviewees resulted from a snowball sampling method influenced by the preselected interviewees. Information provided by interviewees was double checked by asking different interviewees for the same information. All the interviews were recorded with a voice recorder, unless circumstances (noise, bad connection or a guided tour) did not allow this. The interviews were transcribed as soon as possible after the interview took place, preferably the same or the next day. Anonymity of the interviewees was guaranteed; therefore, a coding system is used for referencing the interviews in this chapter (see Appendix 2).

Interview transcriptions were systematically analysed through an open coding process in Atlas.ti around actors and approaches in policy-making, conflicts between actors and interests, environmental regulations, and stakeholder collaboration (see Appendix 5). The interactions among actors in the marine community and the means they use to interact were visualised by mind mapping. The results of the analysis were triangulated and cross-referenced with data from literature, policy documents, news items and (participatory) observations by the researcher. In this iterative triangulation process, multiple rounds of structuring and cross-referencing occurred.

\subsection{Findings}

Over the years, cruise tourism in Bonaire became increasingly connected to the global cruise sphere. Bonaire, in fact, became a new node in the global cruise network. Different networks are operational in this sphere and represent different purposes. While the IMO and the EU mainly provide international standards and legislation for shipping (including cruise shipping), industry associations such as the Cruise Lines International Association, the FCCA and Seatrade Global Cruise represent the interests of cruise lines by creating forums for information exchange and negotiations on cruise tourism development. All these networks affect the cruise tourism flow at Bonaire, but this chapter will zoom in specifically on the relation between the FCCA, representing the most important platform for 
cruise lines and cruise destinations in the Caribbean region, and Bonaire.

"The FCCA is a not-for-profit trade organisation, created in 1972, composed of 19 member cruise lines operating more than 100 vessels in Floridian, Caribbean and Latin American waters. The FCCA seeks to build proactive collaborations with its partner destinations to generate discussions on tourism development, ports, safety, security and other cruise industry issues. Furthermore it cooperates with its partner destinations in order to maximize cruise passenger, cruise line and cruise line employee spending." (Florida Caribbean Cruise Association, 2015a)

Global cruise lines have considerable negotiating power over SIDS because footloose actors, such as foreign cruise ship companies, can easily relocate their operations, while place-bound actors - such as the tourism industry on an island like Bonaire - cannot. As a result, place-bound actors often attempt to adapt to the needs and requirements of the transnational network to benefit from the flows it mobilises. Thus, the transnational cruise network drives the reorganisation of the local cruise network at Bonaire. The interaction between the transnational and local cruise network will be analysed for two distinct flows: cruise ships and passengers.

\subsubsection{Flow of cruise ships}

The FCCA can be seen as the key programmer of cruise tourism in the Caribbean. Networking power within the FCCA serves the following two goals. First, it decides where ships will call, directing the flow of cruise ships toward different islands. Second, it decides what type of tours and excursions are sold on board, which determines the flow of cruise passengers on an island. To be a successful cruise destination in the Caribbean, membership to the FCCA is key. Inclusion in the network is coordinated by a two-tier membership program, which strives to cultivate close, direct working relationships between destinations and FCCA Member Cruise Lines: Associate Membership (\$500 annually) and Platinum Membership (\$25,000 annually) (Florida Caribbean Cruise Association, 2015b). Associate Members are invited to the FCCA Cruise Conference and Trade Show, where there are possibilities to speed date with important cruise lines. One of the interviewees characterises the difference between Associate and Platinum Membership as follows;

"If you are a low fee (\$500 per year) Associate Member at a stakeholder conference, you have to wait for your turn. You will have to speed date with the cruise line executives. Nothing is certain. If you are a high fee $(\$ 25,000$ per year) 
Platinum Member you will, for example, be allowed into a lounge where you can interact formally and informally with cruise line executives. Once you are allowed to enter the lounge as a Platinum Member, you will be taken more seriously. It is up to you to do the proper negotiations." (I-G-16)

This implies that even as an Associate Member you are likely to be disadvantaged or excluded from itinerary planning because of limited networking opportunities.

Bonaire became an Associate Member of the FCCA approximately 20 years ago, but upgraded to Platinum Membership in 2013. With this upgrade, Bonaire's position as node in the transnational cruise network became more important. Tourism Corporation Bonaire (TCB) is the public body in Bonaire responsible for tourism marketing. The aim of TCB is to promote Bonaire as destination for stayover and cruise tourism and to maximise profits both in quantity and quality (I-G16, I-G-17). The cruise destination market in the Caribbean is, however, very competitive. Promotion as a destination, in terms of low costs for cruise companies and high levels of appreciation for tourists, is necessary to attract enough cruise ships (Schep et al., 2012). Bonaire as a cruise destination is therefore represented at the FCCA by a delegation led by TCB, accompanied by the harbour master and two tour operators. There is limited representation of the island's government in marketing for cruise tourism, in contrast to the islands of Curaçao and Aruba, which are often represented by their Commissioner of Tourism (I-G-16). Lobbying and negotiations take place for two distinctive flows within cruise tourism: itinerary planning for the flow of cruise ships to Bonaire and shore excursions planning for the flow of cruise passengers in Bonaire.

TCB and the harbour master function as switchers for the flow of cruise ships, which represent Bonaire's local cruise network at the transnational FCCA network. They are responsible for itinerary planning, which occurs two to three years in advance. Before negotiations start, an incentive package is created and approved by the island government. An important aspect of this package is the negotiating room that the island government gives TCB. For example, if cruise lines plan to visit Bonaire more often than the minimum number of calls per year, they might receive reductions on harbour fees or be allowed to open their casinos and shops on board while they are docked in Bonaire. One of Bonaire's most remarkable negotiations was with Carnival Cruises, currently one of the world's largest cruise lines. For 15 years, Bonaire wanted to be included in Carnival Cruises' itinerary planning. Bonaire's Platinum membership enabled them to seal the deal in 2014, when Carnival Cruises replaced the neighbouring island of Curaçao with Bonaire (I-G-13, I-G-16, I-G-17). In January 2015 Bonaire celebrated the inaugural visit of 
Carnival Cruises with a ceremony portraying a real taste of Bonaire. Signs of appreciation such as plaques, flags, medals and books were exchanged among the captain, the island government and TCB (Rosa and Adams Kimmel, 2015). The ceremony illustrates how the personal achievements of negotiators on behalf of the island government and TCB enabled them to score politically (I-G-6), reflected in this quote.

"In January Carnival came for the first time. We have celebrated this the whole day. The Island Governor and I went on board and talked to the captain. It is an official event, with lots of presents. In the park lots of festivities took place. Shops were open until $23 \mathrm{~h}$. The next day I talked to shop owners, they were happy." (IG-14)

Because of other successful negotiations with large cruise lines such as Pulmantur Cruises and Royal Caribbean Cruises, Bonaire will become an all-year-round cruise destination, hosting up to 400,000 cruise passengers a year (I-G-13, I-G-16, I-G-17, I-M-16).

The switchers attempt to lure cruise lines to Bonaire by weakening regulations and offering cheap deals. The Stichting Nationale Parken Bonaire (STINAPA Bonaire) or National Parks Foundation Bonaire is a NGO commissioned by the island government to manage the two MPAs of Bonaire, the National Marine Park and the Washington Slagbaai National Park (STINAPA Bonaire, 2015d). According to the International Coral Reef Initiative, Bonaire's National Marine Park is one of the best-managed marine parks in the world (Van der Lely et al., 2013). To finance the management of these two MPAs, a nature fee is collected from visitors entering the park. SCUBA divers pay $\$ 25$ for a calendar year or $\$ 10$ for a day, while non-SCUBA divers pay $\$ 10$ for a calendar year. After several delays in the cruise lines' payment of this nature fee for non-SCUBA divers, the dive association - called the Council of Underwater Resort Operators - in Bonaire wrote a letter to the island government refusing to pay any nature fees until the cruise lines pay their fair share (I-M-24). The island government responded by changing the Island Resolution for the Marine Park and creating an exemption for cruise passengers (STINAPA Bonaire, 2015c). This led to a protest from STINAPA Bonaire. According to STINAPA Bonaire:

"The island government claimed it would increase the head tax from \$2 to \$3/day: \$1 for the environment (STINAPA Bonaire), \$1 for the economy (TCB) and $\$ 1$ for society (island government). That was fine; STINAPA Bonaire would receive $\$ 1$ for each passenger, also those that do not enjoy the marine park." (I-CS-8) 
STINAPA Bonaire agreed, as it would save time and resources compared with collecting the nature fee (I-CS-8). However, at the time of the research the division of the head tax had not been implemented; the head tax of $\$ 2.5$ per passenger flows directly into the general budget of the island government (I-CS-8, I-CS-9, IG-7, I-G-17, I-M-16). This head tax is inexpensive compared with other destinations in the Caribbean (Spergel, 2014, I-G-16, I-CS-8). According to several interviewees (I-G-13, I-G-17, I-M-16), there are plans to increase the head tax to $\$ 5$, again with the option to divide it over the three relevant parties, but the island government is afraid this tax increase might discourage cruise lines from visiting Bonaire. This is consistent with findings from previous research, which conclude that competition among cruise destinations results in regulatory laxity (Lester and Weeden, 2004). Often, reductions on harbour fees are covered by the head tax Bonaire collects from cruise passengers of the same ship (I-G-13). As a result, only a small portion of the financial contribution stays on Bonaire. Of this small contribution, none of it is distributed (directly) to STINAPA Bonaire for nature conservation, although the ecosystem of Bonaire is an important attraction for cruise tourism.

Although the switchers' lobbying and marketing efforts are paying off, increasing flows of cruise ships adversely affect the local cruise network of Bonaire in two ways.

First, increasing flows of cruise ships result in growing needs for berthing space and tourist facilities (see also in Korbee, Mol, and Van Tatenhove, 2015) in the small port of Kralendijk, which compromises the space available to cargo ships. Additionally, a new shopping mall was built based on an understanding between the owner of the mall and the island government that all cruise ships would dock at the South Pier, meaning that all cruise passengers would wander through the mall before visiting the centre of Kralendijk (I-G-13, I-M-14, I-M-16, I-M-19). Logistically this is not always possible, as sometimes several cruise ships visit Bonaire on one day along with cargo transport, which affects the view and walking experience of cruise passengers. Therefore, a court case between the owner of the shopping mall and the island government resulted in a ban on cargo containers on the South Pier. Cargo containers now need to be stored elsewhere, leading to additional transportation costs and raising the prices of consumer goods on the island, which ultimately affects the local inhabitants. Increasing flows of cruise tourism also affect the facilities required at the port by the transnational network. According to regulations of the International Convention for the Prevention of Pollution from Ships within IMO, Bonaire, as a contracting party, should provide port reception facilities for handling different types of waste and sewage (International Maritime 
Organization, 2015). However, currently, Bonaire, as a SIDS, does not have the capacity to provide sufficient facilities and can barely process the waste produced on the island (I-G-13, I-G-17: I-M-16, see also Lamers et al., 2015). All cruise ships that berth in Bonaire, except for the outdated cruise ship Freewinds, take their garbage with them and dispose of it at their final destinations (I-G-13, I-M-16). The Dutch Ministry of I\&E, the designated authority since the establishment of Bonaire's new constitutional structure, will invest $€ 9$ million to update the port infrastructure (I-G-5, I-G-13).

Second, the user community became inspired by other important nodes, i.e. flourishing cruise destinations, in the transnational cruise network. In January 2011, the Aruba Tourism Authority evolved from a government agency to a unique independent legal entity. With this new status, the Aruba Tourism Authority is no longer subject to governmental bureaucracy and is now independently financed (I$\mathrm{M}-1$ ). Stakeholders in Bonaire have been similarly inspired to transform the TCB from a state-owned company to a foundation because foundations within the Netherlands can more easily obtain financial support (I-M-16). The foundation would then establish the Tourism Council Bonaire, with a similar organisational structure as the Aruba Tourism Authority. However, the island government raised concerns about how this arrangement would make power disparities between stakeholders more explicit (Dietz, Ostrom, and Stern, 2003). The biggest concern, however, was the fact that the government would no longer be involved in policymaking for tourism, which constitutes $80 \%$ of Bonaire's economy (I-G-14, I-G-16, IM-16). Thus, this initiative stalled.

\subsubsection{Flow of cruise passengers}

Once a cruise line decides (at FCCA events) to call at Bonaire (the first flow), the flow of cruise passengers to Bonaire's attractions is ensured (the second flow). At this point, tour operators begin negotiating with cruise lines about excursion packages, which will be prebooked on the cruise ship. Two competing tour operators, Bonaire Tours and Vacations and Bonaire Destination Services, buy different excursions and products from local service providers, such as dive shops, activity providers and taxi companies. Thus, tour operators function as switchers between the local cruise network of Bonaire and the transnational FCCA cruise network for the flow of cruise passengers.

In the past, Bonaire Tours and Vacations was the only tour operator that cooperated with cruise lines. Bonaire Destination Services was formerly an activity provider included in the prebooked packages of Bonaire Tours and Vacations, but upgraded in 2007 to become a tour operator. Now the company coordinates prebookings with cruise lines as well (I-M-16, I-M-17, I-M-22). Negotiations take 
place regarding the type of excursions, the minimal number of participants required for each excursion to proceed, and payments for empty places. There are strict requirements. Tour operators have to invest in training their guides, safety assessments and liability insurance for every participant. In fact, during the offseason, cruise lines evaluate different tours to ensure the high quality of the excursion as well as of the guides. Once these excursion packages are bought by the cruise line, they will be advertised and sold to the passengers. Typically, these excursions are sold out one year in advance; prices can be up to double what they would be if the excursions were sold on the island (I-M-16, I-M-17, I-M-19, I-M-20, I-M-21). It becomes clear that the income cruise lines earn from prebooked excursions is an important incentive to call at Bonaire. Interviewees claimed that cruise lines would no longer visit Bonaire if prebooked excursions were to decrease tremendously, as they are part and parcel of the cruise lines' business model (I-M-16, I-M-17, I-M-20). In exchange, cruise lines guarantee - to tour operators in Bonaire - the income that will be earned from excursions sold on the ship.

With increasing flows of cruise passengers visiting Bonaire, local place-based actors attempt to benefit by connecting to the transnational cruise network through various means. Some local tourism actors circumnavigate the rules of the transnational cruise network and rely on their own personal connections with cruise lines (I-M-21, I-M-123). When making deals with individuals, cruise lines either charge a percentage of the profit or a fixed rate per year, depending on the number of calls a cruise line makes to Bonaire (I-M-21, I-M-23). Other local tourism actors obey the rules of the game laid out by the FCCA and negotiate with the switchers between both networks, i.e. the tour operators who negotiate about shore excursions with the cruise lines. These excursions can include special products and deals, such as discounts on drinks at bars, products at boutiques, dive excursions at dive shops and taxi rides (I-M-16, I-M-17, I-M-19, I-M-20, I-M21, I-M-25, I-M-26).

Not only connections are used to link up to the transnational cruise network, the entire local organisation and structure of provision, in fact, is increasingly being adapted towards the needs of this transnational network. Increasing flows of cruise passengers forced the local tourism industry on Bonaire to reorganise itself. TCB, which can be identified as the programmer of the local tourism network, initiated this reorganisation by bending criteria and changing the rules of the game for different nodes in this local cruise network (I-G-16, I-G-7, I-M-19). The following three examples demonstrate this.

First, in the past, to ensure consistency and quality among tour guides, a tour 
operator developed an island guide course. This in-depth, 75-h course included lessons from experts on the ecology, history, institutional setting and educational system of Bonaire, as well as a practical session in which participants gave an island tour. The course required $100 \%$ attendance and a minimal score of $80 \%$ to pass the exam. TCB wanted to bend the criteria by limiting the course to eight hours of lessons and lowering the assessment criteria to guarantee a sufficient number of licensed guides to accommodate the increasing flow of cruise passengers. The instructor resigned because she believed the guide certificate would lose its credibility (I-M-19).

Second, several local suppliers in Bonaire became more organised. In the past, taxi drivers and independent tour operators would queue and fight over passengers in front of the cruise pier, which negatively affected the image of Bonaire. A few years ago, with support from TCB, the taxi association decided that taxis were to be removed from the pier and instead called in when booked by the cruise tourists. This resulted in more appreciation of and closer cooperation with the cruise lines, as taxi rides became included in the prebooking system. In the words of the taxi association:

"Last month I was invited on the Royal Princess cruise because I was appreciated for the way our taxi association handles taxis at Bonaire. I got a sign for appreciation from the cruise line." (I-M-26)

Third, both the souvenir market of the Bonaire Arts \& Crafts Association and the work of independent tour providers became subject to similar reorganisation processes. Products sold on the souvenir market were to become more innovative, handmade in Bonaire and sold by non-aggressive methods. Some claim that this distinguishes Bonaire's souvenir market from other markets in the Caribbean (I-M-27, I-CS-12). Some cruise passengers like to book independent tours upon their arrival in Bonaire, as these are less expensive and are composed of smaller groups compared with prebooked tours. In 2010, TCB initiated the Bonaire Explorer's Association, an organisation for independent tour operators, which became a new node in the local network. Members pay an annual membership fee and rental fees, which allow them to use the cruise information booth and tents to sell their tours to arriving cruise passengers (I-G-17, I-M-19).

The reorganisation of the local tourism industry has created a new playing field, resulting in tension among various suppliers. For example, the boundary between taxi rides and guided tours became blurred (I-G-16, I-M-26), which increased competition because the tour booths are located closer to the pier (I-M-16, I-M-26). 
Furthermore, increased infrastructural development, necessary to accommodate growing flows of cruise passengers, affects the vulnerable ecosystem on which Bonaire's tourism depends. Actors in the policy community therefore attempt to counterbalance the negative effects of the increasing flow of cruise passengers by reprogramming the local cruise network in three ways.

First, Bonaire is unique in the Caribbean context because it has a fringing instead of a barrier reef - a shallow reef zone adjacent to the shoreline. As a result, the marine park surrounds the island of Bonaire for a distance of up to 200 $\mathrm{m}$ off the coast and $60 \mathrm{~m}$ in depth. Any infrastructural development close to the shoreline affects the marine park directly. A key example is the expansion of the pier at Karel's Beach Bar, which would lead to environmental impacts including habitat loss for Elkhorn coral, sea urchin, and juvenile fish; water and noise pollution; and additional waste streams (Vermeij, 2011). The island government has weakened its regulations by amending the Marine Park Ordinance and Bonaire's Spatial Development Plan: the zoning of the area where the expansion of the pier would take place has been changed from marine park (the mostprotected status) to center zone (intended for urban development). Pillars for the construction of the pier had already been placed when questions were raised about the limited ecological research on which the permits and regulatory changes were based. Any development in the marine park should be assessed by the Commission Nature Management Bonaire (I-G-13, I-G-15, I-CS-8), which advises the island government. The island government can either follow the Commission's advice or argue against it, and this process should have taken place before the expansion of the pier. However, this did not occur (I-CS-8) and reflects the island government's de-prioritisation of nature conservation. The NGOs Sea Turtle Conservation Bonaire and STINAPA Bonaire sued the island government to prevent damage to Bonaire's unique ecosystem resulting from infrastructural development not complying with the legal framework. After putting the expansion on hold for three years, the Court recently acknowledged that the environmental assessment of the expansion of the pier, ordered by the island government, was inadequate. Permits and the amendment to the Spatial Development Plan for the expansion of the pier were withdrawn (World Wildlife Fund, 2015b). The island government, however, is appealing to the higher court.

Second, the increasing flow of cruise passengers results in visitation peaks at local vulnerable areas. Examples include RAMSAR sites, such as Klein Bonaire, a small uninhabited islet off the west coast that is famous for its white beaches and breeding area for sea turtles, and Sorobon, a popular tourist attraction because of its white beach, mangrove forest and the azure blue water of its Lac Bay 
(STINAPA Bonaire, 2015b). Cruise visitation peaks in these local areas, which are characterised by narrow coastlines and limited facilities and supervision. High visitation leads to environmental impacts such as crowds of tourists, water pollution, loss of marine biodiversity, loss of coral reefs and sea grass, additional waste streams, and sea turtle habitat loss (I-M-16). One tour operator was concerned about the human-wildlife conflict, which may increase in the future because the lengthening cruise season will coincide with the sea turtle nesting season at Klein Bonaire (I-CS-10). It is argued that the independent water taxis transporting cruise tourists to Klein Bonaire should provide information about the area's ecological values, similar to the briefing provided by a well-educated hostess during prebooked tours (I-M-16). Therefore, this concerned tour operator has approached one of the independent water taxis about participating in the prebooked tours:

"It will be the same operation, but more organised with a hostess who briefs the people. The independent water taxi does not realise that yet, that I gave him the burden of being more responsible. My strategy has two sides: increase my revenue and increase the supervision of Klein Bonaire." (I-M-16)

Third, the final attempt to reprogram the local cruise network is being pursued by the Dutch Ministry of Economic Affairs. Although tourism development is an insular responsibility, the Ministry recently commissioned Wolfs consultancy company to conduct a cost-benefit analysis for three scenarios of increased tourism development in relation to Bonaire's ecosystem (Wolfs, Schep, Gallegos, and Beukering, 2015). Currently, there is no long-term planning or vision for (cruise) tourism on Bonaire and the sector's impact on the economy and environment is unknown. Increased cruise tourism in Bonaire, as with many other Caribbean islands, is symbolic of the economic success and/or personal achievement of politicians looking to be re-elected in the next election (I-G-6). With this costbenefit analysis, the Ministry provided instruments to the island government to ensure that decision-making regarding cruise tourism is well informed and takes into account the carrying capacity of Bonaire (I-G-6).

\subsubsection{Marine community}

With increasing flows of cruise ships and passengers visiting Bonaire, more actors have become involved and the marine community governing cruise tourism in Bonaire has also evolved. This raises questions about how the interplay between the transnational and local cruise network influences interactions between the user and policy community within this marine community. 
The absence of leadership, collective action and formal rules leaves decisionmaking and problem-solving regarding cruise tourism in Bonaire in the hands of individual organisations, such as local tour operators and dive and taxi associations. As such, decision-making regarding cruise tourism is largely influenced by social relationships and networking. Figure 4.5. shows that because the user community cannot rely on the policy community, it becomes increasingly footloose by connecting to the transnational FCCA cruise network. This is particularly true for the flow of cruise passengers, where the majority of service providers in the user community attempts to connect to the transnational cruise network, either through the switchers (i.e. the tour operators) or through individual contacts. The ultimate attempt to become footloose from the policy community is related to the intended reorganisation of TCB. The user community would like to reprogram the programmer of the local cruise network of Bonaire as an independent and private entity, outside the governmental arena. This is consistent with Castell's argument that states do not become irrelevant in the network society, but rather they become dependent on a broader network of powerful actors (Spaargaren, Mol, and Buttel, 2006). Thus, the marine community at Bonaire is dominated by the user community.

The policy community, on the other hand, operates more locally. Although some actors in the local policy community, i.e. the Ministry of Economic Affairs and the NGOs, are trying to program an environmental discourse among the local cruise network of Bonaire by means of a cost-benefit analysis, local protest and ongoing law suits, it remains to be seen how successful they will be. Unlike actors in the user community, whose economic growth discourse matches neatly with the FCCA's objectives, the policy community cannot rely on nodes in the transnational network to pursue the same environmental discourse. The dominant discourse of economic growth in both the local and transnational cruise networks pushes environmental considerations aside.

As a result, Bonaire's marine ecosystem is increasingly encountering environmental problems (crowds of tourists, water pollution, loss of biodiversity, waste streams, and habitat loss) caused by increasing flows of cruise tourism and especially by the increased flow of cruise passengers. This is consistent with Castells' flows analysis that considers the ecological wellbeing of the space of places as compromised by the interests of those inhabiting the space of flows. Castells' analysis of the environment, a negative side effect of the dominant power of the space of flows, comes down to a reformulation of the conventional point of environmental economics (externalities) in combination with the traditional 'protest approach' in environmental sociology (social movements organising resistance 
against modernity) (Spaargaren et al., 2006). Therefore, the environment should be protected from the intrusion of global flows by place-based environmental resistance.

\section{Space of flows}

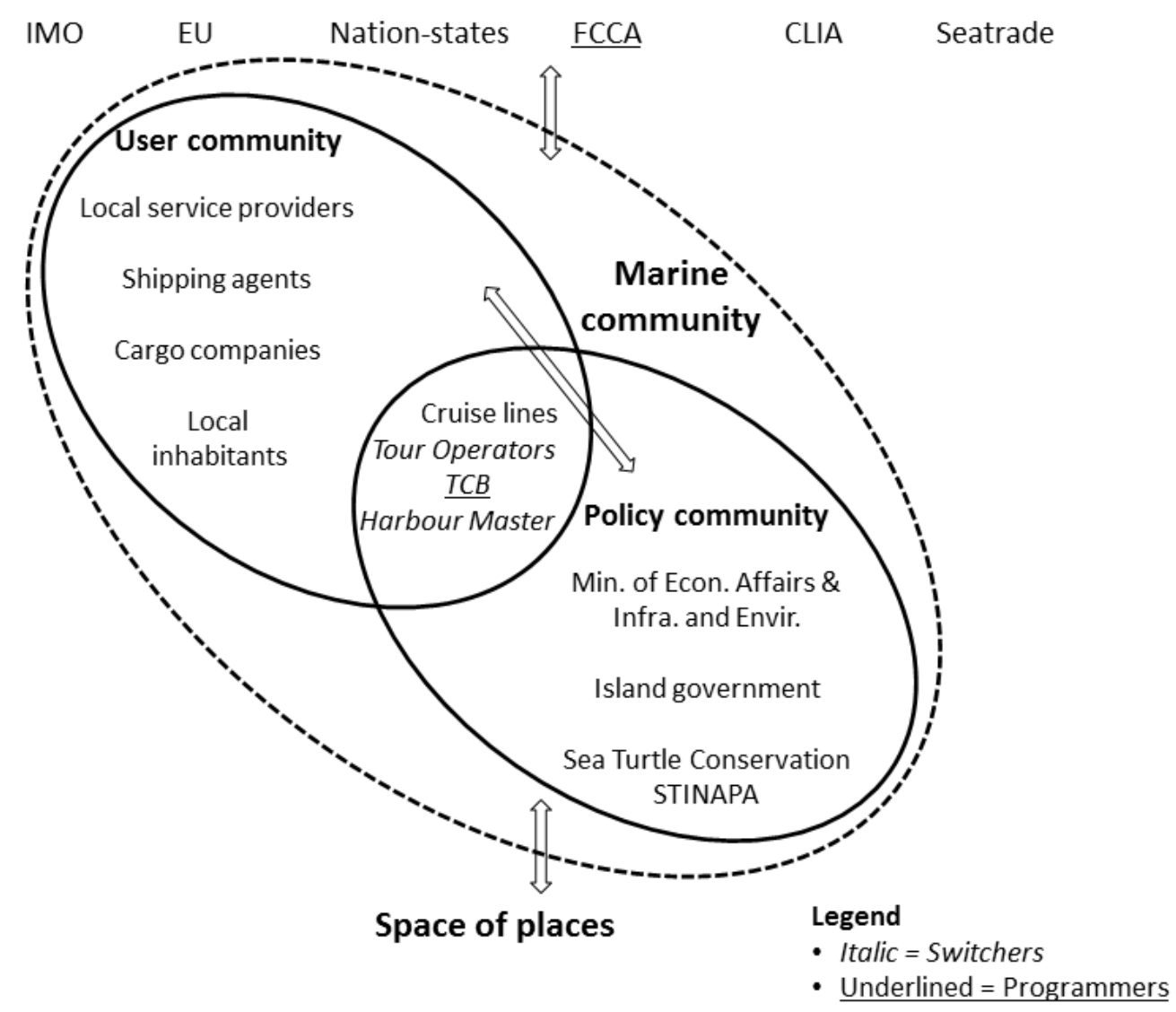

Figure 4.5. Space of flows and space of places interacting within the marine community of cruise tourism in Bonaire

However, the analysis shows that Bonaire, as a small island, has limited resources, knowledge and capacity to implement place-based environmental resource management that could withstand the dynamics and power play of the transnational cruise network. This is clearly reflected in the ongoing court case about the expansion of the Karel Visser pier, which symbolises the tension between infrastructural development (to satisfy the increased flow of cruise passengers) and place-based environmental resistance from NGOs. Another example is the inert political-bureaucratic apparatus in Bonaire, which has compromised both leadership and collective action, resulting in lack of action regarding sustainable cruise tourism. One way to overcome this inaction would be to implement the tourism master plan that was drafted in 2011 but never enacted (I-G-15). The question remains whether this will steer cruise tourism in a 
sustainable direction. Although the strategic development plan 'Bonaire 20102025' acknowledges the need for a diversified economy, it also stresses that tourism will remain the cork that will keep the island afloat economically (Van Werven, Jepma, and Bakker, 2010). Another way to steer policy-making regarding cruise tourism relies on the incorporation of the cost-benefit analysis for cruise tourism in Bonaire, conducted by Wolfs Company and issued by the Ministry of Economic Affairs. In the words of one of the respondents:

"We wait anxiously for facts and figures which can support decision-making and judgments. If that happens, we can start discussing beyond emotions feelings." (I$\mathrm{M}-18)$

Furthermore, place-based environmental resistance might eliminate Bonaire as a node in the itinerary planning of the regional cruise network, as the institutional void allows cruise lines to choose destinations where environmental regulations are most convenient (DeSombre, 2006; Lamers et al., 2015). Therefore, recommendations for sustainable cruise tourism in Bonaire incline more toward the arguments of Mol and Spaargaren, which call for environmental protectionism to be programmed into network nodes in the space of flows (Mol and Spaargaren, 2012). Although the IMO and, to a limited extent, environmental organisations and consumer preferences, are regulatory drivers for sustainable cruise tourism (Klein, 2007; Weaver and Duval, 2008), they mainly address safety, security and the environmental performance of international shipping. Furthermore, the IMO's authority is limited to global cruise ship flows and can therefore not be held responsible for local environmental problems originating from the flow of cruise ships and passengers visiting Bonaire.

A node responsible for environmental problems related to the flow of cruise passengers in the space of flows, to which place-based environmental resistance (in the space of places) could connect, is absent, but needed. Because this marine community is dominated by the user community, which is programmed by and well adapted to the needs of the FCCA in the space of flows, this appears to be the most appropriate institution as it already facilitates negotiations for both types of flows between cruise lines and destinations. This potential governance strategy is not new in cruise tourism; recent research demonstrates that self-regulation within industry associations plays an important role in greening polar cruise tourism (Lamers, Liggett, and Amelung, 2012). 


\subsection{Conclusions}

Cruise tourism flows in Bonaire are governed by transnational and local networks, inducing new socio-economic developments, which in turn affect Bonaire's vulnerable ecosystem and drive the evolving constitution of the marine community. Based on the analysis, the following conclusions are drawn.

First, this chapter concludes that the local tourism network at Bonaire is overwhelmed by the transnational cruise network, especially for the flow of cruise passengers on the island. While the increasing transnational cruise ship flow to Bonaire is already secured, the facilities and infrastructure that will accommodate this increased local cruise passenger flow is lagging behind.

Second, this misfit between the transnational cruise ship flow to Bonaire and the local passenger flow at Bonaire stimulates the marine community, and the user community especially, at Bonaire to become more and better intertwined in the transnational FCCA cruise network. The user community is becoming more aligned with the requirements of the transnational cruise network than with the requirements of the local policy community.

Third, unequal power relations between the dominant transnational cruise network and the rather dependent local cruise network at Bonaire, combined with the eagerness of the marine community, and the user community especially, to become more entangled in the transnational cruise network, has governance implications for sustainable cruise tourism in Bonaire. Both transnational and local cruise networks, strengthened by Bonaire's characteristics as a small island, prioritise economic development, coupled with growing cruise tourism, over nature conservation at Bonaire. As a result, Bonaire's marine ecosystem is increasingly encountering environmental problems caused by increasing flows of cruise tourism and especially by the increased flow of cruise passengers. The concept of marine community therefore challenges Castells' view of the environment as externality, as it stresses the interdependence between a maritime activity and the marine environment in which it exists. This is certainly true for cruise tourism development in Bonaire, which is highly dependent on its marine (and terrestrial) ecosystem. Research has indicated that (cruise) tourists are less likely to come to Bonaire if coral reefs decline or if crowds increase further (Schep et al., 2012). This chapter therefore concludes that the environment should be further programmed within the transnational cruise network to avoid it being treated as an externality, which results in the loss of the unique environmental attributes that attract cruise tourism. 



\section{5.}

Collective self-governance in a marine community: expedition cruise tourism at Svalbard

This chapter has been published as

L.K.J. van Bets, M.A.J. Lamers, and J.P.M. van Tatenhove (2017)

Collective self-governance in a marine community:

expedition cruise tourism at Svalbard Journal of Sustainable Tourism DOI: 10.1080/09669582.2017.1291653 


\section{Abstract}

Collective self-governance is gaining attention in the literature for maintaining the quality of key attractions and promoting sustainable tourism. The long-term success of collective self-governance is dependent on both its internal organisation and its embeddedness in external state and non-state regulations. This chapter presents the marine community concept, consisting of a policy and a user community, as a framework for investigating the internal and external dynamics of collective self-governance and its ability to steer toward sustainable cruise tourism. As methodology, a case study design was chosen which was primarily studied by means of interviews with a spectrum of relevant actors concerning expedition cruise tourism in Svalbard. By applying the marine community to Svalbard expedition cruise tourism governance, the following conclusions are drawn: (1) collective self-governance complements governmental regulation through access to knowledge, conflict resolution and rule-compliance based on disclosure, traceability and trust; (2) collective self-governance's increasing role in the policy community alienates the expedition crew from the user community; and (3) informational overflow by the coexistence of collective selfgovernance and state governance challenges sustainable cruise tourism. Collective self-governance would, therefore, benefit from reflection, especially regarding the role of the user community that functions as an intermediary between state and self-governance regulations.

Key words: Collective self-governance, Expedition cruise tourism, Information systems, Marine community, Svalbard 


\section{Gruising @ Svalhard: a collective governance arrangement}

Collective self-governance gained attention in the literature to promote sustainable tourism. This chapter presents the marine community, consisting of a policy and user community, as a framework to investigate the internal organisation of collective self-governance and its embeddedness in external state and non-state regulations. This will be analysed by exploring how collective selfgovernance employs information systems to steer sustainable tourism in relation to various relationships in the marine community.

Expedition cruise tourism at Svalbard was selected as case study because of co-existence of state governance and collective self-governance, by the industry association AECO.
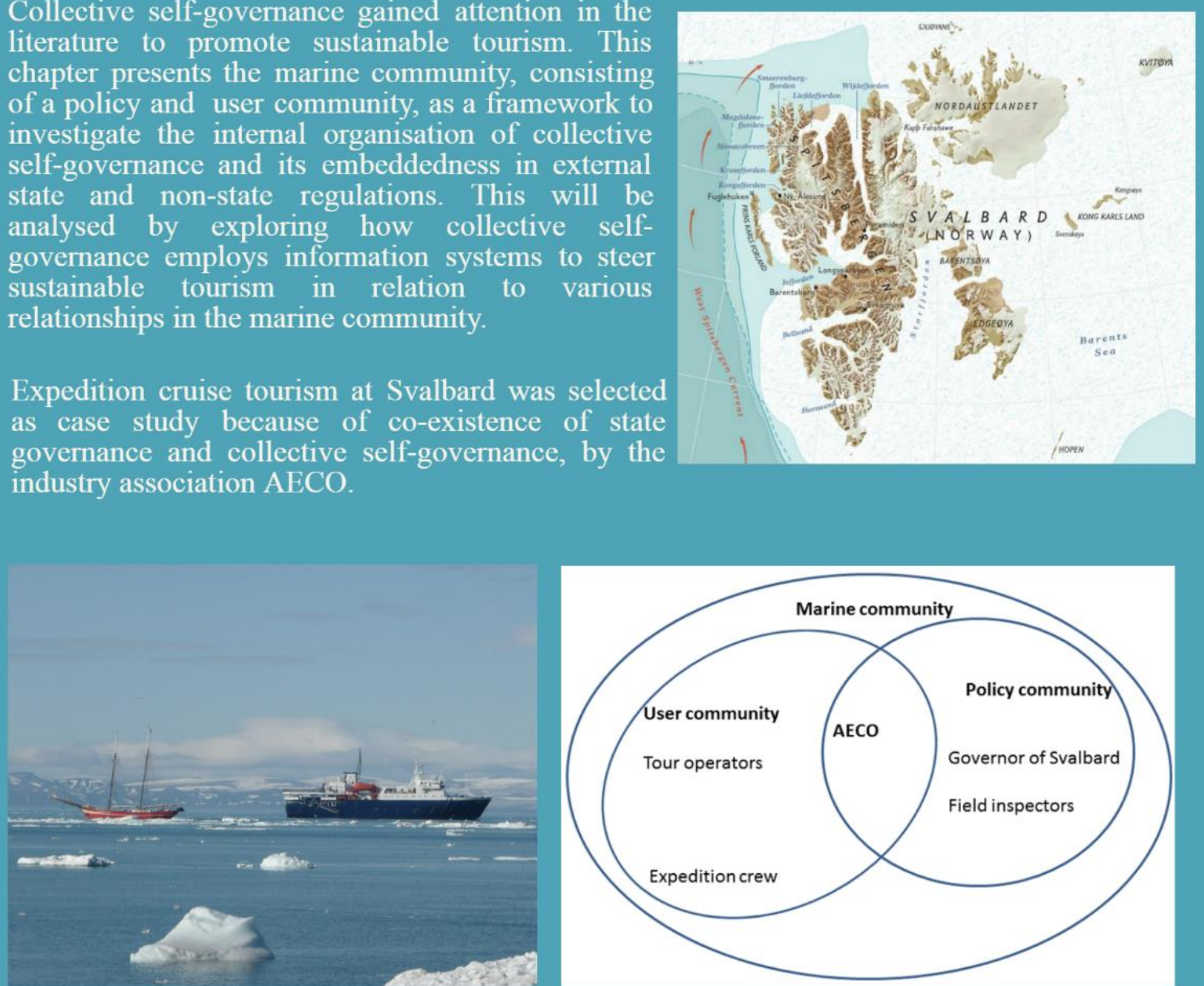

\section{CONCLUSSIONS}

(1) collective self-governance complements governmental regulation through access to knowledge, conflict resolution, and rule-compliance based on disclosure, traceability and trust

(2) collective self-governance's increasing role in the policy community alienates expedition crew from the user community

(3) informational overflow by co-existence of state- and collective self-governance challenges sustainable cruise tourism

W. Wageningen Co-authors: Machiel Lamers and Jan van Tatenhove

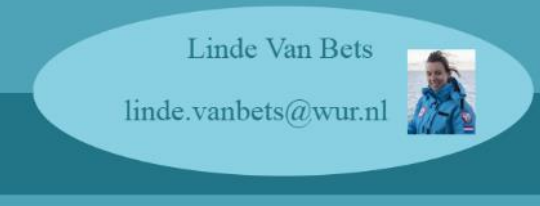

Figure 5.1. Graphical abstract Svalbard 



\subsection{Introduction}

Cruise tourism is the fastest-growing segment of the global tourism industry, with a $62 \%$ increase in demand for cruising in the last 10 years (2005-2015) (Cruise Lines International Association, 2016). The cruise market is highly differentiated (Greenwood and Barron, 2006; Wood, 2000) from cruise vessels equivalent to floating cities) to small-scale expedition cruises to remote and vulnerable environments (Lamers et al., 2008). The exponential growth of cruise tourism in vastly diverse regions leads to a variety of impacts on marine and coastal environments and stirs, therefore, the social and academic debate about the sustainability and governability of the activity (Klein, 2011; Lamers et al., 2015).

In this chapter, sustainable tourism is defined as "tourism that takes full account of its current and future economic, social and environmental impacts, addressing the needs of visitors, the industry, the environment and host communities" (United Nations Environment Programme-World Tourism Organization, 2005, p. 12). Governing cruise tourism sustainably is particularly challenging, as cruise flows and impacts are difficult to regulate by place-bound and sovereign state authorities, such as ports or environmental agencies (Weaver and Duval, 2008; Wood, 2000). In contrast, this institutional void is increasingly being targeted by intergovernmental policy processes, industry self-regulation, civil society initiatives and other non-state governance arrangements.

Governance of cruise tourism has been poorly theorised, particularly its complex transnational and highly mobile character (Lamers et al., 2015; Papathanassis and Beckmann, 2011). To contribute to the conceptual understanding of cruise tourism governance, this chapter focuses on how collective self-governance by the cruise industry develops in a larger community of state actors, local stakeholders and researchers, and how the coexistence of collective self-governance, as a form of non-state governance, with state governance affects sustainable cruise tourism. Collective self-governance is defined as "actors who are major users of the resource, are involved over time in making and adapting rules within collective-choice arenas regarding the inclusion or exclusion of participants, appropriation strategies, obligations of participants, monitoring and sanctioning, and conflict resolution" (Ostrom, 1999, p. 2). In the cruise industry, collective self-governance is driven by mixed objectives, ranging from marketing purposes and economic incentives to play divide-and-rule between ports of call among destinations, based on favourable costs, facilities and regulations among large-scale cruise operators (Van Bets, Lamers, and Van Tatenhove, 2016), to industry responsibility, environmental education and 
stewardship to maintain the quality of key attractions and safety within small-scale expedition cruise tourism (Haase et al., 2009; Splettstoesser, 2000; Student, Lamers, and Amelung, 2016). In other words, industry associations play a crucial role in the governance of both unsustainable and sustainable forms of tourism development. In this chapter, the second type of industry association will be addressed by analysing how collective self-governance driven by environmental stewardship aims to steer toward sustainable cruise tourism.

Collective self-governance in cruise tourism accompanies a general trend toward networked governance between state, market and civil society (Arts and Van Tatenhove, 2006; Kooiman, 2003; Rhodes, 1996), based on participation and collective action of user communities and collaboration between state and nonstate actors (see also Bramwell and Sharman, 1999; Conley and Moote, 2003; Lamers, Van der Duim, Van Wijk, Nthiga, and Visseren-Hamakers, 2014; Nelson and Agrawal, 2008). A common challenge that these arrangements face is that their longer term stability depends on the congruency of both their internal organisation and their embeddedness in external state regulations and other nonstate governance arrangements (e.g. Arts and Goverde, 2006; Haase et al., 2009; Lamers et al., 2014; Van Tatenhove, 2017). This chapter contributes to this debate by arguing that the internal and external congruencies of collective selfgovernance for mobile activities such as cruise tourism increasingly relies on ICT as a (re)source for steering toward sustainable cruise tourism development. This chapter will analyse how cruise tourism makes use of collective self-governance to organise and regulate the industry within the existing institutional regulatory setting, how it employs information systems for this purpose and to what extent this contributes toward sustainable cruise tourism.

The empirical setting of this chapter is the Svalbard archipelago, a group of Norwegian islands in the Arctic Ocean, promoted as the largest wilderness area in Europe with some of the finest scenery and wildlife experiences (Oceanwide Expeditions, 2014). In addition, Svalbard also has a rich cultural heritage because of its history as important base for whaling, fishing and coal mining. The unique cultural and environmental history at Svalbard resulted in an increased interest in Svalbard as a cruise tourism destination since the 1990s. While overseas cruise tourists show an increasing trend, expedition cruises represent a steadier group of visitors to Svalbard (Figure 5.2.).

The environment and cultural heritage of Svalbard, and the Arctic region in general, are already threatened by global environmental change and the impacts of various maritime activities, such as oil and gas, fisheries, and shipping (Ostreng et al., 2013). Growing cruise tourism leads to a new range of opportunities and 
challenges for marine and terrestrial ecosystems, communities and regulatory systems on Svalbard (Hagen, Vistad, Eide, Flyen, and Fangel, 2012; Hovelsrud and Smit, 2010; Viken, 2011) and elsewhere in the Arctic (e.g. Greenland, Iceland and Russia). The Svalbard Environmental Protection Act allows for cruise tourism and other major maritime activities on and around the archipelago if they have environmentally sound management. However, the future of Arctic cruise tourism destinations is varied and dynamic because of various international and national policy developments (e.g. the Polar Code and prohibition of Heavy Fuel oil by the IMO (Governor of Svalbard, 2015) and the Pilot Act) as well as global environmental changes, such as changes in the accessibility or safety of cruise ships because of changes in ice conditions (Ostreng et al., 2013). It is expected that some of the policy developments will cause conventional overseas cruises to Svalbard to decrease in the coming years (Lamers, Olsen, Hovelsrud, Lang, and Jorgensen, 2013).

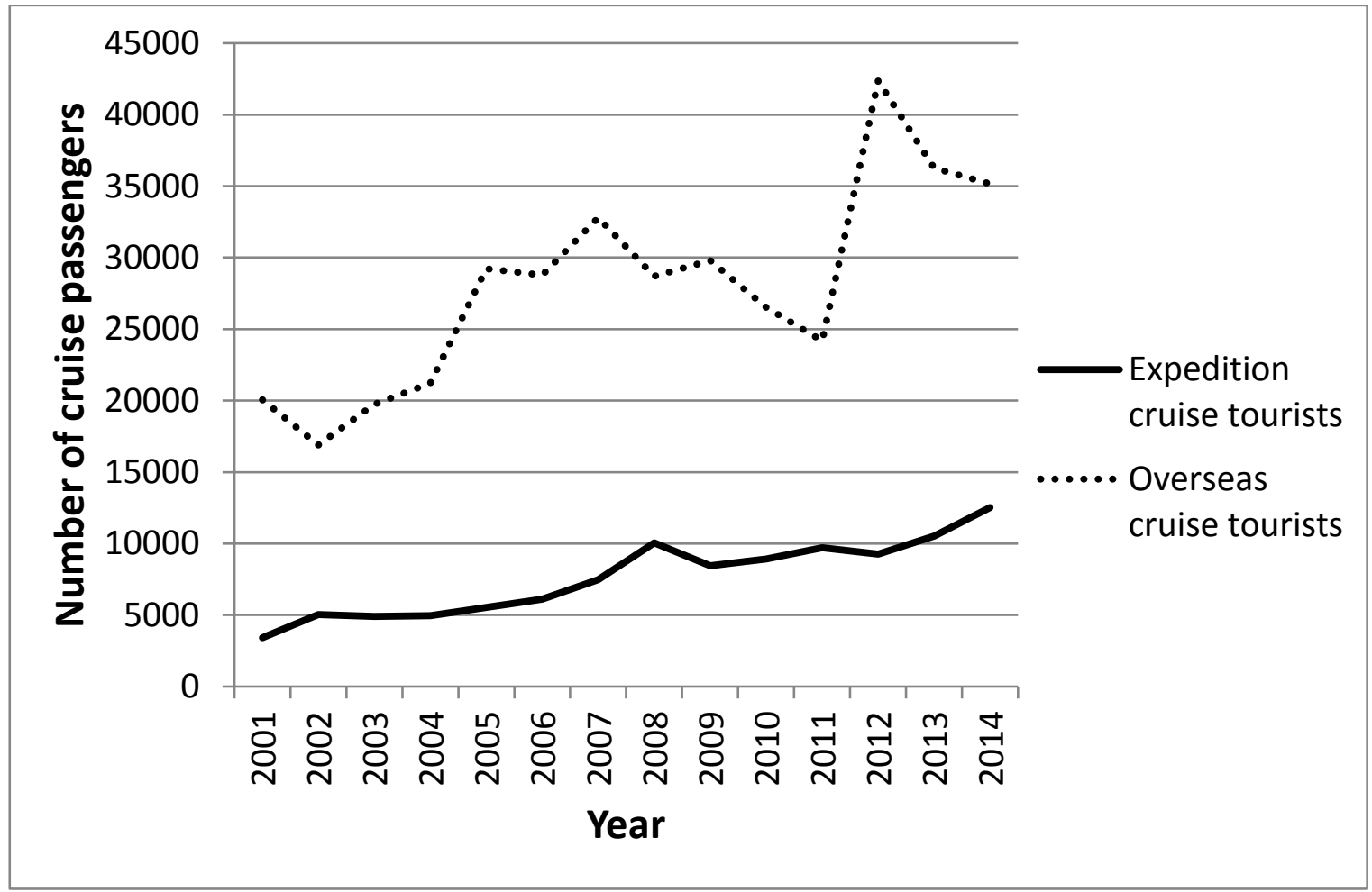

Figure 5.2. Expedition and overseas cruise tourists 2001-2014 (Sysselmannen på Svalbard, 2013)

The chapter will, therefore, focus on expedition cruise tourism in Svalbard. Expedition cruise tourism encompasses a bundle of tourism practices involving small vessels (between 20 and 500 passengers), shore landings and exploration using rubber boats, quality environmental and historical interpretation of biodiversity, landscapes, historical remains and current use, remote and exclusive wilderness experience (i.e. one boat at one landing site at a given time), minimal 
environmental and social impact, human safety and flexibility depending on dynamic weather and sea ice conditions. While every industry has an impact, the expedition cruise tourism sector can work toward becoming more sustainable. The Arctic expedition cruise sector attempts to ensure that expedition cruises are carried out with the utmost consideration for the vulnerable, natural environment, local cultures and cultural remains, as well as the challenging safety hazards at sea and on land (Association of Arctic Expedition Cruise Operators, 2016a). Despite all the abovementioned international and national policy developments already in place, AECO was established in 2003. This industry association represents a clear example of collective self-governance, driven by a collective interest of users in maintaining the quality of the tourist experience. AECO relies on various information systems not only for ensuring and checking rule compliance but also for gaining more knowledge about the whereabouts and environmental impact of the industry and of the cultural and environmental history of Svalbard.

To account for the various levels and actors involved in governance, as well as the internal and external embeddedness of collective self-governance of Svalbard's expedition cruise industry, the concept of marine community is presented, which is a community of users and policy makers involved in the governance of a certain maritime activity (Van Bets, Van Tatenhove, and Mol, 2016). The aim of this chapter is threefold: (1) to provide insights through the marine community concept on the role of collective self-governance in governing cruise tourism; (2) to understand to what extent collective self-governance by the industry can be successful internally as well as externally in relation to Svalbard's institutional setting, which consists of various national and international state initiatives; and (3) to explore how collective self-governance employs information systems to steer sustainable development of expedition cruise tourism in relation to various relationships in the marine community. The following sections introduce the theoretical framework, which addresses the core concepts of marine community, collective self-governance, and information systems and outlines aspects of methodology and method, before the results are presented and discussed.

\subsection{Theoretical framework}

Sustainable tourism development calls for good management of natural, built and sociocultural resources in destinations (Briassoulis, 2002). Resources used for tourism are often shared in common with local inhabitants when visiting them in everyday life. Consequently, these resources are considered common pool resources, implying that their use is subtractable and nonexclusive (Healy, 1994). Sustainable tourism is challenged by its reliance on commons as tourist attractions 
and avoiding their demise (Briassoulis, 2002; Butler, 1999; Hunter, 1997; Johnson, 2002; Saarinen, 2006; Sharpley, 2000). At first, common pool governance by user communities did not appear promising; their eagerness for resource exploitation was believed to be at odds with the goals of resource conservation (Agrawal and Gibson, 1999; Hardin, 1968). Since the 1990s, research has shown that despite some tragedies, user communities can successfully self-govern common pool resources by means of decentralisation, participation, cultural autonomy and conservation (Chambers and McBeth, 1992; Chitere, 1994; Etzioni, 1996; Ostrom et al., 1999).

The commons literature, however, tends to see community development as a black box and does not unravel how interventions of, or interactions between, users and policy makers in the community and their distinct governance arrangements can affect the use of common pool resources. This chapter supports the arguments of Agrawal and Gibson (1999) for a more political approach for studying community development in common pool resource governance. The conceptual framework (Figure 5.3.) relies on the evolution of the community concept in the literature, which diverges from a small-sized and territorially defined community. This chapter rather presents a transnational community of users and policy makers to account for the diverging interests and actors within communities, the involvement and influence of these actors in decision-making, and the internal and external institutional dynamics that shape the governance of common-pool resources (Agrawal and Gibson, 1999).

Against this background, the concept of marine community is presented. A marine community is a community of socio-economic and policy actors and institutions organised around a certain maritime activity that influences or will be affected by the (marine) ecosystem in which the activity occurs (Van Bets, Van Tatenhove, and Mol, 2016). In principle, in a marine community, two interdependent communities can be distinguished analytically: a user and a policy community, as shown in Figure 5.3.

According to Crow and Allan (1994) and Smith (2001), a user community refers to a community of interdependent actors that executes and is affected by the maritime activity and that makes use of the goods and services marine ecosystems provide. In this chapter, the user community consists of AECO, tour operators, expedition crew, travel agencies, the supply industry, researchers, port authorities and local inhabitants. Although a strong focus remains on serving economic interests at sea, environmental values are becoming more apparent in different modes of integrated marine governance (Toonen, 2013). A policy community, therefore, consists of actors that are part of (in)formal institutions and 
governance arrangements that regulate maritime activities to achieve sustainable use and management of marine ecosystems (Atkinson and Coleman, 1992; Sørenson and Torfing, 2005; Walker, 1989). In this chapter, the policy community refers to national and local authorities and environmental organisations. While the user community members rely on private policy to organise themselves, the policy community makes use of public policy to steer governance. User and policy communities have, therefore, a distinct logic, rationality and purpose. Nevertheless, actors and, to a lesser extent, institutions can be part of both a user and a policy community or change from being part of a user community to a policy community or vice versa, depending on the role they fulfill. User and policy communities are increasingly interdependent and interwoven, as both are dependent on and co-govern ecosystem goods and services. As such, a marine community allows for a more dynamic view on community development, marine communities have been studied before in relation to coalition-building (Van Bets, Van Tatenhove, and Mol, 2016), power (Van Bets, Van Tatenhove, and Lamers, 2016), networks and flows theories (Van Bets, Lamers, and Van Tatenhove, 2016), in relation to oil \& gas activities and cruise tourism, but not in the context of collective self-governance.

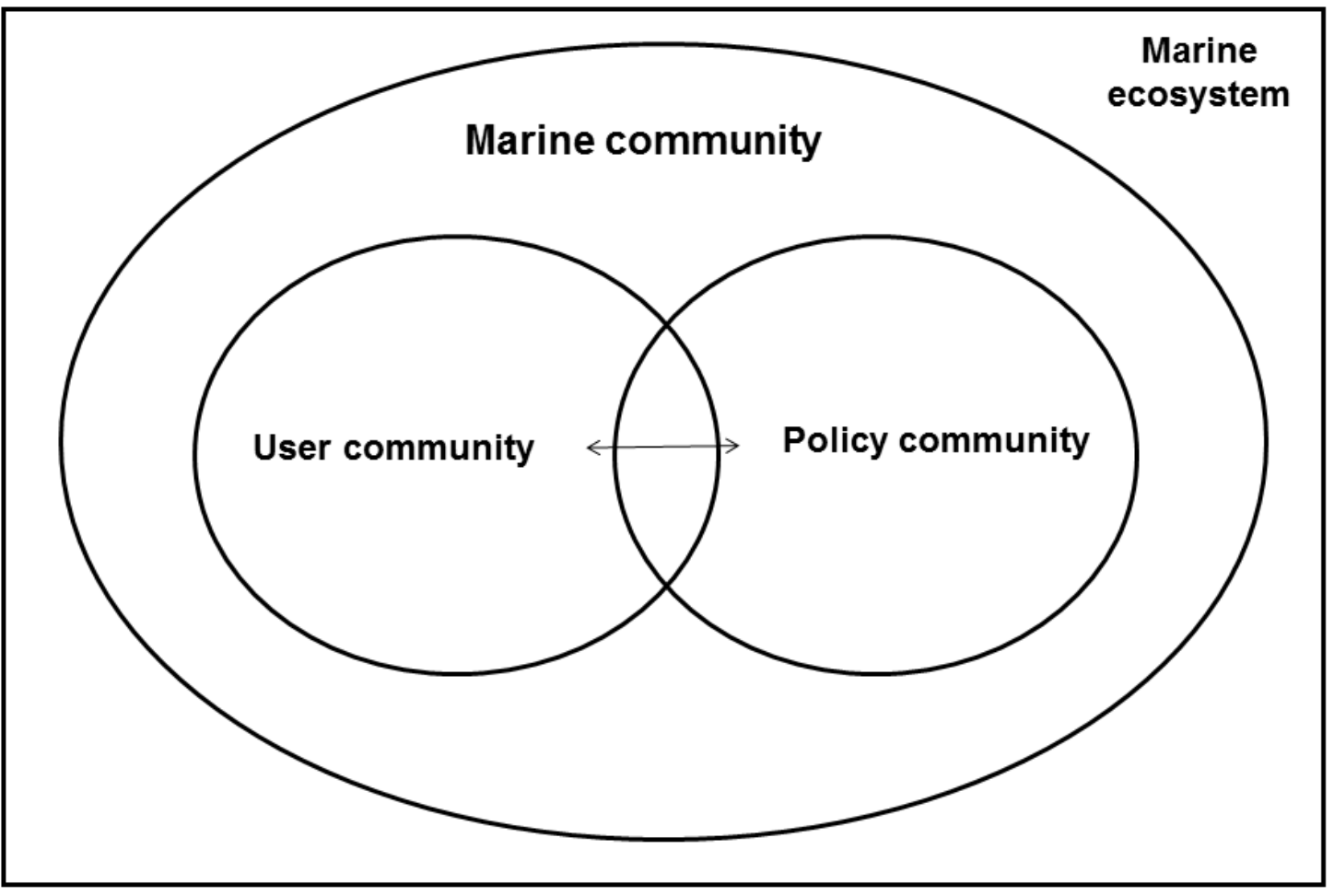

Figure 5.3. The relationship between user and policy communities within a marine community 
Multiple, but distinct, governance arrangements occur simultaneously in a marine community. The governance arrangements differ depending on the extent to which state or non-state actors are involved in governing, vis-à-vis each (Arnouts et al., 2012; Treib, Bähr, and Falkner, 2005; Van Leeuwen and Van Tatenhove, 2010). In the marine community, users make many, but not all, rules that affect the sustainable development of the resource system and its use. Rules made by local, regional and international authorities in the policy community also affect key decisions (Ostrom, 1991, 1997), as they determine to what extent there is room for collective self-governance within the decision-making process. This chapter will analyse how collective self-governance by the industry relates to other state and international governance arrangements and their regulatory systems in a larger community that has state actors, local stakeholders and researchers as central members and how this coexistence of state governance and collective selfgovernance affects sustainable expedition cruise tourism in Svalbard.

Collective self-governance depends on the congruency of internal and contextual factors, including the interplay with other instruments or agencies through co-management (Carlsson and Berkes, 2005; Lamers et al., 2014; Ostrom, 2005; Young, 2002). This chapter wants to emphasise how the use of information enables or constrains internal and external relationships for collective self-governance. Non-state forms of environmental governance have proven to rely considerably on information resources, especially at sea (Pattberg, 2007; Toonen, 2013; Tysiachniouk, 2012). This is also true for the mobile and placeless nature of expedition cruise tourism in Svalbard, where environmental information is particularly powerful to bridge the time-space gap between what is decided at the management level and what is experienced in the local field sites. In this context, this chapter will analyse how collective self-governance makes use of information systems to refer to diverse forms of data, information and knowledge exchange (Mol, 2008)to strengthen the following internal and external relationships: (1) internally within the user community, (2) externally between the user and policy community, and (3) externally between the cruise and research user communities.

\subsection{Methodology and methods}

To gain insights in relationships, complexities and institutional settings within a marine community, a case study design was chosen. A case study allows the researcher to derive an in-depth understanding of the research object by examining a range of factors and potential causal connections, as well as how they change over time. In addition, this methodology is useful to address actors' motives, 
interpretations, constructions of reality and behaviour (Swanborn, 2010; Yin, 2003). Expedition cruise tourism in Svalbard was selected as a case study because it presents a clear case of the coexistence of state governance and collective self-governance, driven by a collective interest of users. Svalbard, an archipelago halfway between the Norwegian mainland and the North Pole (Figure 5.4.), was no-man's land until the beginning of the 1900s, when Norway claimed sovereignty over the islands. This was granted through the Spitsbergen Treaty (1920), which also allows treaty parties to engage in economic activities at Svalbard (Government of the French Republic, 1925).

Tourism on Svalbard emerged in the wake of scientific exploration of the Arctic in the 1800s. Only in the 1990s Svalbard became a popular cruise destination when the Norwegian government decided that coal mining, research and tourism were to be Svalbard's main economic pillars, with environmental protection having priority over natural resource extraction for the archipelago to be 'one of the world's best managed wilderness areas' (Ministry of Justice and the Police, 2008; Overrein, 2001).

Tourism increased, which made the need for regulations urgent (Viken, 2006). Until that time, people referred to Svalbard as the Wild West where cruise operators and visitors could behave like cowboys and take human bones, polar bear skulls, flora and fauna, and fossils without any restrictions (I-M-3, I-M-8). While Svalbard used to be governed by Norwegian Ministries without significant local influence, the 1990s were marked as an era of emerging network governance involving private industry, WWF and local authorities, with blurring borders and power relations among them (Viken, 2006).

Fieldwork at Svalbard was conducted from mid-July to mid-August 2014 in Longyearbyen and Ny-Ålesund and for two weeks in August 2015 during the Netherlands Scientific Expedition Edgeøya Spitsbergen. The semi-structured interviews served for mapping the marine community structure and for identifying how each actor is positioned in this community and which objectives, resources and information they use. All the semi-structured interviews were conducted using the same topic list, covering questions on stakeholders' contacts and interactions in the community, access to knowledge and information, rule compliance, conflict resolution and their perceptions, distracted from the theoretical framework (see Appendix 1). The interviewees represent national and local governmental authorities, tourism associations, expedition crew (qualified guides from five different tour operators, who work on board of the expedition cruise ships and are responsible for landings, safety and the experiential outcome of cruise passengers), environmental organisations, researchers and local inhabitants (see 

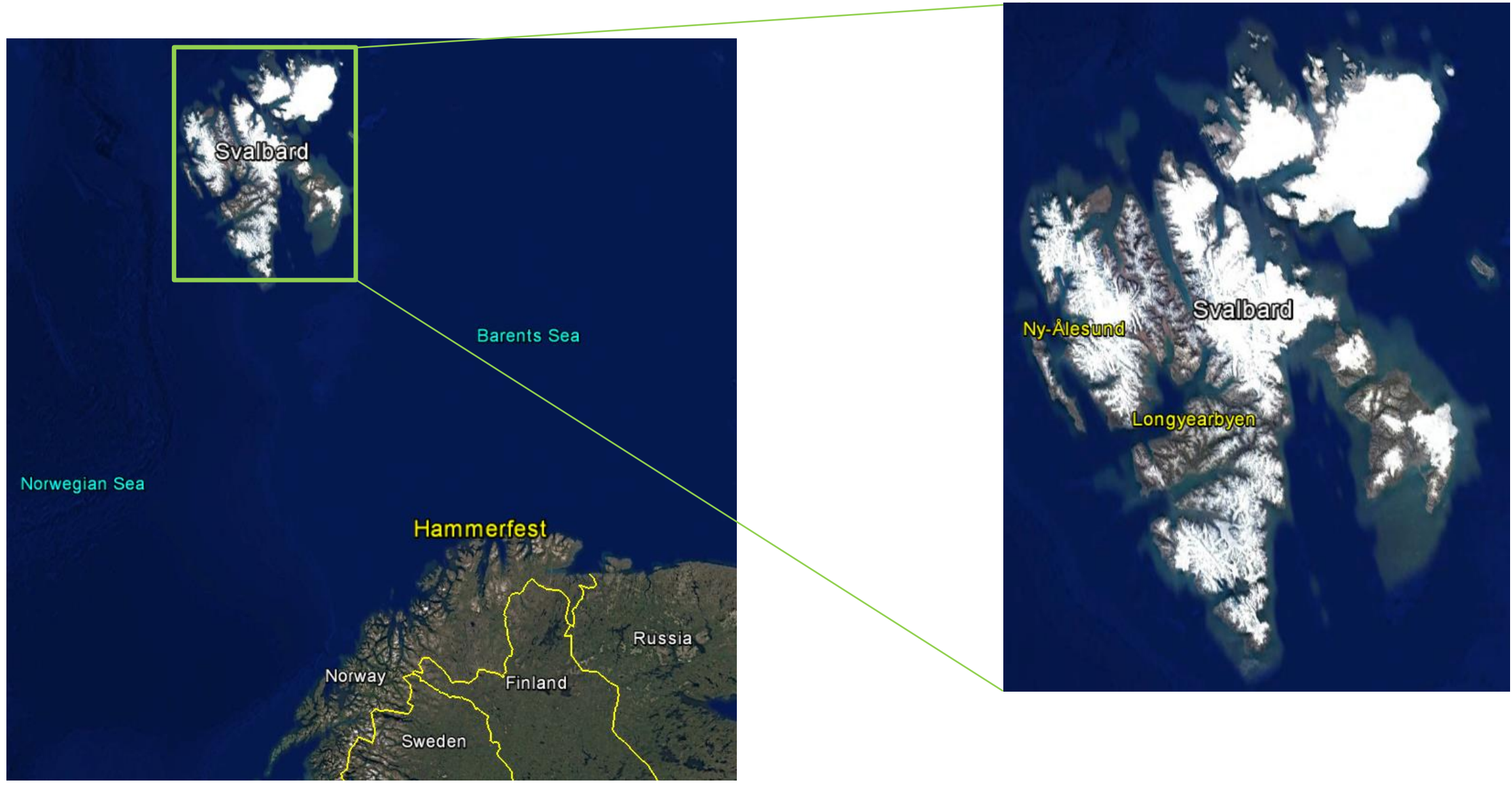

Figure 5.4. The location of Svalbard in the Arctic (Google Earth, 2017d and e) 
Appendix 2). Thirty-one interviews were conducted in total: 23 with a single interviewee and eight with multiple interviewees. Some key interviewees were interviewed on more than one occasion. Twenty-nine interviews were conducted face to face (24 in Svalbard, 4 in Oslo and 1 in the Netherlands), and two more interviews were conducted by Skype. The interviews lasted between 25 and 90 minutes. Before field work started, 11 interview appointments were confirmed with selected stakeholders. Other interviewees resulted from a snowball sampling method influenced by the preselected interviewees (Morgan, 2008). Almost all interviewees were recorded with a voice recorder; in some cases, the circumstances (interview in a cafe) did not allow for this. The interviews were literally transcribed as soon as possible after the interview occurred, preferably the same or the next day. Anonymity of the interviewees was guaranteed by means of a coding system, which is used for citing the interviews in this chapter (see Appendix 2).

Data were structured through coding with ATLAS.ti (see Appendix 6). The interactions among actors in the marine community and the means they use to interact were visualised through mind mapping. Triangulation of data started with double checking by asking different interviewees the same information or by consulting key interviewees on more than one occasion. Afterwards, information was triangulated with policy documents, literature, observations and news items. In the end, triangulation is determined by an iterative process; thus multiple rounds of structuring and cross-referencing occurred (Bogdan and Biklen, 2006; O’Donoghue and Punch, 2003).

\subsection{Findings}

\subsubsection{State governance}

Governance of cruise tourism in Svalbard in the 1990s was state-driven and controlled by the Norwegian Authorities. The coordinating Ministry of Trade, Industry, and Fisheries collaborated with the Ministry of Justice and Public Security and the Ministry of Climate and Environment (Viken, 2011). Since 2002, the Interministerial Committee on Polar Affairs, assisted by its secretariat the Department of Polar Affairs, has coordinated legislation and policy-making in the Polar Regions that fall under the jurisdiction of the abovementioned ministries. The implementation and enforcement of regulations, however, is the responsibility of the Governor of Svalbard (in short Governor), the highest governmental body that represents the Norwegian authorities at Svalbard. To strengthen the Governor's capacity for rule enforcement regarding a mobile activity such as expedition cruise tourism in a large wilderness area such as Svalbard, each summer, six field 
inspectors are hired to check, among other things, whether expedition cruise operators behave responsibly. Field inspectors do not necessarily have to go onboard an expedition cruise ship; merely being in the neighbourhood makes the expedition crew already feel they are being watched continuously (I-M-38). Field inspectors check the ship's paperwork and whether the expedition crew is competent enough, which is rather difficult to prove (I-M-43), or observe how landings are done (I-G-21, I-M-39). In the past, field inspectors were not perceived as legitimate actors to fulfill this role, as they did not possess sufficient knowledge about Svalbard's cultural and natural environment. This has improved significantly (I-M-39). A competitive selection procedure (3\% success rate), one-week training and the team composition (one biologist and one policeman) ensure that field inspectors are well acquainted with regulations at Svalbard (I-G-21, I-M-39). These state actors rely on Norway's public policy for governing expedition cruise tourism (The Ministry of Climate and Environment, 1973; The Ministry of Justice, 1991), together with the Svalbard Environment Protection Act (2001), a collection of updated environmental legislation for Svalbard (The Ministry of Climate and Environment, 2001).

According to those public regulations, expedition cruises have to notify the Governor about their travel plans, draw up site-specific guidelines for certain vulnerable places they visit (Association of Arctic Expedition Cruise Operators, 2016b), and report after each trip about their whereabouts in a post-visit report. In case of non-compliance, formal mechanisms such as fines or imprisonment are in place (The Ministry of Climate and Environment, 1973; The Ministry of Justice, 1991). This interaction is quite intensive because field inspectors report to the Governor every weekday, by phone or marine very high frequency radio. Information exchange about cruise operators' whereabouts and rule compliance distinguishes trustworthy from less serious cruise operators. In response, the Governor can intensify inspections of irresponsible operators. In addition to inspections by field inspectors, the Governor organises a tourism inspection trip around Svalbard during the summer. Despite inspections by both the Governor and its field inspectors, the Governor cannot be everywhere or see everything. Information from the local inhabitants to the Governor or its field inspectors about garbage dumping and tourists walking off the road or in areas where they are not allowed plays an important role, as well. The overall experience, of both the Governor and the field inspectors, suggests that expedition cruise tourism complies with public policy (I-G-20, I-G-21). 


\subsubsection{Collective self-governance}

The Svalbard Environmental Protection Act includes a warning: if the industry does not act responsibly, the Governor will intervene (The Ministry of Climate and Environment, 2001). Consistent with the global tendency toward emerging network governance (Sørenson and Torfing, 2005), this message was an important impetus for collective self-governance in tourism development on Svalbard (Viken, 2011). Hence, in 2003, the AECO, a spinoff of its sister organisation, the International Association of Antarctica Tour Operators (IAATO), was established by eight tour operators 6 : (I-M-44). AECO represents the interests of the cruise industry in a strong pan-Arctic organisation that aims to minimise its environmental impact through collective action. For this reason, approximately 50 cruise operators, which are members of AECO, form the industry association by participation in various committees and resource groups. AECO is operated by a three-person secretariat. The type of cruise operator (expedition cruise, with maximum 300 passengers, conventional cruise, or cruise operator without accommodation on board) and the area in which they operate (in AECO's core areas, presently Svalbard, Jan Mayen, Greenland, Arctic Canada and the national park 'Russian Arctic', or outside AECO's core areas, presently Russia, Canada and Alaska) are prerequisites for different membership categories within AECO. Tour operators can become members if they agree voluntarily to follow, next to various (inter)national laws and regulations, private policies that consist of visitor, site-specific, operational, wildlife and biosecurity guidelines (Association of Arctic Expedition Cruise Operators, 2013).

Compared with the public policy on which the Governor relies, AECO's private policy is more operational and detailed, as it provides, for example, guidance on how to avoid disturbance of animals or limits on the number of cruise ships and passengers at the same landing site, which the Governor's public policy does not account for (I-G-20, I-M-35, I-M-43, I-M-44). Almost all expedition tour operators in Svalbard are members of AECO, compared with $80 \%$ in Greenland and $50 \%$ in Canada (I-M-44).

Private policy is different from conventional public environmental policy because AECO relies on voluntary disclosure strategies to adapt the implementation and enforcement of rules to its own terms of reference (I-M-43, I-M-44). AECO's

\footnotetext{
6 Aurora Expeditions (Sydney, Australia), Hapag-Lloyd (Kreuzfahrten, Hamburg, Germany), Lindblad Expeditions (New York, USA), Oceanwide Expeditions (Vlissingen, The Netherlands), Origo Expeditions (Gothenburg, Sweden), Polar Quest Expeditions (Gothenburg, Sweden), Polar Star Expeditions (Brandal, Norway and Halifax, Canada) and Spitsbergen Travel (Longyearbyen, Norway).
} 
scope, furthermore, concerns the Arctic and not just Svalbard. Collective selfgovernance, consistent with the literature, benefits from international outreach and more importantly its reach beyond sovereign territory (Graham, 2002).

Svalbard's unique cultural and natural environment is what the industry sells. The expedition crew argue it is in their own interest to protect this environment. This argument is strengthened by the fact that tour operators realise they are in the same boat. If one tour operator misbehaves, this will affect the image of the entire user community. Tour operators are colleagues and competitors at the same time (I-M-52). Cases of non-compliance are reported to AECO and discussed with the tour operator or, if necessary, in the incident reporting session at AECO's annual general assembly. In this session, questions can be asked and sanctions (internal fines or probation) taken, and tour operators can learn from each other's incidents and attempt to prevent them in the future (I-M-41, I-M-43, I-M-44).

AECO gains also much information and knowledge about the whereabouts of the cruise industry through sailing plans and post-visit reports members are required to submit by AECO's guidelines. AECO's secretariat functions like a knowledge hub that sends out weekly updates on legislation or research about the industry. To strengthen its position through even more access to valuable knowledge and information, AECO developed the puffin program, through which tour operators can earn and compete for imaginary puffins in exchange for valuable information and knowledge about conferences, research reports or regulation updates they provide to AECO (I-M-44).

\subsubsection{Internal relationship: within the cruise user community}

Collective self-governance supported by information systems enhances the consistency of user community practices. Tour operators become AECO members to profit from representation in a broad industry network and participation in policymaking, as decisions on the implementation of rules or sanctioning of members within AECO are made by majority voting (I-M-44). In the field, the expedition crew benefit from AECO's guidelines, access to information through AECO's expedition cruise database and AECO's contact list. These additional information systems are helpful in the field to avoid overlap in itineraries to provide the unique wilderness feeling for passengers (ideally one ship at a time at each landing site) and to inform each other about spectacular or dangerous encounters (I-M-35, I-M38, I-M-39, I-M-40, I-M-42). Non-AECO cruises are disadvantaged because they do not have access to this information (I-M-44) and are excluded from this user community.

AECO derived its legitimacy from managing information flows to steer rule compliance. This is to a great extent based on trust that its members adhere to the 
guidelines and social control by expedition cruises and passengers that are in the neighbourhood, to check on each other in the field. Information systems are not only used for steering compliance by AECO but also for gaining increased access to knowledge and information possessed by their members, which is illustrated by the following quote:

"We should know about every single report regarding expedition cruise tourism. If we do not know about something, I am pretty sure it does not exist."(I-M-44)

Although rule compliance is based largely on trust, the expedition crew feel they should be trusted even more. The coexistence of government and collective selfgovernance results in over-administration in Svalbard by accumulation of formal and informal rules. Although the expedition crew realise that the need for regulations and paperwork increases proportionally with the growth of the business, they do not agree with the current rate at which paperwork is increasing. To stay in business, the expedition crew have to implement these increasing requirements, and they complain that the reporting and information provisioning is becoming too much to handle (I-M-36, I-M-38). The expedition crew have difficulties with the implementation of both AECO and governmental regulations for several reasons.

First, the rules of the Governor changed much over time and cover different types of areas (protected areas, national parks, bird areas, etc.) with each a specific set of rules, which is rather confusing. In addition, AECO's extensive set of guidelines has to be followed. Some expedition crew argue that the Governor's regulations and AECO's guidelines should be simplified or at least summarised in one document to give a proper overview (I-M-39).

Second, according to the Tourism Regulations, all (cruise) ships must report after every cruise at Svalbard to track and trace their whereabouts and landings in one post-visit report (The Ministry of Justice, 1991). Currently, AECO vessels fill in the post-visit report in AECO's database and send the same report by email to the Governor (I-G-20). Reporting is rather time-consuming, as it includes reporting on landings, destinations, times, anchoring places and coordinates which have to be transformed from degrees, minutes and seconds to other coordination measures. Another time constraint is that AECO's post-visit report system is quite new and does not yet include many landing sites, which must be added manually. Sometimes the expedition crew wonder about the purpose of reporting (I-M-37, IM-40).

Third, according to the expedition crew, AECO's guidelines reflect a 
contradiction between what is decided by decision makers and what is experienced in the field by the expedition crew, as they include minimum requirements that are too strict and too quantified to avoid problems. Guidelines should leave more room for adaptation to local circumstances, as illustrated by this quote:

"According to AECO's wildlife guidelines you can only land maximally 50 passengers in the neighbourhood of a walrus and never go closer than 30 meters. It is quite difficult in the Arctic to estimate 30 meters, as there are limited reference points. I think it also depends on the size of the site and the behaviour of the walrus. Sometimes I can land more sometimes less." (I-M-35)

Furthermore, guidelines are sometimes too general and not adapted to the size of the ship, which can range from 8-300 passengers (I-M-38), as shown in the example below:

"Because of an incident, it is no longer allowed to charge rifles on board, only at the landing site. This is quite dangerous. If I am the only expedition guide on a small cruise ship and I arrive at a landing site, polar bears can be very close, my rifle needs to be loaded then, because I cannot rely on other expedition guides, as it is the case with larger cruise ships." (I-M-38)

As a result, the expedition crew occasionally adapt guidelines to the situation at hand. The expedition crew wonder what other expedition crew do if they do not agree with the guidelines. There are means to talk with AECO if crew do not agree with the guidelines, but it takes a long time for guidelines to be revised. In essence, crew would have to build their own database of their environmental impact to get a revision of the guidelines (I-M-40). However, if this requires writing another report explaining why you do not agree, it could be helpful for the collective interest, but you might not be eager to do so because you are already overloaded with processing information and writing reports (I-M-37).

To illustrate the contradiction between what is decided by decision-makers and what is experienced in the field; it would be helpful if the expedition crew would address the mismatch collectively. Currently, this does not occur for the following reasons. First, there is not much interaction among the expedition crew, or at least not on this topic; there is more small talk about sightings of polar bears. Although it is beyond their scope as AECO is a tour operator association, AECO does attempt to represent expedition crew through field staff conferences it organises, together with IAATO, for members of both associations. However, it remains difficult to 
reach the expedition crew. This is inherent to a structural characteristic of the industry: the expedition crew change often between tour operators or work on a freelance basis. This complicates which tour operator should invest in the expedition crew to attend this conference. In addition, the expedition crew are already quite busy, so time often constrains them as well (I-M-35). Another reason for not attending is the setup of this conference. The expedition crew feel the program is quite generally oriented, with updates on rules and knowledge, but they would like it to be more oriented toward practical problems in the field (I-M-40).

Although the expedition crew acknowledge that it is good that AECO exists to ensure that all expedition cruise ships behave consistently (I-M-35), they question whether AECO is drifting away from its goal, i.e. representing the user community in a self-organised way to avoid more and strict public policy. The more AECO institutionalises, the closer to the policy community it becomes with increasing administrative and reporting duties for the expedition crew to implement in the field (I-M-38). This trade-off between time spent on reporting duties and knowledge exchange, on the one hand, and on the cruise tourism practice, on the other hand, discourages the expedition crew from striving toward AECO's goals. The expedition crew no longer feel that AECO represents the industry; they feel rather that AECO subjects the industry to more bureaucracy because of accumulation of private and public policy rather than it averts the industry from it (I-M-37, I-M-38, IM-39).

\subsubsection{External relationship: user versus policy community}

Information flows between AECO and the Governor are mainly used to streamline policy-making and to check and ensure compliance with state regulations and industry guidelines. Examples of joined efforts between the Governor and AECO are collaborations regarding the revision of the Regulations relating to tourism and other travel in Svalbard, Clean Up Svalbard cruises in which cruise passengers clean up the shores of Svalbard, and AECO's annual Arctic cruise conference (I$\mathrm{G}-20, \mathrm{I}-\mathrm{M}-43$, I-M-44). The coexistence of state- and collective self-governance is beneficial for rule compliance for both parties. Since the establishment of AECO, the authorities have had a representative of the user community to discuss regulations (I-M-41) and can rely on AECO's guidelines and social control to complement the government's capacity in Svalbard to enforce rule compliance (IG-20). The Governor is aware of small issues of non-compliance (cruise passengers walking outside legal areas or a ship approaching an iceberg too close), but in general he trusts the industry to comply with the rules (I-G-20, I-G21). This is especially because of AECO, which takes up the minimum requirements decided by the Governor and adds guidelines on top of those 
requirements $(I-M-19)$. In the end, AECO wants what is best for their users: Svalbard properly protected. Through collective action, they lower their environmental impact (I-G-20). AECO also benefits from this coexistence for the following two reasons: First, AECO provides an optimal program to their cruise passengers that safeguards the unique wilderness feeling because its guidelines provide limits for ships and cruise passengers at the same landing site (I-M-41), something the Governor's framework does not account for (I-G-20). Second, the user community organised itself into an industry association to prevent intervention or stricter regulations imposed by the policy community (I-M-38, I-M-41). In a sense, AECO created this information-driven industry association within the user community to safeguard their SLO and preserve their reputational capital (Toonen and Mol, 2016).

Since its establishment, the network structure of AECO has reinforced its power as strong pan-Arcticorganisation, as its members represent the industry at different events and grant the AECO secretariat access to their expertise and resources. As such, AECO became rather institutionalised and reached its goal "to be recognised as the primary organization representing the concerns and views of the expedition cruise tourism companies operating in the Arctic" (Association of Arctic Expedition Cruise Operators, 2016a). The growing power of AECO also affects its relationship with the policy community, illustrated by the following two examples. First, AECO's development of site-specific guidelines as private policy became recently public policy, adopted by the Governor in a newly published management plan for West-Spitsbergen national parks. Another example concerns AECO's expedition cruise database, which was meant to be a cooperation between AECO and the Governor, but in the end the Governor withdrew. Although the Governor would like to have access to AECO's database, he rather has his own database instead of being dependent on a commercial database for which he would have to pay to access. The AECO database, in addition, does not provide all information the Governor gathers because non-AECO expedition cruises and big overseas cruises are excluded (I-G-3). This resistance to cooperate originates, according to an expedition leader, from a conflict of interest between the policy and user community (I-M-38):

"The Governor wants to protect the cultural and environmental history of Svalbard, while the expedition cruise industry wants to explore it." (I-M-39)

The most important reason for the withdrawal of this joint state-industry database is that it is difficult for the policy community to cooperate with the same user 
community on which it must impose its authority (I-M-43).

\subsubsection{External relationship: between cruise and research user communities}

Information systems do not only regulate the cruise industry, but they also aim to gain more access to accurate knowledge and information. Currently, there is insufficient knowledge available about the cultural and environmental history of Svalbard because of fragmented research efforts. Cruise tourism can contribute to insights on its disturbance to wildlife and ecosystems and how they adapt to the presence of cruise tourism as well as insights on its contribution to nature conservation (Lamers et al., 2014).

The expedition crew are advised by the Governor and AECO to report dead or injured animals, which are protected under Svalbard's Environmental Protection Fund, to the Governor. Sightings of animals should be reported to the Norwegian Polar Institute, a central governmental institution that advises Norwegian authorities on matters concerning polar environmental management. Part of the Norwegian Polar Institute's responsibility is to advise the Governor and AECO on the governance of expedition cruise tourism. Reporting duties are time consuming and compromise time the expedition crew could spend with passengers. Nevertheless, $50 \%$ of the sightings in the Norwegian Polar Institute's database of marine mammals are contributions from the expedition crew (Andersen, 2013). In this way, the research user community benefits from the increased capacity for sightings from the expedition cruise user community. Unfortunately, the expedition crew feel discouraged to report sightings, as they get little in return for the valuable information they provide (I-M-39, I-M-42). The following example demonstrates this one-way knowledge exchange:

"An expedition leader was approached by the Governor to report on two polar bear human encounters. He was willing to do so, but wanted access to the polar bear human interaction database in return because it could provide useful information for future expeditions, but access to the database could not be granted by the circumpolar polar bear range states who own this database. AECO ought to get access to the database but was not successful either." (I-M-39)

Furthermore, reporting to the Governor or the Norwegian Polar Institute sometimes even has an adverse effect on the expedition cruise user community.

"Recently, Lågøya changed into a protected area, because of walruses and Sabine's gulls. You are not allowed to visit the area between 15 May and 15 August. It is not a problem; I know other areas to spot walruses or Sabine's gulls. 
If the Governor would ask me where more nesting areas of Sabine's gulls could be found, I am reluctant to point those places out to them, if they will close those areas as well. I need to know for which purpose they close areas, just closing areas for no specific reason does not make sense to me." (I-M-39)

Although observations by expedition cruises are important to keep the database running (I-G-20), the lack of incentives makes reporting about sightings not a priority for the expedition crew (I-M-42).

\subsection{Conclusion}

This study offers the marine community concept as a new approach to analyse the challenges of collective self-governance for sustainable tourism. The marine community concept is sensitive to both the internal dynamics and the external embeddedness of collective self-governance arrangements, as well as to the role of information systems and flows in these processes. By applying the marine community concept to the case of expedition cruise tourism governance at Svalbard, the following three conclusions, based on the objectives in the introduction, are drawn, and the chapter ends with a recommendation.

First, the marine community concept reveals that the governance of expedition cruise tourism in Svalbard, similar to Arctic Canada and Russia, is characterised by institutional complexity (Dawson, Johnston, and Stewart, 2014; Pashkevich, Dawson, and Stewart, 2015) because of the coexistence of collective selfgovernance (represented by the AECO secretariat and tour operators) and state governance (coordinated by the Governor and its field inspectors), next to international regulations. The expedition crew act as intermediary between public and private policy and to a certain extent also between the expedition cruise user community and research user community. As such, collective self-governance does not replace, but rather complements the state in governing sustainable cruise tourism through increased access to knowledge, conflict resolution and rule compliance based on disclosure, traceability and trust. This is not only beneficial for the state but also for other actors, such as ports, local inhabitants and researchers, who are involved in governance arrangements in relation to cruise tourism. The complexity of a mobile activity such as cruise tourism, therefore, also translates into a similar governance complexity, involving various actors at multiple levels.

Second, the growing self-regulatory power of AECO affects social and power relations and pulls the marine community apart by challenging the internal dynamics and external embeddedness of this collective self-governance 
arrangement. AECO's proactive private policy has put the Governor in a delicate position with a blurry line between industry and state responsibility. This closeness of user and policy communities created distance and mistrust internally in the user community, between AECO and the expedition crew. They no longer feel that AECO represents the industry, which compromises the collective interest of the industry. The ambiguity about AECO's role challenges the governance of expedition cruise tourism in relation to both the internal dynamic (the user community) and external dynamic (the policy community) of collective selfgovernance. This reflects similar findings for AECO's sister association for Antarctica, IAATO. However, the situation of IAATO is different because of the enormous variation in geographical scale (Antarctica, a large land mass surrounded by water, versus the Arctic, an ocean surrounded by land masses and islands, of which Svalbard is one) and different governance context (Antarctica's absence of sovereignty and Svalbard's sovereignty within Norway). Nevertheless, both internal (diverging interests and non-compliance among its members) and external factors (state acceptance and new regulations) challenge the robustness of IAATO's self-regulatory framework (Haase et al., 2009). The expedition crew interviewed for this chapter operate in both the Arctic and Antarctic, and state that IAATO is even more bureaucratic than AECO (I-M-2, I-M-5).

Third, these findings resemble informational governance theory, which postulates that information is no longer merely a resource for decision-making, but for fundamentally restructuring processes, institutions and practices of environmental governance (Mol, 2006, 2008). Similar to findings for shipping and fisheries (Toonen and Mol, 2016), AECO gained value chain power as leading industry association through its information systems. To avoid further reinforcement of AECO's power, the Governor withdrew from a true state-industry partnership. Subsequently, accumulation of state and non-state information systems both for rule compliance and scientific purposes, competition between the interests and organisations behind these information systems (Miller and Bush, 2015), and little coordination or harmonisation between them was observed. The expedition crew, who have to implement all information systems, experienced an information overflow that generated confusion and undermined the credibility and effectiveness of the information systems as well as the information providers behind them (Toonen and Mol, 2016). This information overflow resulted in a trade-off between investing time and resources in information systems on activities and the actual activity itself. When information systems require too much time and resources, users tend to prioritise self-interest over collective interest. This is consistent with the literature, which prescribes that members of self-regulatory 
systems will show greater commitment if they estimate the benefits of collaboration to be higher than the possible costs (Haase et al., 2009; Ostrom, 2005). The strong reliance of collective self-governance on information systems appears to be rather counterproductive in this sense.

This chapter recommends that collective self-governance would benefit from reflection about the information overflow and the prioritisation of self-interest over collective interest. If collective interests were prioritised over self-interest, the expedition crew would collectively share their experiences about the accumulation of information and about the mismatch between management guidelines and field practices, and sustainable tourism would not be compromised by non-compliance with regulations or lack of knowledge exchange because of information overflow. Regular reflection could strengthen incentives for the expedition crew to support the collective interest while benefitting from it. The collective self-governance literature prescribes that resource users be involved in making and adapting rules within collective choice arenas (Ostrom, 1999). 

6.

Marine communities: a conclusion 



\subsection{Introduction}

This thesis embarked on a quest to study environmental governance of maritime activities by marine communities. In a community, resources are limited, and actors engage in governance to develop a shared understanding of how the maritime activity can be sustainably managed in relation to these unique resources. The preceding chapters provide an in-depth analysis of environmental governance by marine communities in four case studies across two marine regions (the Arctic and the Caribbean Netherlands) and two maritime activities (cruise tourism and oil \& gas activities). It becomes clear that environmental problems, which appear initially at the local scale, are affected by economic, social and political developments that increasingly stretch across the globe. Maritime activities are rooted in particular locales but are at the same time increasingly territorially disembedded. Globalisation transforms economic, social and political spaces, which used to be local and national, into spaces that are less coterminous with legal and territorial boundaries (Held et al., 1999). Therefore, the study of the governance of maritime activities cannot be only geographically delimited to the local scale at which the environmental problem is perhaps the most obvious; such analysis needs to account for the interaction between territorially and less territorially defined institutions and actors. Marine communities embrace this interaction to a different extent depending on the environmental problems, marine regions and maritime activities at stake.

In this light, the following research objective and questions were guiding.

\section{Research objective}

The aim of this PhD thesis is twofold: first, to understand environmental governance of maritime activities by different marine communities, and second, to understand how different governance modes, shifts, styles and processes affect the role of the user and policy community in the marine community.

\section{Research questions}

How can the marine community concept enrich our understanding of environmental governance of maritime activities in distinct maritime settings?

1. How are marine communities organised to govern environmental problems in different sectoral and geographical settings?

2. How do marine communities develop in relation to various institutional settings and changes, and how do different governance modes, shifts, styles and processes affect the role of the user and policy community in the marine community? 
These research questions will be answered in this chapter. In the first section, the conclusions of the cross-case comparative analysis will be drawn by comparing governance in marine regions and of maritime activities. Second, theoretical conclusions in relation to marine community as a contemporary governance arrangement will be drawn. The findings will be discussed in relation to theories on governance modes and shifts, policy styles and mobilities. Afterwards, a reflection on the applied methodologies will be provided. To conclude this thesis, guidance for further research and policy implications will be given.

\subsection{Tracking changes in governance by marine communities}

When looking back at the four case studies, it becomes clear that marine community has been a useful concept to identify changes in environmental governance. In this chapter, a cross-case comparative analysis clustered into two sections will be drawn, comparing governance in different marine regions and of different maritime activities.

\subsubsection{Comparing environmental governance in marine regions}

\subsubsection{Caribbean Netherlands}

Climate change is arguably the most serious challenge to conservation within the Caribbean, manifesting as increased sea level rise, more extreme weather events, increases in air and sea surface temperatures and a decrease in rainfall. Already fragile coral reefs are expected to be significantly damaged by warmer and more acidic waters, with far-reaching consequences for the species that inhabit them (Dutch Caribbean Nature Alliance, 2016). Recent examples in Bonaire and Statia illustrate this. On 4-5 October 2016, Hurricane Matthew struck the coast of Bonaire with a heavy storm surge. STINAPA Bonaire surveyed the damage at 18 different reef sites along the coastline of Bonaire and Klein Bonaire, an islet off the west coast of Bonaire. Eleven of the 18 sites suffered from damage in the shallow area ( $<10$ m deep), mainly on fire corals, but sponges and Elkhorn and Staghorn corals were also fragmented or broken (STINAPA Bonaire, 2016). Meanwhile, Statia experienced heavy rains on November 17, 2016. Unprecedented rainfall caused a river to form, leading from the dump straight to Zeelandia beach and carrying the contents of the landfill site with it. Plastic bottles and containers were seen washed onto the shoreline alongside refrigerators and construction materials. Chemical runoff from car batteries and electrical appliances had most likely washed into the ocean. This poses threats to marine life and humans (STENAPA, 2016).

Despite the acknowledged vulnerability of the Caribbean ecosystem, there is likely to be a tension between maritime activities and nature conservation. Coral reefs in 
Bonaire and Statia are located adjacent to the shore; as such, the marine parks surround the entire islands starting immediately from the shoreline. This, amplified by the small territory of the islands, results in likely tension between nature conservation and maritime activities, such as cruise tourism and oil transhipment, which operate close to the shoreline. The high dependency on one sector (cruise tourism and oil transhipment, respectively) for the local economy on each island, in addition, has resulted in economic development being prioritised over nature.

This eagerness for short-term economic growth, together with the lack of decision-making of the island government, has resulted in the user community assuming the governance of cruise tourism in Bonaire. In addition to dedicated organisations, individual actors in the local tourism industry made deals with cruise lines by relying on their social relationships and networking skills. As a result, Bonaire's cruise season is expanding from six months to all year round. Increased cruise tourism in Bonaire may be beneficial to the island's economy in the short term, but the question is how sustainable this development will be. At the same time, increased cruise tourism, threatens the fragile ecosystem and jeopardises the foundations of the island's economy. Uninformed decision-making is illustrated by the attempts to sacrifice parts of the marine park for increased infrastructural development to accommodate growing cruise tourism and the concurrence of the extended cruise season with the nesting season of sea turtles.

In Statia, eagerness for economic development translated to negotiated decision-making between a strong user community, dominated by NuStar, and a weak policy community in times of the Dutch Antilles. This has resulted in negligent environmental management by NuStar, causing environmental problems not only for oil transhipment but also for nature conservation, fisheries and tourism. Urgent environmental problems have required intervention from the Ministry of I\&E since Statia became a special municipality within the Netherlands. Nevertheless, the island government kept prioritising short-term economic development over nature conservation: first, by re-prioritising the second oil terminal over tourism development, contrary to Statia's strategic development plan; second, by speeding up the amendment procedure for the spatial development plan, facilitating a quick amendment of the zone for the second oil terminal; and third, by drafting a new Harbour Ordinance that attempted to reallocate parts of the marine park for harbour development to facilitate increased oil transhipment. In all three cases, the Ministry of I\&E had to intervene because of inappropriate governance procedures.

In both cases, the maritime activities already existed for a longer time and were creating environmental problems because of eagerness for short-term economic 
growth. This was further enhanced by the relative absence of a strong government. Environmental governance in the Caribbean Netherlands therefore aims to cure existing environmental problems.

These findings are consistent with the literature. The Caribbean region is traditionally characterised by a vulnerable balance between terrestrial and marine ecosystems (McElroy, Potter, and Towle, 1990). Recently, construction work, tourism and oil-related activities have increased pressure on the ecosystem. Prioritisation of economic development is known for its far-reaching consequences for environmental management and nature conservation (Hein, 1990). Similar problems regarding environmental management occurred in other Caribbean islands, such as Suriname and, more importantly, Curaçao (Mol et al., 2004; Mol and Van Vliet, 1997). These studies concluded that environmental management is rather curative, dominated by short-term economic development and poorly integrated with other policy domains, providing little impetus for technological innovations (Mol and Van Vliet, 1997).

\subsubsection{The European Arctic}

The European Arctic is also a vulnerable marine region. Currently, it experiences extreme weather because of soaring temperatures. Recent measurements indicated temperatures $20^{\circ} \mathrm{C}$ warmer than normal for most of the Arctic Ocean (Vidal, 2016). In November 2016 and February 2017 Svalbard experienced strong precipitation which triggered landslides and avalanches. Two apartment buildings were destroyed, and the local inhabitants of Longyearbyen had to be evacuated (Icepeople.net, 2017). East of Svalbard near the Franz Joseph Islands, satellite imagery showed a large mass of ice vanishing in late December 2016 (Hilgers and Fennema, 2016). Melting sea ice in the Arctic exposes the ocean beneath to sunlight. Whereas sea ice reflects $80 \%$ of sunlight, the dark ocean absorbs $90 \%$ of sunlight. The ocean warms up even further, amplifying the feedback loop.

Despite moderating temperatures and retreating sea ice, the Arctic remains a harsh and unpredictable environment, in terms of human and environmental safety, to operate in (Patin, 1999). Climate conditions and the Arctic ecosystem determine whether and, in the case of cruise tourism, where the maritime activity will occur. As such, this requires flexibility and caution of the user community. Cruise tourism cannot expand as in the Caribbean because of the darkness and rough ice conditions in winter time, which limit the season to May-September. In Hammerfest, the rough climate has caused severe technical hurdles delaying the start-up of the LNG plant and interrupting operations several times. Therefore, the physical characteristics of the Arctic ecosystem have a larger influence on the operations of maritime activities compared with the Caribbean ecosystem. 
In addition, compared with the Caribbean Netherlands, the European Arctic, along with Greenland and the Faroe Islands, has a more diversified economy. It is important to note that this argument is not valid for the Arctic region in general; circumpolar economic activity is unequally distributed among the different countries (Duhaime and Caron, 2006). A more diversified economy reduces the dependency of the marine community on the maritime activity for its livelihood or local economy. Similar to the Caribbean, the industry in both Arctic cases engaged in policy-making to safeguard their activity. While in the Caribbean this took shape through loose and fragmented initiatives, in the Arctic industry involvement became institutionalised in a public-private partnership and a branch organisation, reflecting the dual role of the industry in the user and policy community. The difference can be partly explained by the fact that changes in governance in the Arctic already occurred a decade ago when the maritime activities were being developed, whereas the changes in governance in the Caribbean are fairly recent. However, the marine communities used different means to safeguard their activity. In Hammerfest, engagement in coalitions was used to gain the commitment and approval of the LNG plant; in Svalbard, information about the industry's whereabouts and footprint was used to safeguard the unique wilderness feeling associated with expedition cruise tourism. Those factors, strengthened by the fact that Norway is one of the richest countries in the world, granted room for a more proactive approach.

The maritime activities in the European Arctic are more recent than in the Caribbean Netherlands. Environmental governance aims to prevent problems from happening in relation to further development of the maritime activity in this vulnerable ecosystem.

The cases resemble findings in the literature. States have traditionally dominated Arctic governance because of their interest in pristine resources. Now the Arctic is becoming a focal point of economic and geopolitical development (Lamers et al., 2016), state involvement has not changed. In both cases, this is reflected by strong involvement of the Norwegian government. Another conclusion in the literature is that ecosystem-based management has been crucial in allowing further economic development in the Arctic while maintaining the resilience of Arctic ecosystems and communities. This approach stresses broad stakeholder engagement and a wide variety of environmental information to legitimate Arctic marine resource activities by guaranteeing minimum levels of human safety or compliance with sustainability standards (Lamers et al., 2016). Stakeholder engagement and environmental information were crucial in Hammerfest and Svalbard, respectively. Both cases, however, also illustrate that these aspects can 
enable Arctic governance only to a certain extent; merely temporary stakeholder involvement or informational overflow can constrain legitimacy, trust and power, which are crucial for environmental governance.

\subsubsection{Comparing environmental governance of maritime activities}

\subsubsection{Cruise tourism}

In both cruise tourism cases, the user community, and more specifically the industry association, played an important role in governance.

In the absence of a strong policy community in Bonaire, the local user community assumed governance of cruise tourism. Upgrading the membership within the FCCA resulted in increased networking and lobbying opportunities with cruise lines. In response to unforeseen cruise tourism development, fragmented efforts by distinct policy actors (a cost-benefit analysis, court cases regarding the amendment of the marine park by NGOs and protests by the dive association over the nature fee) attempted to steer governance in a more sustainable direction; however, these attempts were overpowered by the strong network capacity of the user community. As such, territory-bound regulations (like the Marine Park Ordinance and Bonaire's Spatial Development Plan) and the organisation of the local tourism industry (taxi association, independent tour providers and the souvenir market) were increasingly adapted to the demands of the rather footloose institutions and actors such as the FCCA and cruise lines. As a result, the transnational cruise ship flow increasingly determines the local cruise passenger flow in Bonaire. Local infrastructure to facilitate increasing flows of cruise ships and passengers in Bonaire is lagging behind.

Despite the presence of a strong policy community supported by territory-based and public policy to govern expedition cruise tourism at Svalbard, the user community organised itself into AECO. AECO's private policy is not bound to a specific territory as the majority of the guidelines also apply to other Arctic areas in which cruise operators sail, with site-specific guidelines being the exception. Compared with public policy, private policy is more strict and prescriptive. In contrast with Bonaire, where increasing flows of cruise passengers are a rather unaddressed side effect of increasing flows of cruise ships, AECO is concerned with the organisation of cruise ship flows around Svalbard as well as cruise passenger flows at specific landing sites to safeguard a unique wilderness experience. Although AECO's guidelines are not legally binding and rely on coordination, willingness and social pressure among cruise operators for enforcement, these guidelines have far-reaching consequences. Collective selfgovernance is becoming so powerful because of its network structure, the reliance 
on non-territory-bound regulations and increased access to information that it tends to assume governance by state actors and public policy. This was illustrated by the establishment of site-specific guidelines, a place-based initiative of the industry that was picked up by the Governor of Svalbard and that became mandatory in Norwegian state legislation.

Both industry associations adapted or defined the rules for local places on a global/regional level. However, these industry associations appear to be driven by mixed objectives, ranging from purely marketing purposes and economic incentives steered by the competitive cruise market in the Caribbean (Schep et al., 2012) to industry responsibility, environmental education and stewardship to maintain the quality of key attractions and safety in the polar regions (Haase et al., 2009; Splettstoesser, 2000; Student et al., 2016). This difference in objectives resulted from the understanding that the unique cultural and natural environment is what the industry sells. In Svalbard, there is a good understanding about the relationship between nature conservation and cruise tourism development. In Bonaire, this is insufficiently incorporated into governance.

In conclusion, cruise tourism is expanding its spatial scale continuously, requiring another type of governance. Environmental governance is therefore dominated by the user community because of its ability to govern through transnational and non-territory-based regulations, unlike the unsuccessful policy community, which relied on territory-based regulations.

These conclusions are consistent with the literature. The governance of this complex, transnational and mobile activity cannot rely on traditional governance arrangements by state actors or territory-bound regulation (e.g. Timothy, 2006; Weaver and Duval, 2008). A strong role for cruise companies and industry associations is also reflected in the literature because of their engagement in corporate social responsibility as well as in sustainability partnerships with conservation NGOs (e.g. Cruise Lines International Association, 2010; Haase, Lamers, and Amelung, 2009; Klein, 2007; Sweeting and Wayne, 2006).

\subsubsection{Oil and gas activities}

The operationalisation of marine communities around oil and gas activities portrayed a different story. It has been steered by centralised decision-making at the national level with a strong role for state actors. However, four factors distinguish governance in both marine communities. First, the role of the state is different; while in Statia, the Ministry of I\&E acts as a strong regulator in the policy community, the Norwegian state acts as both a user and policymaker in relation to the LNG plant. This originates from the fact that the Norwegian government pursues a 'Norwegianisation' policy, giving preference to domestic oil companies. 
This is further strengthened by the fact that Statoil is a state-owned company. This leads to the second factor. In Statia, centralised decision-making by the state strived for a proper environmental state, whereas in Hammerfest centralised decision-making by the state is driven by economic growth. Third, the approach taken by the state was different; in Statia, a prescriptive approach was taken to increase supervision of oil activities, whereas in Hammerfest, the Norwegian government took a performance-based approach. This provided more leeway to the industry to achieve the pre-defined performance. Fourth, despite the fact that governance in both cases is driven by place-based regulation, Statia experienced a shift in place-based regulation from island regulation to Dutch regulation driven by Dutch and European standards.

Unlike cruise tourism, the spatial scale of oil and gas activities is smaller, more static and within national boundaries. As a result, the marine communities around oil and gas activities are dominated by a strong policy community driven by national state actors, which sometimes engages in a relationship with the industry. The rather local user community, despite its attempts to influence governance, became subjected to state policy. In both cases, isolation of the local user community from the distant policy community amplified by limited resources and governance capacity resulted in a scale mismatch between the national policy community and the rather local user community within the marine community.

These findings are consistent with the literature. The rather static nature of the activity results in oil and gas activities taking place within territorial waters or exclusive economic zones on the continental shelves of countries. This aligns better with traditional forms of governance by state actors and territory-bound and legally binding regulation (Van Leeuwen, 2010).

The conclusions in the sections on comparing governance in marine regions and in maritime activities answered sub-research question 1.

\subsection{Marine community as a contemporary governance arrangement}

In this section, the sub-research question 2 will be answered by analysing the marine community concept as a contemporary governance arrangement. The findings from the cross-case comparative analysis will be used to identify and theorise about different governance modes, shifts, styles and processes.

\subsubsection{Tracking changes in governance modes and shifts}

In marine communities, a juxtaposition of different governance modes, which have shifted over time, often exists.

A trend in governance shifts can be noticed from hierarchical and closed cogovernance to open co-governance and self-governance modes. This is consistent 
with the global tendency towards an era of emerging network governance that started in the 1990s (Sørenson and Torfing, 2005).

Network governance stresses the following three shifts. (1) A shift from a unicentric to a pluricentric system involving a large number of interdependent actors. Opening up the policy arena for a variety of stakeholders occurred in all cases. (2) A shift from decision-making based on state rule towards negotiated decision-making. This was reflected in the co-governance modes in the cases of Hammerfest and Bonaire. Although stakeholder interaction with fishermen, local inhabitants, NGOs and Sámi was facilitated, the shift towards open co-governance was constrained by centralised decision-making by the public-private partnership, making closed co-government the dominant governance mode. Bonaire's marine community, on the other hand, experienced a small governance shift. In the past, the state-owned TCB performed closed co-governance by negotiating marketing deals with cruise lines. Upgrading Bonaire's membership to the transnational network of the FCCA in 2013 resulted in more networking and lobbying opportunities with cruise lines. This triggered individuals and organisations in the user community to increasingly connect with and adapt to the requirements of the transnational cruise network. These initiatives are rather fragmented and less structured compared with Hammerfest and therefore exemplify open cogovernance. (3) A shift from compliance driven by strong enforcement towards compliance ensured by trust, political obligation and self-constituted rules and norms (Sørensen, Torfing, and Rhodes, 2005). This was most obvious in Svalbard. Tourism at Svalbard used to be governed by the Norwegian government without much local influence or influence from other stakeholders (Viken, 2011), reflecting hierarchical governance. The governance mode changed in response to increased tourism, which made the need for regulations urgent. The 1990s marked a transformation of the marine community involving the private sector, WWF and local authorities and blurring the sector borders and power relations among them (Viken, 2006). This resulted in the establishment of the self-governing industry association AECO in 2003, which tends to overshadow state governance.

Statia, however, is the exception because of its specific political situation. Statia's governance shift is opposite to the contemporary shifts and transformed from closed co-governance to hierarchical governance because of strong Dutch governmental intervention since Statia became a municipality of the Netherlands in 2010. In times of the Dutch Antilles, NuStar and the island government negotiated decision-making, stereotypical of SIDS. Such intertwinement of the user and policy community reflected closed co-governance. Since 2010, and even more strongly since 2015 , the Ministry of I\&E has intervened and imposed strict 
environmental management of oil transhipment at Statia. This reversed the existing power relations, illustrating hierarchical governance. Figure 6.1. illustrates the different governance shifts and modes in the four case studies.

The complexity of governance is more sophisticated and cannot be merely explained by a one-dimensional process ranging from hierarchical to selfgovernance as illustrated in Figure 6.1. In this thesis, the complexity of governance is structured according to two analytical dimensions: governance style and governance process. The governance process builds further on the governance modes in Figure 6.1., while the governance style addresses another dimension of governance, the problem-solving style. These two dimensions will be used to further theorise about governance by marine communities.

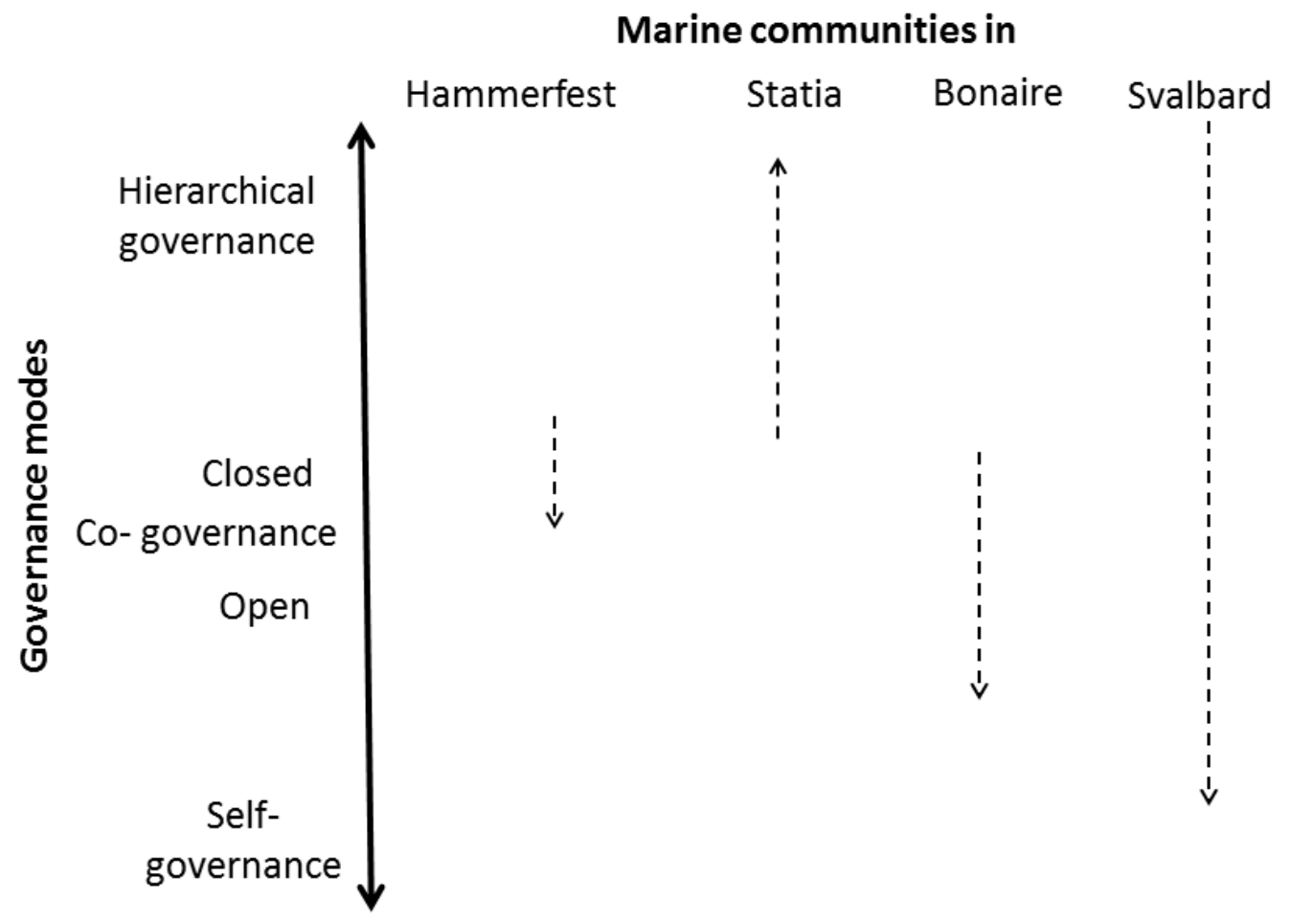

Figure 6.1. Governance shifts and modes for the four case studies

\subsubsection{Tracking changes in governance styles}

The concept of governance style is based upon the policy style concept. In the literature, policy style is linked to policy communities and state actors, where it identifies and explains the interaction between the national government's approach to problem-solving and the culturally conditioned attitudes towards the relationship between the government and core societal actors (Richardson, Gustafsson, and Jordan, 1982; Richardson and Watts, 1985). In this thesis, the problem-solving style is linked to the marine community as a whole because the 
policy and user community are interdependent and co-govern the maritime activity. Therefore, the problem-solving style is defined as a governance style of the marine community in solving environmental problems caused by maritime activities. A governance style can range from reactive to proactive.

With reference to Richardson (1982), a reactive style is rooted in neoliberalism and the importance of the state-society distinction, with the impartial role of the government as a referee. This style is developed to remedy or minimise existing urgent or pressing environmental problems. The overriding common good must be guaranteed by imposing the technically correct solution. Essential in this style is the awaiting and responsive character of government (Richardson, 1982). What challenges reactive problem-solving is not whether the situation is or will become problematic but whether a certain policy mechanism is the best way to handle the problem. Another characteristic of a reactive style is that changes in policy-making or formal rules can happen overnight, triggered by the urgency of the problem.

According to Richardson (1982), a proactive style is rooted in a social-state ideology, emphasising the interdependence of the state and society and pursuing goals, options, appraisal and effectiveness in relation to problem-solving. As a result, power sharing occurs in more cooperative forms of governance and coalition politics (Richardson, 1982). The main challenge associated with a proactive governance style is gaining commitment for a problem which has not yet occurred. This style is chosen deliberately to prevent problems from occurring through reliance on the precautionary principle. Hence, acquiring information and knowledge shapes the basis for an engaged and innovative problem-solving approach (Richardson, 1982).

Although all four cases show features of reactive and proactive governance styles, the comparison of governance in marine regions showed that a curative approach was more explicit in the Caribbean Netherlands (Bonaire and Statia), and a precautionary approach was more foregrounded in the European Arctic (Hammerfest and Svalbard). This distinction resembles a reactive and proactive governance style (shown in Table 6.1. in section 6.3.3).

The reactive governance style in this thesis concerns not only government but the entire marine community and therefore deviates to a certain extent from the literature. In Bonaire and Statia, the island government is not impartial because of intertwinement of the economic and political elite, stereotypical of small islands. This intertwinement between NuStar and the island government, and the environmental problems it has caused, is exactly what triggered the Ministry of I\&E in Statia to intervene in governance as a presumably impartial referee. The intervention of the Ministry marked the beginning of the search for the most 
appropriate policy mechanism to achieve good governance and appropriate environmental management in Statia. When negotiations among NuStar, the Ministry of I\&E and the island government failed to reach a consensus, the Ministry imposed the technically correct solution driven by European and Dutch environmental standards. This reversed the power relationships and triggered several responses. NuStar and SS\&S sought legal resolutions to the environmental permit, while the island government developed a new Harbour Ordinance to overcome the profit tax lost to the Netherlands. In Bonaire, the awaiting character mentioned in the literature can be identified in the inert politicalbureaucratic apparatus. The non-decision-making of the policy community triggered the local user community in Bonaire to develop cruise tourism. This was taken one step further because of the attempt to transform TCB from a stateowned company to a foundation outside governmental control. This is consistent with neoliberalism in which a reactive style is rooted. Policy-making in the Caribbean Netherlands was further characterised by rapid evolvement and quick changes in formal rules in both Statia and Bonaire, consistent with a reactive style. In Bonaire, the pillars for the Karel Visser pier expansion were already built in the marine park before the expansion was cancelled because of inadequate environmental impact assessments. Currently, it is more environmentally damaging to remove than to leave the pillars. With the cancellation of the pier expansion, the permits and amendment of the marine park had to be withdrawn as well. In Statia, the construction of the second oil transhipment terminal was withdrawn for cost-efficiency reasons, and the amendment of the marine park was revised because of the non-binding rendering of the Harbour Ordinance because of inappropriate governance procedures.

In Bonaire, the reactive governance style is oriented to the development of the maritime activity, which aggravates existing environmental problems while creating additional environmental problems. In Statia, the reactive governance style is focused on urgent environmental problems caused by the lenient environmental management of NuStar in the time of the Dutch Antilles. A reactive governance style in the Caribbean Netherlands pulled the user and policy community apart in the marine community, reflecting the state-society distinction. While in Statia, the new constitutional structure and intervention of the Ministry of I\&E distanced the national policy community from the local user community, in Bonaire, it was the user community that became detached from the local policy community by connecting with the FCCA.

More cooperative and power-sharing styles of governance, consistent with a proactive governance style, are clearly demonstrated by the public-private 
partnership in Hammerfest and the establishment of collective self-governance, next to state governance, in Svalbard. The challenge associated with a proactive approach in securing commitment for a not-yet-existing problem was reflected in Hammerfest's marine community, where coalition politics emerged in institutional, strategic and oppositional coalitions to approve the development of the LNG plant. In this process, the local inhabitants of Hammerfest raised environmental, safety and health concerns. These concerns were addressed in public meetings and by environmental impact assessments. AECO, on the other hand, was established proactively for two reasons: to preserve the unique character of the industry and to fend off stricter state policy. Engaged policy-making in Svalbard is driven by information provisioning about the whereabouts and environmental impact of the industry. Access to information created tension between the Governor of Svalbard and AECO and between the management and the expedition leaders in the field.

In the end, both marine communities engaged in a proactive governance style to safeguard their business through accurate information and knowledge and stakeholder involvement. A proactive governance style in the European Arctic reflected the intertwinement of the user and policy community in the marine community, demonstrating the interdependence of the state and society. However, this intertwinement merely occurred at the national level and created a scale mismatch with the local level in both cases. The dual roles of Statoil, the Norwegian government and AECO in the user and policy community were not considered legitimate by the local user community and created mistrust.

\subsubsection{Tracking changes in governance processes}

The governance process defines how policies are developed, implemented and enforced through the use of different regulations and mechanisms by various actors in the user and policy community. A distinction was observed between governing predominantly through transnational and non-territory-bound regulations by the user community for cruise tourism and through territory-bound regulations predominantly by the policy community for oil and gas activities. This distinction resembles Baerenholdt's (2013) concept of 'governmobility'. Governmobility builds on Foucault's notion of governmentality, i.e. the art of governing. Baerenholdt sees in Foucault's analysis that the use of territory in governing societies has become combined, if not substituted, by the use of population. Consequently, repressive power by the sovereign was no longer needed as power relations were governmentalised in the population. In fact, the population became a decentred network of self-regulation elements and individuals (Foucault, 1994). According to Baerenholdt, Foucault's notion of governmentality already hinted towards the role of mobility in the governing of society through populations that move and circulate 
as part of society. Mobility is often associated with flow and freedom as opposed to territorial fixity by bonds and borders. Nonetheless, it also pertains to power and a way of governing. Baerenholdt perceives the contribution of mobility studies (Hannam, Sheller, and Urry, 2006; Urry, 2000, 2007) to the governing of society in the image they draw of societies, made up of various mobility systems that generate new forms of social obligations facilitated by these mobility systems that ensure co-presence with otherwise detached persons or persons at a distance (Baerenholdt, 2013).

Combining both perspectives results in governmobility, short for governing through mobility. Governing through mobility is the self-government of connections, facilitated through various mobility systems and an environment that enables mobility and circulation. This has become a new way of making and binding societies. Social relationships with actors or institutions that are not necessarily proximate are engendered and sustained through various mobility systems such as ICT, transport, travel, meeting places and social and technical skills of networking. It is important to stress that these social relationships are afforded by, but not products of, mobility (Larsen and Urry, 2008). Governing through mobility is opposed to governing of mobility. In governing of mobility, mobility arrangements that often cross the borders of nation-states are governed by arrangements in which the borders of nation-states are used to define who is participating. Territoriality as a governing principle is often enforced by direct, repressive power by the sovereign. Building further on this typology in the second dimension, the governance process, governance of marine communities is distinguished from governance through marine communities. In governance of marine communities, territorial borders are used to govern the maritime activity at stake. Territoriality is furthermore used to define the importance and positioning of actors within the marine community. The use of territoriality as a governing principle results in the upholding of sovereignty rights in the regions where the maritime activities are occurring. In governance through marine communities, the mobility of the maritime activity, and consequently of the marine community governing this maritime activity, is used as a governing principle. Different types of power are used in governance of and through marine communities. The threelayered power framework of relational, dispositional and structural power applied in Chapter 3 will be used to analyse these differences in power. Table 6.1. structures the four case studies according to the governance style and process. 
Table 6.1. Structuring the complexity of governance

\begin{tabular}{|c|c|c|}
\hline $\begin{array}{l}\text { Governance } \\
\text { style }\end{array}$ & $\begin{array}{l}\text { Governance of } \\
\text { marine communities }\end{array}$ & $\begin{array}{l}\text { Governance through } \\
\text { marine communities }\end{array}$ \\
\hline $\begin{array}{l}\text { Reactive governance } \\
\text { style }\end{array}$ & $\begin{array}{l}\text { Hierarchical governance of oil } \\
\text { transhipment in Statia }\end{array}$ & $\begin{array}{l}\text { Open co-governance for cruise } \\
\text { tourism in Bonaire }\end{array}$ \\
\hline $\begin{array}{l}\text { Proactive governance } \\
\text { style }\end{array}$ & $\begin{array}{l}\text { Closed co-governance of LNG } \\
\text { production in Hammerfest }\end{array}$ & $\begin{array}{l}\text { Self-governance for expedition } \\
\text { cruise tourism in Svalbard }\end{array}$ \\
\hline
\end{tabular}

In governance of marine communities, the spatial scale of oil and gas activities is determined by territorial borders. This has resulted in local to national marine communities in which governing of the local user community was performed by the national policy community. In both cases, this was facilitated by traditional governance modes in which territoriality and structural power by the sovereign played an important role. The reactive governance style in Statia relied mainly on external intervention and hierarchical governance of the Dutch Ministry of I\&E for pressing environmental problems regarding the oil terminal. A proactive governance style combined with governance of marine communities was illustrated by closed co-governance of LNG in Hammerfest. Governance of the marine community in Hammerfest was again dominated by external actors; through the public-private partnership between the Norwegian State and its stateowned company Statoil.

Governance of the marine community was in both cases initially driven by the use of territoriality to internalise discourses (structural power). The fact that Statia is now Dutch territory was used to internalise discourses on proper environmental management and good governance according to Dutch and European standards. In Hammerfest, a Norwegianisation discourse and a discourse on revitalisation of Northern Norway territory coupled with offshore oil and gas activities were strived for. These discourses were further implemented by the use of institutional rules (dispositional power). In Statia, this took shape in strict environmental rules and permits (dispositional power); in Hammerfest, Norway's petroleum regulation and tax system facilitated the pursuance of these discourses.

Dispositional power of the Ministry of I\&E was not perceived as legitimate by the local inhabitants of Statia. They argued that governance should be based on the Caribbean small island context of Statia, with limited governance capacity and resources, instead of Statia's territoriality, which resulted in the imposition of Dutch 
and European environmental standards. NuStar and the island government tried to regain dispositional power lost to the Ministry by the use of resources, such as court cases against the environmental permit (relational power), and developing new institutional rules such as the Harbour Ordinance (dispositional power) to overcome the unequal distribution of resources, caused by the transfer of the profit tax of NuStar to the Ministry of I\&E. However, NuStar and the island government are continuously constrained by structural power in terms of environmental standards judged to be fair in the court case about the environmental permit and inappropriate governance procedures that rendered the Harbour Ordinance nonbinding.

A similar situation happened in Hammerfest. To strive for more community development and, to a lesser extent, environmental development in the governance process, coalitions were shaped, reflecting relational power. Coalitions that shared the abovementioned discourse on economic growth coupled with oil and gas activities were granted access to the policy-making arena, reflecting dispositional power. Although fishermen did not have any territorial rights to their fishing grounds, they had valuable resources such as local knowledge and historic use of the area. This granted them even more dispositional power. Furthermore, representation by networks, e.g. the national fishermen's organisation, enabled further dispositional power of the local fishermen in the policy arena vis-à-vis the Norwegian State and Statoil. This is contrary to the weak integration of the Sámi indigenous people within Hammerfest's local community, which disadvantaged them in terms of dispositional power. Stakeholder engagement, however, faded away once Statoil received approval for the LNG plant driven by rather cost-efficient and short-term conflict resolution mechanisms. As such, dispositional power of the institutional coalition determined what could be achieved in terms of relational power in the different coalitions.

Although the actors in the marine communities in both cases shared the same territory, external, distant national actors were not well integrated into the local communities. Structural and dispositional power, driven by territoriality, compromised trust and social relationships within the marine community. Apart from the existing geographical distance, this amplified the relational distance between actors in the marine community. The lack of relational power in the marine community challenges environmental governance.

In governance through the marine community, the spatial scale of cruise tourism is not territorially fixed but rather continuously evolving. The spatial scale of cruise tourism is determined by connections and interactions that facilitate negotiations about cruise tourism flows. As such, this translates into a larger and 
more dynamic marine community. Governing, here, is not imposed on the marine community but rather works through connections and interactions (relational power) within the marine community, especially within the user community. This required new and innovative forms of governance, as reflected in both cases. Selfgovernance by the user community in AECO in Svalbard exemplified a proactive governance style in the Arctic to safeguard its business. Open co-governance in Bonaire was less deliberately organised and characterised a reactive governance style within the Caribbean to benefit from increased cruise tourism despite a rather awaiting role of the local policy community.

Transnational cruise networks, such as AECO and the FCCA, are crucial in governance through marine communities. Access to these networks, however, is granted through different means. In Bonaire, additional financial resources were used to upgrade the membership within the FCCA. This advantageous positioning in the network (dispositional power) granted Bonaire the opportunity to benefit from additional lobbying and networking possibilities, reflecting increased relational power. In Svalbard, voluntarily adhering to additional guidelines (relational power) allowed access to the AECO network. Governance in these networks was further steered by means of relational power; in terms of access to co-present encounters and weak ties among actors involved in cruise tourism. This was facilitated by characteristics of mobility systems like meeting places such as FCCA and AECO conferences and ICT. Relational power in terms of frequent interaction among these transnational cruise networks and cruise lines, tour operators and cruise destinations enabled, on the one hand, integration of these external cruise transnational networks within the marine community (dispositional power). Relational power, on the other hand, granted these transnational cruise networks significant dispositional and structural power in decision-making over other actors in the marine community, mediated by rules and structured asymmetries of resources. This is contrary to the findings in the literature (Arts and Van Tatenhove, 2004), and it becomes the crux of understanding how governance through the marine community contributes to inequality and power relationships. Access to information and knowledge about the environmental impact and whereabouts of expedition cruise tourism in Svalbard, obtained through relational power within AECO, granted AECO dispositional power vis-à-vis the Governor of Svalbard and the expedition crew. In Bonaire, negotiations at the FCCA grant cruise lines enormous dispositional power over cruise destinations. Cruise lines play upon the structured asymmetries of the resources of small islands in the Caribbean (structural power) and their eagerness for short-term economic growth in negotiations to visit convenient cruise destinations. 
Contrary to governance of marine communities, in governance through marine communities, relational power is not perceived as a threat but rather as a means to involve and empower the community. However, there appears to be a threshold to which networking, facilitated by mobility systems, can empower governance through marine communities; the network structure should stay intact and not become too institutionalised or bureaucratic. The use of dispositional and structural power otherwise compromises trust relationships which are essential for governance through marine communities to be successful.

Governance of and through marine communities is theoretically possible by both the user and policy communities. However, in this thesis governance of marine communities was dominated by the policy community and governance through marine communities by the user community.

The marine community concept contributed to the understanding of the complexity of governance by tracking changes in governance modes, shifts, styles and processes. The spatial scale of the maritime activity appeared to be crucial, as it defines the mobility of the activity and subsequently of the marine community. As a result, the maritime activity had a larger influence on environmental governance by marine communities than the marine region in which the activity occurs.

\subsection{Methodological reflection}

In a certain governance context, you can delineate the marine community by identifying stakeholders involved in governing the maritime activity and their interactions. Next, zooming in and out is obtained by following the interactions between different actors in the user and policy communities and the means they use to interact. Zooming in and out is necessary to recognise the appropriate scale at which the marine community, and its governance arrangement, manifests itself. Furthermore, it enables certain aspects of governance by the marine community to be foregrounded while others are bracketed. The zooming in and out process is initially steered by the empirical findings. Afterwards, the process is further enabled through the selected theoretical framework for the following two reasons. First, the use of additional concepts and theories allows for a better in-depth understanding of the marine communities and governance arrangements at stake. Second, those additional concepts and theories steer the identification of the appropriate scale at which the marine community operates and further the empirical analysis. As a result, in every situation where local environmental problems related to maritime activities in a globalising world emerge, a marine community can be identified. The marine community concept can be flexibly applied, and it challenges the researcher to identify the appropriate scale at which 
the marine community exists depending on the governance context.

The methodological approach to operationalise the marine community concept requires reflections on the internal and external validity of the research. The introduction mentioned that the internal validity of this thesis was expected to be enhanced by means of triangulation, semi-structured interviews with a large group of relevant stakeholders, semi-prolonged periods of fieldwork which lengthened the exposure time of the researcher with the object and the cross-checking of findings. However, there are some limitations to how these factors enabled internal validity.

Although semi-structured interviews were conducted with a large representation of stakeholders, the number of interviews per case study differed. For the Hammerfest case, only 14 interviews were conducted compared with 25-35 interviews for the other three cases. In relation to the cases on cruise tourism, this can be explained by the larger size of these marine communities which required more interviews to obtain a proper representation of relevant stakeholders. Statia was a complex case because of the new constitutional status, and it required more interviews to gain a good understanding of the political complexity at stake. The 14 interviews for the Hammerfest case, nevertheless, were conducted with 19 interviewees and reached the point of data saturation, rendering additional interviews unnecessary.

Because of the limited fieldwork budget, only semi-prolonged periods of fieldwork could be conducted. The fieldwork was successful because of a large collection of interviews, but extended fieldwork periods could be more beneficial to have an even greater submersion in the case study at stake. The research would benefit from this because the cases selected in this thesis were not well studied before in the literature, meaning there was limited secondary data available on which the researcher could rely, strengthening the need for the cross-checking of findings. Participatory observation over a long period of time also has its drawbacks as the researcher is the main instrument of data collection; thus, his/her interpretation or focus on a particular issue can lead to bias (Bryman, 2004, p. 284). Regarding the role of the researcher during fieldwork, it is important to mention that during fieldwork in the Caribbean Netherlands, the researcher was advised by other researchers and stakeholders to mention her Belgian identity instead of introducing herself as a researcher from a Dutch university, due to the tension between Bonaire, and especially Statia, with the Netherlands, since they became special municipalities.

An unforeseen factor which complicated data collection was inaccessibility to the field and interviewees in Svalbard. Fieldwork was planned to take place in 
Longyearbyen, the main settlement in Svalbard, and in Ny-Ålesund, the international research centre in Svalbard. Funding for the fieldwork was obtained by the researcher through the Arctic Field Grant 2014 of the Svalbard Science Forum. However, successful funding did not automatically translate into access to the field. Ny-Ålesund is a centre for international arctic scientific research and environmental monitoring, comprised of research stations from ten countries across the world. Social scientific research for this thesis is not the typical research conducted in the predominantly natural science research centre in $\mathrm{Ny}$ Ålesund. This raised concerns among the scientific community in Ny-Ålesund and required additional permission for fieldwork to be granted by the $\mathrm{Ny}$-Ålesund Science Managers Committee in which all research stations are represented. Another factor that complicated the process was the funding of the fieldwork by a Norwegian and not a Dutch fund. Support or accommodation could therefore not be granted by the Netherlands polar research station. After a lengthy procedure of almost six months, permission was finally obtained for fieldwork. In light of the subject of this thesis, the special nature of the research community of Ny-Ålesund could be perceived as a marine community of scientists. Becoming a member of this marine community was not easy; however, once access was granted, the community was very welcoming.

In the introduction, external validity was sought to be strengthened by means of the cross-case comparative analysis which allows for analytical or theoretical generalisation across different contexts such as marine regions and maritime activities. The results of the cross-case comparative analysis showed that the framework can be flexibly used in research, rectified and transformed in many settings, different from the cases studies in this thesis in which it was developed. In the individual case studies, marine communities have been studied in relation to theories on coalition-building, power, networks and flows and collective selfgovernance. The distinction in the cross-case comparative analysis between governance of marine communities and governance through marine communities for a relative static and a highly mobile maritime activity, respectively, covered both ends of the mobility spectrum for maritime activities in the globalising world in which we currently live. The inductive stance to develop the marine community concept has been successful. Now that the marine community has taken shape, a more deductive approach to study marine communities is necessary to test the external validity of this concept. Therefore, marine communities should be studied in relation to other maritime activities. Although the different nature of maritime activities influenced governance processes by marine communities more significantly, compared to the different marine regions in which the marine 
activities occurred, marine communities should also be further investigated in other areas. In this thesis, two vulnerable ecosystems with very different climate conditions were selected. To compare the findings, marine communities in more temperate or less vulnerable ecosystems should be studied. Suggestions for other maritime activities and regions are provided in the next section. Afterwards, some policy implications will be given.

\subsection{Future research}

Although studying environmental governance by marine communities has been fruitful in this thesis, marine community is a new conceptual framework. Further research is needed to enrich the understanding of its application in various theoretical and empirical settings. This thesis suggests the following areas for future research.

First, the theoretical typology based on the governance style and the governance process was not intentionally designed to contrast the cases; however, the empirical cases in this thesis illuminated governance of marine communities predominantly by policy communities and governance through marine communities predominantly by user communities. Theoretically, governing of and through marine communities is possible by both the user and policy communities. Therefore, it would be interesting to analyse governance of marine communities by user communities and governance through marine communities by policy communities to enrich the theoretical understanding of the governance process by marine communities. This could be studied in relation to cruise tourism and oil \& gas activities, as well as to new maritime activities, which will be further elaborated below. In addition to using empirical data, additional concepts and theories could be used to further study the theoretical foundation of governing of and through marine communities. Network capital of Larsen and Urry (2008) and power in the network society of Castells (2009) are relevant for this purpose. Similar to the governance process, the governance style was empirically linked to a reactive approach in the Caribbean and a proactive approach in the Arctic. Opposite case studies or cases in other marine regions could also deepen the theoretical insights in different governance styles by marine communities.

Second, the marine environment still holds an enormous treasure of different empirical settings to study the marine community concept. Marine communities should be studied first in relation to other maritime activities because the maritime activity had a larger influence on environmental governance than the marine region in which it occurred. Fisheries and shipping may be a good starting point, as both maritime activities have been key economic sectors for coastal nations 
and are much older practices than the relatively young maritime activities of cruise tourism and offshore oil and gas production (Toonen and Mol, 2016). The governance of fisheries by marine communities might be different than that of oil \& gas activities and cruise tourism for the following reasons: strong involvement of fishermen as local resource users, strong involvement of not-for-profit organisations and the reliance on different market-based governance tools, e.g. certification. The governance of shipping by marine communities might be different as well because it is steered on a more international level compared with cruise tourism and oil \& gas activities. However, there are some similarities with cruise tourism as both activities tend to rely on industry associations to represent their interest as well as on voluntary-based steering mechanisms.

In addition, marine communities should be studied in other geographical areas around the world, for example in more temperate marine ecosystems such as the North Sea. On the continental shelf of the North Sea, a large variety of activities such as shipping, fisheries, oil and gas, tourism, sand extraction and military take place close to each other. Marine communities in the North Sea will therefore have a more diversified economy than the Caribbean region and experience more conflicts and competing claims for space between different maritime activities than the European Arctic.

Finally, marine communities with a different composition should be studied. In the four case studies in this thesis, market and state actors were key actors. It would be interesting to investigate marine communities with a stronger role for NGOs and the type of steering mechanisms on which they rely. Another difference could be to study marine communities in relation to maritime activities taking place not at small islands but rather in coastal areas.

\subsection{Policy implications}

Maritime activities are to a high degree run by governance of marine communities. An overarching finding in this thesis is that maritime activities cannot only be governed by territorial fixity by bonds and borders as maritime activities stretch across the globe and cross national borders all the time. This thesis revealed a new governance arrangement, defining governance through marine communities next to governance of marine communities. This also has policy implications.

The cruise tourism cases illustrate different interests in governance through marine communities, ranging from marketing purposes and economic incentives to play divide-and-rule between ports of call among destinations to industry responsibility, environmental education and stewardship. How transnational cruise networks make use of the characteristics of mobility systems in governance 
through marine communities contributes to inequality and power relationships, especially in relation to cruise destinations. Despite the fact that Bonaire has access to the transnational cruise network, the global multinational cruise companies still hold considerable negotiation power over small-island states in sustainability issues because footloose actors (e.g. foreign cruise ship operators) can easily relocate their operations, whereas place-specific actors (e.g. local hotel owners and operators) cannot. Despite being locally rooted, cruise destinations should become more networked in cruise destination networks to counteract wheeling and dealing by the cruise lines. Successful cruise destination networks already exist in other parts of the world, for example, Cruise Baltic Northern Europe and the Association of Mediterranean Cruise Ports. Through these networks, all partner destinations are able to offer the same service, high standards and full integration between ports and cities. Such initiatives are best organised on a regional level because of the seasonality of cruise tourism and the high differentiation in the cruise market, from small-scale cruises in remote and vulnerable environments, for example, the polar regions (Lamers et al., 2008), to cruise vessels equivalent to floating cities, such as in the Caribbean (Greenwood and Barron, 2006; Wood, 2000). Although AECO is an Arctic tour operator network, it has good collaboration with destination networks such as Visit Svalbard, Visit Greenland and Cruise Norway. For example, Cruise Iceland recently joined AECO to develop community guidelines for visitors to small communities and remote areas tourism in the North (Association of Arctic Expedition Cruise Operators, 2017a, 2017b). In the Caribbean, the Caribbean Tourism Organization, the Caribbean's tourism development agency, already exists. Financial contribution to the Caribbean Tourism Organization is based on tourist numbers visiting the destination. As a result, some destinations decrease the actual number of tourists to lower the contribution costs, whereas other destinations increase the number of tourist visits for political reasons or to maintain their image. Statistical data about tourism are copied from the destinations without double-checking the data (I-G-16). As a result, in its current shape, the Caribbean Tourism Organization is not capable of functioning as a robust destination network, similar to the abovementioned destination networks.

Governance through marine communities occurs not only in relation to mobile activities, such as cruise tourism, but also in regard to territory-based activities such as oil production, perhaps in more implicit forms. An example is the shift in Norway from prescriptive to performance-based supervision in petroleum. The Norwegian government predefines the performance that needs to be reached, and the industry can decide how to achieve this value. Although this approach provides 
opportunities for governance through the marine community to explore and weigh different scenarios, in Hammerfest, only the institutional coalition is involved in this process. Another example related to Norway's petroleum industry illustrates that when governance through the marine community occurs, policies must be adapted to facilitate this. In 2016, oil production started from the offshore Goliat platform initiated by ENI Norge together with Statoil. The oil industry involved the fishing community in the Goliat project contingency strategy for its unique knowledge of the local waters and its experience with towing equipment and because it can be mobilised at short notice. Fishermen argued they would only participate if three conditions were met: the fishing vessels should be prepared with oil spill response equipment, the fishermen should be trained to develop oil spill response competences and the fishermen should be compensated financially. To facilitate this, the Norwegian Maritime Directorate had to amend its policy to include fishing vessels in oil spill operations (ENI Norge, n.d.). Governance through the fishing community resulted in a good relationship between the oil industry and fishermen, and it strengthened the capacity for oil spill contingency. 


\section{References}

Adviesbureau RBOI-Buro Vijn. (2012). Amendment Plan NuStar Terminals. Oentsjerk (The Netherlands).

Agrawal, A., and C.C. Gibson. (1999). Enchantment and disenchantment: The role of community in natural resource conservation. World Development, 27(4), 629-649.

Águeda Corneloup, de I., and A.P.J. Mol. (2014). Small island developing states and international climate change negotiations: the power of moral "leadership." International Environmental Agreements: Politics, Law and Economics, 14(3), 281-297.

Amelung, B., and M. Lamers. (2007). Estimating the CO2 emissions from Antarctic tourism. Tourism in Marine Environments, (4), 2-3.

Andersen, M., (2013, October). Collaboration: The marine mammals sightings project. Presentation at the 1st Science-Industry Platform on Svalbard Expedition Cruise Tourism workshop, Oslo, Norway.

Angell, E., and K.B. Stokke. (2014). Vulnerability and adaptive capacity in Hammerfest, Norway. Ocean and Coastal Management, 94, 56-65.

Arbo, P., and B. Hersoug. (1997). The globalization of the fishing industry and the case of Finnmark. Marine Policy, 21(2), 121-142.

Arnouts, R., M. van der Zouwen, and B. Arts. (2012). Analysing governance modes and shifts - Governance arrangements in Dutch nature policy. Forest Policy and Economics, 16, 43-50.

Arts, B., and M. Buizer. (2009). Forests, discourses, institutions. Forest Policy and Economics, 11(5-6), 340-347.

Arts, B., and H. Goverde. (2006). The Governance Capacity of (new) Policy Arrangements: A Reflexive Approach. In B. Arts and P. Leroy (Eds.), Institutional Dynamics in Environmental Governance (pp. 69-92). Dordrecht: Springer.

Arts, B., and J.P.M. van Tatenhove. (2004). Policy and power: A conceptual framework between the "old" and "new" policy idioms. Policy Sciences, 37(34), 339-356.

Arts, B., and J.P.M. van Tatenhove. (2006). Political Modernisation. In B. Arts and J.P.M. van Tatenhove (Eds.), Institutional Dynamics in Environmental Governance (pp. 21-43). Dordrecht: Springer.

Ascher, W. (1995). Communities and Sustainable Forestry. San Francisco: ICS Press.

Association of Arctic Expedition Cruise Operators. (2013). AECO membership. Retrieved October 13, 2014, from http://www.aeco.no/membership/.

Association of Arctic Expedition Cruise Operators. (2016a). About us. Retrieved July 27, 2016, from http://www.aeco.no/about-aeco/.

Association of Arctic Expedition Cruise Operators. (2016b). Site guidelines become mandatory in West-Spitsbergen. Retrieved November 24, 2016, from http://www.aeco.no/2015/03/site-guidelines-become-mandatory-in-west- 
spitsbergen/.

Association of Arctic Expedition Cruise Operators. (2017a). Community Guidelines The Northerners People and cultures shaped by nature. Longyearbyen (Svalbard).

Association of Arctic Expedition Cruise Operators. (2017b). Community Specific Guidelines. Longyearbyen (Svalbard).

Atkinson, M. M., and W.D. Coleman. (1992). Policy networks, policy communities and the problems of governance. Governance: An International Journal of Policy and Administration, 5, 154-180. Baerenholdt, J.O. (2013). Governmobility: The Powers of Mobility. Mobilities, 8(1), 20-34.

Baerenholdt, J.O. (2013). Governmobility: The Powers of Mobility. Mobilities, 8(1), 20-34

Balint, P.J., and J. Mashinya. (2006). The decline of a model community-based conservation project: Governance, capacity, and devolution in Mahenye, Zimbabwe. Geoforum, 37(5), 805-815.

Barnett, J., and J. Campbell. (2010). Climate Change and Small Island States, Power, Knowledge and the South Pacific. London: Earthscan Ltd.

Becking, L., and D. Slijkerman. (2012). Generic ecological assessment framework for coastal ecosystems in the Caribbean Netherlands. (Report/IMARES Wageningen UR C122/12). Den Helder: IMARES Wageningen UR.

Berkes, F. (2009). Evolution of co-management: role of knowledge generation, bridging organizations and social learning. Journal of Environmental Management, 90(5), 1692-702.

Berkes, F., J. Colding, and C. Folke. (2003). Navigating social-ecological systems: building resilience for complexity and change. Cambridge: Cambridge University Press.

Bertness, M.D., S.D. Gaines and M.E. Hay. (2000). Marine Community Ecology (1st ed.). Sunderland, MA: Sinauer Associates Inc.

Bestuurscollege St. Eustatius. Besluit van het Bestuurscollege van het openbaar lichaam St. Eustatius inzake de vergunningaanvraag van NuStar Terminals N.V. op grond van de Hinderverordening St. Eustatius 1993 (2013). St. Eustatius: Bestuurscollege St. Eustatius.

Boeije, H. (2010). Analysis in qualitative research (1 ${ }^{\text {st }}$ ed.). London: Sage Publications.

Bogdan, R.C., and S.K. Biklen. (2006). Qualitative research in education: An introduction to theory and methods. New York: Pearson/Allyn \& Bacon.

Boutilier, R. (2014). Frequently asked questions about the social licence to operate. Impact Assessment and Project Appraisal, 5517(September), 37-41.

Bramwell, B., and A. Sharman. (1999). Collaboration in local tourism policymaking. Annals of Tourism Research, 26(2), 392-415.

Briassoulis, H. (2002). Sustainable tourism and the question of the commons. Annals of Tourism Research, 29(4), 1065-1085.

Brida, J.G., and S. Zapata. (2010). Cruise tourism: economic, socio-cultural and environmental impacts. International Journal of Leisure and Tourism 
Marketing, 1(3), 205-226.

Bryman, A. (2004). Social Research Methods (2nd ed.). Oxford: Oxford University Press.

Burn, G., T. Tyler, J. Zadkovich and J. Loftis. (2015). Legal issues in cross-border resource development. Journal of World Energy Law and Business, 8(2), 154-172.

Butler, R.W. (1999). Sustainable tourism: A state-of-the-art review. Tourism Geographies, 1(April 2010), 7-25.

Carlsson, L., and F. Berkes. (2005). Co-management: Concepts and methodological implications. Journal of Environmental Management, 75(1), 65-76.

Carr, A. ,and R. Wilkinson. (2005). Beyond Participation: Boundary Organizations as a New Space for Farmers and Scientists to Interact. Society \& Natural Resources, 18(3), 255-265.

Carroll, A.B. (1991). The pyramid of corporate social responsibility: Toward the moral management of organizational stakeholders. Business Horizons, 34(4), 39-48.

Castells, M. (2009a). Communication power (1 ${ }^{\text {st }}$ ed.). Oxford: Oxford University Press.

Castells, M. (2009b). Power in the Network Society. In M. Castells (Ed.), Communication Power ( $1^{\text {st }}$ ed., pp. 10-53). Oxford: Oxford University Press.

Central Bureau of Statistics. (2010). Statistical yearbook 2010. Willemstad, Curaçao.

Chambers, R. E., and M.K. McBeth. (1992). Community encouragement: Returning to the basis for community development. Journal of the Community Development Society, 23(2), 20-38.

Chitere, O.P. (1994). Community development: its conceptions and practice with emphasis on Africa. Nairobi: Gideon S. Were Press.

Clegg, S.R. (1989). Frameworks of power. London: Sage Publications.

Conley, A., and M. Moote. (2003). Society \& Natural Resources: An Evaluating Collaborative Natural Resource Management Evaluating Collaborative Natural Resource Management. Society and Natural Resources, 16, 37-41.

Convention on Biological Diversity. (2017). What is Marine and Coastal Biodiversity? Retrieved January 19, 2017, from https://www.cbd.int/marine/intro.shtml.

Creswell, J.W. (2014). Research design: qualitative, quantitative and mixed methods approaches ( $4^{\text {th }}$ ed.). California: Sage Publications.

Crow, G., and G. Allan. (1994). Community Life, an Introduction to Local Social Relations. Hemel Hempstead: Harvester Wheatsheaf.

Cruise Lines International Association. (2010). The overview 2010 CLIA Cruise Market Overview. Statistical Cruise Industry Data Through 2009. Fort Lauderdale: Cruise Lines International Association Incorporated.

Cruise Lines International Association. (2016). 2017 Cruise Industry Outlook. Florida: Cruise Lines International Association Incorporated. 
Dawson, J., M.E. Johnston, and E.J. Stewart. (2014). Governance of arctic expedition cruise ships in a time of rapid environmental and economic change. Ocean and Coastal Management, 89, 88-99.

Debrot, A.O., and R. Bugter. (2010, Oktober). Climate change effects on the biodiversity of the BES islands. (Alterra-report 2081/IMARES-report C118/10). Wageningen: IMARES \& Alterra Wageningen UR.

DeSombre, E.R. (2006). Flagging Standards: Globalization and Environmental, Safety, and Labor Regulations at Sea. Cambridge: MIT Press Books (Vol. 1).

De Vaus, D. (2001) Research Design in Social Research, Thousand Oaks/London/New Delhi: Sage Publications.

Dietz, T., E. Ostrom, and P.C. Stern. (2003). The Struggle to Govern the Commons. Science, 302(5652), 1907-1912.

Dobson, S., and A. Gill. (2006). Environmental Policy Challenges for the Cruise Industry: Case Studies from Australia and the USA. In R. Dowling (Ed.), Cruise Ship Tourism. Wallingford: CAB International.

Douglas, C.H. (2006). Small Island States and Territories: Sustainable Development Issues and Strategies - Challenges for Changing Islands in a Changing World. Sustainable Development, 14, 75-80.

Dowling, R. (2006). Cruise Ship Tourism. Wallingford: CAB International.

Duhaime, G., and A. Caron. (2006). The Economy of the circumpolar Arctic. In S. Glomsrod and I. Aslaksen (Eds.), Statistical Analyses: The Economy of the North (pp. 17-26). Oslo-Kongsvinger: Statistics Norway.

Dutch Caribbean Nature Alliance. (2016, September). Bio news 28. Kralendijk: Dutch Caribbean Nature Alliance.

Eilandsraad St. Eustatius. Eilandsverordening tot wijziging van het marien milieu verordening (2015). Eilandsraad St. Eustatius.

Eilandsraad St. Eustatius. Verordening Havengelden Sint Eustatius 2015 (2015). Eilandsraad St. Eustatius.

Elder-Vass, D. (2012). The reality of social construction. Cambridge: Cambridge University Press.

ENI Norge. (n.d.). Oil spill protection - northern Norway leads the way. Retrieved April 7, 2017, from http://www.eninorge.com/en/Mobile/News/NewsArchive/News-Article/?srcid=416.

Etzioni, A. (1996). Positive Aspects of Community and the Dangers of Fragmentation. Development and Change, 27(2), 301-314.

Florida Caribbean Cruise Association. (2015a). About The FCCA. Retrieved May 27, 2015, from http://www.f-cca.com/about.html.

Florida Caribbean Cruise Association. (2015b). FCCA Associate Membership Program. Retrieved July 13, 2015, from http://www.fcca.com/membership.html

Foucault, M. (1994). Governmentality. In P. Rabonow and N. Rose (Eds.), The Essential Foucault (pp. 229-245). New York: NY: The New Press.

Galaz, V., P. Olsson et al. (2008). The problem of fit among phiophysical systems, environmental and resources regimes, and broader governance systems: 
insights and emerging challenges. In Institutions and environmental change: principal findings, applications, and research frontiers (pp. 147-186). Cambridge: MIT Press.

Giddens, A. (1984). The Constitution of Society: Outline of the Theory of Structuration. Cambridge: Polity Press.

Google Earth. (2017a). Image Landsat/Copernicus. 12/31/2016. 14ํ4'36.56" N. 66 어' $36.56 " \mathrm{~W}$.

Google Earth. (2017b). Image Digital Globe. 11/10/2006. 17²09'11.47" N. 630'11.99" W.

Google Earth. (2017c). Image Landsat/Copernicus. 12/31/2015. 12004'29.44" N. 68 ำ19'18.18" W.

Google Earth. (2017d). Image Landsat/Copernicus 12/31/2010. 7323'21.23" N. 230ํ'18.97" E.

Google Earth. (2017e). Image Landsat/Copernicus. 12/31/2012. 77042'39.48" N.

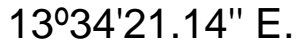

Google Earth. (2017f). Image Digital Globe. 5/11/2013. 7040'07.86" N. 2339'39.53" E.

Government of the French Republic. Treaty between Norway, The United States of America, Denmark, France, Italy, Japan, The Netherlands, Great Britain and Ireland and the British overseas Dominions and Sweden concerning Spitsbergen (1925). Paris (France).

Governor of Svalbard. (2015). Extended ban on heavy fuel oil. Retrieved November 28, 2016, from http://www.sysselmannen.no/en/News/Extendedban-on-heavy-fuel-oil/.

Graham, M. (2002). Democracy by Disclosure: The rise of Technopopulism. Washington D.C.: Brookings Press.

Greenwood, A.B., and P. Barron. (2006). Issues determining the development of cruise itineraries: a focus on the luxury market. In Tourism in Marine Environments (pp. 89-99).

Haase, D., M. Lamers, and B. Amelung. (2009). Heading into uncharted territory? Exploring the institutional robustness of self-regulation in the Antarctic tourism sector. Journal of Sustainable Tourism, 17, 411-430.

Hackel, J.D. (1999). Community conservation and the future of Africa's wildlife. Conservation Biology, 13(4), 726-734.

Hagen, D., O.I. Vistad, N.E. Eide, A.C. Flyen, and K. Fangel. (2012). Managing visitor sites in Svalbard: from a precautionary approach towards knowledgebased management. Polar Research, 31(18432).

Hajer, M.A. (1995). The Politics of Environmental Discourse: Ecological Modernization and the Policy Process. Oxford: Oxford University Press.

Haley, S., L. Chartier, G. Gray, C. Meek, J. Powell, and A. Andrew. (2011). Strengthening Institutions for Stakeholder Involvement and Ecosystem-based Management in the U.S. Arctic Offshore. In A.L. Lovecraft and H. Eicken (Eds). North by 2020. Perspectives on Alaska's Changing Social-Ecological Systems (pp. 457-476). Fairbanks: The University of Alaska Press 
Haley, S., M. Galginaitis, G. Gray, C. Meek, J. Powell, J. Rosenberg, and B. Valcic. (2009, March). Symposium Lessons from Continuity and Change in the Fourth International Polar Year in Fairbanks (Alaska).

Hall, P.A., and R.C.R.Taylor. (1996). Political Science and the Three New Institutionalisms. Political Studies, XLIV, 936-957.

Hammerfest Kommune. (2012). Hammerfest gateway to the Barents Sea, Petroleum Guide. Hammerfest (Norway).

Hannam, K., M. Sheller, and J. Urry. (2006). Editorial: mobilities, immobilities and moorings. Mobilities, 1(1), 1-22.

Hardin, G. (1968). The Tragedy of the Commons. Science, 162, 1243-1248.

Harley, C.D.G., A.R. Hughes, K.M. Hultgren, B.G. Miner, C.J.B. Sorte, C.S. Thornber, ... S.L. Williams. (2006). The impacts of climate change in coastal marine systems. Ecology Letters, 9(2), 228-241.

Healy, R.G. (1994). The "common pool" problem in tourism landscapes. Annals of Tourism Research, 21(3), 596-611.

Hein, P.L. (1990). Between Aldabra and Nauru. In Beller et al. (Eds.), Sustainable Development and environmental management of small islands (pp. 57-75). Paris/Carnforth/Park ridge: UNESCO and Parthenon.

Held, D., D. Goldblatt, A.McGrew, and J.Perraton. (1999). Global Transformations. Cambridge: Polity Press.

Hilgers, S., and S. Fennema. (2016). Onderzoekers slaan alarm: Noordpool smelt snel. Retrieved January 4, 2017, from http://buitenland.eenvandaag.nl/tvitems/70679/onderzoekers_slaan_alarm_noordpool_smelt_snel.

Hoggett, P. (1997). Contested communities. In P. Hoggett (Ed.), Contested Communities. Experiences, struggles, policies. Bristol: Policy Press.

Hovelsrud, G.K. and B. Smit. (2010). Community Adaptation and Vulnerability in Arctic Regions. Berlin: Springer.

Hunter, C. (1997). Sustainable tourism as an adaptive paradigm. Annals of Tourism Research, 24(4), 850-867.

Hutchison, J., M. Spalding, M., and P. Zu Ermgassen. (2014). The Role of Mangroves in Fisheries Enhancement. Cambridge: The University of Cambridge.

Icepeople.net. (2017). Alert: Avalanche destroys two apartment buildings on Vei 228; Part of Lia evacuated. Retrieved February 22, 2017, from http://icepeople.net/2017/02/21/alert-avalanche-destroys-two-apartment-buil dings-on-vei-228-part-of-lia-evacuated/.

International Energy Agency. (2015). World Energy Outlook 2015. Paris (France) International Maritime Organization. (2015). Reception facilities. Retrieved November 12, 2015, from http://www.imo.org/en/OurWork/Environment/Port ReceptionFacilities/Pages/Default.aspx.

International Maritime Organization. (2016). Introduction to IMO. Retrieved November 14, 2016, from http://www.imo.org/en/About/Pages/Default.aspx.

Johnson, D. (2002). Environmentally sustainable cruise tourism: A reality check. 
Marine Policy, 26(4), 261-270.

Klein, R.A. (2007). The Politics of Environmental Activism: A case study of the Cruise Industry and the Environmental Movement. Sociological Research Online, 12(2).

Klein, R.A. (2011). Responsible Cruise Tourism: Issues of Cruise Tourism and Sustainability. Journal of Hospitality and Tourism Management, 18(1), 107116.

Klick, M.T. (2009). The Political Economy of Corporate Social Responsibility and Community Development: A Case Study of Norway's Snohvit Natural Gas Complex. (FNI Report 1/2009). Lysaker: Fridtjof Nansens Institutt

Klok, C., A.O. Debrot, H.W.G. Meesters, J. Stapel, and D.M.E.Slijkerman. (2011, November 16). Second opinion NuStar terminal expansion. (Report number C148/11 [confidential]), Wageningen: IMARES Wageningen UR

Knol, M. (2010). Marine Ecosystem Governance in the Making. Planning for Petroleum Activity in the Barents Sea Lofoten Area. University of Tromso.

Koek, E. (2015, September 21). NuStar zet rechtszaak tegen haventarieven Statia door. Retrieved from http://caribischnetwerk.ntr.nl/2015/09/21/nustar-zetrechtszaak-tegen-haventarieven-statia-door/.

Koelega, S. (2015). Protests against cutting Statia Marine Park in half. Retrieved from http://www.thedailyherald.info/index.php?option=com_content\&view=.

article\&id=56211 :protests-against-cutting-statia-marine-park-in-

half \&catid=1 :islands-news\&ltemid=54.

Koninkrijk der Nederlanden. Wet maritiem beheer BES Geldend van 10-10-2010 t / $\mathrm{m}$ heden (2010). Den Haag (Nederland): Koninkrijk der Nederlanden.

Koninkrijk der Nederlanden. Wet van 17 mei 2010 tot invoering van de regelgeving met betrekking tot de openbare lichamen Bonaire, Sint Eustatius en Saba (Invoeringswet openbare lichamen Bonaire, Sint Eustatius en Saba) (2010). Den Haag: Koninkrijk der Nederlanden.

Koninkrijk der Nederlanden. Wet van 22 december 2011, houdende regels inzake de volkshuisvesting, de ruimtelijke ordening en het milieubeheer in de openbare lichamen Bonaire, Sint-Eustatius en Saba (Wet volkshuisvesting, ruimtelijke ordening en milieubeheer BES) (2012). Den Haag: Koninkrijk der Nederlanden.

Kooiman, J. (2003). Governing as governance. London: Sage Publications.

Korbee, D., A.P.J. Mol, and J.P.M.van Tatenhove. (2015). Ecological considerations in constructing marine infrastructure: The Falmouth cruise terminal development, Jamaica. Marine Policy, 56, 23-32.

Lai, K.-H., V.Y.H. Lun,C.W.Y. Wong, and T.C.E. Cheng. (2011). Green shipping practices in the shipping industry: Conceptualization, adoption, and implications. Resources, Conservation and Recycling, 55(6), 631-638.

Lamers, M., E. Eijgelaar, and B. Amelung. (2015). The Environmental Challenges of Cruise Tourism: Impacts and Governance. In D. Hall,C.M.; Gossling, S.; Scott (Ed.), The Routledge Handbook of Tourism and Sustainability (pp. 430439). Abingdon, UK: Routledge.

Lamers, M., D. Haase, and B. Amelung. (2008). Facing the elements: analysing 
trends in Antarctic tourism. Tourism Review, 63(1), 15-27.

Lamers, M., D. Liggett, and B. Amelung. (2012). Strategic Challenges of Tourism Development and Governance in Antarctica: Taking Stock and Moving Forward. Polar Research, 31(2), 1-13.

Lamers, M., J. Olsen, G. Hovelsrud, I. Lang, and F. Jorgensen. (2013). 1st Science-Industry platform on expedition cruise tourism in Svalbard. Wageningen (The Netherlands).

Lamers, M., A. Pristupa, B. Amelung, and M. Knol. (2016). The changing role of environmental information in Arctic marine governance. Current Opinion in Environmental Sustainability, 18(January 2003), 49-55.

Lamers, M., R. van der Duim, J. van Wijk, R. Nthiga, and I.J. Visseren-Hamakers. (2014). Governing conservation tourism partnerships in Kenya. Annals of Tourism Research, 48, 250-265.

Larsen, J., and J. Urry. (2008). Networking in Mobile Societies. In J. O. Baerenholdt, B. Granas and S. Kesselring (Eds.), Mobility and Place: Enacting Northern European Peripheries (pp. 89-101). Aldershot: Ashgate.

Lee, D., and H. Newby. (1983). The Problem of Sociology: an introduction to the discipline. London: Unwin Hyman.

Lester, J.-A., and C. Weeden. (2004). Stakeholders, the natural environment and the future of Caribbean cruise tourism. International Journal of Tourism Research, 6(1), 39-50.

Levander, A., M. Schmitz, H.G. Avé Lallemant, H., C.A. Zelt, D.S. Sawyer, M.B. Magnani, ... J.Pindell. (2006). Evolution of the Southern Caribbean Plate Boundary. Eos, Transactions, American Geophysical Union, 87(9), 97,100.

Liefferink, D. (2006). The dynamics of policy arrangements: Turning round the tetrahedron. In B. Arts and P. Leroy (Eds.), Institutional Dynamics in Environmental Governance. Dordrecht: Springer.

Lijphart, A. (1968). The Politics of Accommodation. Pluralism and Demcrocacy in the Netherlands. Berkeley: Univerisity of California Press.

Mason, J. (2002). Qualitative Researching (2 ${ }^{\text {nd }}$ ed.). Thousand Oaks/London/New Delhi: Sage Publications.

McElroy, J.L., B. Potter, and E. Towle. (1990). Challenges for sustainable development in small Carribean islands. In Beller et al. (Eds.), Sustainable Development and environmental management of small islands (pp. 229-316). Paris/Carnforth/Park ridge: UNESCO and Parthenon.

Merriam-Webster. (2001). Merriam-Webster's Geographical Dictionary ( $3^{\text {rd }}$ ed., p. 1298). Springfield, MA: Merriam-Webster Inc.

Miller, A.M.M., and S.R. Bush. (2015). Authority without credibility? Competition and conflict between ecolabels in tuna fisheries. Journal of Cleaner Production, 107, 137-145.

Ministerie van Infrastructuur en Milieu. (2015). Brief betreft Inwerkingtreding Besluit Grote Inrichtingen Milieubeheer BES (NuStar). Den Haag (Nederland): Ministerie van Infrastructuur en Milieu. Retrieved from http://www.rijksoverheid.nl/ministeries/ienm.

Ministry of Justice and the Police. Svalbard. Stortingsmelding nr22. (Svalbard 
White Paper 22.) (2008). Oslo: Ministry of Justice and the Police.

Ministry of Petroleum and Energy. Act 29 November 1996, No.72 relating to petroleum activities (1996). Oslo: Ministry of Petroleum and Energy.

Mol, A.P.J. (2008). Environmental Reform in the Information Age: The contours of Informational Governance. Cambridge: Cambridge University Press.

Mol, A.P.J., J.H. Mol, and B.J.M. van Vliet. (2004). Suriname Schoon Genoeg? Hulpbronnengebruik en milieubescherming in een Klein Amazoneland. Utrecht: Van Arkel.

Mol, A.P.J., and G. Spaargaren. (2012). Global Environmental Politics and Governance: A Networks and Flows Perspective. In P. Deuverge (Ed.), Handbook of Global Environmental Politics (2 ${ }^{\text {nd }}$ ed.). Cheltenham: Edward Elgar Publishing.

Mol, A.P.J., and B.J.M. van Vliet. (1997). Tussen zandstrand en asfaltmeer, Milieubeheer op Curaçao. Utrecht: Van Arkel.

Morgan, D.L. (2008). The SAGE Encyclopedia of Qualitative Research Methods. Thousand Oaks/London/New Delhi: Sage Publications.

Murk, T., and J. Klostermann. (2011). TripleP@Sea Smart use of marine ecosystem services providing sustainable Profit of the Planet for People. Wageningen (The Netherlands).

Nelson, F., and A. Agrawal. (2008). Patronage or Participation? Community-based Natural Resource Management Reform in Sub-Saharan Africa. Development \& Change, 39(4), 557-585.

Nilsen, $\varnothing$. (2012). Introduction to Melkøya plant, Presentation by Statoil ASA.

Norwegian Parliament. Finnmark Act (Act No. 85 of June 17, 2005 relating to Legal Relations and Management of Land and Natural Resources in the County of Finnmark) (2005). Retrieved from http://www.wipo.int/wipolex/en/text.jsp?file_id $=244972$.

Norwegian Petroleum Directorate. (2012, January 26). A controlled success. Oslo. Retrieved from http://www.npd.no/en/Publications/Norwegian-ContinentalShelf/No1-2012/A-controlled-success/.

NuStar Energy L.P. (2010). Annual report pursuant to section 13 or 15 (d) Transition report pursuant to section 13 or 15 (d) for the fiscal year ended December 21, 2010. Washington D.C. (USA).

O'Donoghue, T., and K. Punch. (2003). Qualitative Educational Research in Action: Doing and Reflecting. London: Falmer Press.

Oceanwide Expeditions. (2014). Spitsbergen. Retrieved November 6, 2014, from http://www.oceanwide-expeditions.com/destinations/destination/spitsbergen/.

Oliver, D. (2015, March 6). Letter NuStar Proposed port fees threaten Statia Terminal's viability. St. Eustatius.

Ostreng, W., K.M. Eger, B. Floistad, A. Jorgensen-Dahl, A., L. Lothe, M. Mejlaender-Larsen, and T. Wergeland. (2013). Shipping in Arctic waters. A comparison of the Northeast, Northwest and Trans Polar Passages. Heidelberg: Springer. 
Ostrom, E. (1990). Governing the Commons: The Evolution of Institutions for Collective Action. Cambridge: Cambridge University Press.

Ostrom, E. (1999). Self-governance and forest resources. International Workshop on Community-Based Natural Resource Management (CBNRM). Retrieved from http://www.cbnrm.net/pdf/ostrom_001.pdf.

Ostrom, E. (2005). Understanding institutional diversity. Princeton: Princeton University Press.

Ostrom, E., J. Burger, C.B. Field, R.B. Norgaard, and D. Policansky. (1999). Revisiting the commons: local lessons, global challenges. Science (New York, N.Y.), 284(5412), 278-282.

Ostrom, V. (1991). The meaning of American Federalism: constituting a selfgoverning society. Oakland, CA.: ICS Press.

Ostrom, V. (1997). The meaning of democracy and the vulnerability of democracies: a response to Tocqueville's challenge. Ann Arbor, MI: University of Michigan Press.

Overrein, O. (2001). Svalbard-one of the best wilderness areas in the world? Principles for good wilderness management. Tromso (Norway).

Papathanassis, A., and I. Beckmann. (2011). Assessing the "poverty of cruise theory" hypothesis. Annals of Tourism Research, 38(1), 153-174.

Pashkevich, A., J. Dawson, and E.J. Stewart. (2015). Governance of Expedition Cruise Ship Tourism in the Arctic: A Comparison of the Canadian and Russian Arctic. Tourism in Marine Environments, 10(3-4), 225-240.

Patin, S. (1999). Environmental impact of the offshore oil and gas industry (1 ${ }^{\text {st }}$ ed.). East Northport, NY: EcoMonitoring Publishing.

Pattberg, P. (2007). Private Institutions and Global Governance. The New Politics of Environmental Sustainability. Cheltenham: Edward Elgar Publishing.

Pearl of the Caribbean. (2015). Victory for Statia Monuments Foundation in case against Spatial Development Plan. Retrieved from http://smn-news.com/stmaarten-st-martin-news/12964-victory-for-statia-monuments-foundation-incase-against-spatial-development-plan.html.

Pedersen, S. I. (2010). Perspectives on a long-term stakeholder dialogue, Lessons learned from the Snohvit project-Statoil and the Fishermen's Association. Bodo (Norway).

Pelaudeix, C. (2015). Governance of Arctic Offshore Oil \& Gas Activities: Multilevel Governance \& Legal Pluralism at Stake Governance of Arctic Offshore Oil \& Gas Activities: Multilevel Governance \& Legal Pluralism at Stake. In L. Heininen, H. E.-P. and J. Plouffe (Eds.), Arctic Yearbook 2015, Arctic Governance and Governing. (pp. 2014-233). Akureyri: Northern Research Forum.

Petroleum Safety Authority Norway. (2010, March 12). From prescription to performance in petroleum supervision. Oslo (Norway). Retrieved from http://www.psa.no/news/from-prescription-to-performance-in-petroleumsupervision-article6696-878.html.

Pierre, J. (2000). Introduction: understanding governance. In J. Pierre (Ed.), Debating governance; authority, steering, and democracy (pp. 1-10). Oxford: 
Oxford University Press.

Polido, A., E. João, and T.B. Ramos. (2014). Sustainability approaches and strategic environmental assessment in small islands: An integrative review. Ocean \& Coastal Management, 96, 138-148.

Public Entity St. Eustatius. (2012). Memorandum of Reply for the Draft Zoning Amendment Plan NuStar Terminals. St. Eustatius.

Rein, M., and D.A. Schon. (1986). Frame-reflective policy discourse. Beleidsanalyse, 4, 4-18.

Rhodes, R.A.W. (1996). The new governance: Governing without government. Political Studies, 44, 652-667.

Rhodes, R.A.W. (2000). Governance and public administration. In J. Pierre (Ed.), Debating Governance. Authority, Steering and Democracy (1 ${ }^{\text {st }}$ ed.). (pp. 5490). Oxford: Oxford University Press.

Richardson, J.J. (1982). Policy Styles in Western Europe (1'st ed.). London: George Allen and Unwin Ltd.

Richardson, J.J., G. Gustafsson, and G. Jordan. (1982). The concept of policy style. In J.J. Richardson (Ed.), Policy Styles in Western Europe (1st ed.). (pp. 1-16). London: George Allen and Unwin Ltd.

Richardson, J.J., and N. Watts. (1985). National Policy Styles and the Environment: Britain and West Germany Compared (1st ed.). Berlin: Wissenschaftzentrum Berlin für Sozialforschung.

Ritchie, W. (2004). Monitoring Long-Term Environmental Change: Some Lessons from Sullom Voe, Shetland Islands, 3(2), 193-204.

Rosa, M., and C. Adams Kimmel. (2015). Bonaire Celebrates Inaugural Visit of Carnial Cruise Lines. New York. Retrieved from http://adams-pr.com/bonairecelebrates-inaugural-visit-of-carnival-cruise-lines/.

Royal Haskoning. (2011). NuStar Terminal Expansion. Rotterdam (The Netherlands).

Saarinen, J. (2006). Traditions of sustainability in tourism studies. Annals of Tourism Research, 33(4), 1121-1140.

Samson, J. (2015, December 10). Haagse boycot voor Sint Eustatius voorbij. Den Haag (Nederland). Retrieved from http://caribischnetwerk.ntr.nl/2015/12/10/ haagse-boycot-voor-sint-eustatius-voorbij/.

Schep, S., P. van Beukering, L. Brander, and E. Wolfs. (2012). IVM Institute for Environmental Studies The tourism value of nature on Bonaire. Amsterdam (The Netherlands).

Schultz, L., C. Folke, and P. Olsson. (2007). Enhancing ecosystem management through social-ecological inventories: lessons from Kristianstads Vattenrike, Sweden. Environmental Conservation, 34(2), 140.

Sen, S., and J.R. Nielsen. (1996). Fisheries co-management: a comparative analysis. Marine Policy, 20(5), 405-418.

Senyk, J. (2005). Lessons from the Equator Initiative: Community-based management by Pred Nai Community Forestry Group in the mangroves of Southeastern Thailand. Winnipeg: Centre for Community-Based Resource 
Management.

Sharpley, R. (2000). Tourism and Sustainable Development: Exploring the Theoretical Divide. Journal of Sustainable Tourism, 8(1), 1-19.

Short, J.W. (2007). Slightly Weathered Exxon Valdez Oil Persists in Gulf of Alaska Beach Sediments after 16 Years. Environmental Science, 41(4), 1245-1250.

Smith, M.K. (2001). Community. In The Encyclopedia of informal education. Retrieved 16 May 2017 from http://www.infed.org/community/community.htm.

Smits, C.C.A., J.C.S. Justinussen, and R.G. Bertelsen. (2016). Human capital development and a Social License to Operate: Examples from Arctic energy in the Faroe Islands, Iceland and Greenland. Energy Research \& Social Sciences, 16, 112-131.

Sørensen, E., J. Torfing, and R.A.W. Rhodes. (2005). The democratic anchorage of governance networks. Scandinavian Political Studies, 28(3), 195-218.

Sørenson, E., and J. Torfing. (2005). Network governance and Post-Liberal Democracy. Administrative Theory and Praxis, 27(2), 197-237.

Spaargaren, G., A.P.J. Mol, and F.H. Buttel. (2006). Governing Environmental Flows: Global Changes to Social Theory. Cambridge: The MIT Press.

Spergel, B. (2014). The Financial Sustainability of Nature Parks in the Dutch Caribbean. Bonaire: Dutch Caribbean Nature Alliance.

Spies, J. W.E., A.H.A. Soons, G.A.E. Thode, L.F.M. Verhey, and F.H.F. Weekers. (2015). Vijf jaar verbonden Bonaire, St. Eustatius, Saba and Europees Nederland. Den Haag (Nederland).

Splettstoesser, J. (2000). IAATO's Stewardship of the Antarctic Environment: a History of Tour Operator's Concern for a Vulnerable Part of the World. International Journal of Tourism Research, 2, 47-55.

St. Eustatius Awareness \& Development Movement. (2012). Statia people hit the streets in protest to NuStar expansion plans - Dutch press release. Retrieved December 15, 2015, from http://no-to-nustar-expansionsteustatius.blogspot.nl /2012_03_01_archive.html.

Statoil. (2007). Snohvit. Retrieved January 19, 2015, from http://www.statoil.com/en

/ouroperations/explorationprod/ncs/snoehvit/pages/default.aspx.

Statoil. (2011a). Major shareholders. Retrieved December 18, 2014, from http://www.statoil.com/annualreport2011/en/shareholderinformation/pages/ma jorshareholders.aspx.

Statoil (2011b). Taxation of Statoil. Retrieved January 28, 2015, from https://www.statoil.com/annualreport2011/en/ouroperations/applicablelawsand regulations/pages/taxationofstatoil.aspx

Statoil. (2013). Sustainability Report, 44. Retrieved from http://www.statoil.com/en /NewsAndMedia/News/2014/Pages/21Mar_AnnualReport2013.aspx.

STENAPA. (2016, November 2011). Personal communication STENAPA Facebook. 
STINAPA Bonaire. (2015a). Bonaire National Marine Park. Retrieved March 29, 2015, from http://www.bmp.org/.

STINAPA Bonaire. (2015b). Bonaire National Marine Park -RAMSAR. Retrieved August 6, 2015, from http://www.bmp.org/ramsar.html.

STINAPA Bonaire. (2015c). STINAPA- Nature fee = entrance fee to the Bonaire National Marine Park. Retrieved July 14, 2015, from http://www.stinapa.org/na turefee.html.

STINAPA Bonaire. (2015d). STINAPA Bonaire. Retrieved July 31, 2015, from http://www.stinapa.org/index.html.

STINAPA Bonaire. (2016). Bonaire National Marine Park Hurricane Matthew Reef Damage Assessment. Kralendijk (Bonaire). Retrieved from http://www.bmp.org

/ramsar.html.

Student, J., M.A.J. Lamers, and B. Amelung. (2016). Towards a tipping point? Exploring the capacity to self-regulate Antarctic tourism using agent-based modelling. Journal of Sustainable Tourism, 24(3), 412-429.

Suárez-de Vivero, J.L. (2013). The extended continental shelf: A geographical perspective of the implementation of article 76 of UNCLOS. Ocean and Coastal Management, 73, 113-126.

Swanborn, P. (2010). What is a Case Study? (P. Swanborn, Ed.), Case Study Research: What, Why and How? London: Sage Publications.

Sweeting, J E.N., and S.L. Wayne. (2006). A shifting tide: Environmental challenges and cruise industry responses. In R. Dowling (Ed.), Cruise Ship Tourism. Wallingford: CAB International..

Sysselmannen på Svalbard. (2013). Reiselivsstatistikk for svalbard 2013. Retrieved May 16, 2017 from http://www.sysselmannen.no/Documents/Sysselmannen_d ok/Informasjon/REISELIVSSTATISTIKK\%20FOR\%20SVALBARD\%202013.p df

Tacconi, L. (2007). Decentralization, forests and livelihoods: Theory and narrative. Global Environmental Change, 17(3-4), 338-348.

Thatcher, M. (1998). The Development of Policy Network Analyses. From Modest Origins to Overarching Frameworks. Journal of Theoretical Politics, 10(4), 389-416.

The Arctic Council. (2007). Arctic Oil and Gas 2007, Arctic Monitoring and Assessment Programme. Oslo (Norway).

The Ministry of Climate and Environment. Regulations relating to large nature conservation areas and bird reserves in Svalbard as established in 1973 (1973). Oslo (Norway).

The Ministry of Climate and Environment. Svalbard Environmental Protection Act Act of 15 June 2001 No.79 Relating to the Protection of the Environment in Svalbard (2001). Oslo (Norway).

The Ministry of Justice. Regulations relating to tourism and other travel in Svalbard (1991). Oslo (Norway). 
Thomson, I., and R. Boutilier. (2011). Modelling and Measuring the Social License to Operate: Fruits of a Dialogue Between Theory and Practice. Social Licence to Operate .... Retrieved from http://socialicense.com/publications/Modelling and Measuring the SLO.pdf.

Timothy, D.J. (2006). Cruises, Supranationalism and Border Complexities. In R. Dowling (Ed.), Cruise Ship Tourism (pp. 407-413). Wallingford: CAB Internatio-

nal.

Tonnies, F. (1887). Gemeinschaft und Gesellschaft. Leipzig: Fues's Verlag.

Toonen, H.M. (2013). Sea@shore Informational governance in marine spatial conflicts at the North Sea. Wageningen University.

Toonen, H.M., and A.P.J. Mol. (2016). Governing the Marine Environment through Information: Fisheries, Shipping, and Tourism. In B.H. MacDonald, S.S. Soomai, E.M. De Santo and P.G. Wells (Eds.), Science, Information and Policy Interface for Effective Coastal and Ocean Management (pp. 125-151). Boca Raton: CRC Press.

Treib, O., H. Bähr, and G. Falkner. (2005). Modes of Governance: A Note Towards Conceptual Clarification. European Governance Papers (EUROGOV), 5, 122.

Tysiachniouk, M. (2012). Transnational Governance Through Private Authority: The Case of the Forest Stewardship Council Certification in Russia. Wageningen University.

United Nations Environment Programme-World Tourism Organization. (2005). Making tourism more sustainable. A guide for policy makers. Madrid (Spain).

Urry, J. (2000). Sociology beyond Societies: Mobilities for the twenty-first century (1 ${ }^{\text {st }}$ ed.). London: Routledge.

Urry, J. (2007). Mobilities (1 ${ }^{\text {st }}$ ed.). Cambridge: Polity Press.

Van Bets, L.K.J., M.A.J. Lamers, and J.P.M. van Tatenhove. (2016). Governing Cruise Tourism in Bonaire: A Networks and Flows Approach. Mobilities. First online.

Van Bets, L.K.J., J.P.M. van Tatenhove, and M.A.J. Lamers. (2016). A power analysis of a transforming marine community around oil transshipment at St. Eustatius. Ocean \& Coastal Management, 132, 59-69.

Van Bets, L.K.J., J.P.M. van Tatenhove, and A.P.J. Mol. (2016). Liquefied Natural Gas Production at Hammerfest: a transforming marine community. Marine Policy, 69, 52-61.

Van der Lely, J.A.C., P. van Beukering, L. Muresan, D.Z. Cortes, E. Wolfs, and S. Schep. (2013). The Total Economic Value of Nature on Bonaire, Exploring the Future with an Ecological-economic Simulation model. Amsterdam (The Netherlands).

Van der Velde, J., K.M.A. Hoogenboezem-Lanslots, and Y.M. Schenau. (2011). Spatial Development Plan St. Eustatius. (report number NL.IMRO.0000.42107English-0001). Rotterdam (The Netherlands).

Van Kerkhof, J. (2015, September 1). Den Haag haalt streep door werkbezoeken aan Statia. Oranjestad (St. Eustatius). Retrieved from 
http://caribischnetwerk.ntr

.nl/2015/09/01/den-haag-haalt-streep-door-werkbezoeken-aan-statia/.

Van Leeuwen, J. (2010). Who greens the waves? Changing authority in environmental governance of shipping and offshore oil and gas activities. Environmental Policy Series. Wageningen University.

Van Leeuwen, J., and J.P.M. van Tatenhove. (2010). The triangle of marine governance in environmental governance of Dutch offshore platforms. Marine Policy, 34, 590-597.

Van Tatenhove, J.P.M. (2013). How to turn the tide: Developing legitimate marine governance arrangements at the level of the regional seas. Ocean \& Coastal Management, 71, 296-304.

Van Tatenhove, J.P.M. (2015). The environmental state at sea. Environmental Politics, 25(1), 160-179.

Van Tatenhove, J.P.M. (2017). Transboundary Marine Spatial Planning: A Reflexive Marine Governance Experiment? Journal of Environmental Policy \& Planning. First online.

Van Tatenhove, J.P.M., B. Arts, and P. Leroy. (2000). Political Modernisation and the Environment. The Renewal of Environmental Policy Arrangements. Dordrecht: Kluwer Academic Publishers.

Van Twist, M.J.W., and C.J.A.M. Termeer. (1991). Introduction to configuration approach: a process theory for societal steering. In R. in't Veld, L. Schaap, C.J. A.M. Termeer and M.J.W. van Twist (Eds.), Autopoiesis and configuration theory: new approaches to societal steering (pp. 19-30). Dordrect: Kluwer Academic Publishers.

Van Waarden, F. (1992). Dimensions and types of policy networks. European Journal of Political Research, 21(1992), 29-52.

Van Werven, G., C.J. Jepma, and W. Bakker. (2010). Masterplan Strategische Ontwikkeling Bonaire 2010-2025. Groningen (The Netherlands).

Vermeij, M. (2011,October). Environmental impacts associated with the planned expansion of Karel's Beach Bar, Bonaire. Curaçao: Carmabi Foundation

Vidal, J. (2016). Extraordinarily hot Arctic temperatures alarm scientists. Retrieved March 15, 2017, from https://www.theguardian.com/environment/2016/nov/22/ extraordinarily-hot-arctic-temperatures-alarm-scientists.

Viken, A. (2006). Svalbard, Norway. In G. Baldacchino (Ed.), Extreme Tourism: Lessons from the World's Cold Water Islands (pp. 129-144). Oxford: Elsevier.

Viken, A. (2011). Tourism, research and governance on Svalbard: a symbiotic relationship. Polar Record, 47(4), 335-347.

VROM Inspectie. (2010). Nederland een stukje groter en mooier, VROM programma transitie BES eilanden. Den Haag (Nederland).

Walker, J. (1989). Introduction: Policy Communities as a global phenomena. Governance, 29(1), 1-14.

Weaver, A., and D.T. Duval. (2008). International and transnational aspects of the global cruise industry. In C. M. Coles, T.; Hall (Ed.), International Business and Tourism: Global Issues, Contemporary Interactions. London: Routledge. 
Weick, K.E. (1979). The social psychology of organizing ( $2^{\text {nd }}$ ed.). New York: Addison Wesley.

White, J., N. Esteban, and D. MacRae. (2007). Tanker Anchoring Impact Study and Recommendations St Eustatius Marine Park. St. Eustatius.

Willmott, P. (1986). Social Networks, Informal Care and Public Policy. London: Policy Studies Institute.

Wolfs, E., S. Schep, V.L. Gallegos, and P. van Beukering. (2015). What is Bonaire' $s$ Cruise Tourism Worth? Amsterdam (The Netherlands).

Wood, R.E. (2000). Caribbean cruise tourism: Globalisation at sea. Annals of Tourism Research, 27, 345-370.

Wood, R.E. (2002). Caribbean of the East? Global Interconnections and the Southeast Asian Cruise Industry. Asian Journal of Social Science, 30(2), 420440.

World Ocean Council. (2014a). International Ocean Governance: Marine Planning Brief. New York: World Ocean Council.

World Ocean Council. (2014b). Report of the World Ocean Business Forum: Ocean Policy \& Planning 28-30 September 2014. New York: World Ocean Council.

World Wildlife Fund. (2015a). Letter WWF concern around St Eustatius Marine Park changes. Zeist (The Netherlands).

World Wildlife Fund. (2015b, July 22). Overwinning bescherming onderwaterpark Bonaire. Zeist (The Netherlands).

Wuisan, L., J. van Leeuwen, and C.S.A. van Koppen. (2012). Greening international shipping through private governance: A case study of the Clean Shipping Project. Marine Policy, 36(1), 165-173.

Yang, C.-S., C.-S.Lu, J.J. Haider, and P.B. Marlow. (2013). The effect of green supply chain management on green performance and firm competitiveness in the context of container shipping in Taiwan. Transportation Research Part E: Logistics and Transportation Review, 55, 55-73.

Yin, R.K. (2003). Case Study Research: Design and Methods. Case Study Research. Design and Methods ( $3^{\text {rd }}$ ed.). Thousand Oaks/London/New Delhi: Sage Publications.

Young, O.R. (2002). The institutional dimensions of environmental change: fit, interplay and scale ( $1^{\text {st }}$ ed.). Cambridge: MIT Press. 


\section{Appendices}

Appendix 1: Topic list for semi-structured interviews (example Statia)

\begin{tabular}{|c|c|c|}
\hline Theme & Topic & Question \\
\hline \multirow[b]{2}{*}{ Introduction } & Function & - What is your function? \\
\hline & Organisation & $\begin{array}{l}\text { - For what organisation do you } \\
\text { work? }\end{array}$ \\
\hline \multirow{3}{*}{$\begin{array}{l}\text { Marine } \\
\text { community } \\
\text { overview }\end{array}$} & $\begin{array}{l}\text { Contacts } \\
\text { - With whom (not) } \\
\text { - } \text { Why (not) } \\
\text { - } \text { Where } \\
\text { - } \text { Frequency } \\
\text { - } \quad \text { Long-/short-term (how } \\
\text { come) } \\
\text { - } \quad \text { Type of contact } \\
\text { (informal/ formal) } \\
\text { - Means of contact } \\
\text { (phone, email, face-to- } \\
\text { face, social media) }\end{array}$ & $\begin{array}{l}\text { - With whom do you have contact } \\
\text { regarding the oil terminal at } \\
\text { Statia? } \\
\text { - How? Why? }\end{array}$ \\
\hline & $\begin{array}{l}\text { Social networks } \\
\text { - Which } \\
\text { - Why } \\
\text { - By whom } \\
\text { - Long-/short-term } \\
\text { - How } \\
\text { (dis)advantageous? }\end{array}$ & $\begin{array}{l}\text { - How is the oil terminal at Statia } \\
\text { represented in larger social } \\
\text { networks? } \\
\text { - What are the (dis)advantages of } \\
\text { this representation in a larger } \\
\text { social network? }\end{array}$ \\
\hline & $\begin{array}{l}\text { Lack of contacts, missing } \\
\text { actors } \\
\text { - whom } \\
\text { - Why }\end{array}$ & $\begin{array}{l}\text { - How sufficient are current } \\
\text { contacts regarding the oil } \\
\text { terminal at Statia? Why? } \\
\text { - When and why are the current } \\
\text { contacts sufficient for you? }\end{array}$ \\
\hline \multirow{2}{*}{$\begin{array}{l}\text { Policy + user } \\
\text { community }\end{array}$} & $\begin{array}{l}\text { Actors and interactions } \\
\text { - Whom (not) } \\
\text { - How } \\
\text { - why }\end{array}$ & $\begin{array}{l}\text { - Who is involved in management } \\
\text { of the oil terminal at Statia and } \\
\text { why? }\end{array}$ \\
\hline & $\begin{array}{l}\text { Resources } \\
\text { - By whom } \\
\text { - How } \\
\text { - Why (power, rules, } \\
\text { funding) }\end{array}$ & $\begin{array}{l}\text { - How are resources used to } \\
\text { influence policy-making } \\
\text { regarding the oil terminal at } \\
\text { Statia? }\end{array}$ \\
\hline
\end{tabular}




\begin{tabular}{|c|c|}
\hline $\begin{array}{l}\text { - Which are the } \\
\text { most/least important } \\
\text { - when }\end{array}$ & $\begin{array}{l}\text { - How does infrastructure support } \\
\text { policy-making regarding the oil } \\
\text { terminal at Statia? } \\
\text { - Who has access to these } \\
\text { resources? } \\
\text { - How is the distribution of } \\
\text { resources among different } \\
\text { actors? }\end{array}$ \\
\hline $\begin{array}{l}\text { Available Knowledge } \\
\text { - Type } \\
\text { - Sufficiency } \\
\text { - By whom } \\
\text { - How frequent }\end{array}$ & $\begin{array}{l}\text { - How is knowledge collected } \\
\text { about the oil terminal at Statia } \\
\text { (and its socio-economic and } \\
\text { environmental impact)? }\end{array}$ \\
\hline $\begin{array}{l}\text { Knowledge sharing } \\
\text { - Type } \\
\text { - How } \\
\text { - By whom } \\
\text { - Means } \\
\text { - Frequency } \\
\text { - } \text { Accessibility } \\
\end{array}$ & $\begin{array}{l}\text { - How is knowledge shared about } \\
\text { the oil terminal at Statia? }\end{array}$ \\
\hline $\begin{array}{l}\text { Rules } \\
\text { - Type (formal/informal) } \\
\text { - Level (National/local) } \\
\text { - By whom } \\
\text { - Management flexibility } \\
\text { - } \quad \text { Disaster management } \\
\quad \text { plans }\end{array}$ & $\begin{array}{l}\text { - How is the oil terminal at Statia } \\
\text { regulated? } \\
\text { - Which disaster management } \\
\text { plans are in place regarding the } \\
\text { oil terminal at Statia? } \\
\text { - How does the regulatory system } \\
\text { leave room for management } \\
\text { flexibility regarding management } \\
\text { of the oil terminal at Statia? }\end{array}$ \\
\hline $\begin{array}{l}\text { Compliance with rules } \\
\text { - How } \\
\text { - By whom } \\
\text { - Non-compliance } \\
\end{array}$ & - How is rule compliance ensured? \\
\hline $\begin{array}{l}\text { Conflicts } \\
\text { - Which } \\
\text { - } \text { Legal/informal } \\
\text { - } \text { Between whom } \\
\text { - Severity } \\
\text { - } \text { Short-/long-term }\end{array}$ & $\begin{array}{l}\text { - If and how does the oil terminal } \\
\text { at Statia conflict with other } \\
\text { (maritime) activities? }\end{array}$ \\
\hline
\end{tabular}




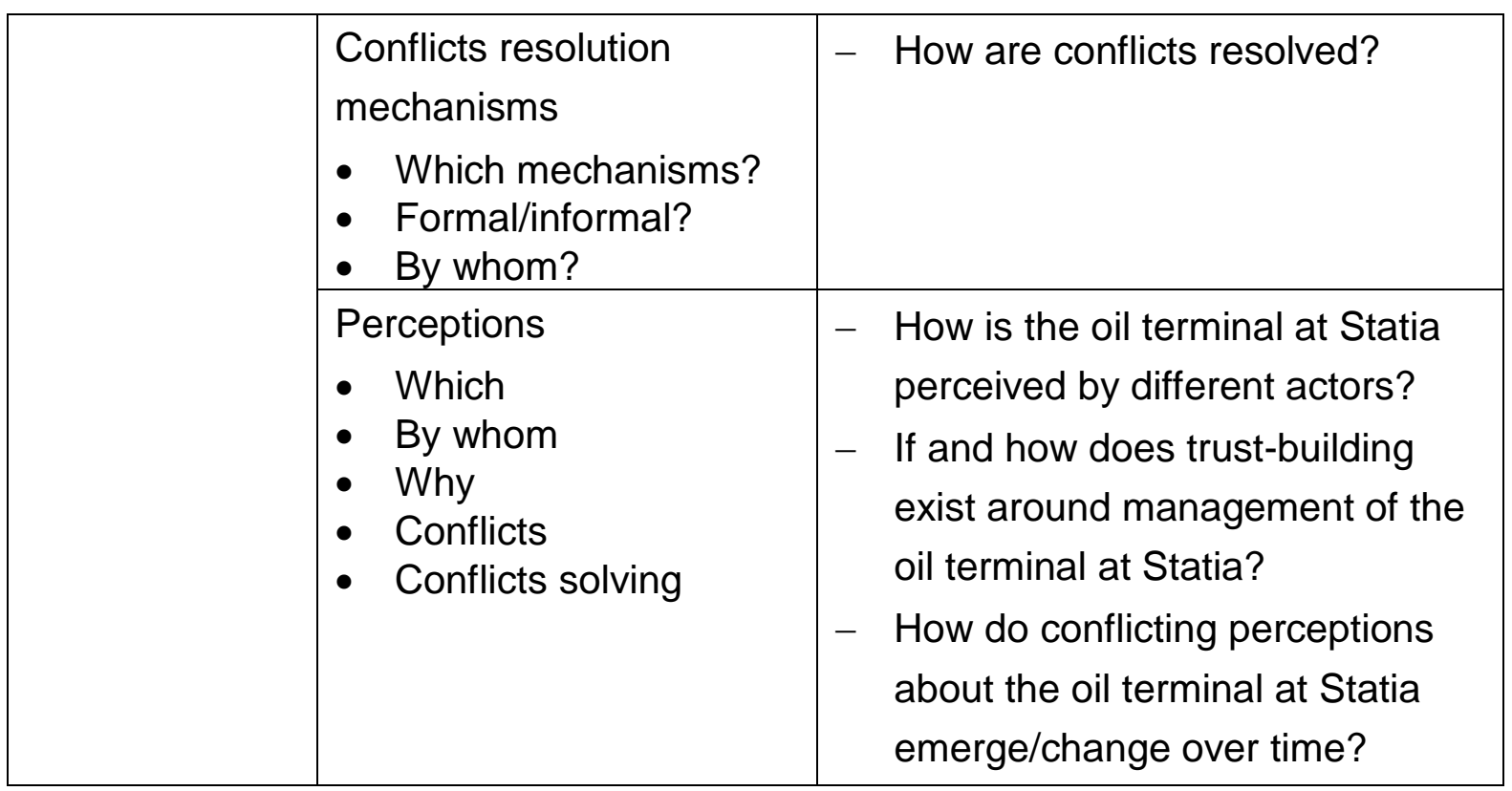




\section{Appendix 2: List of interviews}

\begin{tabular}{|c|c|c|c|c|}
\hline Code & \multicolumn{3}{|c|}{ Interviews with governmental actors } & Interview mode \\
\hline I-G-1 & $\begin{array}{l}\text { Norwegian Petroleum } \\
\text { Safety Authority }\end{array}$ & $28-10-2014$ & Hammerfest & $\begin{array}{l}\text { Videoconferencing } \\
\text { group interview }\end{array}$ \\
\hline I-G-2 & $\begin{array}{l}\text { Norwegian } \\
\text { Environment Agency }\end{array}$ & $15-10-2014$ & Hammerfest & $\begin{array}{l}\text { Face-to-face } \\
\text { group interview }\end{array}$ \\
\hline I-G-3 & Hammerfest Kommune & 20-10-2014 & Hammerfest & Face-to-face \\
\hline I-G-4 & $\begin{array}{l}\text { The Ministry of } \\
\text { Infrastructure and the } \\
\text { Environment, } \\
\text { Netherlands and } \\
\text { Rijkswaterstaat }\end{array}$ & 03-06-2015 & Statia & $\begin{array}{l}\text { Face-to-face } \\
\text { group interview }\end{array}$ \\
\hline I-G-5 & $\begin{array}{l}\text { The Ministry of } \\
\text { Infrastructure and the } \\
\text { Environment, } \\
\text { Rijksdienst Dutch } \\
\text { Caribbean }\end{array}$ & $31-03-2015$ & $\begin{array}{l}\text { Bonaire and } \\
\text { Statia }\end{array}$ & Face-to-face \\
\hline I-G-6 & $\begin{array}{l}\text { The Ministry of } \\
\text { Economic Affairs, } \\
\text { Rijksdienst Dutch } \\
\text { Caribbean }\end{array}$ & 31-03-2015 & $\begin{array}{l}\text { Bonaire and } \\
\text { Statia }\end{array}$ & $\begin{array}{l}\text { Face-to-face } \\
\text { group interview }\end{array}$ \\
\hline I-G-7 & Island Governor & 20-04-2015 & Statia & Face-to-face \\
\hline I-G-8 & $\begin{array}{l}\text { Governmental } \\
\text { Department of Welfare } \\
\text { and Society }\end{array}$ & 20-04-2015 & Statia & Face-to-face \\
\hline I-G-9 & $\begin{array}{l}\text { Governmental } \\
\text { Department of } \\
\text { Economy and } \\
\text { Infrastructure }\end{array}$ & $15-04-2015$ & Statia & Face-to-face \\
\hline I-G-10 & Harbour authority & $16-04-2015$ & Statia & Face-to-face \\
\hline $\mid-G-11$ & Island Council & $16-04-2015$ & Statia & Face-to-face \\
\hline
\end{tabular}


I-G-12 Political party

Movementu di Pueblo

Boneriano

I-G-13 Port Authority

Kralendijk

I-G-14 Commissioner of

Tourism

I-G-15 Governmental

Department of Spatial

Development and

Planning

I-G-16 Tourism Corporation Bonaire a

I-G-17 Tourism Corporation Bonaire $b$

I-G-18 Department of Polar Affairs

I-G-19 Norwegian Ministry of Climate and

Environment

I-G-20 Governor of Svalbard, Tourism Advisor

I-G-21 Governor of Svalbard, 06-08-2014 Svalbard Face-to-face Field inspector

\section{Interviews with market actors}

I-M-1 ENI Norge

I-M-2 Statoil

21-11-2014 Hammerfest Videoconferencing I-M-3 Fishermen and Arctic 21-10-2014 Hammerfest Face-to-face Supreme Seafood AS

I-M-4 Polarbase AS supply 21-10-2014 Hammerfest Face-to-face industry

I-M-5 Aibel supply industry
23-10-2014 Hammerfest Face-to-face group interview

01-04-2015 Bonaire Face-to-face

02-04-2015 Bonaire Face-to-face

01-04-2015 Bonaire Face-to-face

17-03-2015 Bonaire Face-to-face

05-04-2015 Bonaire Face-to-face

01-04-2015 Bonaire Face-to-face

12-08-2014 Svalbard Face-to-face group interview

Face-to-face

Face-to-face 22-10-2014 Hammerfest Face-to-face 


\begin{tabular}{|c|c|c|c|c|}
\hline I-M-6 & NuStar & $10-04-2015$ & Statia & Face-to-face \\
\hline I-M-7 & Fishermen & $15-04-2015$ & Statia & Face-to-face \\
\hline I-M-8 & Shipping agency & 20-04-2015 & Statia & Face-to-face \\
\hline I-M-9 & $\begin{array}{l}\text { Scubaqua and Dive } \\
\text { Statia }\end{array}$ & $10-04-2015$ & Statia & Face-to-face \\
\hline I-M-10 & $\begin{array}{l}\text { Golden Rock Dive } \\
\text { Center }\end{array}$ & 09-04-2015 & Statia & Face-to-face \\
\hline I-M-11 & $\begin{array}{l}\text { St. Eustatius Tourism } \\
\text { Development } \\
\text { Foundation }\end{array}$ & $14-04-2015$ & Statia & Face-to-face \\
\hline I-M-12 & $\begin{array}{l}\text { St. Eustatius Business } \\
\text { Association }\end{array}$ & 14-04-2015 & Statia & Face-to-face \\
\hline I-M-13 & $\begin{array}{l}\text { Aruba Tourism } \\
\text { Authority }\end{array}$ & $10-08-2015$ & Bonaire & Skype \\
\hline I-M-14 & Gift shop Bonaire & 02-04-2015 & Bonaire & Face-to-face \\
\hline I-M-15 & Boutique Vita & 01-04-2015 & Bonaire & Face-to-face \\
\hline I-M-16 & Bonaire Tours $b$ & $31-03-2015$ & Bonaire & Face-to-face \\
\hline I-M-17 & $\begin{array}{l}\text { Bonaire Destination } \\
\text { Services }\end{array}$ & 24-03-2015 & Bonaire & Face-to-face \\
\hline I-M-18 & $\begin{array}{l}\text { Bonaire Hotel \& } \\
\text { Tourism Association }\end{array}$ & 01-04-2015 & Bonaire & Face-to-face \\
\hline I-M-19 & Archie Tours & 03-04-2015 & Bonaire & Face-to-face \\
\hline I-M-20 & $\begin{array}{l}\text { Rent to Fun transport } \\
\text { service }\end{array}$ & 22-03-2015 & Bonaire & Face-to-face \\
\hline I-M-21 & Buddy Dive & 24-03-2015 & Bonaire & Face-to-face \\
\hline I-M-22 & $\begin{array}{l}\text { Bonaire Tours a and } \\
\text { mangrove centre }\end{array}$ & 26-03-2015 & Bonaire & $\begin{array}{l}\text { Face-to-face } \\
\text { group interview }\end{array}$ \\
\hline $\mathrm{I}-\mathrm{M}-23$ & Karel's Beach Bar & 17-03-2015 & Bonaire & Face-to-face \\
\hline I-M-24 & $\begin{array}{l}\text { Carib Inn B\&B and } \\
\text { dive shop }\end{array}$ & 26-03-2015 & Bonaire & Face-to-face \\
\hline I-M-25 & Dive Friends & 21-03-2015 & Bonaire & Face-to-face \\
\hline
\end{tabular}


I-M-26 Bonaire Taxi

Association

I-M-27 Bonaire Arts and Crafts Association

I-M-28 Carnival Cruises a

I-M-29 Carnival Cruises b

I-M-30 Freewinds Church of Scientology Cruise

I-M-31 Royal Cruises

I-M-32 Holland America Cruises a

I-M-33 Holland America Cruises b

I-M-34 Abercrombie \& Kent, Expedition crew

I-M-35 G Adventures, Expedition crew

I-M-36 Polar Quest, Expedition crew a

I-M-37 Polar Quest, Expedition crew b

I-M-38 Oceanwide Expeditions, Expedition crew a

I-M-39 Oceanwide Expeditions, Expedition crew b

I-M-40 Hurtigruten, Expedition 24-07-2014 Svalbard Face-to-face crew

I-M-41 Oceanwide Expeditions, Office staff
29-03-2015 Bonaire Face-to-face

24-07-2015 Bonaire Email

12-03-2015 Bonaire Telephone

23-03-2015 Bonaire Face-to-face

22-03-2015 Bonaire Face-to-face

28-03-2015 Bonaire Face-to-face

22-03-2015 Bonaire Face-to-face

22-03-2015 Bonaire Face-to-face

02-08-2014 Svalbard Face-to-face

20-07-2014 Svalbard Face-to-face

24-07-2014 Svalbard Face-to-face

21-07-2014 Svalbard Face-to-face

18-07-2014 Svalbard Face-to-face

28-07-2014 Svalbard Face-to-face

\section{7-06-2014 Svalbard Face-to-face}


I-M-42 Oceanwide

Expeditions,

Expedition crew c

I-M-43 Association of Arctic

Expedition Cruise

Operators, office staff

a I-M-44 Association of Arctic 25-07-2014 Svalbard Face-to-face Expedition Cruise Operators, crew b

I-M-45 Svalbard Tourism

I-M-46 Kings Bay a

I-M-47 Kings Bay b

I-M-48 Kings Bay c

I-M-49 Kings Bay d

I-M-50 Harbour authority NyÅlesund

I-M-51 Port Authority Longyearbyen

I-M-52 Pole Position Logistics
29-07-2014 Svalbard Face-to-face

19-06-2014 Svalbard Face-to-face

$\begin{array}{lll}\text { 15-07-2014 } & \text { Svalbard } & \text { Face-to-face } \\ \text { 01-08-2014 } & \text { Svalbard } & \text { Face-to-face } \\ & & \text { group interview }\end{array}$

02-08-2014 Svalbard Face-to-face group interview

04-08-2014 Svalbard Face-to-face

06-08-2014 Svalbard Face-to-face

30-07-2014 Svalbard Face-to-face group interview

15-07-2014 Svalbard Face-to-face

25-07-2014 Svalbard Face-to-face

\section{Interviews with civil society actors}

\begin{tabular}{|c|c|c|c|c|}
\hline I-CS-1 & Bellona & $16-10-2014$ & Hammerfest & Face-to-face \\
\hline I-CS-2 & $\begin{array}{l}\text { World Wildlife Fund } \\
\text { Norway }\end{array}$ & $16-10-2014$ & $\begin{array}{l}\text { Hammerfest } \\
\text { and } \\
\text { Svalbard }\end{array}$ & Face-to-face \\
\hline I-CS-3 & STENAPA a & 09-04-2015 & Statia & Face-to-face \\
\hline I-CS-4 & STENAPA b & 09-04-2015 & Statia & Face-to-face \\
\hline I-CS-5 & STENAPA C & $17-04-2015$ & Statia & Face-to-face \\
\hline I-CS-6 & Statia Roots & $16-04-2015$ & Statia & Face-to-face \\
\hline
\end{tabular}


Foundation

$\begin{array}{lllll}\text { I-CS-7 } & \begin{array}{l}\text { Statia Safe \& Sound } \\ \text { Foundation }\end{array} & 13-04-2015 & \text { Statia } & \text { Face-to-face } \\ \text { I-CS-8 } & \text { STINAPA a } & 19-03-2015 & \text { Bonaire } & \text { Face-to-face } \\ \text { I-CS-9 } & \text { STINAPA b } & 27-03-2015 & \text { Bonaire } & \text { Face-to-face } \\ \text { I-CS- } & \text { Sea Turtle } & 19-03-2015 & \text { Bonaire } & \text { Face-to-face } \\ 10 & \text { Conservation Bonaire } & & & \\ \text { I-CS- } & \text { Dutch Caribbean } & 16-03-2015 & \text { Bonaire } & \text { Face-to-face } \\ \text { 11 } & \text { Nature Alliance } & & & \\ \text { I-CS- } & \text { Local inhabitant } & 03-04-2015 & \text { Bonaire } & \text { Face-to-face }\end{array}$
12

\section{Interviews with research actors}

\begin{tabular}{|c|c|c|c|c|}
\hline I-R-1 & Akvaplan Niva & $05-11-2014$ & Hammerfest & Face-to-face \\
\hline I-R-2 & $\begin{array}{l}\text { Norwegian Institute of } \\
\text { Marine Research }\end{array}$ & $06-10-2014$ & Hammerfest & Skype \\
\hline I-R-3 & $\begin{array}{l}\text { Norwegian Institute for } \\
\text { Nature Research }\end{array}$ & $28-10-2014$ & Hammerfest & Skype \\
\hline I-R-4 & $\begin{array}{l}\text { Northern Research } \\
\text { Institute Alta }\end{array}$ & $11-08-2014$ & Hammerfest & Skype \\
\hline I-R-5 & Consultancy & $17-04-2015$ & Statia & Face-to-face \\
\hline I-R-6 & Fisheries researcher a & $15-04-2015$ & Statia & Face-to-face \\
\hline I-R-7 & Fisheries researcher b & $15-04-2015$ & Statia & Face-to-face \\
\hline I-R-8 & $\begin{array}{l}\text { St. Eustatius Centre } \\
\text { for Archaeological } \\
\text { Research }\end{array}$ & $13-04-2015$ & Statia & Face-to-face \\
\hline I-R-13 & Wolfs Company a & $08-07-2015$ & Bonaire & Face-to-face \\
\hline I-R-14 & Wolfs Company b & $27-03-2015$ & Bonaire & Face-to-face \\
\hline I-R-15 & $\begin{array}{l}\text { Norwegian Polar } \\
\text { Institute }\end{array}$ & $29-07-2014$ & Svalbard & Face-to-face \\
\hline I-R-16 & $\begin{array}{l}\text { Italian Research } \\
\text { Station Ny-Ålesund }\end{array}$ & 03-08-2014 & Svalbard & $\begin{array}{l}\text { Face-to-face } \\
\text { group interview }\end{array}$ \\
\hline
\end{tabular}


I-R-17 Chinese Research 02-08-2014 Svalbard Face-to-face Station Ny-Ålesund group interview

I-R-18 Dutch Research 29-08-2014 Svalbard Face-to-face Station Ny-Ålesund

I-R19 Norwegian Research 31-07-2014 Svalbard Face-to-face Station Ny-Ålesund

I-R-20 British Research 30-07-2014 Svalbard Face-to-face Station Ny-Ålesund

\section{I-R-21 Korean Research} 01-08-2014 Svalbard Face-to-face Station Ny-Ålesund group interview

Glossary: CS = Civil Society, $\mathrm{G}=$ Government, $\mathrm{I}=$ Interview $\mathrm{M}=$ Market,, $\mathrm{R}=$ Researcher 


\section{Appendix 3: Coding scheme Hammerfest}

\section{Code description}

Marine community

Resources

Rules

Conflicts

Perceptions

Coalitions

\section{Code}

Contacts

Lack of contacts

Social networks

Interaction

User community

Policy community

Property tax

Plan for development and operation

Public meetings

Semi-structured meetings

Local knowledge

Scientific knowledge

Knowledge exchange

Employment

Centralised decision-making

Norwegianisation

High North Strategy

Norwegian tax efficient system

Conflict resolution mechanisms

Conflict with health

Conflict with safety

Conflict with environment

Stakeholder interaction

Social license to operate

Community development discourse

Economic growth discourse

Environmental development discourse

Institutional coalition

Strategic coalition I

Strategic coalition II

Oppositional coalition 


\section{Appendix 4: Coding scheme Statia}

\section{Code description}

Marine community

Resources

Rules

Conflicts

Perceptions

Phases

\section{Code}

Contacts

Lack of contacts

Social networks

Interaction

User community

Policy community

Corporate Social Responsibility

Court case

Distribution of resources

Environmental impact assessment

Environmental permit

Centralised decision-making

Enhanced surveillance of the Netherlands

Facilities and Activities Ordinance BES

Institutional rules

Statia's nature policy plan

Statia's spatial development plan

Statia's strategic development plan

Harbor Ordinance

Conflict resolution mechanisms

Conflict with fisheries

Conflict with marine park

Second oil terminal

Objections against amending spatial plan

Protest march

Dutch-European environmental standards

Small island environmental standards

Good governance

2010-2015

After 2015

Before 2010 
Power

Dispositional power

Relational power

Structural power 


\section{Appendix 5: Coding scheme Bonaire}

\section{Code description}

Marine community

Resources

Rules

Conflicts

\section{Code}

Contacts

Lack of contacts

Social networks

Interaction

User community

Policy community

Cargo ban

Cost-benefit analysis

Excursion negotiations

FCCA meetings

Island guide course

Itinerary planning negotiations

Head tax

Nature fee

Protest letter CURO

Cargo ban

Prebooked tours

Reorganisation TCB

Taxi organisation

Souvenir market

Independent tours

Marine Park Ordinance

Bonaire's Spatial Development Plan

Conflict with dive tourism

Conflict with local inhabitants

Conflict for space in port

Port infrastructure

Shopping mall

Cargo ban

Conflict with nature conservation 
Klein Bonaire

Sorobon

Marine park amendment

Networks and flows

Cruise passenger flow

Cruise ship flow

Space of flows

Space of places

Switcher

Programmer 


\section{Appendix 6: Coding scheme Svalbard}

\section{Code description}

Marine community

Resources

Rules

Conflicts

Perceptions

Collective self-governance

\section{Code}

Contacts

Lack of contacts

Social networks

Interaction

User community

Policy community

AECO conference

AECO contact list

AECO database

Expedition leader conference

Field inspections

Post visit report

Private policy

Public policy

Site-specific guidelines

Information overflow

Functioning AECO

Knowledge hub

Sightings

Management versus field

Accumulation of rules

Expedition crew interaction

Information overflow

Internal dynamic within cruise tourism

External dynamic with policy community

External dynamic with research user community 


\section{Summary}

Oceans and seas are among the most ecologically vital and socio-economically important systems on the planet. Despite the acknowledged pristine nature of the marine environment, there is a growing interest in exploring the sea for human use such as offshore wind production, extraction of sand, oil and gas, deep sea mining, gene mining and aquaculture. This is the result of, among other things, the food and energy needs of the growing world population, globalisation processes and technological innovation. This intensified use of the sea has led to new governance initiatives to address the resulting environmental effects and risks for the marine environment.

Actors involved in governing maritime activities are not necessarily located in the same geographical place and may not even be in direct contact, but they increasingly interact through global and transnational institutions or networks. Globalisation results in communities characterised by the interplay between territorially defined actors (e.g. national states, port agencies and island communities) and less territorially defined actors (e.g. mobile and transnational industries). The community literature conceptualises communities as small spatial units, homogenous social structures or sets of shared norms. These conceptualisation of communities provide insufficient insights in the type of community involved in environmental governance of maritime activities.

This thesis, therefore, presents the marine community concept as a new analytical lens for studying environmental governance of maritime activities. A marine community is a community of socio-economic and policy actors and institutions organised around a certain maritime activity that influences or will be affected by the (marine) ecosystem in which the activity occurs.

The aim of this PhD thesis is twofold: first, to understand environmental governance of maritime activities by different marine communities, and second, to understand how different governance modes, shifts, styles and processes affect the role of the user and policy community in the marine community.

The central research question is: How can the marine community concept enrich our understanding of environmental governance of maritime activities in distinct maritime settings?

1. How are marine communities organised to govern environmental problems in different sectoral and geographical settings?

2. How do marine communities develop in relation to various institutional 
settings, and how do different governance modes, shifts, styles and processes affect the role of the user and policy community in the marine community?

A case study methodology and cross-case comparative analysis were chosen to study the research question. The selection of cases is based on two distinct marine regions (the Caribbean Netherlands and the European Arctic) and two different maritime activities (cruise tourism and oil \& gas activities). The case studies are investigated through the collection of primary data from semistructured interviews and (participatory) observations, supplemented with secondary data from literature, policy documents, social media, and newspapers.

Chapter 2 illustrates how the marine community of liquefied natural gas production in Hammerfest transforms from a local fisheries marine community into an international oil and gas marine community in Northern Norway, driven by a discourse on economic growth. This is implemented through a strong institutional coalition between the Norwegian State and Statoil in which both actors participate in the user and policy community. Although non-governmental organisations, Sámi indigenous people, fisheries and local inhabitants of Hammerfest engage in strategic and oppositional coalitions to strive for environmental and community development related to liquefied natural gas production, the success of these coalitions is constrained by centralised decision-making by the institutional coalition.

Chapter 3 illustrates the institutional change in the marine community of oil transhipment at St. Eustatius. Since 2010, St. Eustatius is a special municipality of the Netherlands, and since 2015, the Dutch Ministry of Infrastructure \& Environment, instead of the island government, is responsible for the environmental management of the oil terminal at St. Eustatius. The Dutch Ministry relies on Dutch and European standards for environmental management, which deviate from the standards of small islands. This structural power change, however, is not perceived as legitimate by part of the local population of St. Eustatius. This chapter analyses the reversal of the existing power relationships from strong intertwinement of the user and policy community, stereotypical of small island developing states, to the user and policy community drifting apart.

In Chapter 4, the marine community of cruise tourism at Bonaire is situated between the transnational cruise network and the local tourism industry of Bonaire. This case study analyses how two interconnected flows of cruise ships and passengers are governed by this transnational-local interplay. An important conclusion is that the transnational cruise ship flow increasingly determines the 
local cruise passenger flow at Bonaire. As a result, the marine community, and the user community especially, increasingly connects and adapts to the requirements of the transnational cruise network.

Chapter 5 analyses the changes in the marine community of expedition cruise tourism at Svalbard changes because of the establishment of the self-governing Association of Arctic Expedition Cruise Operators. Collective self-governance complements regulation by the Norwegian government through the implementation of an industry code of conduct and providing access to knowledge and information, such as statistical information and a track-and-trace system for cruise ships. At the same time, the demanding information generation and provision of collective self-governance creates distance between the Association of Arctic Expedition Cruise Operators and the Governor of Svalbard in the policy community and the expedition crew in the user community. Information generation and provision becomes a challenge for sustainable cruise tourism. Once information provision requires too much time and resources, self-interest is prioritised over collective interest.

In Chapter 6 the conclusions of the thesis are drawn, based on the cross-case comparative analysis. First, the comparison of environmental governance illustrates the use of different problem-solving styles in marine regions. The islands of Bonaire and St. Eustatius (in the Caribbean Netherlands) are eager for shortterm economic growth. The lack of a strong government results in a curative problem-solving style in relation to urgent environmental problems. In the European Arctic the activities are more recent. Governance, therefore, attempts to prevent problems through stakeholder involvement and informed decision-making. Second, the analysis shows that environmental governance of maritime activities depends upon the mobility of the maritime activity and consequently the level at which regulations are developed and implemented. A difference is observed between governing through transnational regulations predominantly by the user community for cruise tourism and governing through territory-bound regulations predominantly by the policy community for oil and gas.

In the second part of the conclusion, marine communities as a governance arrangement is discussed in relation to theories on governance modes and shifts, policy styles and mobilities. In the first place, changes in governance modes illustrate a shift towards more contemporary modes, such as open co-governance and self-governance, with St. Eustatius being the exception because of its political situation. In this thesis the complexity of governance is further structured according to two analytical dimensions: the governance style, ranging from reactive to proactive, and the governance process, which distinguishes 
governance of the marine community from governance through the marine community. In the analysis it becomes clear that the spatial scale of the maritime activity is crucial as it defines the mobility of the activity and the marine community. Therefore, the thesis concludes that the maritime activity has a larger influence on environmental governance than the marine region. The chapter ends with methodological reflections, future research and policy implications for the new concept of marine community. 


\section{Samenvatting}

Oceanen en zeeën zijn ecologisch vitale en socio-economisch belangrijke systemen. Ondanks de noodzaak van het behoud van ongerepte mariene natuur, is er sprake van toenemend menselijk gebruik, zoals offshore windproductie, winning van zand, olie en gas, diepzeemijnbouw, biotechnologie en aquacultuur. Dit is het gevolg van bijvoorbeeld de voedsel- en energiebehoefte van de groeiende wereldbevolking, processen van mondialisering en technologische innovatie. Het intensief gebruik van de zee heeft geleid tot nieuwe vormen van sturing om milieueffecten en risico's in het mariene milieu te beperken.

Het reguleren en (be)sturen van maritieme activiteiten gebeurt niet meer alleen vanuit geografisch identificeerbare machtscentra, maar ook door middel van globale en transnationale instituties en netwerken. Mondialisering leidt tot gemeenschappen van actoren die samen maritieme activiteiten beheren, en die in meerdere (bijv. nationale staten, havenbedrijven en eilanden) of mindere mate (bijv. mobiele en transnationale industrieën) gebonden zijn aan grondgebied. De wetenschappelijke literatuur over gemeenschappen onderscheidt gemeenschappen als kleine, plaatselijke eenheden, homogene sociale structuren of verzamelingen van waarden. Deze conceptualiseringen van gemeenschappen geven onvoldoende inzicht in het type gemeenschap, betrokken bij het milieubestuur van maritieme activiteiten.

Dit proefschrift presenteert daarom het concept mariene gemeenschap als een nieuwe analytische lens om het milieubestuur van maritieme activiteiten te bestuderen. Een mariene gemeenschap is een gemeenschap van socioeconomische en beleidsactoren en instituties, georganiseerd rondom een bepaalde maritieme activiteit die het mariene ecosysteem, waarin de activiteit plaatsvindt, beïnvloedt of er door beïnvloed wordt.

Het doel van dit proefschrift is tweevoudig: ten eerste, het begrijpen van het (be)sturen van milieuproblemen in mariene gemeenschappen, en, ten tweede, inzicht verschaffen in de wijze waarop bestuursmodellen, bestuursstijlen en bestuursprocessen de rol van de gebruikersgemeenschap en beleidsgemeenschap binnen een mariene gemeenschap beïnvloeden.

De centrale vraag van dit onderzoek is: Hoe kan het concept mariene gemeenschap het inzicht in het (be)sturen van maritieme activiteiten in verschillende maritieme omstandigheden vergroten?

1. Hoe zijn mariene gemeenschappen georganiseerd om milieuproblemen binnen verschillende (maritieme) sectoren en in verschillende geografische 
omstandigheden aan te pakken?

2. Hoe ontwikkelen mariene gemeenschappen zich in relatie tot verscheidene institutionele omstandigheden en hoe beïnvloeden verschillende bestuursmodellen, bestuursstijlen en bestuursprocessen de rol van de gebruikersgemeenschap en beleidsgemeenschap binnen de mariene gemeenschap?

In dit onderzoek zijn vier cases geanalyseerd en zijn deze cases vervolgens met elkaar vergeleken. De selectie van de cases is gebaseerd op twee verschillende mariene regio's (Caribisch Nederland en het Europese Noordpoolgebied) en twee verschillende maritieme activiteiten (cruisetoerisme en olie- en gasproductie). De cases zijn onderzocht door het verzamelen van primaire data uit semigestructureerde interviews en (participatieve) observaties, aangevuld met secundaire data uit literatuur, beleidsdocumenten, sociale en reguliere media.

Hoofdstuk 2 laat zien hoe de mariene gemeenschap rondom de productie van vloeibaar aardgas in Hammerfest verandert van een lokale vissersgemeenschap naar een internationale olie- en gas gemeenschap in Noord-Noorwegen, als gevolg van een discours van economische groei. Dit komt tot uitdrukking in een sterke institutionele coalitie tussen de Noorse staat en Statoil, waarin beide actoren deelnemen in zowel de gebruikers- als de beleidsgemeenschap. Ondanks het feit dat milieuorganisaties, de inheemse Sámi bevolking, vissers en lokale inwoners van Hammerfest zich organiseren in strategische en oppositionele coalities om zo meer milieu- en gemeenschapsontwikkeling te realiseren in relatie tot de productie van vloeibaar gas, wordt het succes van deze coalities beperkt door gecentraliseerde besluitvorming van de institutionele coalitie.

Hoofdstuk 3 illustreert de institutionele verandering van de mariene gemeenschap rond olieoverslag op St. Eustatius. Sinds 2010 is St. Eustatius een speciale gemeente van Nederland en sinds 2015 is het Nederlandse Ministerie van Infrastructuur en Milieu, in plaats van het eilandbestuur, verantwoordelijk voor milieuregulering van de olieterminal. Het Nederlandse Ministerie vertrouwt op Nederlandse en Europese milieu- en reguleringsstandaarden, die afwijken van de standaarden op het eiland. Deze structurele machtsverandering wordt echter niet legitiem beschouwd door een deel van de lokale bevolking van St. Eustatius. Dit hoofdstuk analyseert de verandering van de machtsrelaties; van een sterke vervlechting, tot een ontkoppeling van de gebruikers- en beleidsgemeenschap.

In Hoofdstuk 4 bevindt de mariene gemeenschap rond cruisetoerisme op Bonaire zich tussen het transnationale cruisenetwerk en de lokale toerismeindustrie in Bonaire. Deze case analyseert hoe de stromen cruiseschepen en - 
passagiers worden bestuurd door deze transnationale-lokale interactie. Een belangrijke conclusie is dat de transnationale organisatie van cruiseschepen in toenemende mate de lokale besturing van cruise passagiers op Bonaire bepaalt. Het gevolg is dat de mariene gemeenschap, met name de gebruikersgemeenschap, zich steeds meer verbindt met, en zich aanpast aan de eisen van het transnationale cruisenetwerk.

Hoofdstuk 5 analyseert veranderingen in de mariene gemeenschap rondom expeditie-cruisetoerisme in Spitsbergen door de oprichting van de vereniging van Arctische expeditie-cruiseoperators. Het zelfbestuur van deze vereniging vult de regelgeving van de Noorse overheid aan door het opleggen van gedragscodes en het verschaffen van toegang tot kennis en informatie, zoals statistieken en een track and trace systeem voor cruiseschepen. Tegelijkertijd creëert de veeleisende informatievergaring en -voorziening van het collectief zelfbestuur afstand tussen de vereniging van Arctische expeditie-cruiseoperators en de Noorse overheid in de beleidsgemeenschap en de expeditie crew in de gebruikersgemeenschap.

In hoofdstuk 6 worden conclusies getrokken op basis van de vergelijkende analyse van de cases. Allereerst laat de vergelijking van het (be)sturen van milieuproblemen zien dat er in de mariene regio's verschillende bestuursstijlen worden gehanteerd. De eilanden Bonaire en St. Eustatius (in Caribisch Nederland) willen op korte termijn economische groei realiseren. Het ontbreken van een sterke overheid leidt tot een curatieve stijl om dringende milieuproblemen op te lossen. In het Europese Noordpoolgebied zijn de activiteiten recenter. Men probeert daarom milieuproblemen te voorkomen door belanghebbenden al vanaf het begin van het besluitproces te betrekken en door gedegen besluitvorming te voeren op basis van accurate informatie en kennis. Ten tweede maakt de analyse duidelijk dat het (be)sturen van milieuproblemen samenhangt met het mobiele karakter van de maritieme activiteit met als gevolg daarvan het schaalniveau waarop regels worden geformuleerd en geïmplementeerd. De analyse laat een duidelijk verschil zien tussen sturing door transnationale regels, voornamelijk door de gebruikersgemeenschap bij cruise toerisme, en door regels gebonden aan het grondgebied, voornamelijk door de beleidsgemeenschap bij olie en gas.

In het tweede deel van de conclusie wordt het sturen van milieuproblemen door mariene gemeenschappen bediscussieerd in relatie tot theorieën over bestuursmodellen, beleidsstijlen en mobiliteitsstudies. In de eerste plaats illustreren de veranderingen in bestuursmodellen een verschuiving naar publiekprivate samenwerking en zelfbestuur, met St. Eustatius als uitzondering door zijn politieke situatie. In dit proefschrift wordt de complexiteit van milieubestuur verder uitgewerkt aan de hand van twee analytische dimensies: de bestuursstijl, die 
varieert van reactief naar proactief, en het bestuursproces, variërend van besturing van de mariene gemeenschap tot besturing door de mariene gemeenschap. De analyse maakt duidelijk dat de ruimtelijke schaal van de maritieme activiteit cruciaal is om bestuursprocessen te begrijpen. Dit bepaalt namelijk het mobiele karakter van de activiteit en van de mariene gemeenschap. Daarom concludeert dit proefschrift dat de maritieme activiteit meer invloed heeft op het milieubestuur, ten opzichte van de mariene regio. Het hoofdstuk eindigt met methodologische reflecties, toekomstig onderzoek en beleidsimplicaties. 


\title{
WASS Education Certificate
}

\author{
Linde K.J. van Bets \\ Wageningen School of Social Sciences (WASS) \\ Completed Training and Supervision Plan
}

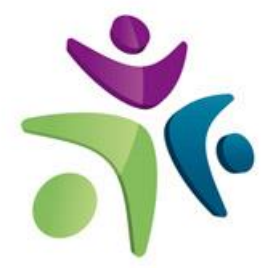

Wageningen School

of Social Sciences

\begin{tabular}{|c|c|c|c|}
\hline Name of the learning activity & Department/Institute & Year & ECTS* \\
\hline \multicolumn{4}{|l|}{ A) Project related competences } \\
\hline $\begin{array}{l}\text { YRM60806 Qualitative data analysis: } \\
\text { procedures and strategies }\end{array}$ & Wageningen University & 2013 & 6 \\
\hline ENP-35306 Political Theory & Wageningen University & 2013 & 6 \\
\hline $\begin{array}{l}\text { Master class Conceptual Foundations } \\
\text { of Modern Environmental Governance }\end{array}$ & WASS & 2014 & 1 \\
\hline $\begin{array}{l}\text { Techniques for writing and presenting a } \\
\text { scientific paper }\end{array}$ & WUR graduate schools & 2014 & 1,2 \\
\hline Master class the Anthropocene & SENSE & 2015 & 1 \\
\hline $\begin{array}{l}\text { Co-organiser marine meetings } \\
\text { Environmental Policy Group }\end{array}$ & Wageningen University & 2013-2016 & 1 \\
\hline Writing $\mathrm{PhD}$ research proposal & Wageningen University & 2013 & 6 \\
\hline $\begin{array}{l}\text { Writing grant proposal for Arctic Field } \\
\text { Grant } 2014\end{array}$ & Svalbard Science Forum/Norway & 2013 & 1 \\
\hline \multicolumn{4}{|l|}{ B) General research related competences } \\
\hline Introduction course & WASS & 2013 & 1 \\
\hline $\begin{array}{l}\text { 'Sustainable Ecosystem Management } \\
\text { and Use by Marine Communities in the } \\
\text { Arctic and the Dutch Caribbean' }\end{array}$ & $\begin{array}{l}\text { TripleP@Sea research project } \\
\text { meetings (Wageningen) }\end{array}$ & 2013-2016 & 1 \\
\hline $\begin{array}{l}\text { 'Adaptation of Arctic marine } \\
\text { communities' }\end{array}$ & $\begin{array}{l}\text { Pole to Pole Day 2014/ } \\
\text { Association of Polar Early Career } \\
\text { Scientists (Leiden) }\end{array}$ & 2014 & 1 \\
\hline $\begin{array}{l}\text { 'Adaptation of marine communities: } \\
\text { Expedition Cruise Tourism on Svalbard' }\end{array}$ & $\begin{array}{l}\text { Eighth International Congress of } \\
\text { Arctic Social } \\
\text { Sciences/International Arctic } \\
\text { Social Sciences ICASS VIII } \\
\text { (British Columbia, Canada) }\end{array}$ & 2014 & 1 \\
\hline $\begin{array}{l}\text { 'Sustainable Ecosystem Management } \\
\text { and Use by Marine Communities in two } \\
\text { exemplary regions' }\end{array}$ & $\begin{array}{l}\text { Workshop NWO social science } \\
\text { researchers in the Caribbean } \\
\text { (Utrecht) }\end{array}$ & 2015 & 1 \\
\hline
\end{tabular}


'Expedition Cruise Tourism at

Svalbard: Collective Self-Governance as Driver for Change

'Collective self-governance in a marine community: Expedition in cruise tourism in Svalbard'

'Arctic Marine Communities: Social Science Insights in the Importance and Challenges of Long-term Polar Research Studies'

'Governance through marine gh communities: A Comparative Analysis Conference/Centre for Maritime of Cruise Tourism in Bonaire and Research Svalbard'
International conference

2016

1

"Disclosing Sustainability: The

Transformative Power of

Transparency/ Environmental

Policy Group (Wageningen)

$5^{\text {th }}$ conference/ International

2016

Polar Tourism Research Network (Raufarhöfn, Iceland)

Netherlands Polar Programme

2016

Symposium 2016 (NWO, Den

Hague)

C) Career related competences/personal development

$\mathrm{PhD}$ competence assessment

WASS

2013

0.3

Website and social media manager

Wageningen University

2013-2016

2

Course assistant ENP-30306

Wageningen University

2014

1

International Environmental Policy

Organisation PhD trips 2014 (Belgium)

Wageningen University

2014-2016 2

and 2016 (Germany and Switzerland)

Supervision thesis ring

Wageningen University

2015-2016 1

Teaching Bachelor Course Sociology

NHTV Breda

2016-2017

1

and Tourism

Netherlands Scientific Expedition to

University of Groningen

2015

*One credit according to ECTS is on average equivalent to 28 hours of study load 


\section{About the author}

Linde K.J. van Bets, was born on June $1^{\text {st }}, 1987$ in Bonheiden, Belgium. She studied Latin-Greek at the secondary education Ursulinen in Mechelen. Because of her project work on environmentally friendly living in the final year of high school, she became intrigued by environmental studies. At that time, environmental studies, and more specifically environmental policy studies, did not yet exist in academia in Belgium. In 2005 she moved to the Netherlands and studied the Bachelor Environmental Sciences at Wageningen University, with a major in Environmental Policy and Management. Linde continued her studies in Wageningen by starting the new master programme Aquaculture and Marine Resource Management, specialising in Governance of Marine and Coastal Systems.

After her graduation she moved back to Belgium and gained experience with European marine policy-making by working for the NGOs Seas at Risk and Surfrider Foundation Europe in Brussels. Afterwards she worked as project officer for the study programme Integrated Coastal Zone Management at the University of Applied Sciences Van Hall Larenstein in Leeuwarden. In March 2013, Linde started her PhD research at the Environmental Policy Group at Wageningen University.

\section{List of publications}

Van Bets, L.K.J., M.A.J. Lamers, and J.P.M. van Tatenhove. (2017). Collective SelfGovernance in a Marine Community: Expedition Cruise Tourism at Svalbard. Journal of Sustainable Tourism. First online. (Chapter 5 in this thesis)

Van Bets, L.K.J., M.A.J. Lamers, and J.P.M. van Tatenhove. (2016). Governing cruise tourism at Bonaire: a networks and flows approach. Mobilities. First online. (Chapter 4 in this thesis)

Van Bets, L.K.J., J.P.M. van Tatenhove, and M.A.J. Lamers. (2016). A power analysis of a transforming marine community around oil transhipment at St. Eustatius. Ocean and Coastal Management, 132, 59-69. (Chapter 3 in this thesis)

Van Bets, L.K.J., J.P.M. van Tatenhove, and A.P.J. Mol. (2016). Liquefied natural gas production at Hammerfest: A transforming marine community. Marine Policy, 69, 52-61. (Chapter 2 in this thesis)

N. Polman, S. Reinhard, L.K.J. van Bets, and T. Kuhlman. (2016). Governance of ecosystem services on small islands: three contrasting cases for St. Eustatius in the Dutch Caribbean. Island Studies Journal, 11(1), 265-284. 


\section{Acknowledgements}

This $\mathrm{PhD}$ thesis about marine communities was not possible without my own community of support. Therefore I like to take the opportunity to express my gratitude to all the people that helped me reach this point.

First of all I want to thank my promotors Arthur Mol and Jan van Tatenhove and co-promotor Machiel Lamers for supervising me. I benefitted a lot from their confidence in me, constructive feedback, the open door policy for all my questions and their support in finding a coherency between empirical work and theory in my writing. Next to the regular PhD work, I am happy that I could share special moments with my supervisors like a double high five with Jan when securing the Arctic Field Grant for fieldwork in Svalbard and attending the Royal Palace Symposium about the future of coral reefs in the Caribbean with him and participating in the Netherlands Scientific Expedition Edgeøya Spitsbergen, where Machiel and I conducted research together.

I am thankful to the TripleP@Sea project, of which my PhD research is part. My words of thanks go to Tinka Murk, the project manager, and to Martine van den Heuvel-Greve and Diana Slijkerman, the project coordinators for the Arctic and Caribbean regions respectively. This project gave me the opportunity to conduct research in incredible places like Spitsbergen, Hammerfest, Bonaire and St. Eustatius and, next to that, gain unique skills like diving and a polar bear safety training. Furthermore I want to thank all the interviewees, who contributed greatly to this thesis.

I am glad that I could enjoy my PhD journey in the comfortable environment of the Environmental Policy Group. I enjoyed working at ENP very much and want to thank everyone for making me feel at home. I want to thank Arthur and Simon for giving me a lot of freedom as website manager for the department, a role which I enjoyed very much, next to the PhD research. A great thank you to the secretary Corry for all her help with my many questions and the computer breaks I could enjoy in her office.

I want to thank my $\mathrm{PhD}$ colleagues for the many $\mathrm{PhD}$ meetings, drinks, dinners, parties we shared, with the PhD trips to Belgium, Germany and Switzerland as highlights. I want to thank Martijn and Robin for their help with the graphical abstracts for each of the case studies. Office mates are the ones that got to observe my $\mathrm{PhD}$ journey up-close. Marjanneke, Imke, Tracey, Agnes, Anke, Moises, Natalia and Gilbert, I want to thank you for all your support. Jillian, I will never forget your enthusiasm and friendship. Lastly, I want to thank my 
paranymphs Mandy and Mariska for all the fun and laughter we shared. That was the perfect distraction during the $\mathrm{PhD}$. I feel really comfortable with both of you by my side.

Furthermore I want to thank my former study mates and friends in Belgium and the Netherlands for the conversations we shared about ups and downs in (PhD) life. I especially want to thank Katrien Steurs for continuously making me aware to be self-confident, Katrien Cootjans for having so much faith in me, Shelitha for making me reflect during our inspiring conversations and Lone for having a listening ear for all my concerns.

Next I want to thank my family-in-law. The weekends in Panningen, Tilburg and Haarlem always felt a little bit like holidays and a nice change of scenery from Wageningen.

Finally, my family has been an important home base for me. What I will remember the most from the last four years are the always lively discussions during the weekends in Belgium about various topics and the opportunities to spend writing weeks or holidays next to the swimming pool in the garden. A special thank you to my brother Reinout for his help with the layout of my thesis.

Finally, I want to thank my partner Joeri. Doing both our PhD at the same time was an adventure. I am glad that we experienced this journey together. Now both our PhDs are finished, I cannot wait to see what the next adventures will bring us. 
The research described in this thesis was financially supported by the TripleP@Sea innovation programme (KV-IV-007) of Wageningen University \& Research, to contribute to smart use of marine ecosystem services providing sustainable profit of the plant for people.

Cover design: Michiel van Noppen

Printed by: Digiforce 